\title{
Aging-dependent effects of repetitive loading exercise and antioxidant supplementation on oxidative stress in skeletal muscle
}

Michael J. Ryan

West Virginia University

Follow this and additional works at: https://researchrepository.wvu.edu/etd

\section{Recommended Citation}

Ryan, Michael J., "Aging-dependent effects of repetitive loading exercise and antioxidant supplementation on oxidative stress in skeletal muscle" (2010). Graduate Theses, Dissertations, and Problem Reports. 3093.

https://researchrepository.wvu.edu/etd/3093

This Dissertation is protected by copyright and/or related rights. It has been brought to you by the The Research Repository @ WVU with permission from the rights-holder(s). You are free to use this Dissertation in any way that is permitted by the copyright and related rights legislation that applies to your use. For other uses you must obtain permission from the rights-holder(s) directly, unless additional rights are indicated by a Creative Commons license in the record and/ or on the work itself. This Dissertation has been accepted for inclusion in WVU Graduate Theses, Dissertations, and Problem Reports collection by an authorized administrator of The Research Repository @ WVU.

For more information, please contact researchrepository@mail.wvu.edu. 


\title{
Aging-Dependent Effects of Repetitive Loading Exercise and Antioxidant Supplementation on Oxidative Stress in Skeletal Muscle
}

Michael J. Ryan, BS, M.Ed.

Dissertation submitted to the School of Medicine at West Virginia University in partial fulfillment of the requirements for the degree of

Doctor of Philosophy in

Exercise Physiology

Committee Members:

\author{
Stephen E. Alway, Ph.D., Chair \\ Robert G. Cutlip, Ph.D. \\ Michael R. Gunther, Ph.D. \\ G. Gregory Haff, Ph.D. \\ John M. Hollander, Ph.D.
}

Department of Exercise Physiology

Morgantown, West Virginia

2010

Keyword: Aging; Oxidative Stress; Resistance Training; Antioxidants; Skeletal Muscle Copyright 2010 Michael J. Ryan 


\title{
Abstract \\ Aging-Dependent Effects of Repetitive Loading Exercise and Antioxidant Supplementation on Oxidative Stress in Skeletal Muscle
}

\author{
Michael J. Ryan
}

\begin{abstract}
Aging is associated with a reduced ability to buffer oxidants along with an increase in oxidant production, resulting in chronic oxidative stress. Oxidative stress is a putative factor responsible for reducing function ability of skeletal muscle and increasing oxidative damage. The objective of this set of investigations was to evaluate the efficacy of reducing oxidative stress on improving muscle function the adaptive response of skeletal muscle to repetitive loading exercise in aging rodents. To achieve this objective, three methods of reducing oxidative stress were utilized; the antioxidant vitamins E\&C were used to buffer oxidants, the nutraceutical resveratrol was used to inhibit oxidant production and the pharmacological agent allopurinol was used to attenuate oxidant production specifically through the inhibition of xanthine oxidase activity. This set of investigations show evidence that muscles from aged animals have high basal levels of xanthine oxidase, and this is further exacerbated by resistance exercise. Antioxidant treatment in aged rodents will reduce oxidative stress associated with both aging and exercise. Furthermore, an increase in xanthine oxidase activity is a major contributor to the oxidative stress associated with resistance exercise (i.e. repetitive loading). Modulation of exercise-induced oxidative stress will effect adaptation of the endogenous antioxidant system and different therapeutic methods of reducing oxidative stress in aged muscle produce slightly different results in muscle function. The results suggest that resistance training increases xanthine oxidase activity, which contributes to exercise-induced oxidative stress in muscles of aged mice. Furthermore, resistance exercise invokes a distinctive response in the endogenous antioxidant enzymes that differ from that typically observed with aerobic exercise.
\end{abstract}


Table of Contents

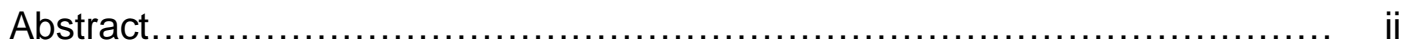

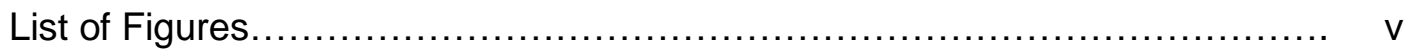

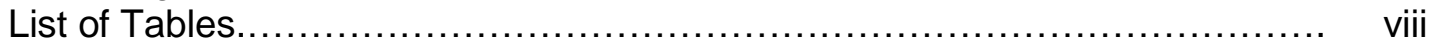

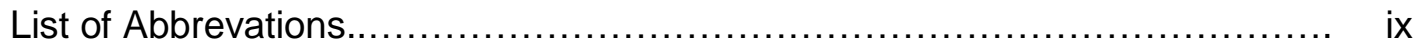

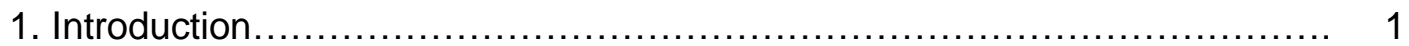

1.1 Central Hypothesis.............................................. 3

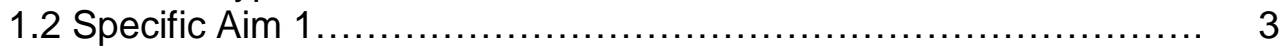

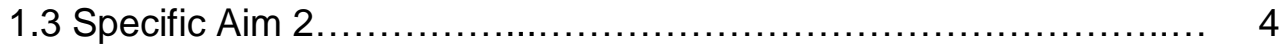

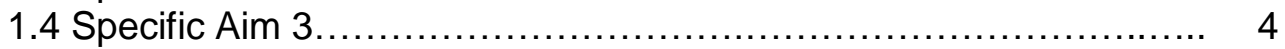

1.5 References..................................................... 5

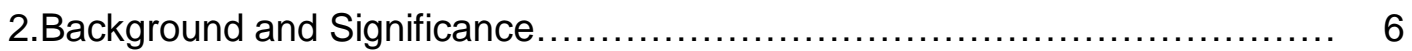

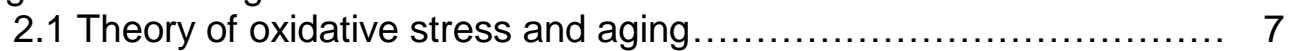

2.2 Oxidative stress in aging muscle..................................... 7

2.3 Effects of aging on the endogenous antioxidant defenses............ 8

2.4 Oxidative stress in muscle wasting ................................. 9

2.5 Mechanisms of oxidant production during exercise .................. 10

2.5.1 Oxidant production by neutrophils and other phagocytes.... 10

2.5.2 Oxidant production by mitochondria during exercise......... 11

2.5.3 Xanthine oxidase activity in exercising muscle.............. 13

2.6 Loading in aging muscle........................................... 14

2.7 Oxidative stress in muscle loading ................................. 15

2.8 Antioxidant supplementation and oxidative stress.................. 16

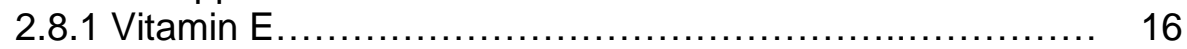

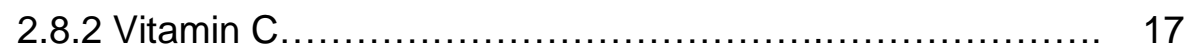

2.8.3 Vitamin E \& C combined....................................... 17

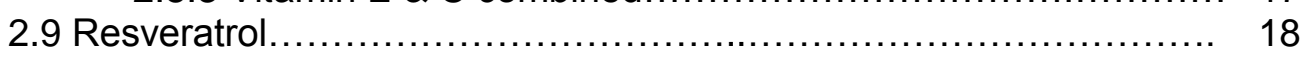

2.10 Summary \& Conclusion......................................... 19

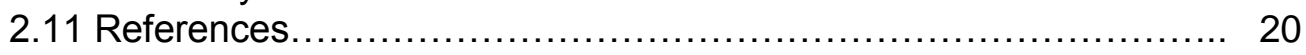

3. Aging-dependent regulation of antioxidant enzymes and redox status in chronically

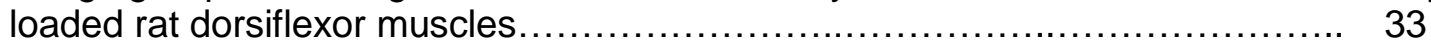

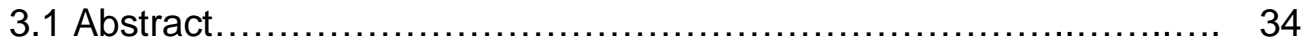

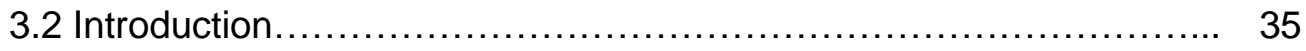

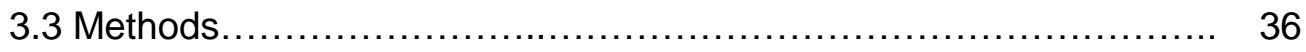

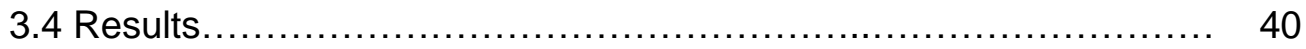

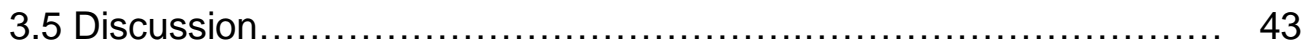

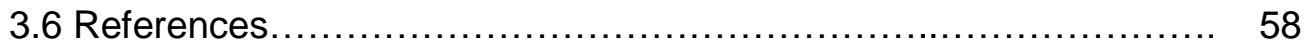

4. Effects of vitamin $E \& C$ supplementation on regulation of muscle function, oxidative stress and antioxidant enzymes in chronically loaded young and aged rat dorsiflexor

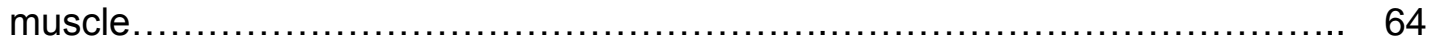

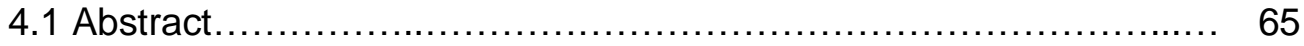

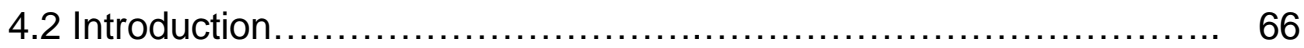

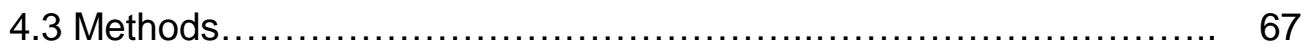

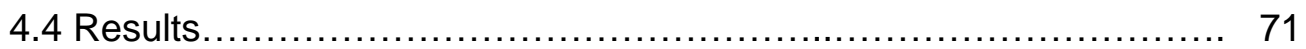

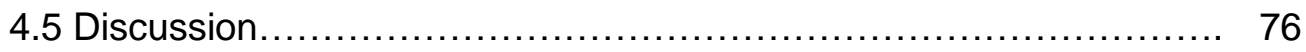

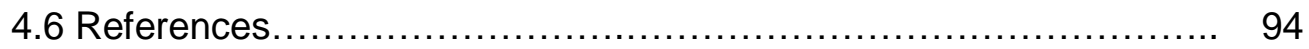




\section{Table of Contents (cont.)}

5. Regulation of oxidative stress and xanthine oxidase activity by resveratrol supplementation after isometric contractions in gastrocnemius muscles from young adult and aged mice 98

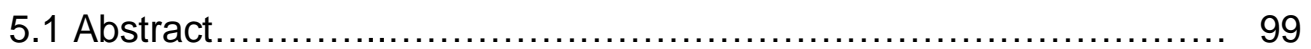

5.2 Introduction ......................................................... 100

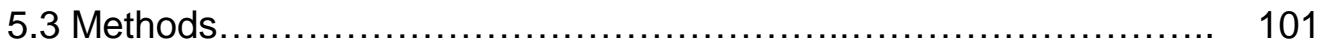

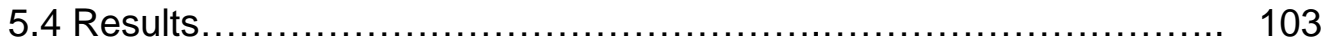

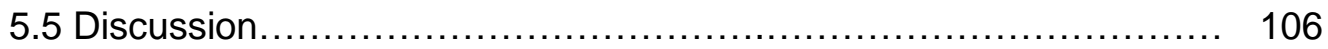

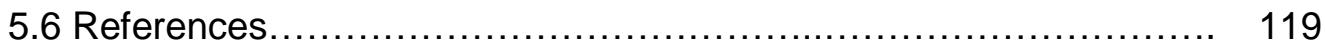

6. Inhibition of xanthine oxidase reduces oxidative stress and improves muscle function in exercised skeletal muscle from aged mice.................................. 123

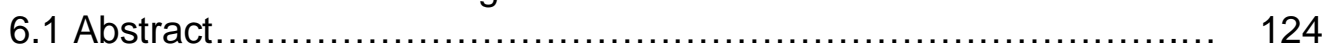

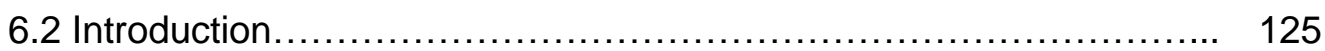

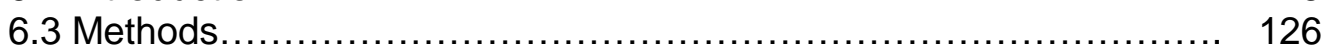

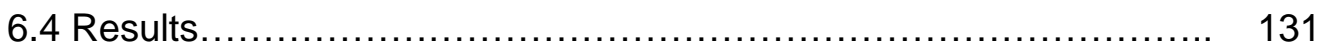

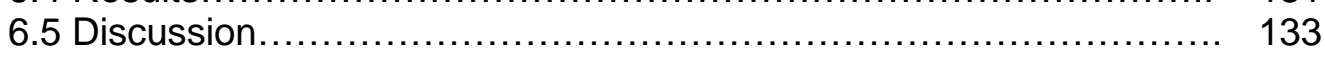

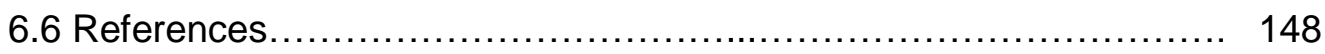

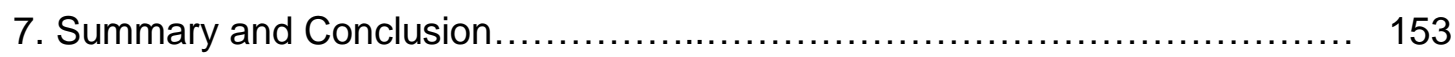

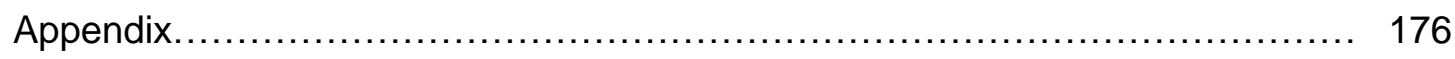




\section{List of Figures}

2.1 Mechanism for Oxidant Production via Xanthine

Oxidase ......................................................... 14

3.1 Repetitive loading induces muscle hypertrophy in the Tibialis Anterior Muscle.

3.2 Repetitive loading increased muscle functional measurements in young adult dorsiflexor muscles while maintaining function in aged dorsiflexor

muscles.

3.3 Concentration of hydrogen peroxide $\left(\mathrm{H}_{2} \mathrm{O}_{2}\right)$ are elevated with $\mathrm{RL}$ \& aging.

3.4 Ratio of reduced glutathione to oxidized glutathione (GSH/GSSG) ...... 50

3.5 Repetitive loading decreases lipid peroxidation in tibialis anterior muscles of aged rats.

3.6 Aging increased the quantity of DNA damage while RL had no effect.... 52

3.7 Glutathione peroxidase (GPx) activity decreased with repetitive loading.. 53

3.8 Catalase activity increased with repetitive loading and aging ............ 54

3.9 CuZn superoxide dismutase (CuZnSOD) protein levels and activity increased with repetitive loading in the tibialis anterior muscles of young but not old rats.

3.10 Mn superoxide dismutase (MnSOD) protein levels increased with repetitive loading in tibialis anterior muscles of young rats....

4.1 Repetitive loading induces muscle hypertrophy in the Tibialis Anterior Muscle.

4.2 Repetitive loading increased muscle functional measurements in young adult dorsiflexor muscles while maintaining function in aged dorsiflexor

muscles.

4.3 Vitamin E\&C supplementation attenuated the increase in hydrogen peroxide $\left(\mathrm{H}_{2} \mathrm{O}_{2}\right)$ concentration associated with exercise \& aging.

4.4 Ratio of reduced glutathione to oxidized glutathione (GSH/GSSG) \& total glutathione content.

4.5 Vitamin E\&C supplementation decreased evidence of oxidative damage associated with repetitive loading exercise and aging. 
4.6 Glutathione peroxidase (GPx) regulation with repetitive loading and Vitamin E\&C

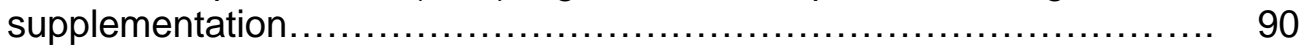

4.7 Catalase regulation with repetitive loading and Vitamin E\&C supplementation

4.8 CuZn superoxide dismutase (CuZnSOD) regulation with repetitive loading and Vitamin E\&C supplementation.

4.9 Mn superoxide dismutase (MnSOD) regulation with repetitive loading and Vitamin E\&C supplementation.

5.1 Maximal plantar flexor isometric force after 3 consecutive days of isometric exercise.

5.2 Resveratrol attenuated the increase in hydrogen peroxide $\left(\mathrm{H}_{2} \mathrm{O}_{2}\right)$ concentration associated with exercise and aging ................................. 114

5.3 Resveratrol attenuated the increase in xanthine oxidase activity and hypoxanthine

5.4 Total glutathione content \& ratio of reduced glutathione to oxidized glutathione (GSH/GSSG)....

5.5 Resveratrol supplementation decreased lipid peroxidation associated with isometric exercise, but not aging ...................................... 116

5.6 Glutathione peroxidase (GPx) activity, GPx-1 mRNA, catalase activity and catalase mRNA regulation with isometric exercise and resveratrol supplementation

5.7 Superoxide dismutase activity and mRNA regulation with isometric exercise and resveratrol supplementation.

6.1 Mechanism of oxidant production via xanthine oxidase pathway. 140

6.2 Allopurinol attenuated the increase in xanthine oxidase activity and hypoxanthine associated with exercise.

6.3 Inhibition of xanthine oxidase activity attenuated the increase in hydrogen peroxide $\left(\mathrm{H}_{2} \mathrm{O}_{2}\right)$ concentration and lipid peroxidation associated with exercise.

6.4 Concentration of total glutathione, oxidized glutathione (GSSG) and the ratio of reduced glutathione (GSH) / GSSG. 143

6.5 Glutathione peroxidase (GPx) and Manganese superoxide dismutase (MnSOD) activity \& mRNA regulation with isometric exercise and allopurinol treatment. 
6.6 Catalase and Copper zinc superoxide dismutase (CuZnSOD) activity, protein expression \& mRNA regulation with isometric exercise and allopurinol

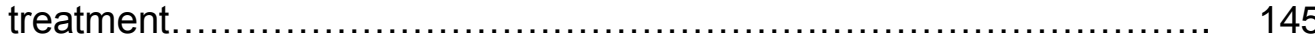

6.7 Aging increases apoptotic signaling.................................. 146

6.8 Maximal isometric forces from the plantar flexor muscles............... 147

7.1 Across study comparison of regulation of the endogenous antioxidant

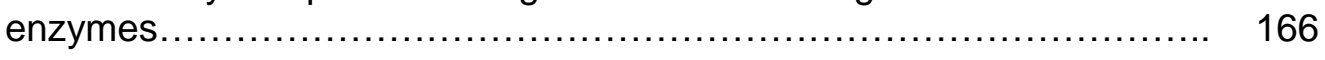

7.2 Corrected concentrations for hydrogen peroxide.................... 167 


\section{List of Tables}

4.1 Body Mass of Young and Aged Rats Pre and Post 14 sessions of repetitive

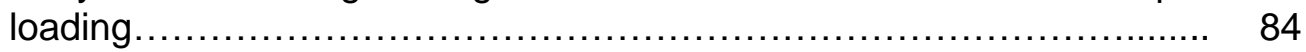

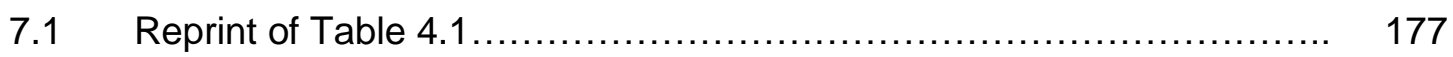

7.2 Body Mass of Young and Aged Mice............................. 178 


\section{List of Abbreviations}

\begin{tabular}{|c|c|}
\hline 8-OHdG & 8-hydroxy-2'-deoxyguanosine \\
\hline AAALAC & American Association for Accreditation of Laboratory Animal Care \\
\hline AAC & Aged, Allopurinol, Control non-exercised \\
\hline AAE & Aged, Allopurinol, Exercised \\
\hline ACC & Aged, Control (non-antioxidant treatment), Control non-exercise \\
\hline ACE & Aged, Control (non-antioxidant treatment), Exercised \\
\hline ADP & adenosine diphosphate \\
\hline AIF & apoptosis inducing factor \\
\hline Akt-mTOR-S6K & Akt/protein kinase B-mammalian target of rapamycin-p70 S6 kinase \\
\hline AMP & adenosine monophosphate \\
\hline AMPK & AMP-activated protein kinase \\
\hline ANOVA & analyses of variance \\
\hline $\mathrm{AO}$ & antioxidant \\
\hline AP-1 & activator protein 1 \\
\hline ARC & Aged-resveratrol-control non-exercised \\
\hline ARE & Aged-resveratrol-exercised \\
\hline ATC & Aged, Treatment (antioxidant), Control non-exercised \\
\hline ATE & Aged, Treatment (antioxidant), Exercised \\
\hline ATP & adenosine-5'-triphosphate \\
\hline BHT & butylated hydroxytoluene \\
\hline BW & body weight \\
\hline C57BL/6 & C57 black 6 mice \\
\hline cDNA & complimentary DNA \\
\hline CuZnSOD & copper-zinc superoxide dismutase \\
\hline DMC & Dynamic Muscle Control \\
\hline DNA & deoxyribonucleic acid \\
\hline DTT & dithiothreitol \\
\hline EC-SOD & extra-cellular superoxide dismutase \\
\hline EDTA & ethylenediaminetetraacetic acid \\
\hline EGTA & ethylene glycol tetraacetic acid \\
\hline ESR & electron spin resonance \\
\hline FADD & Fas-associated death domain protein \\
\hline FoxO1 & forkhead transcription factor- 1 \\
\hline GPx & Glutathione Peroxidase \\
\hline GSH & reduced glutathione \\
\hline GSSG & oxidized glutathione \\
\hline $\mathrm{H}_{2} \mathrm{O}_{2}$ & hydrogen peroxide \\
\hline HAE & 4-hydroxyalkenals \\
\hline IGF-1 & insulin-like growth factor-1 \\
\hline IL-6 & interleukin- 6 \\
\hline LDL & low density lipoprotein \\
\hline LSD & least significant difference \\
\hline MANOVA & multiple analyses of variance \\
\hline MAPK & mitogen-activated protein kinase \\
\hline MDA & malondialdehyde \\
\hline MnSOD & manganese superoxide dismutase \\
\hline mRNA & messenger RNA \\
\hline NADPH & nicotinamide adenine dinucleotide phosphate \\
\hline
\end{tabular}




$\begin{array}{ll}\text { NF-kB } & \text { nuclear factor kappaB } \\ \text { NFM } & \text { non-fat milk protein } \\ \text { NF-Y } & \text { nuclear factor-Y } \\ \text { NIA } & \text { National Institute on Aging } \\ \text { NO } & \text { nitric oxide } \\ \text { NOS } & \text { nitric oxide synthase } \\ \text { NS } & \text { non-supplemented } \\ \text { OD } & \text { optical density } \\ \text { PBS } & \text { phosphate-buffered saline } \\ \text { RFU } & \text { relative fluorescent units } \\ \text { RL } & \text { repetitive loading (exercise) } \\ \text { RNA } & \text { ribonucleic acid } \\ \text { ROS } & \text { reactive oxygen species } \\ \text { rRNA } & \text { ribosomal RNA } \\ \text { RT-PCR } & \text { reverse transcription-polymerase chain reaction } \\ \text { PAGE } & \text { polyacrylamide gel electrophoresis } \\ \text { PGC-1a } & \text { PPARy co-activator } \\ \text { PPAR } & \text { peroxisome proliferator-activated receptor } \\ \text { SEM } & \text { standard error of the mean } \\ \text { SERCA } & \text { sarco/endoplasmic reticulum Ca }{ }^{2+} \text {-ATPase } \\ \text { Sirt1 } & \text { silent mating type information regulation } 2 \text { homolog } \\ \text { SOD } & \text { superoxide dismutase } \\ \text { TA } & \text { tibialis anterior muscle } \\ \text { TBS-T } & \text { tris-buffered saline with 0.05\% Tween-20 } \\ \text { tGSH } & \text { total glutathione } \\ \text { TNF-a } & \text { tumor necrosis factor alpha } \\ \text { RDA } & \text { recommended daily allowances } \\ \text { USDA } & \text { United States Department of Agriculture } \\ \text { VO }{ }_{2 m a x} & \text { maximum oxygen uptake } \\ \text { YAC } & \text { Young, Allopurinol, Control non-exercise } \\ \text { YAE } & \text { Young, Allopurinol, Exercised } \\ \text { YCC } & \text { Young, Control (non-antioxidant treatment), Control non-exercise } \\ \text { YCE } & \text { Young-resveratrol-control non-exercise } \\ \text { YRC } & \text { Young-resveratrol-exercised } \\ \text { YRE } & \\ & \end{array}$




\section{Chapter 1}

\section{Introduction \& Specific Aims}

Michael J. Ryan 


\section{Introduction}

Aging is a natural process that is regulated by both genetic and environmental factors. It is associated with the degenerative modifications of all cell types. Although, the rate of cellular degeneration associated with aging differs among tissues and species, it is a process that is evolutionarily conserved. One of the major sites of age-related degeneration is in skeletal muscle. Loss of skeletal muscle mass and strength during senescence is termed sarcopenia. Sarcopenia has detrimental consequences in the elderly, as it may limit their ability to perform the necessary daily physical activities needed to maintain their independence. Simple daily tasks, such as rising from a seated position, become increasingly more difficult as muscle function declines. Additionally, sarcopenia is strongly associated with increased morbidity and mortality (4) costing families and taxpayers in excess of $\$ 18.5$ billion per year (2). Given that the elderly is the fastest growing proportion of our population, these cost are expected to exponentially increase. Reducing the prevalence of sarcopenia by a mere $10 \%$ could result in savings of over $\$ 1.1$ billion per year to the U.S. healthcare system. Understanding the mechanisms involved in sarcopenia is a critical step in helping clinicians develop safe and effective therapies designed to delay the onset of sarcopenia. Such therapies have the potential to assist the elderly in maintaining their independence and improve their quality of life along with reducing the finical burden to the American taxpayer.

There are many factors that contribute to sarcopenia; reduced physical activity, altered hormonal status, denervation of muscle fibers, inflammation and damage caused by a lifetime of exposure to reactive oxygen species (ROS) $(1 ; 3)$, all of which are associated with oxidative stress. Exercise training cannot prevent sarcopenia, but may reduce the prevalence of sarcopenia. Oxidants generated during exercise may play key roles (both positive and negatively) in the muscles' adaptive responses to chronic exercise. Advanced age is associated with an increase in oxidant production and a decreased capacity to buffer oxidants, resulting in a chronic state of oxidative stress. Oxidative stress damages DNA, lipids, proteins, and leads to elevated apoptotic signaling, thereby limiting the ability of muscle from aged animals to adapt appropriately to increased stresses, including exercise. Xanthine oxidase is one such source of oxidative stress in exercised muscles, but this oxidant activator has not been extensively studied in aged animals and/or humans. It is possible that buffering oxidant production may improve the muscle's ability to adapt to exercise, thereby reducing the affects of sarcopenia.

The overall goals of this project are to: (a) characterize the endogenous antioxidant pathways in aged skeletal muscle and their adaptive response to repetitive loading (repetitive stimulation of the muscle while movement is restricted), (b) to determine the effectiveness of dietary antioxidant supplementation to enhance the adaptive response to repetitive loading in aged skeletal muscle and (c) to determine the contribution of xanthine oxidase in the production of oxidants during repetitive isometric contractions in young adult and aged skeletal muscle. 


\subsection{Central Hypothesis}

The central hypothesis of this project is that skeletal muscles from aged animals will show increased evidence of oxidative stress following acute bouts of resistance exercise (repetitive loading) that sequentially influence adaptation to chronic exercise. However, increased basal levels of oxidative stress associated with aging will negatively influence the normal adaptive response the exercise that has been established in young adult animals. Antioxidant supplementation will increase the aged muscles' oxidative buffering capacity, thus attenuating the increase in oxidative stress associated with aging and improving adaptation to resistance exercise. Increased xanthine oxidase activity will be a contributing factor to the increase in oxidative stress in response to resistance exercise (i.e. repetitive loading) and aging.

\subsection{Specific Aim 1: To determine if aging negatively regulates the endogenous} anti-oxidant pathways during adaptation to repetitive loading and if antioxidant supplementation will improve these adaptive responses.

The dorsiflexors muscles of the left limb in young and aged rats will be loaded 3 times a week for 4.5 wks using 80 maximal stretch-shortening contractions per session while the contralateral (right) limb will serve as the intra-animal control. The animals will receive a diet consisting of a vitamin complex (vitamin E \& vitamin C) or a control diet. Markers of oxidative stress will be measured in tibialis anterior muscles.

Hypothesis 1: Dietary supplementation with Vitamin E\&C would attenuate the increase in basal levels of oxidative stress associated with aging allowing for a more complete adaptation in oxidative enzymes and improvements in muscle function after 4.5 weeks repetitive loading in the aged rats.

Sub-hypothesis 1.1: The tibialis anterior muscles from aged rats will experience greater levels of oxidative stress than the tibialis anterior from young adult rats.

Sub-hypothesis 1.2: Chronic repetitive loading will increase the oxidative buffering capacity and decrease the oxidant production of the tibialis anterior muscle, thus reducing the oxidative stress associated with aging.

Sub-hypothesis 1.3: Aging will attenuate the adaptive responses in the endogenous antioxidant pathways and this will be closely associated with attenuated functional adaptations to repetitive loading in skeletal muscle.

Sub-hypothesis 1.4: Dietary supplementation with a vitamin complex will lessen the oxidant activity in tibialis anterior muscles subjected to repetitive loading.

Sub-hypothesis 1.5: In muscles from aged rats, a combination of the antioxidant supplementation and repetitive loading exercise will reduce oxidative stress to a greater extent than either treatment independently.

Sub-hypothesis 1.6: In repetitively loaded muscles from both young adults and aged rats, antioxidant supplementation will improve muscle function as represented by increases in force production. 
1.3 Specific Aim 2: To determine the efficacy of resveratrol supplementation as a possible countermeasure for the oxidative stress associated with aging exercise in skeletal muscle.

The plantar flexors of the left limb from young adult and aged mice will be activated by 20 , five-second isometric contractions $(10 \mathrm{v}, 100 \mathrm{~Hz}, 200 \mu \mathrm{s}$ pulses) for 3 consecutive days. This protocol was selected to induce oxidative stress without causing damage to the muscle. The contralateral limb will serve as the intra-animal control. Mice will be randomly assigned to either a control (non-supplemented) diet or a diet supplemented with $0.05 \%$ trans-resveratrol.

Hypothesis 2: Fortification of normal mice chow with resveratrol will reduce the indices of isometric exercise-induced oxidative stress and attenuate the loss of force during acute repetitive isometric contractions from muscles of aged mice.

Sub-hypothesis 2.1: Resveratrol supplementation will lower indices of oxidative stress associated with aging and acute exercise in muscle from young adults and aged mice.

Sub-hypothesis 2.2: Resveratrol supplementation will improve muscle function and attenuate the loss of force during acute repetitive isometric contractions from muscles of both young adults and aged mice.

1.4 Specific Aim 3: To determine: (a) the contribution of xanthine oxidase as a source of oxidant production during repetitive isometric contractions in young adult and aged skeletal muscle, and (b) the effect of xanthine oxidase inhibition on the decreased functional capacity and increased apoptotic signaling associated with repetitively loaded skeletal muscle from aged animals.

Electrically-stimulated isometric contractions $(10 \mathrm{v}, 100 \mathrm{~Hz}, 200 \mu \mathrm{s}$ pulses) of the plantar flexors of the left limb will be conducted for 3 consecutive days in young and aged mice. The animals will receive a time released xanthine oxidase inhibitor tablet (Allopurinol) prior to repetitive loading and its' effects on markers of oxidative stress and apoptosis will be measured.

Hypothesis 3: The inhibition of xanthine oxidase will eliminate the majority of isometric exercise-induced oxidative stress thus preserving the muscles functional capacity while reducing mitochondrial apoptotic signaling in aged animals after exercise.

Sub-hypothesis 3.1: Repetitive isometric contractions will increase xanthine oxidase activity resulting in an increase in indices of oxidative stress. Allopurinol administration will abolish xanthine oxidase activity thus decreasing indices of oxidative stress.

Sub-hypothesis 3.2: Inhibition of xanthine oxidase (via allopurinol) will improve the redox environment within muscle attenuating the decrease in the functional capacity in aged animals after three days of isometric exercise.

Sub-hypothesis 3.3: Xanthine oxidase activity is elevated in aged muscles which in part, lead to increased apoptotic signaling; moreover reducing xanthine oxidase will decrease apoptotic signaling in aged muscle after exercise allowing for increased adaptation and improved force production. 
Reference List

1. Fulle S, Protasi F, Di Tano G, Pietrangelo T, Beltramin A, Boncompagni S, Vecchiet $\mathbf{L}$ and Fano $\mathbf{G}$. The contribution of reactive oxygen species to sarcopenia and muscle ageing. Experimental Gerontology 39: 17-24, 2004.

2. Janssen I, Shepard DS, Katzmarzyk PT and Roubenoff R. The healthcare costs of sarcopenia in the United States. J Am Geriatr Soc 52: 80-85, 2004.

3. Leeuwenburgh C, Fiebig R, Chandwaney R and Ji LL. Aging and exercise training in skeletal muscle: responses of glutathione and antioxidant enzyme systems. Am J Physiol 267: R439-R445, 1994.

4. Metter EJ, Talbot LA, Schrager M and Conwit R. Skeletal muscle strength as a predictor of all-cause mortality in healthy men. J Gerontol A Biol Sci Med Sci 57: B359B365, 2002. 


\section{Chapter 2}

\section{Background and Significance}

Michael J. Ryan 


\section{Background and Significance}

2.1 Theory of oxidative stress and aging

Aging is a naturally occurring process that causes deleterious modifications at a genetic, cellular, tissue, and system level in all organisms. Presently, the fundamental mechanisms of aging are poorly understood, but a growing body of evidence supports an increase in oxidative stress as one of the principal components. In 1956, Harman suggested that aging occurs because of the accumulation of irreversible damage from free radicals to biologically important macromolecules (61). Advanced aging is associated with increases in lipid peroxidation, protein carbonyl formation and DNA damage. These forms of oxidative damage lead to altered receptor function, ion transport systems, enzyme activation/deactivation, and altered gene expression. Over the past two decades it has been shown that the accumulation of oxidative damage is dependent on more than just free radicals, but also all oxidizing agents or oxidants.

\subsection{Oxidative stress in aging muscle}

Oxidative stress is defined as a state in which the cellular production of oxidants exceeds the cells' physiological buffering capacity. Concomitantly with oxidative stress, advanced aging is associated with a loss of muscle mass and strength, known as sarcopenia. Reductions in muscle strength with aging are directly correlated with decreases in muscle mass $(3,39,96)$. Muscle strength has been reported to decline an average of $20-40 \%$ in healthy men and women during the seventh and eighth decades of life (45). Muscle fiber size, determined by cross sectional area, is also reduced an average of $40 \%$ between the ages of 20 and 60 (45). Sarcopenia is a contributing factor to the loss of independence and frailty often observed in older adults (157).

Oxidative stress is associated with sarcopenia, however whether oxidative stress is a cause or a result of sarcopenia is unknown. Aging-induced oxidative stress can be an important mechanism hindering muscular adaptation to loading $(18,24,79,80)$. In aged animals, the ability to buffer increased oxidant production is reduced in comparison to muscle from young animals (53). Within skeletal muscle, oxidative stress has been shown to depress muscle specific force (30), alter myofilament function $(5,87,88)$, and /or alter contraction-induced calcium release $(7,43,48,127)$. Chronic oxidative stress may also reduce muscle force by increasing recovery time associated with injury $(86,163)$. Furthermore, increases in oxidant production regulate redox-sensitive signaling pathways $(76,78,92)$ which can lead to the upregulation of catabolic gene expression $(41,101,104,159)$ and activate apoptotic pathways $(84,102,137)$ in muscle.

Oxidative stress associated with aging has been reported in most tissue types, (106, $146,164)$ including skeletal muscle $(52,55,128,145)$. Bejma and Ji (18) demonstrated that skeletal muscle from aged rats had a dramatic increase ( $80 \%)$ in oxidant production. Elevations in oxidants are associated with cellular damage and ultimately apoptosis in various cell types, $(44,145)$ including skeletal muscle cells $(53,85)$. Recent data from muscle biopsies obtained from young and aged men showed that 8-hydroxy-2'-deoxyguanosine (8-OHdG), protein carbonyls, the manganese isoform of superoxide dismutase (MnSOD) and catalase activity are significantly higher in muscles taken from elderly men (55); similar results have been seen in rodents (128). The contractile proteins, actin and myosin, do not show evidence of increased oxidative damage (148), leading to speculation that increased oxidant production in muscle may have more important roles in regulating genes (i.e. transcription/translation) and metabolic mechanisms (i.e. electron transport chain). Muscle from aged animals has been shown to have a decreased quantity of full-length mitochondrial DNA and increased 
mitochondrial deletions compared to young animals (55). Additionally, aging has been associated with a decrease in mitochondrial membrane integrity due to the depolarization of the mitochondrial membrane and decreased mitochondrial respiratory activity (112). A decrease in mitochondrial membrane integrity combined with a reduction in antioxidant enzyme activity leads to an unfavorable release and accumulation of oxidants within the cells (112). This is supported by evidence that shows that the majority of oxidants produced in skeletal muscle from aged animals originates within the mitochondria (18).

There is conflicting data on whether xanthine oxidase contributes to the increased oxidant production associated with advanced age. Both the heart (133) and gastrocnemius muscles (65) from aged rodents exhibit increased xanthine oxidase activity when compared to young, however this has not been observed by all (47). The contribution of increased xanthine oxidase activity leading to oxidative stress and apoptotic signaling associated with aging is insufficiently characterized.

\subsection{Effects of aging on the endogenous antioxidant defenses}

It has been widely recognized that glutathione peroxidase (GPx), catalase, Copper-Zinc containing isoform of superoxide dismutase (CuZnSOD) and MnSOD enzymes make up part of the endogenous antioxidant defense system that is essential for aerobic organisms to survive. These enzymes form the front line in the defense against oxidant attack and work in unison with several other non-enzymatic molecules (i.e. cellular vitamin E\&C concentrations) to avoid oxidative damage. Superoxide dismutase catalyzes the reduction of superoxide anion into hydrogen peroxide $\left(\mathrm{H}_{2} \mathrm{O}_{2}\right)$, which is subsequently detoxified by catalase and GPx. Three different isoforms of superoxide dismutase have been identified; they include the previously mentioned CUZnSOD and MnSOD along with extra-cellular superoxide dismutase (EC-SOD). CuZnSOD contains $\mathrm{Cu}$ and $\mathrm{Zn}$ atoms at its catalytic site and is primarily located in cytoplasm of cells, though small amounts of the enzyme have been found in the mitochondrial intermembrane space (120). Conversely, MnSOD is localized to the inner mitochondrial matrix and contains a manganese atom in its catalytically active center. Like CuZnSOD, EC-SOD contains $\mathrm{Cu}$ and $\mathrm{Zn}$ atoms at its catalytic site. EC-SOD is primarily located on the extracellular side of cell surface membranes and throughout the extracellular matrix as well as, although to a lesser extent, circulating within the blood plasma (49). It has been reported that within mouse skeletal muscle, the concentration of CuZnSOD is 27 times greater than that of MnSOD and 166 times greater than EC-SOD (105).

Advanced aging is associated with a reduced capability of the endogenous antioxidant defenses to convert oxidants into more inert species $(74,121)$. It appears that the agedependent increase in oxidant production overwhelms the endogenous antioxidant defense system resulting in oxidative stress. As a result there is a general elevation in the activity of the antioxidant enzymes within aged skeletal muscle $(77,121)$ which is regulated primarily at the post-translational level (67).

The most identifiable age- associated change in the endogenous antioxidant defenses is an increase in activity of $\operatorname{MnSOD}(55,67,74,95,98,121)$. Theoretically this aging induced adaptation in MnSOD would be a result of the increased oxidant production from within the mitochondria from aged muscle. By and large there is thought to be an increase in GPx activity in aged muscle $(67,74,98)$, however not all have reported age-dependent changes in GPx activity $(67,68,121)$. Similar to GPx activity, catalase activity has generally been reported to increase within muscle from aged animals $(55,67,77,95,98)$. However, this response may slightly differ depending on the muscle being investigated $(67,98)$. 
An age-associated reduction in CuZnSOD efficiency appears to be a good candidate for explaining increased superoxide levels leading to long-term oxidative damage and eventual loss of skeletal muscle. CuZnSOD deficient mice demonstrate a $30 \%$ reduction in lifespan and decreased muscle mass in predominantly type II muscle (gastrocnemius and plantaris) but no changes were observed in the soleus which is composed of primarily type I fibers (117). Recent data (160) also suggest that CuZnSOD levels are lower in muscle tissue of aged pigs.

Pansarasa et al. (121) have found that humans 66-75 years of age have significantly lower total SOD activity, but greater MnSOD activity than younger humans, suggesting that there is a decrease in CuZnSOD activity. Regrettably, there is not an agreement within the scientific literature that there is a decrease in CuZnSOD activity with age. It has been observed that long lived animals (i.e. humans and naked mole rats) do not show this decrease in CuZnSOD and other oxidative enzymes $(34,55)$. In Fisher 344 rats, it has been shown that CuZnSOD activity increases during ageing and this increase may be due to both translational and posttranslational control (67). CuZnSOD levels increase in cells of young animals after exercise (66), and although Vasilaki et al. (150) report an increased level of CuZnSOD activity in muscles of old animals after a single bout of electrically activated muscle contractions, it is possible that old muscles may fail to respond in this manner when undergoing chronic repetitive loading. Furthermore, even if CuZnSOD does increase either similarly or greater in old vs. young muscles with repetitive loading, it is unknown if this will be sufficient to counteract the loadinginduced and intrinsic (age-associated) increase in oxidant production in (116) aged muscles.

\subsection{Oxidative stress in muscle wasting}

A consensus of the available scientific data supports the conclusion that even healthy aging is associated with an escalation in oxidative damage and increased oxidant production. This could be the primary reason for augmented myonuclear apoptosis in aged skeletal muscles $(91,99,125,126,136)$. However, the exact process of how increased oxidant production may influence and /or regulate apoptotic signaling is unknown. Both oxidative stress and increased myonuclear apoptosis have been implicated in the pathogenesis of sarcopenia. Muscle wasting, leading to atrophy, is accompanied by a reduction in protein synthesis, and/or an activation of proteolysis. These events may be initiated and/or mediated by oxidative stress (114). Furthermore, oxidative stress may also contribute to the activation of myonuclear apoptotic cascades in skeletal muscle $(136,137)$. It has been suggested that a number of small, random, deleterious effects of increased oxidants could explain the degenerative process in skeletal muscle resulting in sarcopenia. Muscle atrophy has been shown to be associated with many different pathways of oxidant production; generation of oxidants by xanthine oxidase (90), production of nitric oxide (NO) via nitric oxide synthase (NOS)(72), formation of oxidants by increased cellular levels of reactive iron $(65,89,161)$, increases in NADPH oxidase (18), and increased oxidant production via the mitochondrial $(18,26,33,99)$. Additional evidence implicating that oxidative stress is linked with muscle atrophy is the observed increase in lipid peroxidation, glutathione oxidation and protein carbonyl formation from atrophic muscle $(56,87$, 88, 90, 97). Furthermore, increased oxidant generation has been implicated as a reason for muscle dysfunction associated with sarcopenia (117). Fulle et al. (53) have suggested the following mechanisms for how reactive oxygen species may contribute to muscle atrophy: (a) biochemical alterations of cell structures (i.e. peroxidation of cell membranes that increase oxidant production during physical activity), (b) the increased fragility of muscle that accompanies mechanical injury and subsequent inflammation, (c) reduced satellite cell/muscle stem cell proliferation in conjunction with reduced protein synthesis thus limiting the antioxidant defense and repair capacity, and (d) reduced dietary antioxidant intake. However, there are no data that address the role of oxidative stress produced by repetitive loading exercise in aged 
muscle. The underlying cause for increased oxidant formation associated with exercise in aged muscle is unknown; this information is essential to develop useful strategies for improving muscle adaptations to loading in elderly individuals.

\subsection{Mechanisms of oxidant production during exercise}

It is widely accepted that exercise increases oxidant production even though there are only a few studies that supply direct in vivo evidence of this. Measuring free radicals within biological systems is problematic because they are highly reactive and maintain low steadystate concentrations. Electron paramagnetic resonance spectroscopy, also referred to as electron spin resonance (ESR) spectroscopy, coupled with the use of spin traps, is perhaps the most specific and direct method of measuring free radical species (12). Electron paramagnetic resonance spectroscopy has been employed to show that the concentration of free radical species increase after exercise in both rat muscle (38) and human blood (10). Further studies using 2', 7'-dichlorodihydrofluorescein as an intracellular probe for $\mathrm{H}_{2} \mathrm{O}_{2}$ show strong evidence that after exercise oxidant production is heightened $(18,72,108)$. Oxidants in muscle are primarily derived in the form of two molecules; superoxide and nitric oxide. Superoxide anions will rapidly dismutate to $\mathrm{H}_{2} \mathrm{O}_{2}$ (and water) but can form hydroxyl radicals and other smallmolecular-weight oxidants or reactive oxygen species. In addition, $\mathrm{NO}$ originating within exercising muscle may act as a precursor for the formation of peroxynitrite, peroxynitrous acid, and other nitrogen-derived oxidizing molecules or reactive nitrogen species (72).

Skeletal muscle generates reactive oxygen species and reactive nitrogen species at low basal levels under resting conditions but during exercise the metabolic demand to sustain muscle contractions increase, resulting in an increase in oxidant production. It is generally accepted that there are three major sources of oxidant production with exercise; neutrophils and other infiltrating immune cells, mitochondrial respiration and xanthine oxidase activity $(31,72$, $100,131)$. Oxidant production from each source is dependent on the mode, duration, and intensity of exercise. During strenuous exercise there will be two phases of increased oxidant production. The first increase in intramuscular oxidant generation will occur during and immediately following a bout of exercise. This will be characterized by increases in oxidants within the working muscle and systemic oxidative stress is found in other tissues $(144,151)$. The second increase in oxidant generation is delayed and tends to be more localized to the working muscle, specifically damaged fibers. The delayed response is a product of phagocytic cell invasion $(103,164)$ resulting from injury and is not associated with an increase in the metabolic demand during exercise.

\subsubsection{Oxidant production by neutrophils and other phagocytes}

Strenuous exercise involving eccentric muscle contractions has been shown to result in substantial injury potentiating the release of cytokines. Cytokines can activate neutrophils and other phagocytes promoting their release into the circulation. The activated neutrophils produce oxidants to aid in the removal of damaged tissue and assist in the repair process after exercise. Neutrophil-derived oxidant production is directed at damaged tissue and can overwhelm the muscles endogenous antioxidant defense mechanisms (124). This process appears to be essential for removal of damaged tissue and muscle fiber regeneration. It is theorized that phagocytic oxidant production could damage neighboring healthy fibers, but there is no direct evidence supporting this idea. Neutrophil activation during exercise does not appear to increase lipid markers of oxidative stress in the circulation to any significant degree (124). Furthermore, stereological analysis of muscle 72 hours after repetitive loading showed there was a large increase in phagocytic cells within the interstitial space surrounding damaged myofibers, but the phagocytic infiltrates were not associated with healthy non-degenerative fibers (14). Phagocytic 
cells cause an increase in intramuscular oxidants hours after a bout of exercise, but evidence of oxidative stress in non-injured myofibers may be overestimated when assessed by means of muscle homogenate. Antioxidant supplementation has been suggested as a possible countermeasure for the increased production of oxidants via phagocytic cells. When neutrophils are stimulated in vitro, antioxidant supplements such as $\mathrm{N}$-acetylcysteine have been shown to be effective at buffering the increase in oxidants (124), whereas vitamin $E$ supplementation reduced the infiltration of neutrophils into muscle cells (124).

Although there is a lack of data showing evidence that oxidants produced via inflammatory infiltrates cause oxidative damage to neighboring healthy cells, a more oxidizing redox environment may alter muscle function $(5,30)$. Myofibrillar $\mathrm{Ca}^{2+}$ sensitivity appears to be especially susceptible to changes in the redox environment (5). The use of antioxidant supplements may prevent, or at least minimize, the formation of an unfavorable redox environment generated from neutrophils and other phagocytes.

\subsubsection{Oxidant production by mitochondria during exercise}

It is widely assumed that mitochondria are the major source of oxidant production during exercise $(42,53)$. Mitochondria have been shown to produce superoxide, hydrogen peroxide, and possibly hydroxyl radicals. There is considerable data showing a correlation between increased oxidative metabolism and increased oxidant production and oxidative damage (15). It has been accepted for over thirty years that superoxide generation in the mitochondria is produced via a membrane-bound multi-enzyme redox system (27) referred to as the mitochondrial electron transport chain. Surprisingly, there is little direct evidence from intact cells that the production of oxidants via the mitochondrial electron transport chain causes oxidative damage (79). Although the mitochondrial electron transport chain is very efficient, its own make up is based on controlling a series of alternating one-electron oxidation-reduction reactions that can predispose each electron carrier to side reactions with molecular oxygen. As an example, ubiquinone, which excepts electrons from complex I and II of the mitochondrial electron transport chain, cycles between the quinone (fully oxidized form) to semiquinone (oneelectron reduction product) to quinol (fully reduced by two electrons), there is a tendency for an electron to pass or "leak" to oxygen generating superoxide. Nevertheless, acute bouts of increased oxidant production within the mitochondria (such as during exercise) are unlikely to cause oxidative damage because of high levels of superoxide dismutase and GPx.

Early work on isolated mitochondria estimated that 2-5\% of the total $\mathrm{O}_{2}$ consumed was converted to oxidants via the leakage of electrons from the mitochondrial electron transport chain (22). Leakage of electrons is most common at complex I and complex III of the electron transport chain $(22,64,115,131)$. Muller et al. (115), published data that indicates that complex III can release superoxide to both sides of the inner mitochondrial membrane, providing a potential source for cytosolic superoxide generation. Additionally, complex I-dependent superoxide formation is exclusively released into the matrix and no detectable levels of superoxide escape from intact mitochondria (115).

The early estimations of oxidant production from the mitochondrial electron transport chain were obtained using isolated mitochondria in state IV respiration (22). Furthermore, oxidant production during exercise was predicted by multiplying state IV respiration by the increase in $\mathrm{VO}_{2}$ during exercise (which in humans is $\sim 20$ times higher during exercise than during rest). State IV (resting) respiration is defined as oxygen consumption within isolated mitochondria in the presence of substrate without any ADP or inhibitors. State III (active) respiration is achieved by the addition of large amounts of ADP. Experiments using isolated 
mitochondria have shown oxidant production is dramatically reduced by the addition of ADP (a State IV to State III conversation) (63).

During exercise, muscle contractions produce an increased demand for ATP which is initially met by the ATP-PC system, glycolysis and glycogenolysis. Electron transport is stimulated as the concentration of ADP from anaerobic metabolism increases. ADP and an inorganic phosphate bind to ATP synthase, thus permitting protons to travel down their chemiosmotic gradient into the mitochondrial matrix. The energy released as protons pass through the channel into the inner mitochondrial matrix is utilized to bind the inorganic phosphate to ADP producing ATP; this process is known as oxidative phosphorylation. The additional ADP formed during exercise is transported into the matrix which increases the rate that ADP and inorganic phosphate bind to ATP synthase, thus leading to more protons traveling through the channel into the inner mitochondrial matrix. As energy from the chemiosmotic gradient is consumed, the mitochondrial electron transport chain accelerates, pumping protons back out of the inner mitochondrial membrane in an attempt to maintain the gradient.

As more high-energy electrons pass through the mitochondrial electron transport chain there is a greater demand for molecular oxygen which acts as the final electron accepter. In this way oxygen consumption is coupled to ADP phosphorylation by ATP synthase through the protons chemiosmotic gradient.

The respiratory states of isolated mitochondria have been studied to gain a better knowledge of how mitochondria work, but one must remember that by definition in vivo there is no such thing as state IV respiration $(15,100)$. Even during rest when the energy demand is low, mitochondria are constantly carrying out oxidative phosphorylation at rates that are proportional to the availability of ADP. Since ADP is always present, in vivo mitochondria are somewhere in between state III \& IV $(79,100)$. It has been suggested that oxidant production from the mitochondria during exercise (when metabolic activity is high and ADP abundant) has been over estimated (100).

In 2002, J. St-Pierre et al. (140) re-examined the rate at which mitochondria produced oxidants. This data indicated that the maximum estimation of electrons flowing through the mitochondrial electron transport chain resulting in oxidant production was $\sim 0.15 \%$, or less than $10 \%$ of the original minimum estimate. Additional evidence indicating that mitochondrial production of oxidants might be overestimated has recently been found using $2{ }^{\prime}, 7^{\prime}$ dichlorodihydrofluorescein to probe for oxidant production in contracting C2C12 myotubes(108). 2', 7'-dichlorodihydrofluorescein is a specific method for measuring $\mathrm{H}_{2} \mathrm{O}_{2}$ in cells. Results showed the 2',7'-dichlorodihydrofluorescein was distributed evenly throughout the cells with no evidence of accumulation at any specific intracellular site, or localization to mitochondria. In a similar set of experiments myotubes differentiated from isolated skeletal muscle satellite cells from wild-type, heterozygous MnSOD knockout mice (Sod2(+/-)), and MnSOD over-expressers (Sod2-Tg) to show oxidant production in non-contracting myotubes increased in the Sod2(+/-), whereas in the Sod2-Tg oxidant production decreased (149). These results suggest that in quiescent myotubes mitochondrial production of oxidants is largely influenced by the amount of antioxidant enzymes present in the system. In contrast, when the myotubes were electrically stimulated, oxidant production was unaltered by reducing or increasing MnSOD, signifying that oxidants in contracting myotubes are primarily generated by methods outside of the mitochondria (149). 
In the previously mentioned studies, simply because 2',7'-dichlorodihydrofluorescein activity was not localized to the mitochondria does not mean that oxidant production is not occur there. Mitochondria will produce superoxide that is quickly converted into $\mathrm{H}_{2} \mathrm{O}_{2}$ which has the capability to pass through lipid membranes. Therefore, it is impossible to rule out that the increase in 2',7'-dichlorodihydrofluorescein activity was caused by increased superoxide production within the mitochondria, which was converted to $\mathrm{H}_{2} \mathrm{O}_{2}$, then diffused throughout the cell. Although this explanation is possible, the previously mentioned studies do not show data supporting increased mitochondrial oxidant production during exercise. Furthermore, it seems unlikely that $\mathrm{H}_{2} \mathrm{O}_{2}$ would diffuse so evenly throughout the cell. A more likely scenario is that the fluorescent intensity would be greatest at the source of $\mathrm{H}_{2} \mathrm{O}_{2}$ production and evenly dissipate outward from that point. Furthermore, if $\mathrm{H}_{2} \mathrm{O}_{2}$ was produced in the mitochondria during exercise and evenly diffused throughout the cell at a concentration above control levels, then it would be expected that mitochondria isolated from exercised muscle would show evidence of higher $\mathrm{H}_{2} \mathrm{O}_{2}$ concentrations. However, Bejma and $\mathrm{Ji}(18)$ failed to find any change in 2',7'-

dichlorodihydrofluorescein oxidation in isolated mitochondria from post-exercised muscle when compared to pre-exercised mitochondria, although post- exercised muscle homogenate demonstrated a $38 \%$ (young) to 50\% (aged) increase in 2',7'-dichlorodihydrofluorescein oxidation post-exercise.

Bejma and Ji's (18) data support the likelihood that sources outside the mitochondria are, at least in part, responsible for oxidant production during exercise; nevertheless they suggest that mitochondria are responsible for the majority of the increased oxidant production associated with aging. In all likelihood, if mitochondrial oxidant production during exercise is not substantial enough to overwhelm the antioxidant defenses, thus failing to cause oxidative damage, then at least slight increases in mitochondrial derived oxidants may be involved in the adaptive response to exercise. Furthermore, this is not an attempt to minimize the important role that mitochondria play in the increased oxidant production associated with aging and disease states. However, the lack of evidence showing mitochondria are the primary source of oxidant production associated with exhaustive exercise is sufficient to warrant the investigation of alternative sources of oxidant production.

\subsubsection{Xanthine oxidase activity in exercising muscle}

Increased activity of the xanthine oxidase enzyme within the vascular endothelium (69) is an important source of extracellular oxidant production in the vascular endothelium $(57,69)$ and has been shown to be a contributing factor associated with oxidative stress during exercise $(9,46,57,62,131,152)$. Vina et al. $(152,153)$ have shown that exhaustive exercise leads to an increase in blood xanthine oxidase activity in rats and humans. Furthermore, the inhibition of xanthine oxidase with allopurinol administration prevented exercise-induced glutathione oxidation (GSH/GSSG ratio) and lower indices of lipid peroxidation (MDA) after exercise. It has been hypothesized that the activation of xanthine oxidase enzyme during exhaustive exercise is similar to the process observe during ischemia-reperfusion injury $(110,123,152)$. Under normal physiological conditions, xanthine dehydrogenase is the principal form of the enzyme, which oxidizes both hypoxanthine and xanthine to form uric acid via the reduction of NAD ${ }^{+}$to NADH. However, during repetitive muscle contractions, the increased ATP utilization and a brief localized period of ischemia will facilitate adenine nucleotide degradation, thus breaking down of ATP to AMP and eventually hypoxanthine. Simultaneously to the increase in hypoxanthine xanthine dehydrogenase will be converted to xanthine oxidase either reversibly by oxidation, or irreversibly via proteolysis $(32,119)$. Conversion of xanthine dehydrogenase to xanthine oxidase has been shown to be dependent on both calcium and oxidant concentrations (111). During muscle contractions, intracellular calcium concentrations are elevated, which in turn may 
activate proteases that cause the irreversible conversion of xanthine dehydrogenase to xanthine oxidase. Furthermore, increased oxidant production may lead to the oxidation of Cysteine residues on xanthine dehydrogenase that forms disulfide bonds resulting in the reversible conversion to xanthine oxidase.

During muscle relaxation the influx of oxygen rich blood would allow xanthine oxidase to catalyze the reaction of hypoxanthine and oxygen to form xanthine and superoxide. Within the muscle homogenate, at least part of the increased $\mathrm{H}_{2} \mathrm{O}_{2}$ concentration associated with exercise is expected to be the result of an increased accumulation of superoxide formed by xanthine oxidase activity, which has been dismutated into $\mathrm{H}_{2} \mathrm{O}_{2}$ via a reaction catalyzed by superoxide dismutase. See Figure 2.1.

Figure 2.1

\section{Mechanism for Oxidant Production via Xanthine Oxidase}

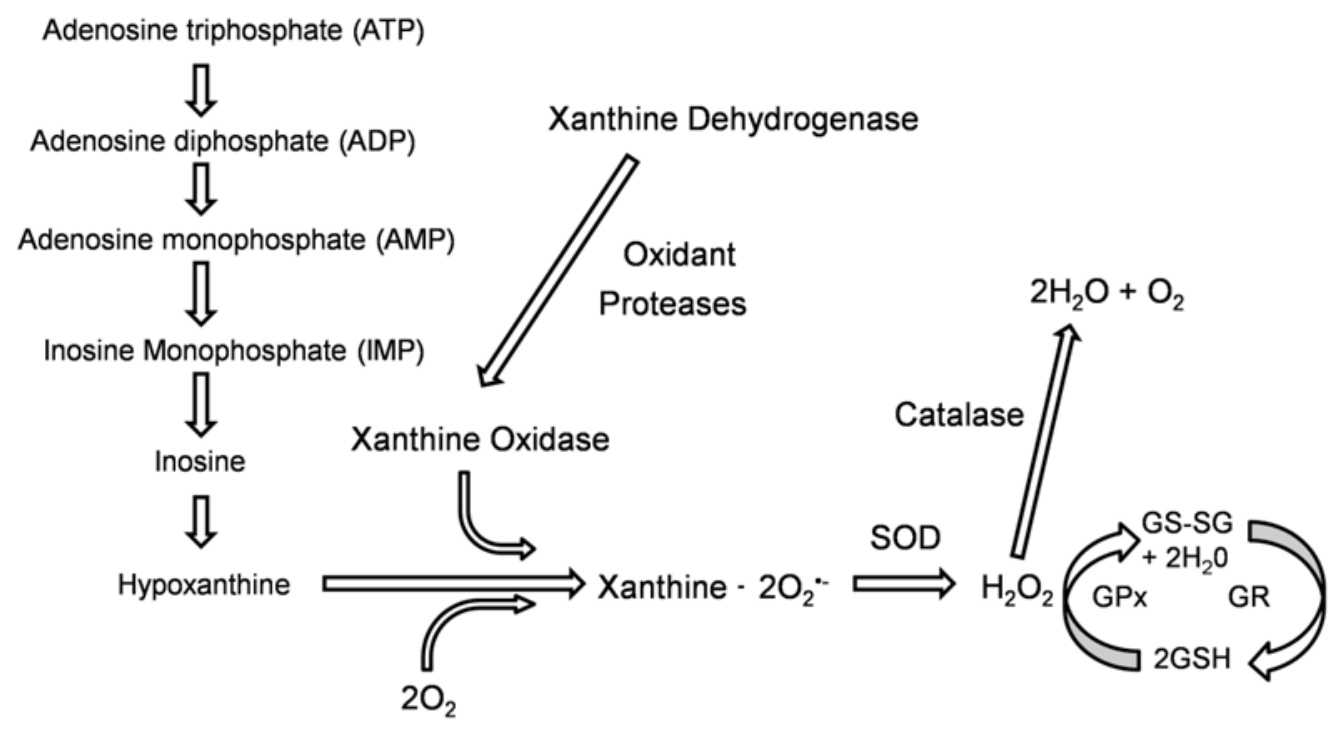

\subsection{Loading in aging muscle}

Resistance training involves progressively increasing the load or resistance applied to a contracting muscle or groups of muscles. This form of exercise can provide several healthy benefits in older adults that include; increases in muscular strength, improved range of motion, decreased likelihood of falling, improved body composition and increases in bone density. Presently, resistance training is the most effective and safe intervention to attenuate or recover some of the loss of muscle mass and strength that is associated with aging (81). Within skeletal muscle the normal adaptive response to progressive overload results in muscle satellite cell activation, an increase in gene transcription and synthesis of muscle-specific proteins resulting in muscle hypertrophy (4). Chronic adaptation to resistance exercise over many weeks in older women and men has been shown to improve muscular strength and also induce muscle fiber hypertrophy $(29,51,59,93,130,135)$; however, these adaptations are generally smaller than that reported in young adults. The mechanisms that regulate this attenuated adaptation to resistance exercise in the aged (40) is not known, but one possibility is due, at least in part, to 
elevated oxidative stress. Previous studies have observed that after resistance training type II fibers are preferentially hypertrophied in both young and aged adults $(29,59,93,130,135)$. Type II fibers tend to be more susceptible to oxidative damage than type I fibers (117), therefore the increased oxidant production associated with aging could hinder the type II fibers' ability to adapt to training.

Aged rodents are frequently used as models for exercise training in humans, but there are few studies that have examined the effects of resistance training in aged rodents. One reason is the lack of sufficient and accepted training models. Although some rodent species will perform endurance exercise voluntarily, resistance exercise is difficult to accomplish in rodents. Successful models of progressive resistance training for rats have been developed (162), which have included securing progressively heavier loads to their tails, while the rats ascended a mesh incline to receive a piece of food. Other approaches include voluntary plantar flexion to receive a food reward (158). Although these methods accomplish some degree of muscle hypertrophy and elicited a training response, the rest interval between repetitions could not be controlled, nor could older animals be conditioned to comply

It has recently been observed in rats that aging results in an impaired ability of the tibialis anterior muscles to adapt chronic repetitive loading exercise $(13,35,36)$. In young adult rats the same stimulus results in an increase in force, muscle mass, and myofiber cross-sectional area (36). The aged rats have been shown to display increases in pro-apoptotic signaling in activated muscle satellite cells (91) along with a diminished regenerative capacity and/or limited local muscle remodeling (13) that limited skeletal muscle adaptation to chronic repetitive loading exercise. Furthermore, this age-dependent divergence in the adaptive responses to repetitive loading exercise is exaggerated with increased velocity of movement (35). While the complete mechanisms for limiting the adaptive response to exercise in the aged muscle are unknown, it is hypothesized that the increased level of oxidative stress in muscles of aged animals may in part reduce the ability of muscle to adapt to repetitive loading.

\subsection{Oxidative Stress in Muscle Loading}

Resistance training has been identified as an effective means to delay the onset of sarcopenia, but there is still a paucity of studies that have evaluated oxidative stress during resistance training in humans. Studies that have evaluated high intensity or heavy resistance exercise have shown evidence of increased oxidant production $(2,11,70,109)$. However, few studies have examined oxidative stress and the long term benefits and/or consequences of resistance training within the increasingly oxidative environment that is associated with advanced age. Studies that investigating resistance training and oxidative stress in the elderly have found that chronic training will reduce the occurrence of oxidative damage $(122,154)$; however theses studies did not investigate the source of oxidant production or adaptation in the endogenous antioxidant system. Increased oxidative stress may reduce the muscles' ability to adapt to increased demands, as is the case with repetitive loading exercise. Mitochondria and activated satellite cells are the most common targets for oxidative damage in exercising muscle $(17,138)$. When activated, the normally quiescent satellite cells become more metabolically active and began to undergo mitosis, leaving them vulnerable to oxidant attack and thus can be subsequently eliminated (e.g., by myonuclear apoptosis). The inability to properly incorporate satellite cells as new myonuclei, may contribute to the maladaptation of skeletal muscle to repetitive loading seen in aged animals. Although it is clear that oxidative damage accumulates with aging, the role of mitochondria in aging and oxidative damage has several unanswered questions (17). 
Since aging is associated with increased oxidative stress and diminished muscular strength, it is likely that increases in oxidants take part in reducing muscle function during repetitive loading. It has recently been shown that muscle force falls within $24 \mathrm{hrs}$ after repetitive loading, and does not recover during the first 7 days (37). It is hypothesized that the loss of muscular force is mediated, directly or indirectly, by the increase in oxidant production during repetitive loading. This hypothesis is supported by the fact that force is diminished in muscles that are exposed to exogenous oxidants $(5-7,118)$.

Recent data have suggested that an increased production of free radicals, particularly during isometric or shortening contractions, may have beneficial adaptive effects (107). Isometric exercise could prove to be a useful tool in examining oxidative stress during exercise because the magnitude of damage following isometric exercise is relatively low (107).

Two interventions that show promise in reducing age-related oxidative stress are exercise training and antioxidant supplementation. Moderate non-fatiguing exercise has been shown to enhance the buffering capacity of these enzymes and therefore exercise can be thought of as a therapeutic means for offsetting high levels of oxidative stress $(75,128,144)$. However, the possibility exists that intensive exercise may exacerbate oxidant production in muscles with aging, which could be detrimental to muscle function. These experiments will help to shed light on the topic of resistance/anaerobic training and its effects on oxidative stress in aged animals.

\subsection{Antioxidant supplementation and oxidative stress}

The effect of dietary antioxidant supplementation on reducing exercise and age-induced increases in oxidative stress has been given a good deal of attention throughout the years. In 1952 , Staton (141) reported that 30 days of supplementation with $100 \mathrm{mg}$ vitamin $\mathrm{C}$ resulted in lower accounts of muscle soreness after exercise when compared to a placebo. Harman (61) was one of first to suggest that nutritional supplements that are hydrogen donors could be beneficial in combating increases in oxidative stress and free radicals associated with aging. Many of the early studies that examined antioxidant supplementation and exercise centered on athletic performance. The rationale is simple; exercise is associated with increased energy expenditure and, as a consequence, oxidant production increases with metabolism; dietary antioxidants may help alleviate this process.

\subsubsection{Vitamin E}

Vitamin $E$ ( $\alpha$-tocopherol) is an antioxidant and potent free radical scavenger that is suggested to have a protective effect in reducing or preventing oxidative injury to tissue. The antioxidant activity of vitamin $\mathrm{E}$ is based on the ease with which the hydrogen on the hydroxyl group of the chromogen ring can be donated to neutralize a free radical. Vitamin $E$ is lipidsoluble and considered the predominant antioxidant protecting cellular membranes. Dietary supplementation of vitamin $\mathrm{E}$ has been shown to increase tissue resistance to exercise-induced oxidative damage, specifically lipid peroxidation $(71,113,143)$. Furthermore, rodents $(28,38)$ and humans (113) that are deficient in vitamin $E$ show massive increases in oxidant production and lipid peroxidation after exercise. McBride et al. (109) examined the effects of resistance training and vitamin $\mathrm{E}$ supplementation within humans. They found indicators of oxidative stress (lipid peroxidation measured by MDA) to increase immediately after heavy resistance training in both the supplemented group and the non-supplemented groups. However, six and 24 hours post exercise the supplemented groups MDA levels were back to baseline, whereas MDA levels were still elevated in the non-supplemented group. Although, there is opposing data that suggests supplementing with vitamin $E$ could not completely protect elderly men from oxidative 
damage caused by exercise (2). One possible reason was that exercise decreased levels of vitamin $\mathrm{C}$ in the elderly which could have reduced the effectiveness of vitamin $E(2)$.

\subsubsection{Vitamin C}

Vitamin C (ascorbic acid) is a highly effective water-soluble antioxidant primarily found in the cytosol and extracellular fluid. Even in small amounts, vitamin $\mathrm{C}$ can protect proteins, lipids, carbohydrates, and nucleic acids from damage by oxidants generated during normal metabolism. What makes vitamin $\mathrm{C}$ such an effective antioxidant is its ability to interact directly with reactive oxygen and nitrogen species; superoxide, hydroperoxyl radicals, aqueous peroxyl radicals, singlet oxygen, ozone, peroxynitrite, nitrogen dioxide, nitroxide radicals, and hypochlorous acid, thereby preventing additional substrates from oxidation $(20,60)$. Jakeman and Maxwell (73) demonstrated that vitamin C, but not vitamin E, supplementation prior to eccentric exercise exerted a protective effect against muscle damage. Opposing results showed consumption of 200 mg vitamin C twice daily for three days after a 90 minute shuttlerun increased plasma concentrations of vitamin $\mathrm{C}$, but the supplemented group failed to show improvements over the placebo group in muscle soreness, inflammatory response, or recovery of muscle function (147). Unfortunately neither of the preceding studies presents data on specific markers of oxidative stress.

\subsubsection{Vitamin E \& C combined.}

A combination of Vitamin $E \& C$ has been shown to have a better antioxidant effect than either of the two vitamins alone (129). When vitamin $E$ is oxidized, it forms a slightly more stable intermediate tocopheroxyl radical. vitamin $\mathrm{C}$ can reduce the tocopheroxyl radical, regenerating vitamin $E(20,60)$. In animal models of exercise, oxidants can lead to increased formation of protein carbonyls (2), plasma levels of MDA (109) and neutrophil chemotaxis (14); thus vitamin $E$ and vitamin $C$ supplementation may prevent these increases in cellular damage, neutrophil infiltration, and edema following an acute bout of exercise. Additional data suggest that prior supplementation with vitamin $E$ \& $C$ ameliorates muscle functional decrements (decease in maximal force during isometric contractions) following eccentric muscle contractions (134). During heavy resistance training or maximal isometric contraction, there are brief periods of ischemia followed by reperfusion; an extreme example of this is exerciseinduced claudication, common in patients with peripheral vascular disease. Recent findings suggest that, neutrophil chemotaxis is caused by increased xanthine oxidase-derived oxidants (82). Furthermore, vitamin E \& C supplementation can inhibit oxidative damage, neutrophil infiltration and edema following an acute bout of contractile-induced claudication (83). Although, studies of exercise-induced claudication are extreme, they provide evidence that support the hypothesis of increased xanthine oxidase activity during exercise and the use of vitamin E \& C supplementation to buffer oxidant production within the proposed model.

In a study of professional soccer players, dietary supplementation of vitamin $E$ \& $C$ was shown to reduce lipid peroxidation and muscle damage after high intensity workouts, but failed to enhance athletic performance (166). Additionally, Rokitzki et al. (129) demonstrated in marathon runners that oral consumption of vitamin $E \&$ C for four and half weeks prior to competition lessened the increase in creatine kinase compared to a placebo group, which is indicative of reduced muscle damage. Supplementation schemes should take into a count the mode of exercise and where oxidants are being produced. Alessio et al. (2) has shown that aerobic training will produce greater protein carbonyl formation than isometric contraction, whereas isometric contractions produced greater evidence of lipid peroxidation. During a resistance exercise session increased oxidant production originating from outside the muscle fiber (i.e. xanthine oxidase from endothelial cells or eccentric contraction-induced damage from 
phagocytic cells) may overwhelm natural cellular antioxidant defenses including membrane bound vitamin $\mathrm{E}$, leading to lipid peroxidation. The combined supplementation of vitamin $\mathrm{E} \& \mathrm{C}$ could serve as a potent pro-oxidant scavenger, and chain-breaking antioxidant following intense exercise (58).

\subsection{Resveratrol}

Recent research has suggested that resveratrol has several beneficial health effects that include its use as an anti-cancer, anti-viral, anti-inflammatory, and anti-aging nutraceutical. Resveratrol (3,4',5-trihydroxystilbene), a phytoalexin, is produced naturally by numerous plants as a defense mechanism against infection by pathogens. Resveratrol works as an antibacterial and anti-fungal chemical, and is part of the hypersensitive response mechanism during the short-term immune response. During the hypersensitive response, resveratrol is employed to increase production of oxidants that assist in killing invading cells and initiate apoptosis in the area bordering the infection, essentially creating a physical barrier restricting the growth and spread of pathogens to other parts of the plant. When induced by stress, injury, infection or UVirradiation, plants synthesize resveratrol from $p$-coumaroyl CoA and malonyl CoA $(1,132,139)$. Resveratrol is a small fat-soluble molecule that occurs in two isoforms, a trans- $(E)$ and a cis(Z) configuration. The cis-isoform is easily oxidized and degraded when exposed to light, heat, and oxygen, while the trans- isoform is more stable under normal atmospheric conditions at room temperature (19).

When taken orally, trans-resveratrol is well-absorbed by mammals (i.e. humans, rats and mice), but its bioavailability is low due to its rapid metabolite limitation $(8,155,156)$. When young adult men and women were given a $25 \mathrm{mg}$ oral dose of trans-resveratrol, only traces of the unchanged resveratrol were detected in circulating blood plasma (155). The bioavailability of resveratrol in mammals is imperative to understanding how resveratrol supplementation achieves its beneficial effects. There has been a great deal of cell culture research that has exposed the cells to non-metabolized resveratrol at concentrations that are often 10-100 times greater than peak concentrations observed in human plasma after oral consumption. For that reason, we must be cautious in attempting to translate data attained through cell culture work to biological function in vivo. In vitro experiments have shown resveratrol to be effective at scavenging other oxidants (142) and inhibiting low density lipoprotein (LDL) oxidation (25, 50). However, there is little evidence supporting the role of resveratrol as an important oxidant scavenger in vivo (23). Based on the low bioavailability of resveratrol, there are other dietary (i.e. vitamin $\mathrm{E} \& \mathrm{C}$ ) and endogenous antioxidants (i.e. glutathione, catalase, superoxide dismutase) that are present in much higher circulating and intracellular concentrations than resveratrol and are more likely to make a greater contribution to the oxidant defense. Given that after oral consumption the concentration of resveratrol is low, it has been hypothesized that biologically active resveratrol metabolites, which peak at concentrations around $2 \mathrm{mM} / \mathrm{L}$ in the plasma 30-60 minutes after consumption, could elicit much of the beneficial effects of resveratrol seen in mammals (155).

Even though the bioavailability of resveratrol at the tissue level is low, supplementation studies have shown beneficial results $(16,94)$. Oral resveratrol supplementation has been associated with longer lifespan, reduced insulin-like growth factor-1 (IGF-I) levels, increased AMP-activated protein kinase (AMPK) and peroxisome proliferator-activated receptor-c coactivator $1 \alpha($ PPAR- $\alpha$ ) activity, increased mitochondrial number, and improved motor function (16). Treatment of mice with resveratrol has also been shown to significantly increase running time to exhaustion and consumption of oxygen in muscle, suggesting an improved aerobic capacity (94). In mammals, resveratrol supplementation modulates lifespan and metabolism 
through the inhibition of insulin signaling pathways, AMPK, PGC-1a and activation of Sirt1 (16, $21,94,165)$. Recent work in skeletal muscle has also shown SIRT1 deacetylation of PGC-1a, will activate mitochondrial fatty acid oxidation genes (54) as well as enhance components of the electron transport chain, oxidative enzymes, and ATPases (94). Increases in these enzymes could contribute to an increased supply of ATP, which would explain the improved muscle endurance linked to resveratrol supplementation.

\subsection{Summary \& Conclusion}

Advanced aging is accompanied by sarcopenia as a consequence of muscle fiber loss and atrophy of the individual muscle fibers. Advanced aging is also associated with an increase in oxidant production and a decrease ability to buffer oxidants. The resulting oxidative stress has been shown to contribute to the activation of myonuclear apoptosis $(136,137)$, a decrease in protein synthesis and activation of proteolysis, (114) all of which play a role in muscle atrophy. Sarcopenia will inevitably lead toward circumstances in which an elderly person is unable to accomplish everyday tasks. Resistance training has been identified as an effective means to delay sarcopenia, but there is still a paucity of studies that have evaluated oxidative stress during resistance training in humans. Even fewer studies have examined oxidative stress and the long term benefits and/or consequences of resistance training within the increasingly oxidative environment that is associated with advanced age. The majority of human studies are only able to report on a few markers of oxidative stress from blood samples', leaving one with only assumptions of what is happening within muscle tissue. Thus, animal models are important to collect larger amounts of tissue for extracting data. Unfortunately, there are even fewer studies that have investigated oxidative stress and resistance training in rodents than has been reported in humans. The proposed studies will be amongst a limited few that have exclusively examined oxidative stress with resistance exercise within an aging model. Furthermore, nutritional supplement companies have invested large sums of money into promoting antioxidant supplementation as an ergogenic aid to resistance training and aging, with only a minimal amount of research supporting their claims. A better understanding of how antioxidant supplements can be best employed to combat oxidative stress associated with aging and exercise would be beneficial to all. A further understanding of potential sources of oxidant production associated with resistance training will also allow for better identification of potential supplements and/or course of supplement therapy.

The major goal of this research is to better understand the role of oxidative stress in the adaptive hypertrophic response to repetitive loading in muscle and how it changes with advance aging. It is hypothesized that skeletal muscles from aged animals will show increased evidence of oxidative stress, while exercise (repetitive loading) and antioxidant supplementation would increase the aged muscles' oxidative buffering capacity and decrease the muscles oxidant production, thus attenuating the increase in oxidative stress associated with aging. Furthermore, resistance exercise (i.e. repetitive loading) and aging will be associated with an increase in xanthine oxidase activity which could be a contributing factor to oxidative stress. Hopefully the results from the proposed investigations will lead to further translational studies that promote a safe and more effective combination of resistance training and antioxidant treatment in the elderly population. The long term goal is developing an effective treatment for sarcopenia, which, in turn, will have a great benefit to the individual and their quality of life during their later years. Furthermore, such a treatment may potentially have a great economical value to society, given the expanding costs associated with caring for the increasing elderly population. 
Reference List

1. Aggarwal BB, Bhardwaj A, Aggarwal RS, Seeram NP, Shishodia S and Takada Y. Role of resveratrol in prevention and therapy of cancer: preclinical and clinical studies. Anticancer Res 24: 2783-2840, 2004.

2. Alessio HM, Hagerman AE, Fulkerson BK, Ambrose J, Rice RE and Wiley RL. Generation of reactive oxygen species after exhaustive aerobic and isometric exercise. Med Sci Sports Exerc 32: 1576-1581, 2000.

3. Alway SE, Coggan AR, Sproul MS, Abduljalil AM and Robitaille PM. Muscle torque in young and older untrained and endurance-trained men. Journals of Gerontology Series A-Biological Sciences and Medical Sciences 51: B195-B201, 1996.

4. Alway SE, Siu PM, Murlasits $\mathbf{Z}$ and Butler DC. Muscle hypertrophy models: Applications for research on aging. Can J Appl Physiol 30: 591-624, 2005.

5. Andrade FH, Reid MB, Allen DG and Westerblad H. Effect of hydrogen peroxide and dithiothreitol on contractile function of single skeletal muscle fibres from the mouse. $J$ Physiol 509 ( Pt 2): 565-575, 1998.

6. Andrade FH, Reid MB, Allen DG and Westerblad H. Effect of nitric oxide on single skeletal muscle fibres from the mouse. J Physiol 509 ( Pt 2): 577-586, 1998.

7. Anzueto A, Brassard JM, Andrade FH, Lawrence RA, Maxwell LC, Levine SM and Jenkinson SG. Effects of Hyperoxia on Rat Diaphragm Function. Journal of Applied Physiology 77: 63-68, 1994.

8. Asensi M, Medina I, Ortega A, Carretero J, Bano MC, Obrador E and Estrela JM. Inhibition of cancer growth by resveratrol is related to its low bioavailability. Free Radic Biol Med 33: 387-398, 2002.

9. Ashraf M and Samra ZQ. Subcellular-Distribution of Xanthine-Oxidase During Cardiac Ischemia and Reperfusion - An Immunocytochemical Study. J Submicr Cyt Path 25: 193-201, 1993.

10. Ashton T, Young IS, Peters JR, Jones E, Jackson SK, Davies B and Rowlands CC. Electron spin resonance spectroscopy, exercise, and oxidative stress: an ascorbic acid intervention study. J Appl Physiol 87: 2032-2036, 1999.

11. Avery NG, Kaiser JL, Sharman MJ, Scheett TP, Barnes DM, Gomez AL, Kraemer WJ and Volek JS. Effects of vitamin E supplementation on recovery from repeated bouts of resistance exercise. J Strength Cond Res 17: 801-809, 2003.

12. Bacic G, Spasojevic I, Secerov B and Mojovic M. Spin-trapping of oxygen free radicals in chemical and biological systems: new traps, radicals and possibilities. Spectrochim Acta A Mol Biomol Spectrosc 69: 1354-1366, 2008. 
13. Baker BA, Hollander MS, Mercer RR, Kashon ML and Cutlip RG. Adaptive stretchshortening contractions: diminished regenerative capacity with aging. Appl Physiol Nutr Metab 33: 1181-1191, 2008.

14. Baker BA, Mercer RR, Geronilla KB, Kashon ML, Miller GR and Cutlip RG. Stereological analysis of muscle morphology following exposure to repetitive stretchshortening cycles in a rat model. Appl Physiol Nutr Metab 31: 167-179, 2006.

15. Barry B.Halliwell and John M.Gutteridge. Free Radicals in Biology and Medicine. Oxford University Press, USA, 2006.

16. Baur JA, Pearson KJ, Price NL, Jamieson HA, Lerin C, Kalra A, Prabhu VV, Allard JS, Lopez-Lluch G, Lewis K, Pistell PJ, Poosala S, Becker KG, Boss O, Gwinn D, Wang M, Ramaswamy S, Fishbein KW, Spencer RG, Lakatta EG, Le Couteur D, Shaw RJ, Navas P, Puigserver P, Ingram DK, de Cabo $R$ and Sinclair DA.

Resveratrol improves health and survival of mice on a high-calorie diet. Nature 444: 337342, 2006.

17. Beckman KB and Ames BN. Mitochondrial aging: open questions. Ann N Y Acad Sci 854: 118-127, 1998.

18. Bejma $\mathbf{J}$ and $\mathbf{J i} \mathbf{L L}$. Aging and acute exercise enhance free radical generation in rat skeletal muscle. J Appl Physiol 87: 465-470, 1999.

19. Bertelli AA, Gozzini A, Stradi R, Stella S and Bertelli A. Stability of resveratrol over time and in the various stages of grape transformation. Drugs Exp Clin Res 24: 207-211, 1998.

20. Beyer RE. The Role of Ascorbate in Antioxidant Protection of Biomembranes Interaction with Vitamin-e and Coenzyme-Q. Journal of Bioenergetics and Biomembranes 26: 349-358, 1994.

21. Borra MT, Smith BC and Denu JM. Mechanism of human SIRT1 activation by resveratrol. Journal of Biological Chemistry 280: 17187-17195, 2005.

22. Boveris A and Chance B. The mitochondrial generation of hydrogen peroxide. General properties and effect of hyperbaric oxygen. Biochem J 134: 707-716, 1973.

23. Bradamante S, Barenghi L and Villa A. Cardiovascular protective effects of resveratrol. Cardiovascular Drug Reviews 22: 169-188, 2004.

24. Brickson S, Hollander J, Corr DT, Ji LL and Best TM. Oxidant production and immune response after stretch injury in skeletal muscle. Med Sci Sports Exerc 33: 20102015, 2001.

25. Brito $\mathbf{P}$, Almeida $\mathbf{L M}$ and Dinis TC. The interaction of resveratrol with ferrylmyoglobin and peroxynitrite; protection against LDL oxidation. Free Radic Res 36: 621-631, 2002.

26. Capel F, Demaison L, Morio B, Rimbert V, Mirand PP and Mosoni L. Role of mitochondria in the development of oxidative stress in skeletal muscle during aging. Productions Animales 19: 305-317, 2006. 
27. Chance $\mathbf{B}$, Sies $\mathbf{H}$ and Boveris $\mathbf{A}$. Hydroperoxide metabolism in mammalian organs. Physiol Rev 59: 527-605, 1979.

28. Chang CK, Huang HY, Tseng HF, Hsuuw YD and Tso TK. Interaction of vitamin E and exercise training on oxidative stress and antioxidant enzyme activities in rat skeletal muscles. Journal of Nutritional Biochemistry 18: 39-45, 2007.

29. Charette SL, Mcevoy L, Pyka G, Snowharter C, Guido D, Wiswell RA and Marcus R. Muscle Hypertrophy Response to Resistance Training in Older Women. J Appl Physiol 70: 1912-1916, 1991.

30. Clanton TL, Zuo L and Klawitter P. Oxidants and skeletal muscle function: physiologic and pathophysiologic implications. Proc Soc Exp Biol Med 222: 253-262, 1999.

31. Clarkson PM. Antioxidants and Physical Performance. Critical Reviews in Food Science and Nutrition 35: 131-141, 1995.

32. Corte ED and Stirpe F. The regulation of rat liver xanthine oxidase. Involvement of thiol groups in the conversion of the enzyme activity from dehydrogenase (type D) into oxidase (type O) and purification of the enzyme. Biochem J 126: 739-745, 1972.

33. Cortopassi GA and Wong A. Mitochondria in organismal aging and degeneration. Biochimica et Biophysica Acta-Bioenergetics 1410: 183-193, 1999.

34. Csiszar A, Labinskyy N, Orosz Z, Xiangmin Z, Buffenstein R and Ungvari Z. Vascular aging in the longest-living rodent, the naked mole rat. Am J Physiol Heart Circ Physiol 293: H919-H927, 2007.

35. Cutlip RG, Baker BA, Geronilla KB, Kashon ML and Wu JZ. The influence of velocity of stretch-shortening contractions on muscle performance during chronic exposure: age effects. Appl Physiol Nutr Metab 32: 443-453, 2007.

36. Cutlip RG, Baker BA, Geronilla KB, Mercer RR, Kashon ML, Miller GR, Murlasits Z and Alway SE. Chronic exposure to stretch-shortening contractions results in skeletal muscle adaptation in young rats and maladaptation in old rats. Appl Physiol Nutr Metab 31: 573-587, 2006.

37. Cutlip RG, Geronilla KB, Baker BA, Chetlin RD, Hover I, Kashon ML and Wu JZ. Impact of stretch-shortening cycle rest interval on in vivo muscle performance. Med Sci Sports Exerc 37: 1345-1355, 2005.

38. Davies KJ, Quintanilha AT, Brooks GA and Packer L. Free radicals and tissue damage produced by exercise. Biochem Biophys Res Commun 107: 1198-1205, 1982.

39. Degens H and Alway SE. Skeletal muscle function and hypertrophy are diminished in old age. Muscle Nerve 27: 339-347, 2003.

40. Degens H and Alway SE. Control of muscle size during disuse, disease, and aging. International Journal of Sports Medicine 27: 94-99, 2006. 
41. DeMartino GN and Ordway GA. Ubiquitin-proteasome pathway of intracellular protein degradation: implications for muscle atrophy during unloading. Exerc Sport Sci Rev 26: 219-252, 1998.

42. Di Meo S and Venditti P. Mitochondria in exercise-induced oxidative stress. Biol Signals Recept 10: 125-140, 2001.

43. Diaz PT, She ZW, Davis WB and Clanton TL. Hydroxylation of salicylate by the in vitro diaphragm: evidence for hydroxyl radical production during fatigue. J App/ Physiol 75: 540-545, 1993.

44. Dirks AJ and Leeuwenburgh C. Aging and lifelong calorie restriction result in adaptations of skeletal muscle apoptosis repressor, apoptosis-inducing factor, X-linked inhibitor of apoptosis, caspase-3, and caspase-12. Free Radic Biol Med 36: 27-39, 2004.

45. Doherty TJ. Aging and sarcopenia. Journal of Applied Physiology 95: 1717-1727, 2003.

46. Duarte JA, Appell HJ, Carvalho F, Bastos ML and Soares JM. Endothelium-derived oxidative stress may contribute to exercise-induced muscle damage. Int J Sports Med 14: 440-443, 1993.

47. Eskurza I, Kahn ZD and Seals DR. Xanthine oxidase does not contribute to impaired peripheral conduit artery endothelium-dependent dilatation with ageing. J Physio/ 571: 661-668, 2006.

48. Eu JP, Sun J, Xu L, Stamler JS and Meissner G. The skeletal muscle calcium release channel: coupled O2 sensor and NO signaling functions. Cell 102: 499-509, 2000.

49. Fattman CL, Schaefer LM and Oury TD. Extracellular superoxide dismutase in biology and medicine. Free Radic Biol Med 35: 236-256, 2003.

50. Frankel EN, Waterhouse AL and Kinsella JE. Inhibition of human LDL oxidation by resveratrol. Lancet 341: 1103-1104, 1993.

51. Frontera WR, Meredith CN, Oreilly KP, Knuttgen HG and Evans WJ. Strength Conditioning in Older Men - Skeletal-Muscle Hypertrophy and Improved Function. J Appl Physiol 64: 1038-1044, 1988.

52. Fugere NA, Ferrington DA and Thompson LV. Protein nitration with aging in the rat semimembranosus and soleus muscles. Journals of Gerontology Series A-Biological Sciences and Medical Sciences 61: 806-812, 2006.

53. Fulle S, Protasi F, Di Tano G, Pietrangelo T, Beltramin A, Boncompagni S, Vecchiet $\mathbf{L}$ and Fano $\mathbf{G}$. The contribution of reactive oxygen species to sarcopenia and muscle ageing. Experimental Gerontology 39: 17-24, 2004.

54. Gerhart-Hines Z, Rodgers JT, Bare O, Lerin C, Kim SH, Mostoslavsky R, Alt FW, $\mathbf{W u ~ Z}$ and Puigserver P. Metabolic control of muscle mitochondrial function and fatty acid oxidation through SIRT1/PGC-1alpha. EMBO J 26: 1913-1923, 2007. 
55. Gianni P, Jan KJ, Douglas MJ, Stuart PM and Tarnopolsky MA. Oxidative stress and the mitochondrial theory of aging in human skeletal muscle. Exp Gerontol 39: 13911400, 2004.

56. Girten B, Oloff C, Plato P, Eveland E, Merola AJ and Kazarian L. Skeletal muscle antioxidant enzyme levels in rats after simulated weightlessness, exercise and dobutamine. Physiologist 32: S59-S60, 1989.

57. Gomez-Cabrera MC, Close GL, Kayani AC, McArdle A, Vina J and Jackson MJ. Effect of xanthine oxidase-generated extracellular superoxide on skeletal muscle force generation. Am J Physiol Regul Integr Comp Physiol 298: R2-R8, 2010.

58. Groussard C. Oxidative stress and anaerobic exercise. Science \& Sports 21: 62-67, 2006.

59. Häkkinen K, Kraemer WJ, Pakarinen A, Triplett-McBride T, McBride JM, Häkkinen A, Alen M, McGuigan MR, Bronks R and Newton RU. Effects of heavy resistance/power training on maximal strength, muscle morphology, and hormonal response patterns in 60-75-year-old men and women. Can J Appl Physiol 27: 213-231, 2002.

60. Halliwell B. Vitamin C: antioxidant or pro-oxidant in vivo? Free Radic Res 25: 439-454, 1996.

61. Harman D. Aging: a theory based on free radical and radiation chemistry. $J$ Gerontol 11: 298-300, 1956.

62. Hellsten Y, Hansson HA, Johnson L, Frandsen $\mathbf{U}$ and Sjodin B. Increased expression of xanthine oxidase and insulin-like growth factor I (IGF-I) immunoreactivity in skeletal muscle after strenuous exercise in humans. Acta Physiol Scand 157: 191197, 1996.

63. Herrero A and Barja G. ADP-regulation of mitochondrial free radical production is different with complex I- or complex II-linked substrates: implications for the exercise paradox and brain hypermetabolism. J Bioenerg Biomembr 29: 241-249, 1997.

64. Herrero A and Barja G. Sites and mechanisms responsible for the low rate of free radical production of heart mitochondria in the long-lived pigeon. Mechanisms of Ageing and Development 98: 95-111, 1997.

65. Hofer T, Marzetti E, Xu J, Seo AY, Gulec S, Knutson MD, Leeuwenburgh C and Dupont-Versteegden EE. Increased iron content and RNA oxidative damage in skeletal muscle with aging and disuse atrophy. Exp Gerontol 43: 563-570, 2008.

66. Hoffman-Goetz $L$ and Spagnuolo PA. Effect of repeated exercise stress on caspase 3, $\mathrm{Bcl}-2$, HSP 70 and CuZn-SOD protein expression in mouse intestinal lymphocytes. $J$ Neuroimmunol 187: 94-101, 2007.

67. Hollander J, Bejma J, Ookawara T, Ohno H and Ji LL. Superoxide dismutase gene expression in skeletal muscle: fiber-specific effect of age. Mech Ageing Dev 116: 33-45, 2000. 
68. Hollander MS, Baker BA, Ensey J, Kashon ML and Cutlip RG. Effects of age and glutathione levels on oxidative stress in rats after chronic exposure to stretch-shortening contractions. Eur J Appl Physiol 108: 589-597, 2010.

69. Houston M, Estevez A, Chumley P, Aslan M, Marklund S, Parks DA and Freeman BA. Binding of xanthine oxidase to vascular endothelium. Kinetic characterization and oxidative impairment of nitric oxide-dependent signaling. J Biol Chem 274: 4985-4994, 1999.

70. Hudson MB, Hosick PA, McCaulley GO, Schrieber L, Wrieden J, McAnulty SR, Triplett NT, McBride JM and Quindry JC. The effect of resistance exercise on humoral markers of oxidative stress. Med Sci Sports Exerc 40: 542-548, 2008.

71. Itoh H, Ohkuwa T, Yamazaki Y, Shimoda T, Wakayama A, Tamura S, Yamamoto T, Sato $\mathbf{Y}$ and Miyamura M. Vitamin E supplementation attenuates leakage of enzymes following 6 successive days of running training. Int J Sports Med 21: 369-374, 2000.

72. Jackson MJ, Pye D and Palomero J. The production of reactive oxygen and nitrogen species by skeletal muscle. J Appl Physiol 102: 1664-1670, 2007.

73. Jakeman $\mathbf{P}$ and Maxwell S. Effect of antioxidant vitamin supplementation on muscle function after eccentric exercise. Eur J Appl Physiol Occup Physiol 67: 426-430, 1993.

74. Ji LL. Antioxidant enzyme response to exercise and aging. Med Sci Sports Exerc 25: 225-231, 1993.

75. Ji LL. Exercise-induced modulation of antioxidant defense. Ann N Y Acad Sci 959: 8292, 2002.

76. Ji LL. Antioxidant signaling in skeletal muscle: A brief review. Experimental Gerontology 42: 582-593, 2007.

77. Ji LL, Dillon D and Wu E. Alteration of antioxidant enzymes with aging in rat skeletal muscle and liver. Am J Physiol 258: R918-R923, 1990.

78. Ji LL, Gomez-Cabrers MC and Vina J. Role of nuclear factor kappa B and mitogenactivated protein kinase signaling in exercise-induced antioxidant enzyme adaptation. Applied Physiology Nutrition and Metabolism-Physiologie Appliquee Nutrition et Metabolisme 32: 930-935, 2007.

79. Ji LL, Leeuwenburgh C, Leichtweis S, Gore M, Fiebig R, Hollander J and Bejma J. Oxidative stress and aging. Role of exercise and its influences on antioxidant systems. Ann N Y Acad Sci 854: 102-117, 1998.

80. Ji LL and Peterson DM. Aging, exercise, and phytochemicals: promises and pitfalls. Ann N Y Acad Sci 1019: 453-461, 2004.

81. Jones TE, Stephenson KW, King JG, Knight KR, Marshall TL and Scott WB. Sarcopenia--mechanisms and treatments. J Geriatr Phys Ther 32: 39-45, 2009. 
82. Judge AR and Dodd SL. Oxidative damage to skeletal muscle following an acute bout of contractile claudication. Atherosclerosis 171: 219-224, 2003.

83. Judge AR, Selsby JT and Dodd SL. Antioxidants attenuate oxidative damage in rat skeletal muscle during mild ischaemia. Exp Physiol 93: 479-485, 2008.

84. Kagan VE, Tyurina YY, Bayir H, Chu CT, Kapralov AA, Vlasova II, Belikova NA, Tyurin VA, Amoscato A, Epperly M, Greenberger J, Dekosky S, Shvedova AA and Jiang J. The "pro-apoptotic genies" get out of mitochondria: oxidative lipidomics and redox activity of cytochrome c/cardiolipin complexes. Chem Biol Interact 163: 15-28, 2006.

85. Kamel HK. Sarcopenia and aging. Nutr Rev 61: 157-167, 2003.

86. Kaneko T, Tahara S, Taguchi T and Kondo H. Accumulation of oxidative DNA damage, 8-oxo-2'-deoxyguanosine, and change of repair systems during in vitro cellular aging of cultured human skin fibroblasts. Mutat Res 487: 19-30, 2001.

87. Kondo H, Kodama J, Kishibe T and Itokawa Y. Oxidative Stress During Recovery from Muscle Atrophy. FEBS Lett 326: 189-191, 1993.

88. Kondo H, Miura M and Itokawa Y. Antioxidant Enzyme-Systems in Skeletal-Muscle Atrophied by Immobilization. Pflugers Arch 422: 404-406, 1993.

89. Kondo H, Miura M, Kodama J, Ahmed SM and Itokawa Y. Role of Iron in Oxidative Stress in Skeletal-Muscle Atrophied by Immobilization. Pflugers Archiv-European Journal of Physiology 421: 295-297, 1992.

90. Kondo H, Nakagaki I, Sasaki S, Hori S and Itokawa Y. Mechanism of Oxidative Stress in Skeletal-Muscle Atrophied by Immobilization. Am J Physiol 265: E839-E844, 1993.

91. Krajnak K, Waugh S, Miller R, Baker B, Geronilla K, Alway SE and Cutlip RG. Proapoptotic factor Bax is increased in satellite cells in the tibialis anterior muscles of old rats. Muscle Nerve 34: 720-730, 2006.

92. Kramer HF and Goodyear LJ. Exercise, MAPK, and NF-kappa B signaling in skeletal muscle. Journal of Applied Physiology 103: 388-395, 2007.

93. Kryger Al and Andersen JL. Resistance training in the oldest old: consequences for muscle strength, fiber types, fiber size, and MHC isoforms. Scand J Med Sci Sports 17: 422-430, 2007.

94. Lagouge M, Argmann C, Gerhart-Hines Z, Meziane H, Lerin C, Daussin F, Messadeq N, Milne J, Lambert P, Elliott P, Geny B, Laakso M, Puigserver $P$ and Auwerx J. Resveratrol improves mitochondrial function and protects against metabolic disease by activating SIRT1 and PGC-1alpha. Cell 127: 1109-1122, 2006.

95. Lambertucci RH, Levada-Pires AC, Rossoni LV, Curi R and Pithon-Curi TC. Effects of aerobic exercise training on antioxidant enzyme activities and mRNA levels in soleus muscle from young and aged rats. Mech Ageing Dev 128: 267-275, 2007. 
96. Larsson L, Grimby $\mathbf{G}$ and Karlsson J. Muscle strength and speed of movement in relation to age and muscle morphology. J Appl Physiol 46: 451-456, 1979.

97. Lee MD, Tuttle R and Girten B. Effect of spaceflight on oxidative and antioxidant enzyme activity in rat diaphragm and intercostal muscles. J Gravit Physiol 2: 68-69, 1995.

98. Leeuwenburgh C, Fiebig R, Chandwaney R and Ji LL. Aging and exercise training in skeletal muscle: responses of glutathione and antioxidant enzyme systems. $A m \mathrm{~J}$ Physiol 267: R439-R445, 1994.

99. Leeuwenburgh C, Gurley CM, Strotman BA and Dupont-Versteegden EE. Agerelated differences in apoptosis with disuse atrophy in soleus muscle. Am J Physiol Regul Integr Comp Physiol 288: R1288-R1296, 2005.

100. Leeuwenburgh $\mathbf{C}$ and Heinecke JW. Oxidative stress and antioxidants in exercise. Current Medicinal Chemistry 8: 829-838, 2001.

101. Li YP, Chen Y, Li AS and Reid MB. Hydrogen peroxide stimulates ubiquitin-conjugating activity and expression of genes for specific E2 and E3 proteins in skeletal muscle myotubes. Am J Physiol Cell Physiol 285: C806-C812, 2003.

102. Lysiak JJ, Zheng S, Woodson R and Turner TT. Caspase-9-dependent pathway to murine germ cell apoptosis: mediation by oxidative stress, BAX, and caspase 2. Cell Tissue Res 328: 411-419, 2007.

103. Malech HL and Gallin JI. Current concepts: immunology. Neutrophils in human diseases. N Engl J Med 317: 687-694, 1987.

104. Mantovani G, Madeddu C, Maccio A, Gramignano G, Lusso MR, Massa E, Astara G and Serpe R. Cancer-related anorexia/cachexia syndrome and oxidative stress: an innovative approach beyond current treatment. Cancer Epidemiol Biomarkers Prev 13: 1651-1659, 2004.

105. Marklund SL. Extracellular superoxide dismutase and other superoxide dismutase isoenzymes in tissues from nine mammalian species. Biochem J 222: 649-655, 1984.

106. Martin JA, Brown TD, Heiner AD and Buckwalter JA. Chondrocyte senescence, joint loading and osteoarthritis. Clin Orthop Relat Res S96-103, 2004.

107. McArdle A and Jackson MJ. Exercise, oxidative stress and ageing. J Anat $197 \mathrm{Pt} 4$ : 539-541, 2000.

108. McArdle F, Pattwell DM, Vasilaki A, McArdle A and Jackson MJ. Intracellular generation of reactive oxygen species by contracting skeletal muscle cells. Free Radic Biol Med 39: 651-657, 2005.

109. McBride JM, Kraemer WJ, Triplett-McBride T and Sebastianelli W. Effect of resistance exercise on free radical production. Med Sci Sports Exerc 30: 67-72, 1998. 
110. McCord JM, Roy RS and Schaffer SW. Free radicals and myocardial ischemia. The role of xanthine oxidase. Adv Myocardiol 5: 183-189, 1985.

111. McNally JS, Saxena A, Cai H, Dikalov S and Harrison DG. Regulation of xanthine oxidoreductase protein expression by hydrogen peroxide and calcium. Arterioscler Thromb Vasc Biol 25: 1623-1628, 2005.

112. Meng $\mathbf{Q}$, Wong $\mathbf{Y T}$, Chen $\mathbf{J}$ and Ruan $\mathbf{R}$. Age-related changes in mitochondrial function and antioxidative enzyme activity in fischer 344 rats. Mech Ageing Dev 128: 286-292, 2007.

113. Meydani M, Evans WJ, Handelman G, Biddle L, Fielding RA, Meydani SN, Burrill J, Fiatorone MA, Blumberg JB and Cannon JG. Protective Effect of Vitamin-e on Exercise-Induced Oxidative Damage in Young and Older Adults. American Journal of Physiology 264: R992-R998, 1993.

114. Moylan JS and Reid MB. Oxidative stress, chronic disease, and muscle wasting. Muscle Nerve 35: 411-429, 2007.

115. Muller FL, Liu YH and Van Remmen H. Complex III releases superoxide to both sides of the inner mitochondrial membrane. J Biol Chem 279: 49064-49073, 2004.

116. Muller FL, Song W, Jang YC, Liu Y, Sabia M, Richardson A and Van Remmen H. Denervation-induced skeletal muscle atrophy is associated with increased mitochondrial ROS production. Am J Physiol Regul Integr Comp Physiol 293: R1159-R1168, 2007.

117. Muller FL, Song W, Liu YH, Chaudhuri A, Pieke-Dahl S, Strong R, Huang TT, Epstein CJ, Roberts LJ, Csete M, Faulkner JA and Van Remmen H. Absence of CuZn superoxide dismutase leads to elevated oxidative stress and acceleration of agedependent skeletal muscle atrophy. Free Radic Biol Med 40: 1993-2004, 2006.

118. Murrant CL, Andrade FH and Reid MB. Exogenous reactive oxygen and nitric oxide alter intracellular oxidant status of skeletal muscle fibres. Acta Physiol Scand 166: 111121, 1999.

119. Nishino T and Nishino T. The conversion from the dehydrogenase type to the oxidase type of rat liver xanthine dehydrogenase by modification of cysteine residues with fluorodinitrobenzene. J Biol Chem 272: 29859-29864, 1997.

120. Okado-Matsumoto A and Fridovich I. Subcellular distribution of superoxide dismutases (SOD) in rat liver: Cu,Zn-SOD in mitochondria. J Biol Chem 276: 3838838393, 2001.

121. Pansarasa O, Bertorelli L, Vecchiet J, Felzani G and Marzatico F. Age-dependent changes of antioxidant activities and markers of free radical damage in human skeletal muscle. Free Radic Biol Med 27: 617-622, 1999.

122. Parise G, Phillips SM, Kaczor JJ and Tarnopolsky MA. Antioxidant enzyme activity is up-regulated after unilateral resistance exercise training in older adults. Free Radical Biology and Medicine 39: 289-295, 2005. 
123. Parks DA, Williams TK and Beckman JS. Conversion of xanthine dehydrogenase to oxidase in ischemic rat intestine: a reevaluation. Am J Physiol 254: G768-G774, 1988.

124. Peake $\mathbf{J}$ and Suzuki K. Neutrophil activation, antioxidant supplements and exerciseinduced oxidative stress. Exercise Immunology Review 10: 129-141, 2004.

125. Pistilli EE, Jackson JR and Alway SE. Death receptor-associated pro-apoptotic signaling in aged skeletal muscle. Apoptosis 11:2115-2126, 2006.

126. Pistilli EE, Siu PA and Alway SE. Molecular regulation of apoptosis in fast plantaris muscles of aged rats. Journals of Gerontology Series A-Biological Sciences and Medical Sciences 61: 245-255, 2006.

127. Posterino GS and Lamb GD. Effects of reducing agents and oxidants on excitationcontraction coupling in skeletal muscle fibres of rat and toad. J Physio/ 496 ( Pt 3): 809825, 1996.

128. Radak Z, Naito H, Kaneko T, Tahara S, Nakamoto H, Takahashi R, Cardozo-Pelaez $\mathbf{F}$ and Goto $\mathbf{S}$. Exercise training decreases DNA damage and increases DNA repair and resistance against oxidative stress of proteins in aged rat skeletal muscle. Pflugers Arch 445: 273-278, 2002.

129. Rokitzki L, Logemann E, Sagredos AN, Murphy M, Wetzelroth W and Keul J. LipidPeroxidation and Antioxidative Vitamins Under Extreme Endurance Stress. Acta Physiologica Scandinavica 151: 149-158, 1994.

130. Roman WJ, Fleckenstein J, Straygundersen J, Alway SE, Peshock R and Gonyea WJ. Adaptations in the Elbow Flexors of Elderly Males After Heavy-Resistance Training. J Appl Physiol 74: 750-754, 1993.

131. Sachdev S and Davies KJA. Production, detection, and adaptive responses to free radicals in exercise. Free Radic Biol Med 44: 215-223, 2008.

132. Schoppner A and Kindl H. Purification and properties of a stilbene synthase from induced cell suspension cultures of peanut. J Biol Chem 259: 6806-6811, 1984.

133. Schoutsen B and de Jong JW. Age-dependent increase in xanthine oxidoreductase differs in various heart cell types. Circ Res 61: 604-607, 1987.

134. Shafat $\mathbf{A}$, Butler $\mathbf{P}$, Jensen $\mathbf{R L}$ and Donnelly $\mathbf{A E}$. Effects of dietary supplementation with vitamins $C$ and $E$ on muscle function during and after eccentric contractions in humans. Eur J Appl Physiol 93: 196-202, 2004.

135. Sharman MJ, Newton RU, Triplett-McBride T, McGuigan MR, McBride JM, Häkkinen A, Häkkinen $\mathbf{K}$ and Kraemer WJ. Changes in myosin heavy chain composition with heavy resistance training in 60- to 75-year-old men and women. Eur $\mathrm{J}$ Appl Physiol 84: 127-132, 2001.

136. Siu PM and Alway SE. Id2 and p53 participate in apoptosis during unloading-induced muscle atrophy. Am J Physiol:Cell Physiology 288: C1058-C1073, 2005. 
137. Siu PM and Alway SE. Mitochondria-associated apoptotic signalling in denervated rat skeletal muscle. J Physiol 565: 309-323, 2005.

138. Siu PM, Pistilli EE, Butler DC and Alway SE. Aging influences cellular and molecular responses of apoptosis to skeletal muscle unloading. Am J Physiol:Cell Physiol 288: C338-C349, 2005.

139. Soleas GJ, Diamandis EP and Goldberg DM. Resveratrol: a molecule whose time has come? And gone? Clin Biochem 30: 91-113, 1997.

140. St Pierre J, Buckingham JA, Roebuck SJ and Brand MD. Topology of superoxide production from different sites in the mitochondrial electron transport chain. $J$ Biol Chem 277: 44784-44790, 2002.

141. Staton WM. The influence of ascorbic acid in minimizing post-exercise muscle soreness in young men. Reasearch Quarterly 23: 356-360, 1952.

142. Stojanovic S, Sprinz H and Brede O. Efficiency and mechanism of the antioxidant action of trans-resveratrol and its analogues in the radical liposome oxidation. Arch Biochem Biophys 391: 79-89, 2001.

143. Sumida S, Tanaka K, Kitao H and Nakadomo F. Exercise-induced lipid peroxidation and leakage of enzymes before and after vitamin E supplementation. Int J Biochem 21: 835-838, 1989.

144. Terblanche SE. The effects of exhaustive exercise on the activity levels of catalase in various tissues of male and female rats. Cell Biology International 23: 749-753, 1999.

145. Terman A and Brunk UT. Myocyte aging and mitochondrial turnover. Experimental Gerontology 39: 701-705, 2004.

146. Terman A, Dalen H, Eaton JW, Neuzil J and Brunka UT. Aging of cardiac myocytes in culture - Oxidative stress, lipofuscin accumulation, and mitochondrial turnover. Strategies for Engineered Negligible Senescence: Why Genuine Control of Aging May be Foreseeable 1019: 70-77, 2004.

147. Thompson D, Williams C, Garcia-Roves P, McGregor SJ, McArdle F and Jackson MJ. Post-exercise vitamin $\mathrm{C}$ supplementation and recovery from demanding exercise. Eur J Appl Physiol 89: 393-400, 2003.

148. Thompson LV, Durand D, Fugere NA and Ferrington DA. Myosin and actin expression and oxidation in aging muscle. Journal of Applied Physiology 101: 15811587, 2006.

149. Vasilaki A, Csete M, Pye D, Lee S, Palomero J, McArdle F, Van Remmen H, Richardson A, McArdle A, Faulkner JA and Jackson MJ. Genetic modification of the manganese superoxide dismutase/glutathione peroxidase 1 pathway influences intracellular ROS generation in quiescent, but not contracting, skeletal muscle cells. Free Radic Biol Med 41: 1719-1725, 2006. 
150. Vasilaki A, McArdle F, Iwanejko LM and McArdle A. Adaptive responses of mouse skeletal muscle to contractile activity: The effect of age. Mech Ageing Dev 127: 830-839, 2006.

151. Venditti P, Masullo $\mathbf{P}$ and Di Meo S. Effect of exercise duration on characteristics of mitochondrial population from rat liver. Archives of Biochemistry and Biophysics 368: 112-120, 1999.

152. Vina J, Gimeno A, Sastre J, Desco C, Asensi M, Pallardo FV, Cuesta A, Ferrero JA, Terada LS and Repine JE. Mechanism of free radical production in exhaustive exercise in humans and rats; role of xanthine oxidase and protection by allopurinol. IUBMB Life 49: 539-544, 2000.

153. Vina J, Gomez-Cabrera MC, Lloret A, Marquez R, Minana JB, Pallardo FV and Sastre J. Free radicals in exhaustive physical exercise: Mechanism of production, and protection by antioxidants. lubmb Life 50: 271-277, 2000.

154. Vincent KR, Vincent HK, Braith RW, Lennon SL and Lowenthal DT. Resistance exercise training attenuates exercise-induced lipid peroxidation in the elderly. Eur $J$ Appl Physiol 87: 416-423, 2002.

155. Walle T, Hsieh F, DeLegge MH, Oatis JE and Walle UK. High absorption but very low bioavailability of oral resveratrol in humans. Drug Metab Dispos 32: 1377-1382, 2004.

156. Wenzel E, Soldo T, Erbersdobler H and Somoza V. Bioactivity and metabolism of trans-resveratrol orally administered to Wistar rats. Mol Nutr Food Res 49: 482-494, 2005.

157. Wickham C, Cooper C, Margetts BM and Barker DJ. Muscle strength, activity, housing and the risk of falls in elderly people. Age Ageing 18: 47-51, 1989.

158. Wirth O, Gregory EW, Cutlip RG and Miller GR. Control and quantitation of voluntary weight-lifting performance of rats. J Appl Physiol 95: 402-412, 2003.

159. Wouters EF, Creutzberg EC and Schols AM. Systemic effects in COPD. Chest 121: 127S-130S, 2002.

160. Xu CL, Wang YZ, Guo J, Liu JX and Feng J. Comparison of age-related differences in expression of antioxidant enzyme mRNA and activity in various tissues of pigs. Comp Biochem Physiol B Biochem Mol Biol 147: 445-451, 2007.

161. Xu J, Knutson MD, Carter CS and Leeuwenburgh C. Iron accumulation with age, oxidative stress and functional decline. PLoS ONE 3: e2865, 2008.

162. Yarasheski KE, Lemon PW and Gilloteaux J. Effect of heavy-resistance exercise training on muscle fiber composition in young rats. J Appl Physiol 69: 434-437, 1990.

163. Yoshimura T, Kawashima M, Nakamura T, Isowa N, Bando T, Hasegawa S, Kondo $\mathbf{H}$, Toyokuni $\mathbf{S}$ and Wada $\mathbf{H}$. A novel selectin blocker alleviates oxidative stress of lung reperfusion injury. J Surg Res 101: 91-98, 2001. 
164. Zerba E, Komorowski TE and Faulkner JA. Free radical injury to skeletal muscles of young, adult, and old mice. Am J Physiol 258: C429-C435, 1990.

165. Zhang JD. Resveratrol inhibits insulin responses in a SirT1-independent pathway. Biochemical Journal 397: 519-527, 2006.

166. Zoppi CC, Hohl R, Silva FC, Lazarim FL, Neto JM, Stancanneli M and Macedo DV. Vitamin $\mathrm{C}$ and e supplementation effects in professional soccer players under regular training. J Int Soc Sports Nutr 3: 37-44, 2006. 


\section{Chapter 3}

\section{Aging-dependent regulation of antioxidant enzymes and redox status in chronically loaded rat dorsiflexor muscles}

As published in J Gerontol A Biol Sci Med Sci 2008; 63:1015-1026.

Michael J. Ryan ${ }^{1}$, Holly J. Dudash ${ }^{1}$, Megan Docherty ${ }^{1}$, Kenneth B. Geronilla ${ }^{1,2}$, Brent A. Baker $^{2}$, G. Gregory Haff ${ }^{1}$, Robert G. Cutlip ${ }^{2}$, and Stephen E. Alway ${ }^{1}$

'Laboratory of Muscle Biology and Sarcopenia, Division of Exercise Physiology, West Virginia University School of Medicine, Morgantown, West Virginia 26506

${ }^{2}$ Health Effects Laboratory Division, National Institute for Occupational Safety and Health, Morgantown, West Virginia 26505 


\begin{abstract}
We have examined whether aging attenuates oxidant buffering capacity and decreases oxidant production after chronic repetitive loading $(R L)$. The dorsiflexors from one limb of young adult and aged rats were loaded 3 times per week for 4.5 weeks using 80 maximal stretch-shortening contractions per session. $\mathrm{RL}$ increased $\mathrm{H}_{2} \mathrm{O}_{2}$ in the tibialis anterior muscle of young and aged rats and decreased the ratio of reduced/oxidized glutathione and lipid peroxidation in aged but not young adult animals. Glutathione peroxidase (GPx) activity and catalase activity increased with $R L$ in muscles from both young and aged rats. $R L$ increased CuZnSOD and MnSOD protein concentration and CuZnSOD activity in muscles from young animals but not old animals. There were no changes in protein content for GPx-1 and catalase or mRNA for any of the enzymes studied. These data show that aging reduces the adaptive capacity of muscles to buffer increased oxidants imposed by chronic repetitive loading.
\end{abstract}




\section{Introduction}

Oxidative stress is an important mechanism that may at least in part underlie the aging-induced attenuation of muscle physiological adaptation to increased loading $(5 ; 6$; $35 ; 36)$. Increased oxidant production is buffered in muscles of young animals and humans, but it is possible that aging reduces the ability for muscles to buffer oxidants. This is important because when the buffering of oxidants is compromised, oxidant stress will arise which can lead to cellular damage. Oxidative stress depresses muscle specific force (7), and alters myofilament function as a result of muscle loading $(41 ; 42)$ or contraction-induced calcium release $(2 ; 19 ; 61)$. Oxidative stress may also contribute to loss of muscle force by reducing recovery from injury (40). Increases in oxidant production have also been shown to stimulate redox-sensitive signaling pathways (32; 33; 46), upregulate catabolic gene expression in muscle $(17 ; 49 ; 51)$ and activate apoptosis $(38 ; 50)$ in muscle.

It is clear that muscle atrophy is associated with increases in oxidants and oxidative stress $(43 ; 47)$ evident by increases in lipid peroxidation, glutathione oxidation, protein carbonyls, free iron content, and xanthine oxidase levels. Oxidative stress is also elevated with both aging and loading in chondrocytes (52), synovial cells (74) and muscle cells (21). The generation of oxidants and oxidative stress has been implicated in mechanisms of muscle dysfunction and sarcopenia (55). However, there are no data that address the role of cumulative oxidative stress in repetitive loading in aging muscles. Furthermore, the underlying cause for increased oxidant formation in aging muscle is unknown, but this information is essential if we are to develop useful strategies for improving adaptations to loading in aging.

The mitochondrial theory of aging predicts that an increase in oxidative stress is responsible for cellular damage and ultimately apoptosis and cell death of various cell types (18) including skeletal muscle cells (22; 39). Although actin and myosin proteins do not appear to have increased oxidative damage with aging in rats (71), recent data showed that 8-hydroxy-2'-deoxyguanosine (8-OHdG), protein carbonyls, MnSOD activity and catalase activity were significantly higher in muscle biopsies obtained from older men as compared to young men (24). Full-length mitochondrial DNA was also lower and mitochondrial DNA deletions were prominent in muscles from old as compared to young men (23). These data support the conclusion that even healthy aging is associated with oxidative damage to proteins and DNA in skeletal muscle. This may be a primary reason for increased nuclear apoptosis that has been reported in aged muscles $(45 ; 58 ; 59 ; 65)$. Oxidative stress may reduce the muscle's ability to adapt to increased demands, as is the case in repetitive loading. Although mitochondria may be the intrinsic initiators of oxidative stress, mitochondria, along with activated satellite cells may be the target for oxidative stress in loaded muscle. If activated satellite cells are reduced or eliminated (e.g., by apoptosis) muscle adaptation to loading would be reduced or eliminated. Although it is clear that oxidative damage accumulates with aging, the role of mitochondria in aging and oxidative damage still has several unanswered questions, including the involvement of mitochondria in apoptosis (4).

Because aging is associated with increases in oxidative stress, it is likely that oxidants have a role in reducing muscle function in aging and repetitive loading. Cutlip and colleagues have recently shown that muscle force falls within $24 \mathrm{hrs}$, and does not recover during the first 7 days of repetitive loading (14). We hypothesize that loss of 
muscular force is mediated, directly or indirectly, by the increase in oxidant activity during repetitively loading. This is known to occur in muscles exposed to exogenous ROS $(1 ; 2$; 57). An aging-associated reduction in CuZnSOD appears to be a good candidate for explaining increased superoxide levels leading to long-term oxidative damage and eventual loss of skeletal muscle, because CuZnSOD deficient animals have a lower life span and decreased muscle mass (55). Recent data (73) also suggest that CuZnSOD levels are lower in muscles and other tissues of old rodents, whereas, long lived animals do not show this decrease in CuZnSOD and other oxidative enzymes (8). CuZnSOD levels increase in cells of young animals after exercise (26), and although Vasilaki et al. (72) report an increased level of CuZnSOD in muscles of old animals after a single bout of electrical stimulation, it is possible that old muscles may fail to respond in this manner with chronic repetitive loading. Furthermore, even if CuZnSOD does increase either similarly or greater in old vs. young muscles with repetitive loading, it is not known if this will be sufficient to counteract the loading-induced oxidant and intrinsic oxidant produced by aging mitochondria (54) in old muscles.

It has been widely recognized that GPx-1, catalase, CuZnSOD and MnSOD enzymes provide a defense system, which are essential for the survival of aerobic organisms. Moderate non-fatiguing exercise has been shown to enhance the buffering capacity by increasing the specific activity of these enzymes and therefore exercise is thought to be a therapeutic tool for offsetting high levels of oxidative stress (31). However, the possibility exists that intensive exercise may exacerbate oxidant production in muscles with aging, which may be detrimental to muscle function.

Aging rodents are frequently used as models for exercise training in humans, but there are few studies that have examined the effects of resistance training in aged rats. We have recently observed that repetitive loading results in a mal-adaptation in tibialis anterior muscles of old rats, whereas the same stimulus in the tibialis anterior muscle from young adult rats results in an increase in force, muscle mass, and myofiber cross-sectional area (13). While the mechanisms for these mal-adaptations to exercise in the aged muscle are unknown, we hypothesized that the increased level of oxidative stress in muscles of aged animals may in part reduce the ability of muscle to adapt to repetitive loading.

In this study we tested the hypothesis that: (I) tibialis anterior (TA) muscles from aged rats would show greater evidence of oxidative stress compared to muscles from young adult animals, (ii) chronic repetitive loading would increase the TA muscles' oxidative buffering capacity and decrease the muscles oxidant production, thus attenuating the increase in oxidative stress associated with aging, and (III) aging would attenuate adaptive responses in antioxidant pathways and this would be closely associated with attenuated hypertrophic adaptations to repetitive loading in aging.

\section{Methods}

The left TA muscles of old (30 months of age; $n=8$ ) and young (12 weeks of age; $\mathrm{n}=8$ ) Fischer 344 Brown $x$ Norway rats were subjected to repetitive loading exercise, which consisted of 3 sessions per week for 4.5 weeks, of 80 super-physiological eccentric / concentric contraction cycles per session (12). Muscle functional data were collected from a subset of four animals per group. The right TA was used as a contra-lateral control for each animal. The sessions were performed on a custom-built dynamometer by 
electrically stimulating the common peroneal nerve, causing contraction of the dorsi flexor muscles and moving the footplate through plantar flexion (15). This method has been previously shown to produce a hypertrophic response in young adult rats (11). All animals had free access to rat chow and water. At the end of the 4.5 week loading period the rats were anesthetized with $2 \%$ isoflurane and the chronically loaded and control muscles were quickly removed, cleaned of excess connective tissue and weighed. The animals were euthanized by an overdose of pentobarbital. A section of each muscle was obtained for the determination of the ratio of reduced glutathione (GSH) to oxidized glutathione (GSSG). The remaining muscle was quickly frozen in liquid nitrogen and stored in a $-80^{\circ} \mathrm{C}$ freezer until analysis.

RNA Isolation. Sixty micrograms of the TA muscle was homogenized in $1 \mathrm{ml}$ of Tri-Reagent (Molecular Research Center, Cincinnati, $\mathrm{OH}$ ) with a motorized blade homogenizer. Muscle homogenates were transferred to sterile $1.5 \mathrm{ml}$ Eppendorf tubes and centrifuged at $12,000 \mathrm{rpm}$ for 10 -minutes at $4^{\circ} \mathrm{C}$. Supernatants were transferred to a sterile $1.5 \mathrm{ml}$ tube then $100 \mu \mathrm{l}$ of 1-bromo-3-chloropropane (BCP, Molecular Research Center, Cincinnati, $\mathrm{OH}$ ) was added to the supernatant. The sample was vortexed for $15 \mathrm{~s}$ and incubated at room temperature for 15-minutes. The samples were centrifuged $\left(12,000 \mathrm{rpm}\right.$ for 15 -minutes at $\left.4^{\circ} \mathrm{C}\right)$ and the top aqueous phase that contains RNA was transferred to a sterile $1.5 \mathrm{ml}$ tube followed by addition of $500 \mu \mathrm{l}$ isopropanol and incubation at room temperature for 10-minutes. Samples were centrifuged at $12,000 \mathrm{rpm}$ for 8minutes at $4^{\circ} \mathrm{C}$, which collected the solubilized RNA into a small pellet. The RNA pellet was washed in $1 \mathrm{ml}$ of $75 \%$ ethanol and centrifuged at $7500 \mathrm{rpm}$ for 5 -minutes at $4^{\circ} \mathrm{C}$. The supernatant was removed and the RNA pellet was air dried in a fume hood and resuspended in $22 \mu \mathrm{l}$ of sterile distilled $\mathrm{H}_{2} \mathrm{O}$. The RNA was treated with DNAse I using a DNA-free kit (Ambion, Austin, TX) and quantified using a BioRad SmartSpec 3000. RNA purity was accessed using a mimimum 260:280 ratio of 1.7. Samples with values less than this were re-treated for DNA contamination and quantified.

Reverse Transcription-Polymerase Chain Reaction (RT-PCR). Two micrograms of total RNA were reversed transcribed using random primers (Invitrogen/Life Technologies, Bethesda MD) via the following protocol. $1.0 \mu \mathrm{l}$ of random primers and $1.0 \mu \mathrm{l}$ of $10 \mathrm{mM}$ dNTP mixture were added to $2 \mu \mathrm{g}$ of RNA. Samples were heated to $65^{\circ} \mathrm{C}$ for 5minutes followed by $3^{\circ} \mathrm{C}$ for 5 -minutes in a Biometra T3 thermocycler. $7.0 \mu \mathrm{l}$ of a master mix containing $5 x$ First Strand buffer, DTT, and RNase-Out, were added to each sample. Tubes were returned to the thermocycler and incubated at $25^{\circ} \mathrm{C}$ for 10 -minutes followed by $42^{\circ} \mathrm{C}$ for 2-minutes. $1.0 \mu \mathrm{l}$ of SuperScript II reverse transcriptase was added to each tube and lightly mixed by pipetting the solution up and down. Samples were returned to the thermocycler to be incubated at $42^{\circ} \mathrm{C}$ for 50 -minutes, $70^{\circ} \mathrm{C}$ for 15 -minutes, and then cooled to $3^{\circ} \mathrm{C}$ until removed for storage. This procedure yielded $20 \mu \mathrm{l}$ of complimentary DNA (cDNA) which was stored at $-80^{\circ} \mathrm{C}$ or used for PCR analyses.

Primers for the genes of interest were constructed according to the following primer sequences: CuZnSOD sense-5'-AGGCCGTGTGCGTGCTGA-3'; anti-sense-5'CCCAATCACACCACAAGCCA-3'; GPx-1 sense-5'-CCTCGTGGCCTGGTGGTCCT-3'; anti-sense-5'-AGGGGTTGCTAGGCTGCTTGGA-3'. The following primers were previously published from our lab: MnSOD sense-5'-GCGGGGGCCATATCAATCAC AG3'; anti-sense-5'-GGCGGCAATCTGTAAGCGACCT-3'; Catalase sense- 5'CGGGAACCCAATAGGAGATAAA-3'; anti-sense-5'-CCACGAGGGTCACGAACTGT-3' 
$(67 ; 69)$. To make certain analyzes were done in the linear range of amplification, preliminary tests were done to determine the proper number of PCR cycles. PCR products were verified by restriction digestion based on predicted PCR sequences. To control for any loading errors, the signal from the gene of interest was expressed as a ratio to the 18S RNA signal from the same PCR product. $49 \mu \mathrm{l}$ of a master mix containing, $10 \mathrm{X}$ PCR buffer with $\mathrm{MgCl} 2,5 \mathrm{mM}$ dNTPs, $100 \mathrm{ng} / \mathrm{ml}$ of primer pairs, $18 \mathrm{~S}$ primer pairs, and $1.0 \mu$ l of Taq DNA polymerase, were combined with $1.0 \mu \mathrm{l}$ of cDNA for PCR amplification. Amplification of PCR products were performed in a thermocycler using: a denaturing step at $95^{\circ} \mathrm{C}$ for $45 \mathrm{~s}$, an annealing step for $45 \mathrm{~s}$, and an extension step at $72^{\circ} \mathrm{C}$ for $45 \mathrm{~s}$.

Following amplification, $20 \mu$ l of each reaction were electrophoresed on $1.5 \%$ agarose gels. Gels were stained with ethidium bromide to visualize the PCR products. The PCR signals were recorded via a digital camera (Kodak 290) and the signals were quantified in arbitrary units as optical density $x$ band area, using 1D Kodak image analysis software (Eastman Kodak Company, Rochester, NY).

Protein Fractionation. Seventy-five mg of TA muscle samples were separated for cytoplasmic and nuclear protein fractions, using methods reported previously by our lab $(66 ; 70)$. However, a lower concentration of dithioreitol (DTT) was used in these experiments to prevent later interference with enzyme activity assays. Muscle samples were homogenized in $500 \mu \mathrm{l}$ of ice-cold lysis buffer $\left(10 \mathrm{mM} \mathrm{NaCl}, 1.5 \mathrm{mM} \mathrm{MgCl}_{2}, 20 \mathrm{mM}\right.$ HEPES at $\mathrm{pH} 7.4,20 \%$ glycerol, $0.1 \%$ Triton $\mathrm{X}-100$, and $10 \mu \mathrm{M}$ dithioreitol) with a mechanical homogenizer. Muscle homogenates transferred to $1.5 \mathrm{ml}$ Eppendorf tubes and centrifuged at $800 \mathrm{rpm}$ for 5 -minutes at $4^{\circ} \mathrm{C}$. Supernatants were collected and centrifuged three more times at $3500 \mathrm{~g}$ for 5 -minutes at $4^{\circ} \mathrm{C}$. The resulting supernatant was collected as nuclei-free cytosolic fraction and divided into two equal portions; the first portion was frozen at $-80^{\circ} \mathrm{C}$ until needed, in the second portion protease inhibitor cocktail containing $104 \mathrm{mM} 4$-[2-aminoethyl]-benzenesulfonylflouride hydrochloride (AEBSF), 0.8mM aprotinin, 2mM leupeptin, 4mM bestatin, $1.5 \mathrm{mM}$ pepstatin A and $1.4 \mathrm{mME}-64$ (SigmaAldrich, St. Louis, Mo, USA) was added before the sample was frozen at $-80^{\circ} \mathrm{C}$. Protein concentrations for each sample were determined in triplicate via a DC protein concentration assay (Bio Rad, Hercules, CA). The cytosolic fraction was used in the following assays: $\mathrm{H}_{2} \mathrm{O}_{2}$ concentration, Catalase activity, GPx activity, CuZn \& MnSOD activity and western immunoblots.

Western Immunoblots. The protein content of glutathione peroxidase-1 (GPx-1), catalase, copper-zinc superoxide dismutase, (CuZnSOD) and manganese superoxide dismutase (MnSOD) was measured in the cytosolic muscle fractions. 30 $\mu \mathrm{g}$ of protein was loaded into each well of a 4-12\% gradient polyacrylamide gel (Novex, Invitrogen) and separated by routine SDS-polyacrylamide gel electrophoresis (PAGE) for 1.5 hours at $20^{\circ} \mathrm{C}$ followed by transfer to a nitrocellulose membrane. All membranes were blocked in $5 \%$ non-fat milk protein (NFM) for 1-hour at room temperature. In general, membranes were incubated in appropriate dilutions of primary antibodies (diluted in 1\% NFM in trisbuffered saline with $0.05 \%$ Tween-20 (TBS-T) overnight in a $4^{\circ} \mathrm{C}$ cold room. Membranes were washed in TBS-T followed by incubation in appropriate dilutions of secondary antibodies (diluted in 5\% NFM in TBS-T) conjugated to horseradish peroxidase. Signals were developed using a chemi-luminescent substrate (ECL Advanced, Amersham Bioscience) and visualized by exposing the membranes to X-ray films (BioMax MS-1; Eastman Kodak). Digital records were captured by a Kodak 290 camera and protein 
bands quantified using 1-D analysis software (Eastman Kodak, USA). Bands were quantified as optical density (OD) $\mathrm{x}$ band area and expressed in arbitrary units.

$\mathrm{H}_{2} \mathrm{O}_{2}$ levels. A fluorescent hydrogen peroxide $\left(\mathrm{H}_{2} \mathrm{O}_{2}\right)($ Cell Technology, Mountain View, CA) detection kit was used to determine the amount of $\mathrm{H}_{2} \mathrm{O}_{2}$ in the muscle tissue. Reagents and standards were prepared as recommended by the manufacturer. Briefly, $50 \mu \mathrm{L}$ of controls, samples or $\mathrm{H}_{2} \mathrm{O}_{2}$ dilutions were mixed with $50 \mu \mathrm{L}$ of the reaction cocktail in each well to initiate the reaction. The plate was incubated in the dark for 10 minutes, at $20^{\circ} \mathrm{C}$ and fluorescence was detected with an excitation at $530 \mathrm{~nm}$ and measured at $590 \mathrm{~nm}$. All analyses were done in duplicate and samples were normalized to muscle protein concentration in each sample via a DC protein concentration assay (Bio-Rad, Hercules, $\mathrm{CA})$.

GSH/GSSG Ratio. A BIOXYTECH GSH/GSSG-412 (Oxis Research) assay was performed to determine the reduced glutathione/oxidized glutathione (GSH/GSSG) ratio. Muscle tissue ( $40 \mathrm{mg}$ ) was homogenized immediately after dissection in $530 \mu \mathrm{l}$ cold $5 \%$ metaphosphoric acid (MPA) for the GSH sample and for the GSSG sample $~ 40 \mathrm{mg}$ of muscle tissue was homogenized immediately after dissection in $500 \mu \mathrm{l}$ cold $5 \%$ metaphosphoric acid and $30 \mu \mathrm{l}$ of M2VO scavenger. Homogenates were then frozen in liquid nitrogen and stored at $-80^{\circ} \mathrm{C}$ until analyzed.

Samples were thawed and cold 5\% MPA was added to each sample, 290 $\mu$ land $350 \mu$ for GSSG and GSH, respectively. Samples were mixed, and then centrifuged at $1000 \times \mathrm{g}$ for 10 minutes. For the GSSG sample, 25 $\mu$ MPA extract and 350 $\mu$ l GSSG buffer

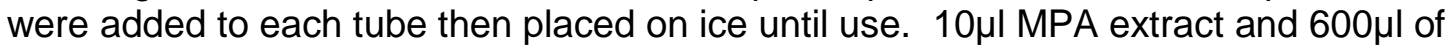
assay buffer was added to the GSH sample then placed on ice. $50 \mu \mathrm{l}$ of sample and $50 \mu \mathrm{l}$ of chromogen and enzyme were mixed in a cuvette followed by 5 minute incubation at room temperature. 50 $\mathrm{\mu l}$ of NADPH was added to each cuvette and the absorbance of each sample was read every $60 \mathrm{~s}$ at $412 \mathrm{~nm}$ for 3 minutes. The concentration for each sample was determined via a DC protein concentration assay (Bio Rad, Hercules, CA). Signals from each sample were normalized to the corresponding protein content of that sample.

8-hydroxy-2'-deoxyguanosine (8-OHdG). Oxidized DNA was determined by a BIOXYTECH 8-OhdG ELISA (enzyme linked immunoassay) (Oxis Research). DNA was extracted from the muscle via DNeasy Tissue Kit (Qiagen). DNA was used if it had a minimum 260:280 ratio of 1.8 . 50 $\mu$ l of purified DNA was mixed with $50 \mu$ of primary antibody. Samples were then incubated at $37^{\circ} \mathrm{C}$ for one hour. The wells were washed then incubated in $100 \mu \mathrm{l}$ of secondary antibody at $37^{\circ} \mathrm{C}$ for one hour. $100 \mu \mathrm{l}$ of chromogen was added to each well, shaken then incubated at room temperature in the dark for 15 minutes. The reaction was terminated and the samples were read at an absorbance of 450 $\mathrm{nm}$. Samples were normalized to the DNA concentration measured via a plate reader (ND1000, NanoDrop, Wilmington, DE). All analyses were done in duplicate.

Lipid peroxidation. Malondialdehyde (MDA) and 4-hydroxyalkenals (HAE) were measured using reagents from Oxis International, CA (Bioxytech LPO-586). A 75-100 mg section of each muscle was homogenized in $500 \mu \mathrm{l}$ of buffer containing ice-cold phosphate-buffered saline (PBS, $20 \mathrm{mM}$, pH 7.4) and $5 \mu \mathrm{L} 0.5 \mathrm{M}$ butylated hydroxytoluene $(\mathrm{BHT})$ in acetonitrile per $1 \mathrm{ml}$ of tissue homogenate. Assay reagents were added following the manufacturer's recommendations. Briefly, the muscle homogenate was centrifuged at 
$3000 \mathrm{~g}$ at $4^{\circ} \mathrm{C}$ for 10 minutes and the supernatant was used for the assay and protein determination. After incubation in the appropriate reagents, the sample was incubated at $45^{\circ} \mathrm{C}$ for 60 minutes, and then centrifuged at $15,000 \mathrm{~g}$ for 10 minutes. An absorbance reading of the supernatant was obtained at 586nm. Samples were normalized for differences in the amount of muscle protein in each sample as determined by a DC protein concentration assay (Bio-Rad, Hercules, CA).

Catalase Activity. A catalase activity assay kit (\# 219265, EMD/Calbiochem, San Diego, CA) was used to determine the activity level of catalase in repetitively loaded and control muscles, according to the manufacturer's recommendations. After the appropriate incubations, the samples were read at absorbance of $520 \mathrm{~nm}$. All analyses were completed in duplicate and samples were normalized to muscle protein in each sample via a DC protein concentration assay (Bio-Rad, Hercules, CA).

Manganese Superoxide Dismutase (MnSOD) and Copper-Zinc Superoxide Dismutase (CuZnSOD). A commercially available SOD Assay Kit II (\#574601, EMD/Calbiochem, San Diego, CA) was used to measure total and MnSOD activity. CuZnSOD was determined by subtracting the value for MnSOD activity from the total SOD activity. The assay was preformed with modifications to the manufacturer's directions and all samples and standards were measured in duplicate. Briefly, the muscle was homogenized in a buffer (20mM HEPES buffer, pH 7.2, containing 1mM EGTA, 210mM mannitol, and $70 \mathrm{mM}$ sucrose) and centrifuged at $1000 \mathrm{~g}$ for 10 minutes. The assay was performed in a 96-well plate with each sample being treated with and without $10 \mu \mathrm{L}$ of 3 $\mathrm{mM}$ potassium cyanide. Potassium cyanide was used to inhibit CuZnSOD, resulting in the detection of only MnSOD activity. The reagents and samples were protected from white light and incubated at $26^{\circ} \mathrm{C}$ for 20 minutes with periodic shaking. The absorbance was measured at $450 \mathrm{~nm}$ using a 96-well plate reader (Dynex Tech., Chantilly VA., USA).

Glutathione Peroxidase (GPx). A commercially available cellular GPx Assay Kit (\#35319, EMD/Calbiochem, San Diego, CA) was used to measure GPx activity in the cytosolic fractions of the muscle homogenates. The assay was performed with slight modifications to the manufacturer's directions. Briefly, a portion of each muscle was homogenized in a buffer containing $50 \mathrm{mM}$ Tris- $\mathrm{HCl}, \mathrm{pH} 7.5,5 \mathrm{mM}$ EDTA, $1 \mathrm{mM}$ DTT. The homogenate was centrifuged at $10,000 \mathrm{~g}$ for $15 \mathrm{~min}$ at $4^{\circ} \mathrm{C}$ and the supernatant was used for the assay. All reagents and sample were equilibrated to $25^{\circ} \mathrm{C}$ and the remaining assay procedures followed manufacturer's specifications. The absorbance was measured at 340 nm using a 96-well plate reader (DYNEX technologies, Chantilly Va., USA). Each sample and control was performed in duplicate.

Statistical analyses. Statistical analyses were performed using an SPSS 13.0 software package. A multiple analyses of variance (MANOVA) were used to examine differences between age and treatment $(R L)$. Statistical significance was accepted at $P<$ 0.05 . Data are reported as mean \pm standard error mean (SEM).

\section{Results}

Body Mass. The average body mass of the young animals was $326.5 \pm 14.7 \mathrm{~g}$ before muscle loading, and $317.2 \pm 12.2 \mathrm{~g}$ after the 4.5 weeks of training, but this did not represent a significant change in body mass. However, the body mass of aged animals 
had a small but significant decrease from $597.3 \pm 17.9 \mathrm{~g}$ before training to $558.3 \pm 13.3 \mathrm{~g}$ after the 4.5 weeks of training.

Muscle Wet Weight. Repetitive loading for 4.5 weeks resulted in a significant increase in tibialis anterior muscle wet weight in the exercised limb of both the young adult $(11.5 \pm 1.6 \%, p<0.001)$ and the aged adult $(7.5 \pm 1.9 \%, p<0.05)$ rats as compared with the contra-lateral control muscle. (Figure 3.1)

\section{$\underline{\text { Insert Figure } 3.1}$}

Muscle Functional Measurements. Maximal isometric muscle force, positive work, and negative work were used to measure the functional capacity of the dorsiflexors, of which the greatest contributor is the tibialis anterior muscle. There was no significant difference between the young adult and the aged animals for maximal Isometric force (Figure 3.2A), positive work (Figure 3.2B) or negative work (Figure 3.2C) observed at the

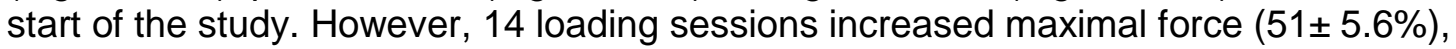

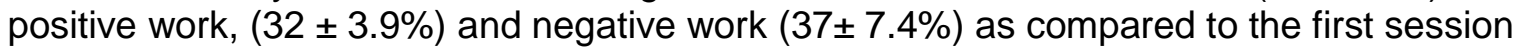
for young adult animals. In contrast, there was no significant change in any of the parameters used to assess functional changes in muscles of the aged animals over the training period.

\section{$\underline{\text { Insert Figure } 3.2}$}

$\mathrm{H}_{2} \mathrm{O}_{2}$. Muscle levels of $\mathrm{H}_{2} \mathrm{O}_{2}$ were elevated in the loaded muscles as compared to the age-matched control limb $(p<0.001)$, suggesting a treatment effect and that chronic loading elevated oxidative stress. Both control and experimental muscles had higher levels of $\mathrm{H}_{2} \mathrm{O}_{2}$ than their treatment matched muscles of young adult rats $(\mathrm{p}<0.001)$. This suggests a systemic aging effect of oxidative stress on muscles. (Figure 3.3) $\mathrm{H}_{2} \mathrm{O}_{2}$ concentration data expressed as a $\mu \mathrm{mol} / \mathrm{mg}$ protein are discussed in the Limitation and Future Directions section within chapter 7. (Figure 7.2)

\section{$\underline{\text { Insert Figure } 3.3}$}

GSH/GSSG ratio. There was no training-induced difference in the GSH/GSSG ratio in muscles from young adult animals when comparisons were made to the control muscles. However, there was a significant reduction in the GSH/GSSG ratio of both control $(p<0.05)$ and loaded $(p<0.01)$ muscles of aged muscles as compared to treatmentmatched muscles in the young adult animals. The GSH/GSSG ratio was lower $(p<0.05)$ in the loaded muscles of the aged rats as compared to the young adult rats. (Figure 3.4) These data suggest that aging increased oxidative stress and therefore lowered the GSH/GSSG ratio as compared to muscles in young adult animals and that aging reduced that ability to tolerate increased oxidative stress in chronically loaded skeletal muscles.

\section{$\underline{\text { Insert Figure } 3.4}$}

Lipid Peroxidation. Aging increased the level of lipid oxidation as shown by greater MDA + HAE levels in control muscles of old rats as compared to muscles from young adult animals ( $p<0.01$; Figure 3.5). Repetitive loading appeared to activate adaptive responses in muscles of old animals because MDA + HAE levels were lower in 
the loaded than control muscles of aged animals. No significant difference in MDA + HAE levels was observed among the control or chronically loaded muscles of young adult animals.

\section{$\underline{\text { Insert Figure } 3.5}$}

DNA Damage. Aging induced a significantly $(p<0.05)$ increased basal level of DNA damage because the amount of $8-\mathrm{OHdG}$ detected in control muscles was significantly greater in aged vs. young adult muscles. Repetitive loading reduced the level of $8-\mathrm{OHdG}$ in muscles of old animals to that which was measured in muscles of young adult animals. Chronic loading did not change 8-OHdG in muscles of young adult animals. (Figure 3.6) These data imply that chronic loading offsets the level of oxidative stressinduced DNA damage in aging rats.

\section{$\underline{\text { Insert Figure } 6}$}

GPx Activity. There was a loading effect but no age effect on GPx activity. Chronic repetitive loading increased GPx activity in muscles from both young and aged animals $(p<0.001)$, but no differences were found between young and aged rodents. No significant differences were found among GPx-1 mRNA or protein levels within any of the muscle samples.

\section{$\underline{\text { Insert Figure } 3.7}$}

Catalase activity. Catalase activity increased with repetitive loading in muscles from the young adult rats $(p<.05)$, but there was no significant change in catalase levels in muscles of the aged animals. Catalase activity was higher in control muscles of aged vs. young adult animals, and it increased in loaded muscles of aged animals as compared to young adult animals $(p<.05)$. (Figure 3.8$)$ No differences were found between catalase mRNA or protein levels within any of the TA muscles.

\section{$\underline{\text { Insert Figure } 3.8}$}

CuZn Superoxide dismutase activity. CuZnSOD protein levels increased by $100 \%(p<0.05)$ (Figure 3.9A) and CuZnSOD enzyme activity (Figure 3.9B) increased by $43 \%$ in $(p<0.05)$ in repetitively loaded muscles from young animals as compared to the contra-lateral control muscles. However, these appeared to be post-translationally regulated because no differences in CuZnSOD mRNA levels in control or loaded muscles from young animals were observed. Aging suppressed any loading-induced changes in CuZnSOD, because there were no differences in mRNA, protein, or enzyme activity in the chronically loaded muscles compared to control muscles from aged animals.

\section{$\underline{\text { Insert Figure } 3.9}$}

MnSOD. MnSOD protein levels were increased by $75 \%$ in the loaded muscles of the young animals as compared to their contra-lateral control muscles $(p<0.01)$ as determined by western blot analyses (Figure 3.10); however, the increase in MnSOD protein did not affect the activity levels nor was it driven by the alterations in MnSOD mRNA. No changes in any of the variables were seen in the aged animals. 


\section{$\underline{\text { Insert Figure } 3.10}$}

\section{Discussion}

Chronic adaptation to resistance exercise over many weeks in older women and men has been shown to improve muscular strength and also induce muscle fiber hypertrophy $(20 ; 63)$. However, it is not clear if the lower extent of muscle hypertrophy that generally results from chronic loading in aging (16) is due, at least in part, to elevated levels of oxidants. In this study, we found increases in muscle hypertrophy and muscle force and work in chronically loaded muscles of young adult rats. Although there was some degree of muscle enlargement in old animals with repetitive loading for 4.5 weeks, there was no improvement in muscle function, suggesting that muscle hypertrophy (based on muscle-wet weight) may not have been a result of increases in contractile proteins in muscles of aged rats. Although this varies slightly from a previous study using the same protocol, where a decrease in muscle mass and function was observed in old animals (10), it is likely that different cohorts of animals obtained from the NIA colony have slightly different responses and adaptive capabilities. Nevertheless, the current study and the previous study (9) are generally consistent in showing an attenuated functional response to repetitive loading with aging. While we cannot rule out the possibility that part of the increase in muscle wet weight may have been the result of increases in collagen or other contractile proteins, we did not detect evidence of inflammation (e.g., macrophages) or infiltrates in the loaded muscles of aged animals (Baker et al, unpublished observations).

Findings of the current study are that control muscles of aged rats had higher levels of oxidative stress as indicated by elevated $\mathrm{H}_{2} \mathrm{O}_{2}, 8-\mathrm{OHdG}$ and MDA+HAE as compared to control muscles of young adult animals. These findings are consistent with observations from other laboratories showing that aging is associated with increased levels of oxidative stress in skeletal muscles and may be related, at least in part to reduced muscle function with aging $(3 ; 53 ; 64)$.

While chronic adaptation to loading, that was 3 times weekly for 4.5 weeks, increased oxidant levels of $\mathrm{H}_{2} \mathrm{O}_{2}$, aging did not prevent improvement in several indices of oxidative stress in loaded skeletal muscles of aged rodents (e.g., lipid peroxidation, and oxidative damage to DNA). Nevertheless, there was only a partial ability to adapt to greater levels of oxidative stress with aging. Of particular note, CuZnSOD and MnSOD were not different in the chronically loaded muscles of aged rodents compared to the control muscles, despite increased oxidative loads (e.g., $\mathrm{H}_{2} \mathrm{O}_{2}$ ) and evidence of oxidative damage. We speculate that a failure to elevate CuZnSOD as part of an adaptive process for repetitive loading may be critically important for explaining the increased DNA and lipid oxidative damage with aging, because reduced levels of this anti-oxidant protein has been shown to coincide with reduced muscle mass and function (55).

In contrast, the adaptation was more complete in muscles of young adult animals. For example, indices of oxidative stress (GSH/GSSG ratio) and oxidative damage (MDA $+\mathrm{HAE}$ and 8-OHdG) were similar in control and chronically loaded muscles from young animals. This suggests that the tibialis anterior muscles were able to efficiently adapt and buffer the increase in oxidant production in muscles of young adult animals. Furthermore, there was no significant difference in oxidative stress markers from the non-exercised control muscle. Adaptation in chronically loaded muscles from young adult animals appeared to occur via an increase in catalase and CuZnSOD activity, two enzymes that 
are primarily located in the cytosol. This implies that the increase in oxidant production may not be primarily originating from the mitochondria, but may instead be generated in the cytosol, possibly through the xanthine oxidase pathway. We speculate that an increase in signaling of the xanthine oxidase pathway could increase the production of superoxide in the cytosol, thus increasing the localized stimuli for CuZnSOD production and activity as well as an increase in $\mathrm{H}_{2} \mathrm{O}_{2}$ production. We have found that acute bouts of repetitive loading increased xanthine oxidase activity in tibialis anterior muscle homogenate from mice (unpublished data).

In the present study, enzyme activity for CuZnSOD increased by about $43 \%$, which is similar to previous findings from our lab using the same electrically evoked repetitive loading model (56). The lack of an increase in CuZnSOD mRNA would suggest post transcriptional modification that activates protein synthesis. Similarly, Hollander and colleagues $(27 ; 29)$ found increases in CuZnSOD protein levels without changes in mRNA after a single bout of endurance exercise. The current study differed from data presented by Hollander et al $(28 ; 30)$, in that previously they showed no increase in CuZnSOD enzyme activity after an acute bout of exercise, where the present study shows increases in enzyme activity. This may be a result of a cumulative effect resulting from chronic adaption to repetitive stimulation over the 4.5 week period of the present study.

Xanthine oxidase-mediated oxidative stress in the cytosol has been shown to increase activation of NF-KB signaling resulting in an increase in the transcription of $\mathrm{mRNA}$ for MnSOD. The lack of a detectable increase in MnSOD mRNA in the current study does not mean that it did not occur. There are two possible explanations; first protein levels for MnSOD are controlled by post translational modifications, similar to that found in CuZnSOD, and secondly, that transcription of MnSOD mRNA initially increased within the tibialis anterior, which in turn led to an increase in MnSOD protein levels which acted as a negative feedback regulatory mechanism to slow down transcription of MnSOD mRNA. Either possibility would explain the results we found in the current study.

Various stages of post-translational modulation are required to make the MnSOD enzyme catalytically active. We speculate that without increased oxidant production within the mitochondria, the MnSOD protein would not have the stimulus needed for modification to its active form, thus we did not find any changes in MnSOD activity levels. The lack of an increase in MnSOD activity also helps support our suggestion that the mode of exercise we tested did not substantially increase oxidant production within the mitochondria.

Chronic exercise has been shown to either maintain or increase levels of GPx activity at least in aerobic high volume, low intensity types of exercise (25; 37). While generally, high-intensity exercise training has been shown to be more effective than lowintensity exercise in increasing of muscle GPx activity (62). Therefore, it was not surprising that repetitive muscle loading induced an increase in GPx activity in muscles from both the young adult and aged animals. However, there were no significant changes in the mRNA or protein levels for GPx-1 between either young vs. aged or control vs. exercise, this data suggests that repetitive loading induced a post-transcriptional increase in GPx activity within skeletal muscles of both young and aged animals. Similarly to GPx activity, catalase activity increased with repetitive loading exercise. GPx is an enzyme that is primarily thought to be responsible for reducing $\mathrm{H}_{2} \mathrm{O}_{2}$ and/or organic hydroperoxides to 
water or alcohol and is located in both the cytosol and the mitochondria. Catalase catalyzes the breakdown of $\mathrm{H}_{2} \mathrm{O}_{2}$ to form water and $\mathrm{O}_{2}(34 ; 48)$. The current data suggests that intense resistance training will lead to an increase in GPx and catalase activity in response to exercise induced $\mathrm{H}_{2} \mathrm{O}_{2}$ accumulation.

In conclusion, the data in this study show that muscles from aged rats have higher levels of oxidative stress and oxidative damage (e.g., to DNA and lipids) than muscles of young adult rats. Mechanical loading further exacerbates oxidative stress in muscles of aged rodents, but this appears to be well buffered in muscles of young adult animals. In response to high intensity chronic loading, there is a partial adaptation of oxidative enzymes to attempt to compensate for the increased oxidative insult in muscles of aged rats. However, this adaptation is incomplete, because CuZnSOD and MnSOD do not increase in chronically loaded muscles of aged rodents, but increase significantly after chronic adaptation to loading in muscles of young adult animals. The increases in GPx and catalase activity appear to be in response to loading induced elevations in $\mathrm{H}_{2} \mathrm{O}_{2}$. These data show that aging reduces the adaptive capacity of muscles to buffer the increased oxidant production imposed by chronic repetitive loading. This may compromise the muscles' abilities to hypertrophy or to improve muscle function in aged animals. Furthermore, it is possible that greater unbuffered levels of oxidative stress in muscles of old animals may trigger increased levels of apoptosis that are associated with lower muscle mass and attenuated hypertrophic adaptation in aging $(44 ; 60 ; 68)$. 


\section{Figure Legends}

Figure 3.1 Repetitive loading induces muscle hypertrophy in the Tibialis Anterior Muscle. Data are expressed as tibialis anterior muscle wet weight in grams. *, significance difference between age-matched control and RL TA muscle assigned at $p<0.05 ; \dagger$, a significant difference $(p<0.05)$ from young treatment-matched control muscles.

Figure 3.2 Repetitive loading increased muscle functional measurements in young adult dorsiflexor muscles while maintaining function in aged dorsiflexor muscles. (A) Maximal force generated from the young and aged dorsiflexor muscles during each of the 14 training sessions. Data are expressed as the average maximum force for all animals in Newtons $(\mathrm{N})$ produced during each exercise session $\pm \mathrm{SE}$. Solid line represents the linear regression for all age-matched points. ${ }^{*}$, a significant difference $(p<0.05)$ between young adult and aged dorsiflexor muscles. (B) Positive work generated from a single eccentric /concentric movement preformed at the start of each training session from the young and aged dorsiflexor muscles during each of the 14 training sessions. Data is expressed as the mean \pm SEM. Solid line represents the linear regression for all age-matched points. *, a significant difference $(p<0.05)$ between young adult and aged dorsiflexor muscles. (C) Negative work generated from a single eccentric /concentric movement preformed at the start of each training session from the young and aged dorsiflexor muscles during each of the 14 training sessions. Data is expressed as the mean \pm SEM. Solid line represents the linear regression for all age-matched points. *, a significant difference $(p<0.05)$ between young adult and aged dorsiflexor muscles.

Figure 3.3 Concentration of hydrogen peroxide $\left(\mathrm{H}_{2} \mathrm{O}_{2}\right)$ are elevated with $\mathbf{R L}$ \& aging. The $\mathrm{H}_{2} \mathrm{O}_{2}$ concentration was determined by a fluorometric assay. Data is expressed as Relative Fluorescent Unit (RFU) per mg of total protein in TA homogenate. The normalized data are presented as mean \pm SEM. ${ }^{*}$, significant difference $(p<0.05)$ of repetitively loaded $(R L)$ muscle from contra-lateral control muscle. $\dagger$, significant difference $(p<0.05)$ from young treatment- matched control.

Figure 3.4 Ratio of reduced glutathione to oxidized glutathione (GSH/GSSG). Data are depicted as the ratio of GSH to GSSG normalized to total protein content. Lower ratios are an indication of increased oxidative stress. The normalized data are presented as mean \pm SEM. * , significant difference $(p<0.05)$ of $R L$ muscle from contralateral control muscle. $\dagger$, significant difference $(p<0.05)$ from young treatment- matched control.

Figure 3.5 Repetitive loading decreases lipid peroxidation in tibialis anterior muscles of aged rats. Data are combined malondialdehyde (MDA) and 4hydroxyalkenals (HAE) normalized to total protein content. The data are presented as mean \pm SEM. ${ }^{*}$, significant difference $(p<0.05)$ of $R L$ muscle from contra-lateral control muscle. $\dagger$, significant difference $(p<0.05)$ from young treatment- matched control.

Figure 3.6 Aging increased the quantity of DNA damage while RL had no effect. Data is expressed as ng concentration of 8-hydroxy-2'-deoxyguanosine (8-OHdG) per $\mathrm{ml}$ of TA homogenate per $\mu \mathrm{g}$ of DNA. The normalized data are presented as mean \pm 
SEM. *, denotes significant difference $(p<0.05)$ of $R L$ TA muscle from contra-lateral control muscle. $\dagger$, significant difference $(p<0.05)$ from young treatment- matched control.

Figure 3.7 Glutathione peroxidase (GPx) activity decreased with repetitive loading. Data is expressed as $\mathrm{mU}$ of GPx per $\mathrm{ml}$ of homogenate per $\mathrm{mg}$ of protein. The normalized data are presented as mean \pm SEM. ${ }^{*}$, significant difference $(p<0.05)$ of RL TA muscle from contra-lateral control muscle; $\dagger$, significant difference $(p<0.05)$ from young treatment- matched control.

Figure 3.8 Catalase activity increased with repetitive loading and aging.

Data is expressed as units $(U)$ of catalase per $\mathrm{ml}$ of homogenate per $\mathrm{mg}$ of protein. The normalized data are presented as mean \pm SEM. * , significant difference $(p<0.05)$ of $R L$ TA muscle from contra-lateral control muscle; $\dagger$, significant difference $(p<0.05)$ from young treatment- matched control.

Figure 3.9 CuZn superoxide dismutase (CuZnSOD) protein levels and activity increased with repetitive loading in the tibialis anterior muscles of young but not old rats. (A) CuZn Superoxide dismutase (CuZnSOD) protein expression was determined in the total cytosolic fraction by western immunoblot. The data is expressed as optical density $(\mathrm{OD}) \mathrm{x}$ band area, and expressed in arbitrary units. The inserts show representative blots for CuZnSOD and $\beta$-tubulin in young and aged (control and RL) TA muscle. The normalized data are presented as mean \pm SEM. *, significant difference $(p<0.05)$ of RL TA muscle from contra-lateral control muscle. (B) CuZnSOD activity data is expressed as $\mathrm{U}$ of CuZnSOD per $\mathrm{ml}$ of homogenate per $\mathrm{mg}$ of protein. The normalized data are presented as mean \pm SEM. *, significant difference $(p<0.05)$ of RL TA muscle from contra-lateral control muscle.

Figure 3.10 Mn superoxide dismutase (MnSOD) protein levels increased with repetitive loading in tibialis anterior muscles of young rats. Mn Superoxide dismutase (MnSOD) protein expression was determined in the total cytosolic fraction by western immunoblot. The data is expressed as optical density (OD) $x$ band area, and expressed in arbitrary units. The inserts show representative blots for MnSOD and $\beta$ tubulin in young and aged (control and RL) TA muscle. The normalized data are presented as mean \pm SEM. * , denotes significant difference $(p<0.05)$ of RL TA muscle from contralateral control muscle. 
Figure 3.1

\section{Tibialis Anterior Muscle Wet Weight}

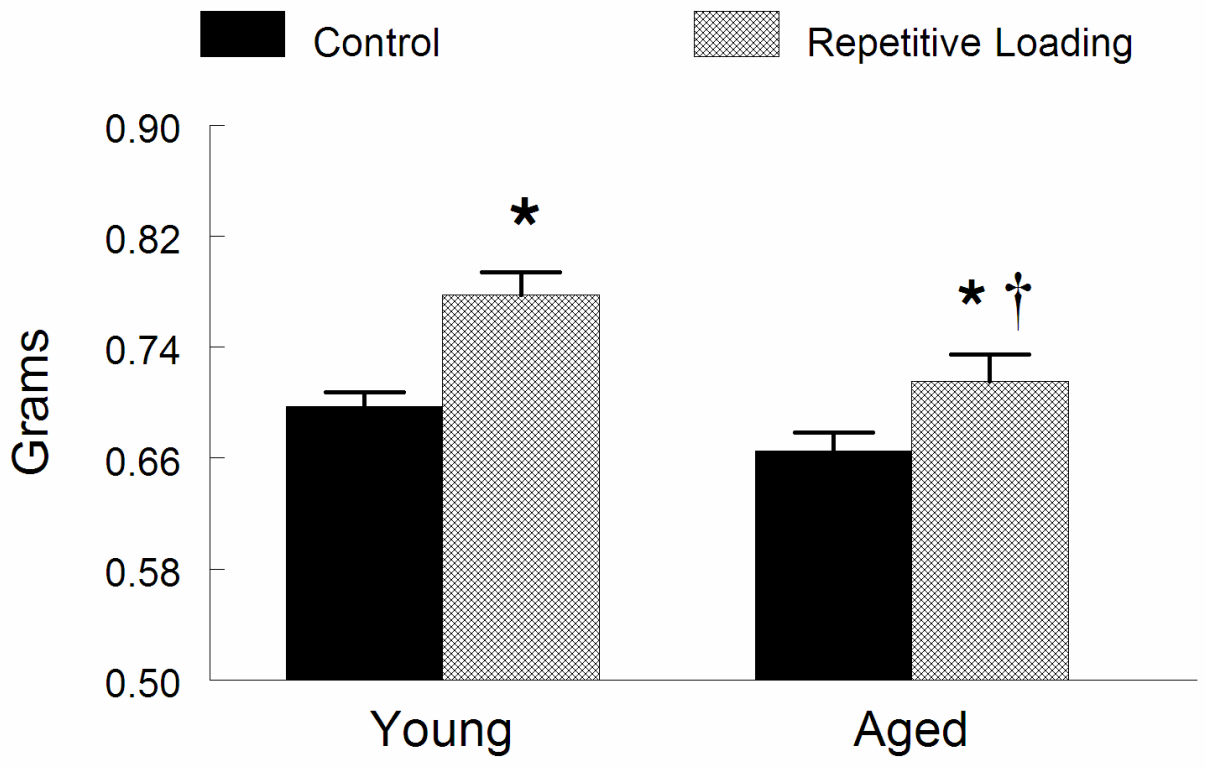


Figure 3.2

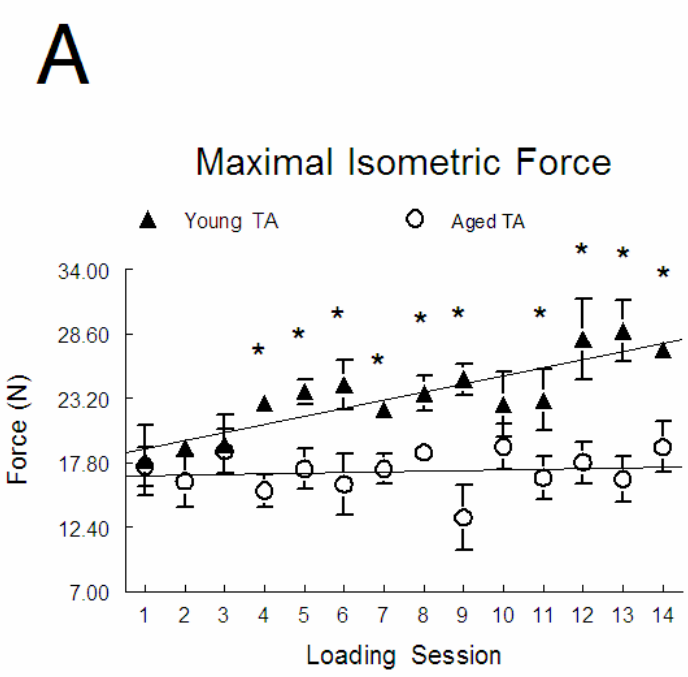

B

- Young TA Positive Work

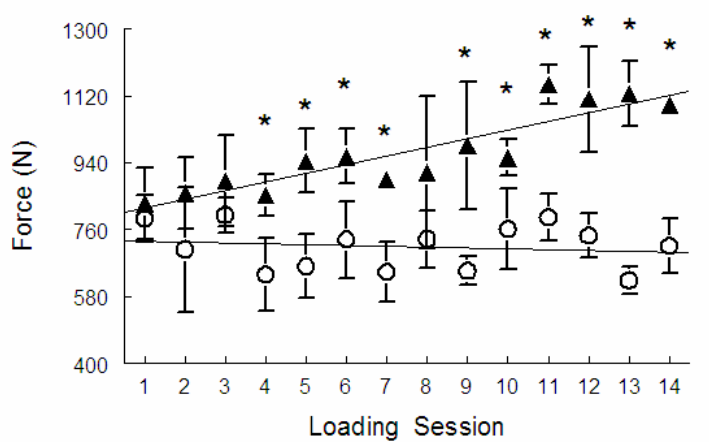

C

Negative Work

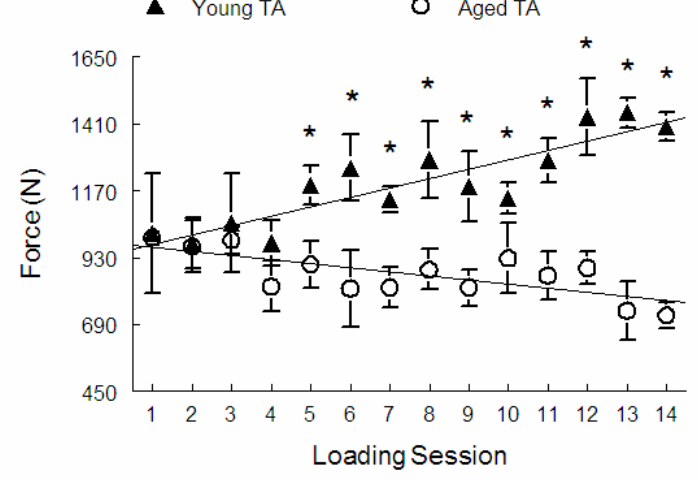


Figure 3.3

\section{Hydrogen Peroxide $\left(\mathrm{H}_{2} \mathrm{O}_{2}\right)$}

Control

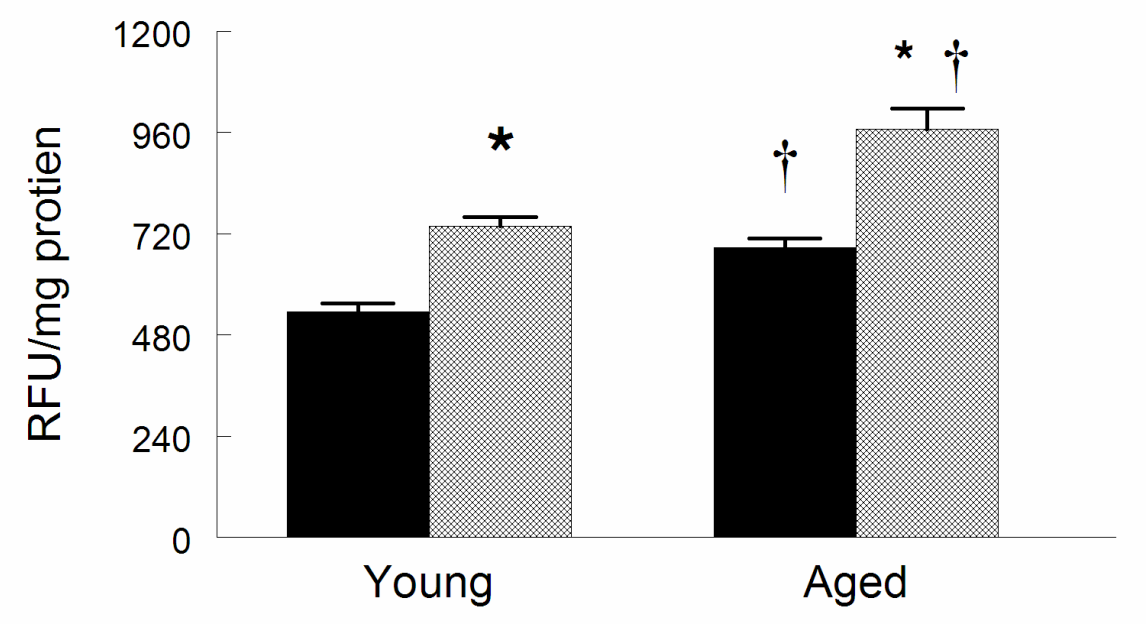


Figure 3.4

\section{GSH/GSSG Ratio}

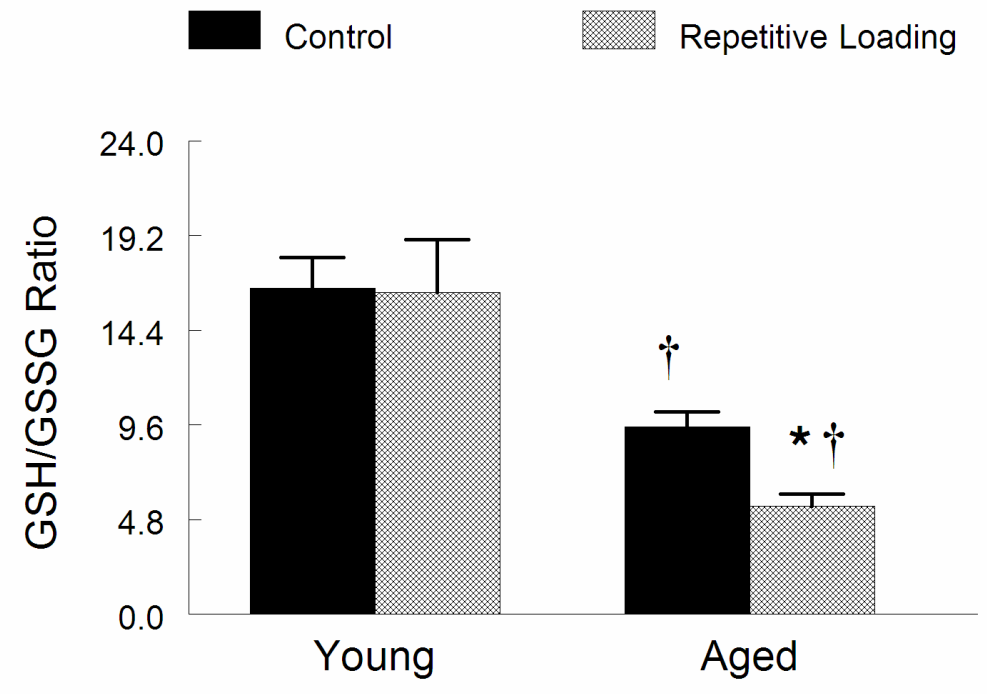


Figure 3.5

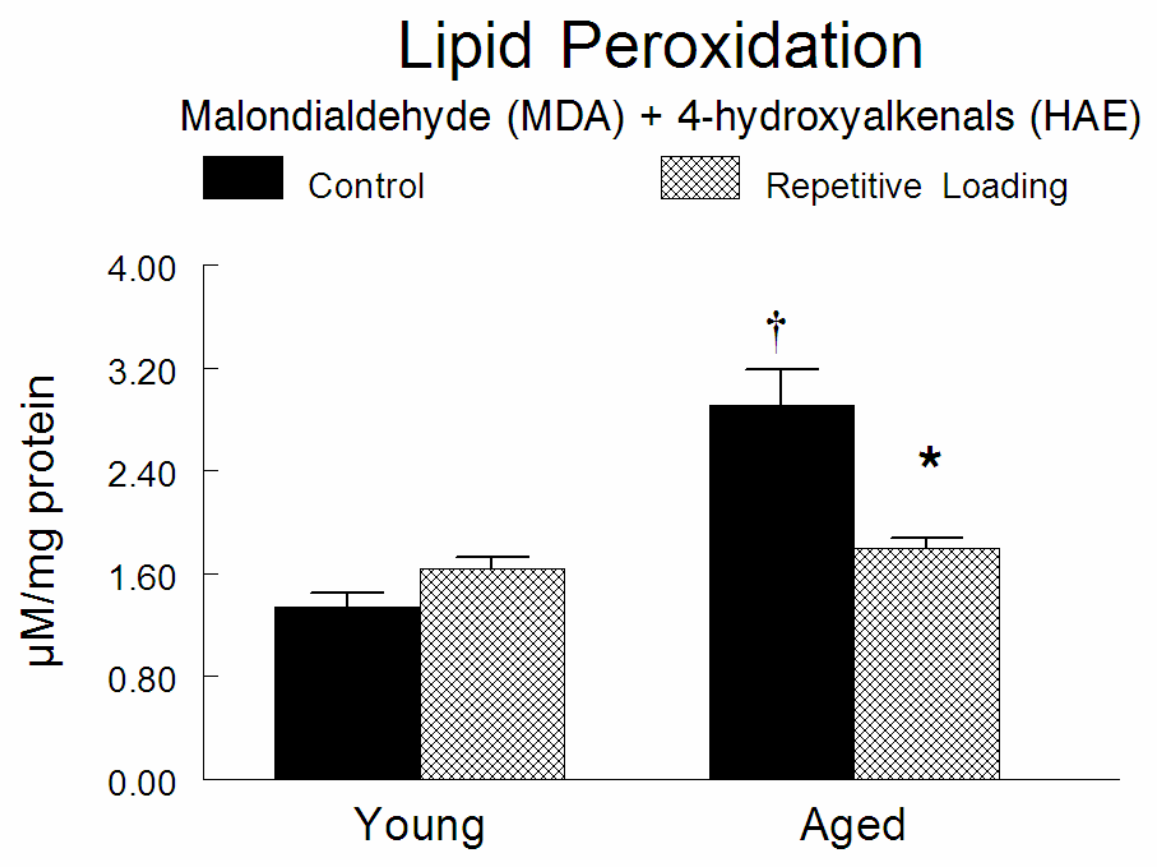


Figure 3.6

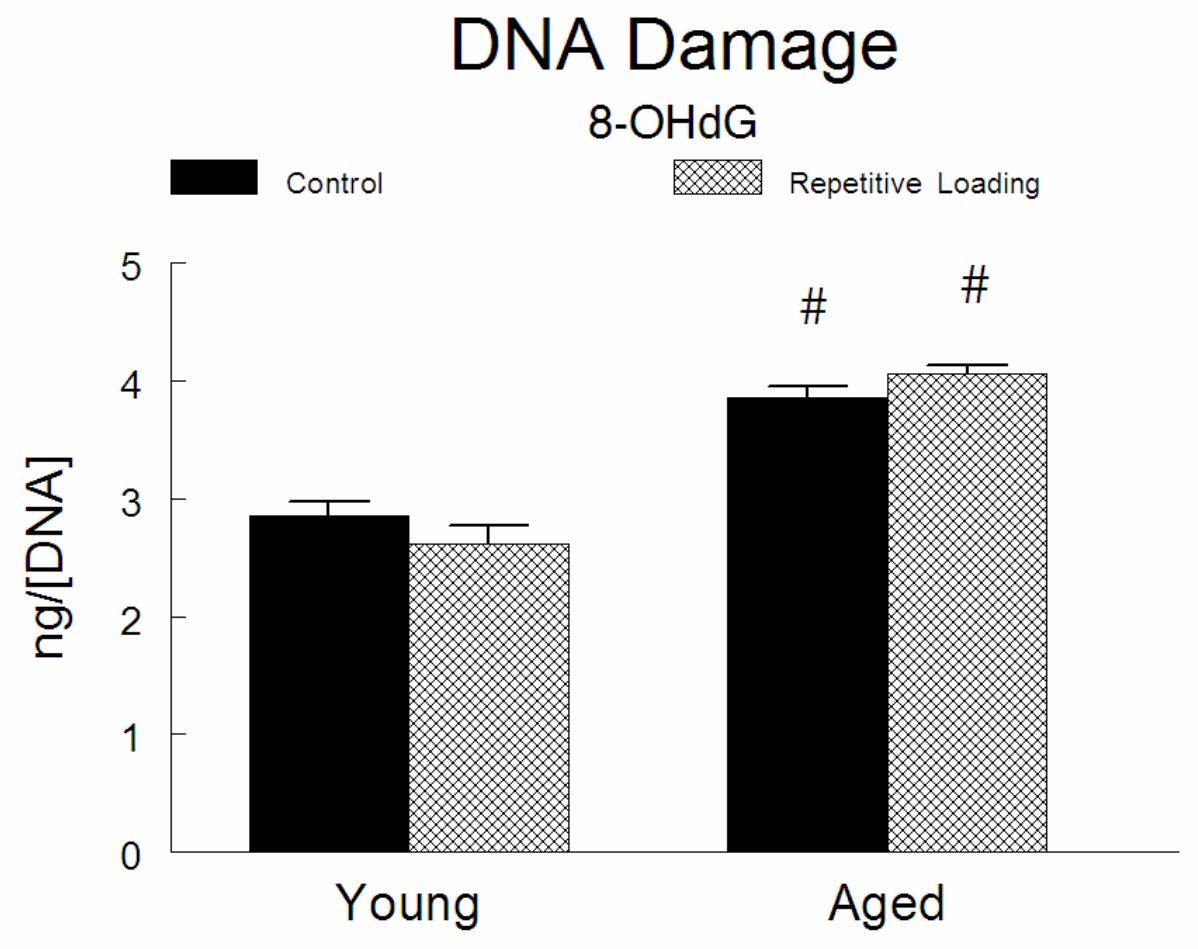


Figure 3.7

\section{GPx Activity}

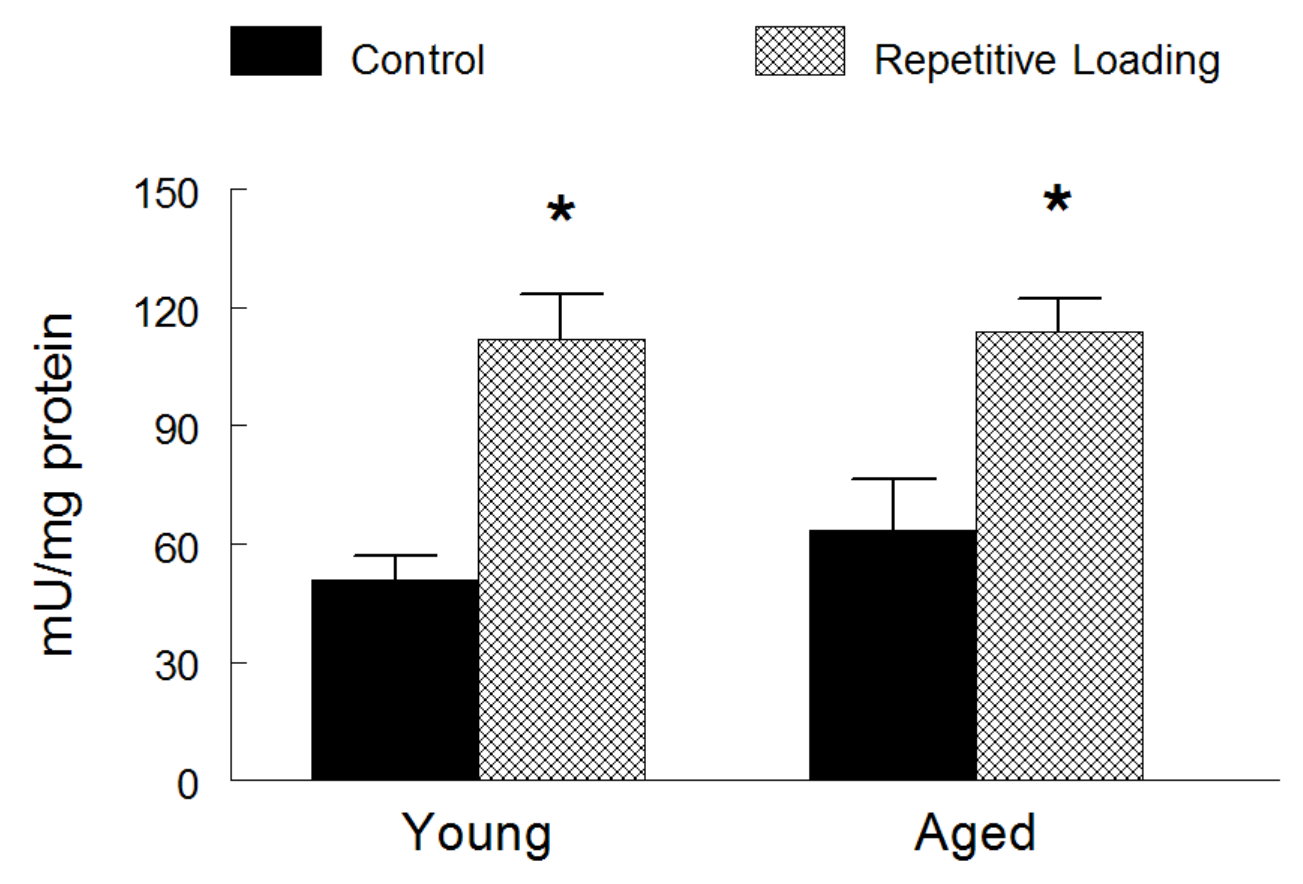


Figure 3.8

\section{Catalase Activity}

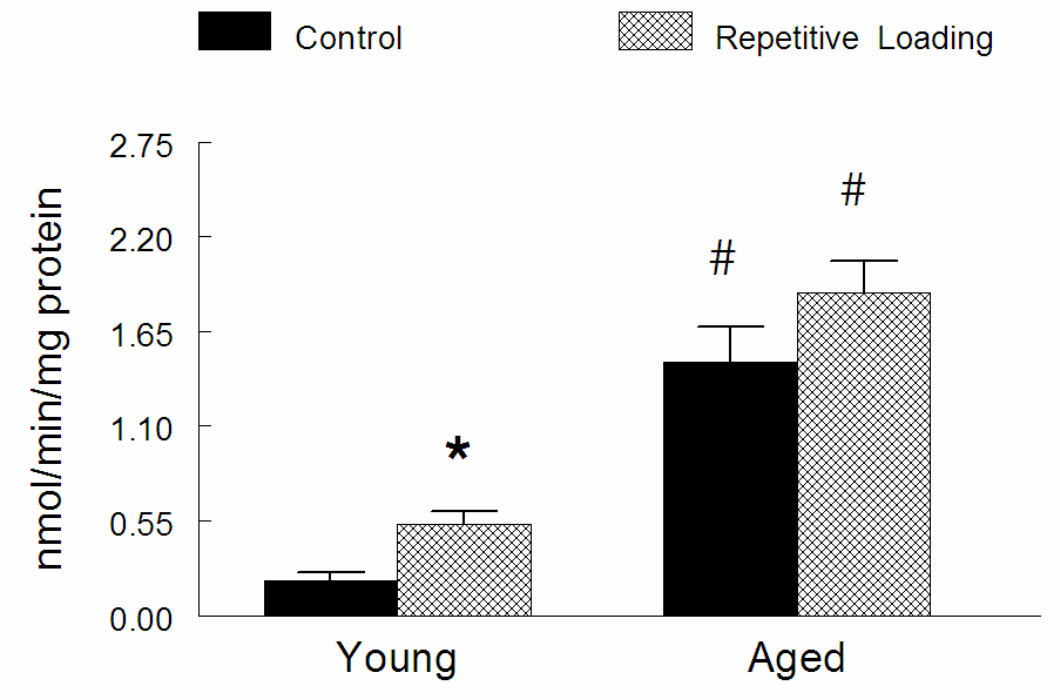


Figure 3.9

A

CuZn SOD Protein

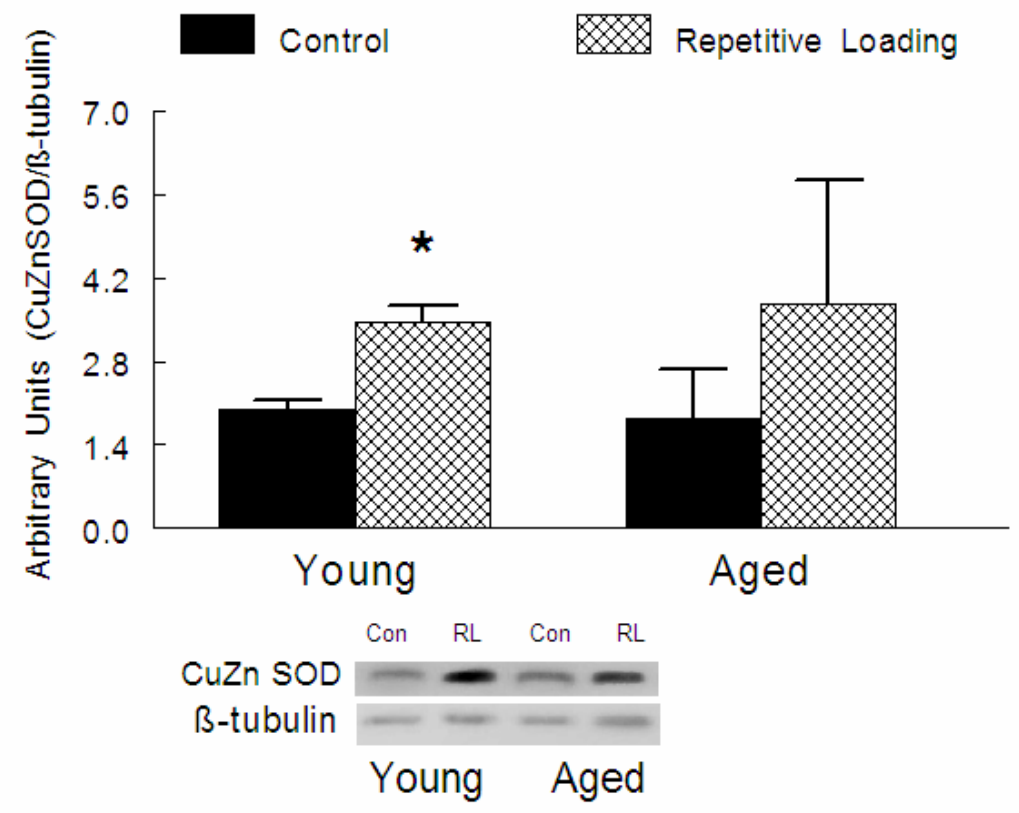

B

CuZn SOD Activity

Control

Repetitive Loading

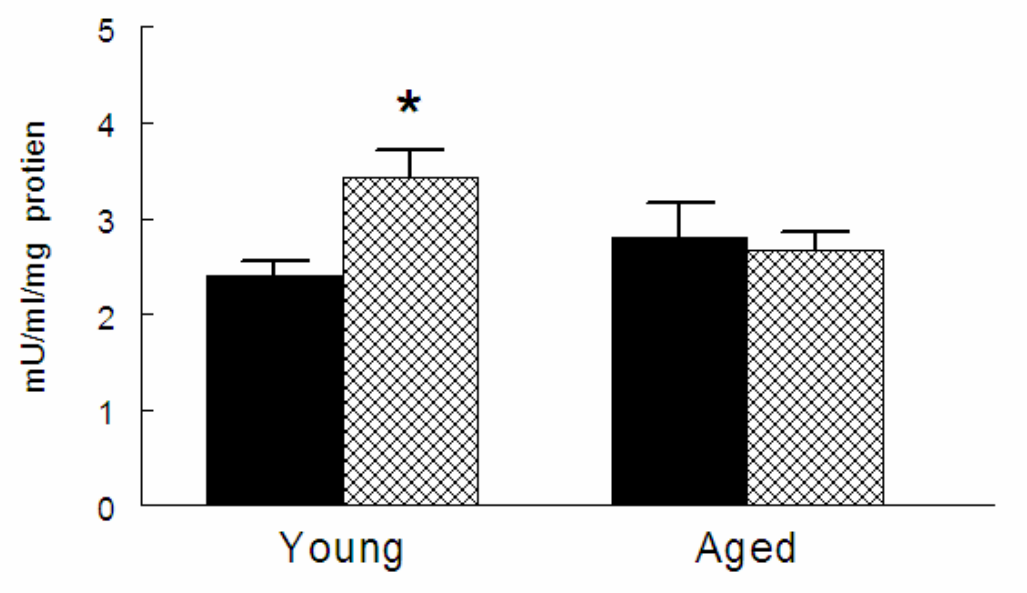


Figure 3.10

\section{Mn SOD Protein}

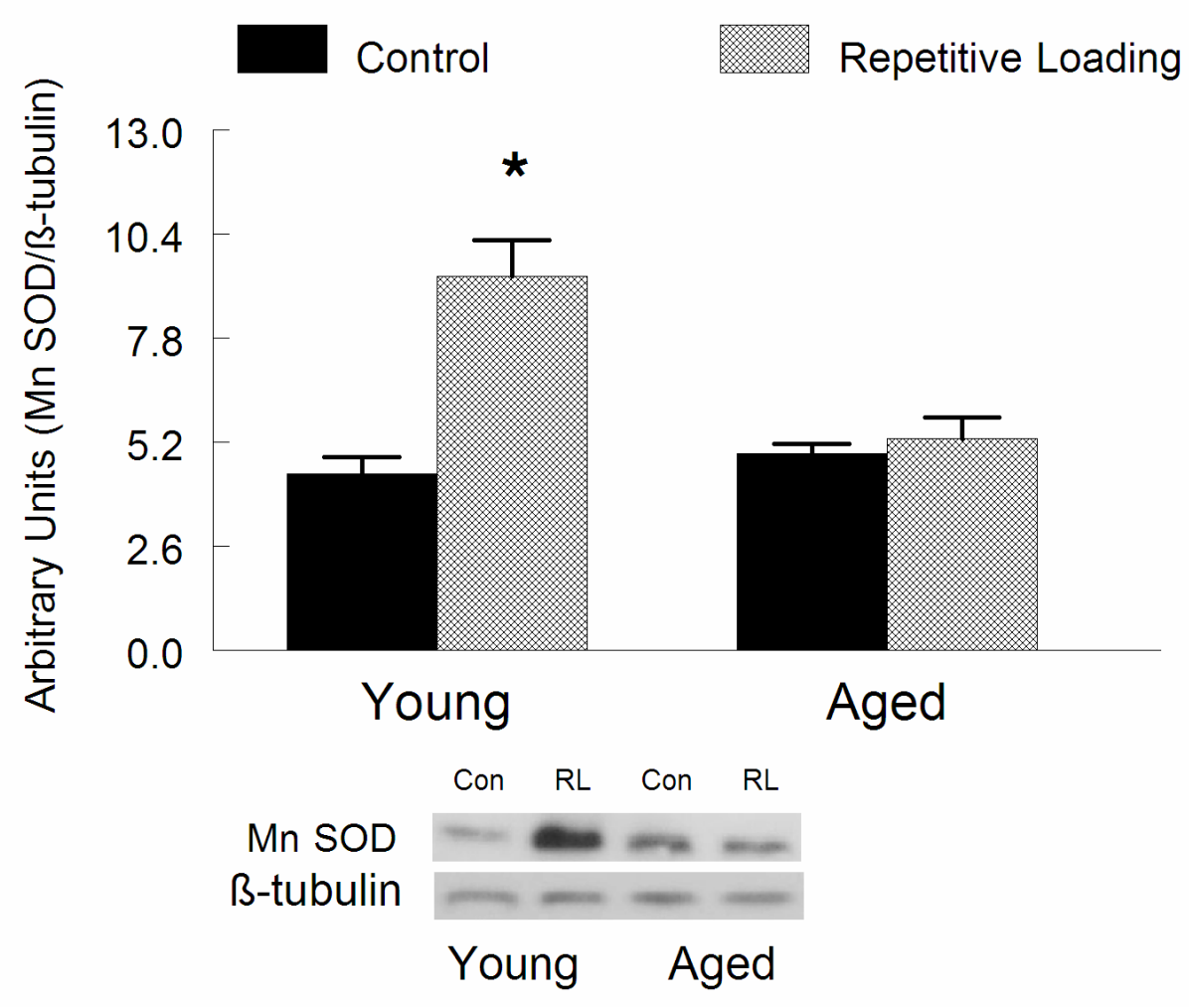


Reference List

1. Andrade FH, Reid MB, Allen DG and Westerblad H. Effect of hydrogen peroxide and dithiothreitol on contractile function of single skeletal muscle fibres from the mouse. $J$ Physiol 509 ( Pt 2): 565-575, 1998.

2. Anzueto A, Brassard JM, Andrade FH, Lawrence RA, Maxwell LC, Levine SM and Jenkinson SG. Effects of Hyperoxia on Rat Diaphragm Function. Journal of Applied Physiology 77: 63-68, 1994.

3. Asano S, Rice KM, Kakarla S, Katta A, Desai DH, Walker EM, Wehner P and Blough ER. Aging influences multiple indices of oxidative stress in the heart of the Fischer 344/NNia x Brown Norway/BiNia rat. Redox Rep 12: 167-180, 2007.

4. Beckman KB and Ames BN. Mitochondrial aging: open questions. Ann N Y Acad Sci 854: 118-127, 1998.

5. Bejma $\mathbf{J}$ and $\mathbf{J i} \mathbf{L L}$. Aging and acute exercise enhance free radical generation in rat skeletal muscle. J Appl Physiol 87: 465-470, 1999.

6. Brickson S, Hollander J, Corr DT, Ji LL and Best TM. Oxidant production and immune response after stretch injury in skeletal muscle. Med Sci Sports Exerc 33: 2010-2015, 2001.

7. Clanton TL, Zuo L and Klawitter P. Oxidants and skeletal muscle function: physiologic and pathophysiologic implications. Proc Soc Exp Biol Med 222: 253-262, 1999.

8. Csiszar A, Labinskyy N, Orosz Z, Xiangmin Z, Buffenstein R and Ungvari Z. Vascular aging in the longest-living rodent, the naked mole rat. Am J Physiol Heart Circ Physiol 293: H919-H927, 2007.

9. Cutlip RG, Baker BA, Geronilla KB, Mercer RR, Kashon ML, Miller GR, Murlasits Z and Alway SE. Chronic exposure to stretch-shortening contractions results in skeletal muscle adaptation in young rats and maladaptation in old rats. Applied Physiology Nutrition and Metabolism-Physiologie Appliquee Nutrition et Metabolisme 31: 573-587, 2006.

10. Cutlip RG, Baker BA, Geronilla KB, Mercer RR, Kashon ML, Miller GR, Murlasits Z and Alway SE. Chronic exposure to stretch-shortening contractions results in skeletal muscle adaptation in young rats and maladaptation in old rats. Applied Physiology Nutrition and Metabolism-Physiologie Appliquee Nutrition et Metabolisme 31: 573-587, 2006.

11. Cutlip RG, Baker BA, Geronilla KB, Mercer RR, Kashon ML, Miller GR, Murlasits Z and Alway SE. Chronic exposure to stretch-shortening contractions results in skeletal muscle adaptation in young rats and maladaptation in old rats. Applied Physiology Nutrition and Metabolism-Physiologie Appliquee Nutrition et Metabolisme 31: 573-587, 2006.

12. Cutlip RG, Baker BA, Geronilla KB, Mercer RR, Kashon ML, Miller GR, Murlasits Z and Alway SE. Chronic exposure to stretch-shortening contractions results in skeletal muscle adaptation in young rats and maladaptation in old rats. Applied Physiology Nutrition and Metabolism-Physiologie Appliquee Nutrition et Metabolisme 31: 573-587, 2006. 
13. Cutlip RG, Baker BA, Geronilla KB, Mercer RR, Kashon ML, Miller GR, Murlasits Z and Alway SE. Chronic exposure to stretch-shortening contractions results in skeletal muscle adaptation in young rats and maladaptation in old rats. Applied Physiology Nutrition and Metabolism-Physiologie Appliquee Nutrition et Metabolisme 31: 573-587, 2006.

14. Cutlip RG, Geronilla KB, Baker BA, Chetlin RD, Hover I, Kashon ML and Wu JZ. Impact of stretch-shortening cycle rest interval on in vivo muscle performance. Med Sci Sports Exerc 37: 1345-1355, 2005.

15. Cutlip RG, Stauber WT, Willison RH, McIntosh TA and Means KH. Dynamometer for rat plantar flexor muscles in vivo. Med Biol Eng Comput 35: 540-543, 1997.

16. Degens $\mathbf{H}$ and Alway SE. Control of muscle size during disuse, disease, and aging. International Journal of Sports Medicine 27: 94-99, 2006.

17. DeMartino GN and Ordway GA. Ubiquitin-proteasome pathway of intracellular protein degradation: implications for muscle atrophy during unloading. Exerc Sport Sci Rev 26: 219-252, 1998.

18. Dirks AJ and Leeuwenburgh $\mathbf{C}$. Aging and lifelong calorie restriction result in adaptations of skeletal muscle apoptosis repressor, apoptosis-inducing factor, X-linked inhibitor of apoptosis, caspase-3, and caspase-12. Free Radic Biol Med 36: 27-39, 2004.

19. Eu JP, Sun J, Xu L, Stamler JS and Meissner G. The skeletal muscle calcium release channel: coupled O2 sensor and NO signaling functions. Cell 102: 499-509, 2000.

20. Ferketich AK, Kirby TE and Alway SE. Cardiovascular and muscular adaptations to combined endurance and strength training in elderly women. Acta Physiol Scand 164: 259267, 1998.

21. Fugere NA, Ferrington DA and Thompson LV. Protein nitration with aging in the rat semimembranosus and soleus muscles. Journals of Gerontology Series A-Biological Sciences and Medical Sciences 61: 806-812, 2006.

22. Fulle S, Protasi F, Di Tano G, Pietrangelo T, Beltramin A, Boncompagni S, Vecchiet L and Fano $G$. The contribution of reactive oxygen species to sarcopenia and muscle ageing. Exp Gerontol 39: 17-24, 2004.

23. Gianni P, Jan KJ, Douglas MJ, Stuart PM and Tarnopolsky MA. Oxidative stress and the mitochondrial theory of aging in human skeletal muscle. Experimental Gerontology 39: 1391-1400, 2004.

24. Gianni P, Jan KJ, Douglas MJ, Stuart PM and Tarnopolsky MA. Oxidative stress and the mitochondrial theory of aging in human skeletal muscle. Experimental Gerontology 39: 1391-1400, 2004.

25. Hatao H, Oh-Ishi S, Itoh M, Leeuwenburgh C, Ohno H, Ookawara T, Kishi K, Yagyu H, Nakamura $\mathbf{H}$ and Matsuoka T. Effects of acute exercise on lung antioxidant enzymes in young and old rats. Mech Ageing Dev 127: 384-390, 2006. 
26. Hoffman-Goetz $L$ and Spagnuolo PA. Effect of repeated exercise stress on caspase 3, $\mathrm{Bcl}-2$, HSP 70 and CuZn-SOD protein expression in mouse intestinal lymphocytes. $J$ Neuroimmunol 187: 94-101, 2007.

27. Hollander J, Bejma J, Ookawara T, Ohno H and Ji LL. Superoxide dismutase gene expression in skeletal muscle: fiber-specific effect of age. Mech Ageing Dev 116: 33-45, 2000.

28. Hollander J, Bejma J, Ookawara T, Ohno H and Ji LL. Superoxide dismutase gene expression in skeletal muscle: fiber-specific effect of age. Mech Ageing Dev 116: 33-45, 2000.

29. Hollander J, Gore M, Fiebig R, Mazzeo R, Ohishi S, Ohno H and Ji LL. Spaceflight downregulates antioxidant defense systems in rat liver. Free Radical Biology and Medicine 24: 385-390, 1998.

30. Hollander J, Gore M, Fiebig R, Mazzeo R, Ohishi S, Ohno H and Ji LL. Spaceflight downregulates antioxidant defense systems in rat liver. Free Radical Biology and Medicine 24: 385-390, 1998.

31. Ji LL. Exercise-induced modulation of antioxidant defense. Ann N Y Acad Sci 959: 82-92, 2002.

32. Ji LL. Antioxidant signaling in skeletal muscle: a brief review. Exp Gerontol 42: 582-593, 2007.

33. Ji LL, Gomez-Cabrera MC and Vina J. Role of nuclear factor kappaB and mitogenactivated protein kinase signaling in exercise-induced antioxidant enzyme adaptation. Appl Physiol Nutr Metab 32: 930-935, 2007.

34. Ji LL and Leeuwenburgh C. Glutathione Depletion with Buthionine Sulfoximine - Effect on Antioxidant Defense and Oxidative Stress with Exercise. Faseb Journal 9: 140, 1995.

35. Ji LL, Leeuwenburgh C, Leichtweis S, Gore M, Fiebig R, Hollander J and Bejma J. Oxidative stress and aging. Role of exercise and its influences on antioxidant systems. Ann N Y Acad Sci 854: 102-117, 1998.

36. Ji LL and Peterson DM. Aging, exercise, and phytochemicals: promises and pitfalls. Ann N Y Acad Sci 1019: 453-461, 2004.

37. Judge S, Jang YM, Smith A, Selman C, Phillips T, Speakman JR, Hagen T and Leeuwenburgh $\mathbf{C}$. Exercise by lifelong voluntary wheel running reduces subsarcolemmal and interfibrillar mitochondrial hydrogen peroxide production in the heart. American Journal of Physiology-Regulatory Integrative and Comparative Physiology 289: R1564-R1572, 2005.

38. Kagan VE, Tyurina YY, Bayir H, Chu CT, Kapralov AA, Vlasova II, Belikova NA, Tyurin VA, Amoscato A, Epperly M, Greenberger J, Dekosky S, Shvedova AA and Jiang J. The "pro-apoptotic genies" get out of mitochondria: oxidative lipidomics and redox activity of cytochrome c/cardiolipin complexes. Chem Biol Interact 163: 15-28, 2006. 
39. Kamel HK. Sarcopenia and aging. Nutr Rev 61: 157-167, 2003.

40. Kaneko T, Tahara S, Taguchi T and Kondo H. Accumulation of oxidative DNA damage, 8-oxo-2'-deoxyguanosine, and change of repair systems during in vitro cellular aging of cultured human skin fibroblasts. Mutat Res 487: 19-30, 2001.

41. Kondo H, Kodama J, Kishibe $\mathbf{T}$ and Itokawa $\mathbf{Y}$. Oxidative Stress During Recovery from Muscle Atrophy. FEBS Lett 326: 189-191, 1993.

42. Kondo H, Miura M and Itokawa Y. Antioxidant Enzyme-Systems in Skeletal-Muscle Atrophied by Immobilization. Pflugers Archiv-European Journal of Physiology 422: 404-406, 1993.

43. Kondo H, Miura M and Itokawa Y. Antioxidant Enzyme-Systems in Skeletal-Muscle Atrophied by Immobilization. Pflugers Archiv-European Journal of Physiology 422: 404-406, 1993.

44. Krajnak K, Waugh S, Miller R, Baker B, Geronilla K, Alway SE and Cutlip RG. Proapoptotic factor Bax is increased in satellite cells in the tibialis anterior muscles of old rats. Muscle \& Nerve 34: 720-730, 2006.

45. Krajnak K, Waugh S, Miller R, Baker B, Geronilla K, Alway SE and Cutlip RG. Proapoptotic factor Bax is increased in satellite cells in the tibialis anterior muscles of old rats. Muscle \& Nerve 34: 720-730, 2006.

46. Kramer HF and Goodyear LJ. Exercise, MAPK, and NF-kappaB signaling in skeletal muscle. J Appl Physiol 103: 388-395, 2007.

47. Lee MD, Tuttle $\mathbf{R}$ and Girten B. Effect of spaceflight on oxidative and antioxidant enzyme activity in rat diaphragm and intercostal muscles. J Gravit Physiol 2: 68-69, 1995.

48. Leeuwenburgh C and Ji LL. Glutathione Depletion in Rested and Exercised Mice Biochemical Consequence and Adaptation. Archives of Biochemistry and Biophysics 316: 941-949, 1995.

49. Li YP, Chen Y, Li AS and Reid MB. Hydrogen peroxide stimulates ubiquitin-conjugating activity and expression of genes for specific E2 and E3 proteins in skeletal muscle myotubes. Am J Physiol Cell Physiol 285: C806-C812, 2003.

50. Lysiak JJ, Zheng S, Woodson R and Turner TT. Caspase-9-dependent pathway to murine germ cell apoptosis: mediation by oxidative stress, BAX, and caspase 2. Cell Tissue Res 328: 411-419, 2007.

51. Mantovani G, Madeddu C, Maccio A, Gramignano G, Lusso MR, Massa E, Astara G and Serpe R. Cancer-related anorexia/cachexia syndrome and oxidative stress: an innovative approach beyond current treatment. Cancer Epidemiol Biomarkers Prev 13: 1651-1659, 2004.

52. Martin JA, Brown TD, Heiner AD, Buckwalter JA and Smith RL. Chondrocyte senescence, joint loading and osteoarthritis. Clin Orthop S96-103, 2004. 
53. McArdle A, Vasilaki A and Jackson M. Exercise and skeletal muscle ageing: cellular and molecular mechanisms. Ageing Res Rev 1: 79-93, 2002.

54. Muller FL, Song W, Jang YC, Liu Y, Sabia M, Richardson A and Van Remmen H. Denervation-induced skeletal muscle atrophy is associated with increased mitochondrial ROS production. Am J Physiol Regul Integr Comp Physiol 293: R1159-R1168, 2007.

55. Muller FL, Song W, Liu YH, Chaudhuri A, Pieke-Dahl S, Strong R, Huang TT, Epstein CJ, Roberts LJ, Csete M, Faulkner JA and Van Remmen H. Absence of CuZn superoxide dismutase leads to elevated oxidative stress and acceleration of age-dependent skeletal muscle atrophy. Free Radic Biol Med 40: 1993-2004, 2006.

56. Murlasits Z, Cutlip RG, Geronilla KB, Rao KM, Wonderlin WF and Alway SE. Resistance training increases heat shock protein levels in skeletal muscle of young and old rats. Exp Gerontol 41: 398-406, 2006.

57. Murrant CL, Andrade FH and Reid MB. Exogenous reactive oxygen and nitric oxide alter intracellular oxidant status of skeletal muscle fibres. Acta Physiol Scand 166: 111-121, 1999.

58. Pistilli EE, Jackson JR and Alway SE. Death receptor-associated pro-apoptotic signaling in aged skeletal muscle. Apoptosis 11: 2115-2126, 2006.

59. Pistilli EE, Siu PA and Alway SE. Molecular regulation of apoptosis in fast plantaris muscles of aged rats. Journals of Gerontology Series A-Biological Sciences and Medical Sciences 61: 245-255, 2006.

60. Pistilli EE, Siu PA and Alway SE. Molecular regulation of apoptosis in fast plantaris muscles of aged rats. Journals of Gerontology Series A-Biological Sciences and Medical Sciences 61: 245-255, 2006.

61. Posterino GS and Lamb GD. Effects of reducing agents and oxidants on excitationcontraction coupling in skeletal muscle fibres of rat and toad. J Physiol 496 ( Pt 3): 809825, 1996.

62. Powers SK and Lennon SL. Analysis of cellular responses to free radicals: focus on exercise and skeletal muscle. Proceedings of the Nutrition Society 58: 1025-1033, 1999.

63. Roman WJ, Fleckenstein J, Stray-Gundersen J, Alway SE, Peshock R and Gonyea WJ. Adaptations in the elbow flexors of elderly males after heavy- resistance training. $J$ Appl Physiol 74: 750-754, 1993.

64. Semba RD, Ferrucci L, Sun K, Walston J, Varadhan R, Guralnik JM and Fried LP. Oxidative stress and severe walking disability among older women. Am J Med 120: 10841089, 2007.

65. Siu PM and Alway SE. Id2 and p53 participate in apoptosis during unloading-induced muscle atrophy. American Journal of Physiology-Cell Physiology 288: C1058-C1073, 2005. 
66. Siu PM and Alway SE. Id2 and p53 participate in apoptosis during unloading-induced muscle atrophy. American Journal of Physiology-Cell Physiology 288: C1058-C1073, 2005.

67. Siu PM and Alway SE. Id2 and p53 participate in apoptosis during unloading-induced muscle atrophy. American Journal of Physiology-Cell Physiology 288: C1058-C1073, 2005.

68. Siu PM and Alway SE. Id2 and p53 participate in apoptosis during unloading-induced muscle atrophy. American Journal of Physiology-Cell Physiology 288: C1058-C1073, 2005.

69. Siu PM, Bryner RW, Martyn JK and Alway SE. Apoptotic adaptations from exercise training in skeletal and cardiac muscles. Faseb Journal 18: 1150-+, 2004.

70. Siu PM, Pistilli EE, Murlasits Z and Alway SE. Hindlimb unloading increases muscle content of cytosolic but not nuclear Id2 and p53 proteins in young adult and aged rats. $J$ Appl Physiol 100: 907-916, 2006.

71. Thompson LV, Durand D, Fugere NA and Ferrington DA. Myosin and actin expression and oxidation in aging muscle. Journal of Applied Physiology 101: 1581-1587, 2006.

72. Vasilaki A, McArdle F, Iwanejko LM and McArdle A. Adaptive responses of mouse skeletal muscle to contractile activity: The effect of age. Mech Ageing Dev 127: 830-839, 2006.

73. Xu CL, Wang YZ, Guo J, Liu JX and Feng J. Comparison of age-related differences in expression of antioxidant enzyme mRNA and activity in various tissues of pigs. Comp Biochem Physiol B Biochem Mol Biol 147: 445-451, 2007.

74. Yamaza T, Masuda KF, Atsuta I, Nishijima K, Kido MA and Tanaka T. Oxidative stressinduced DNA damage in the synovial cells of the temporomandibular joint in the rat. $J$ Dent Res 83: 619-624, 2004. 


\title{
Chapter 4
}

\section{Vitamin $E$ and $C$ supplementation reduces oxidative stress and improves antioxidant enzymes and positive muscle work in chronically loaded dorsiflexor muscles of aged rats}

\author{
Michael J. Ryan ${ }^{1}$, Holly J. Dudash ${ }^{1}$, Megan Docherty ${ }^{1}$, Kenneth B. Geronilla ${ }^{1,2}$, Brent A. \\ Baker $^{2}$, G. Gregory Haff ${ }^{1}$, Robert G. Cutlip ${ }^{2}$, and Stephen E. Alway ${ }^{1,3}$ \\ ${ }^{1}$ Laboratory of Muscle Biology and Sarcopenia, Division of Exercise Physiology, West \\ Virginia University School of Medicine, Morgantown, West Virginia 26506 \\ ${ }^{2}$ Health Effects Laboratory Division, National Institute for Occupational Safety and \\ Health, Morgantown, West Virginia 26505 \\ ${ }^{3}$ Center for Cardiovascular and Respiratory Sciences, West Virginia University School of \\ Medicine, Morgantown, West Virginia 26506
}




\section{Abstract}

Aging is associated with increased oxidative stress that can be further elevated in skeletal muscle levels of oxidative stress are further elevated with exercise. The purpose of this study was to determine if dietary antioxidant supplementation would improve muscle function and cellular markers of oxidative stress in response to chronic repetitive loading in aging. The dorsiflexors of the left limb of aged and young adult Fischer 344 Brown x Norway rats were loaded 3 times a week for 4.5 weeks using 80 maximal stretch-shortening contractions per session. The contralateral limb served as the intra-animal control. The rats were randomly assigned to a diet supplemented with Vitamins E\&C or normal non-supplemented rat chow. Biomarkers of oxidative stress were measured in the tibialis anterior muscle. Repetitive loading increased the muscle wet weight in all groups and maximal isometric force, negative and positive work in the young adult tibialis anterior muscle. Only positive work increased in the aged animals that were supplemented with Vitamin E\&C. Markers of oxidative stress $\left(\mathrm{H}_{2} \mathrm{O}_{2}\right.$, GSH/GSSG ratio, malondialdehyde and 8-OHdG) increased in the tibialis anterior muscles from aged and young adult animals with repetitive loading, but Vitamin E\&C supplements attenuated this increase. MnSOD activity increased with supplementation in the young adult animals. CuZnSOD and catalase activity increased with supplementation in young adult and aged animals and GPx activity increased with exercise in the non-supplemented young adult and aged animals. The increased levels of endogenous antioxidant enzymes after Vitamin E\&C supplementation appear to be regulated by post-transcriptional modifications that are affected differently by age, exercise and supplementation. These data suggest that antioxidant supplementation improves indices of oxidative stress associated with repetitive loading exercise and aging and improve the positive work output of muscles in aged rodents. 


\section{Introduction}

Aging causes deleterious modifications at genetic, cellular, tissue, and system levels in all organisms. Presently, the fundamental mechanisms of aging are poorly understood, but a growing body of evidence supports the idea that oxidative stress is an important contributing factor to deterioration of organ and cell function that is associated with aging $(2,13,17,38,43)$.

The age-associated loss of skeletal muscle mass and strength (i.e. sarcopenia), is an unavoidable part of aging. Sarcopenia is likely mediated, at least in part, by a lifetime of damage from oxidants. This is likely because aging is associated with an increase in oxidant production and a decrease in the capacity to buffer oxidants, resulting in a chronic state of oxidative stress. Oxidative stress can damage biomolecules (DNA, lipids and proteins), decrease muscle protein synthesis, elevate apoptotic signaling and protein degradation (13). Although exercise is one approach that may counterbalance sarcopenia, oxidative stress that is developed during muscle contractions may limit the ability of muscle from aged animals to hypertrophy in response to exercise $(6,28,38)$.

Vitamin E (i.e., $\alpha$-tocopherol) and Vitamin C (i.e., ascorbic acid) are antioxidants that are thought to have a protective effect by either reducing or preventing oxidative damage. Lipid soluble Vitamin $E$ prevents lipid peroxidation chain reactions in cellular membranes by interfering with the propagation of lipid radicals. Vitamin $\mathrm{C}$ is a water-soluble antioxidant found in the cytosol and extracellular fluid that can interact directly with free radicals, thus preventing oxidative damage (5). Due to their different sub-cellular locations, a combination of Vitamins $\mathrm{E}$ and $C$ has been shown to have a better antioxidant effect than either of the two vitamins alone $(35,37)$.

Oxidants generated near cellular membranes can oxidize Vitamin E forming a tocopheroxyl radical. Vitamin $\mathrm{C}$ may reduce the Vitamin $\mathrm{E}$ radical, thereby regenerating Vitamin $\mathrm{E}$. This reaction forms the semi-dihydroascorbate (Vitamin $\mathrm{C}$ radical), which in turn is reduced by a glutathione (GSH)(37). Rodents (7) and humans (3) that are deficient in Vitamin E show massive increases in pro-oxidant production and lipid peroxidation after exercise. Furthermore, low plasma concentrations of Vitamin E, associated with nutritional deficiencies often seen in the elderly $(16,25)$, have been shown to contribute to a decline in physical function within these individuals (3). In contrast, dietary supplementation of Vitamin $E$ has been shown to increase tissue resistance to exercise-induced oxidative damage $(19,23,30)$. In addition, recent data suggests that antioxidant supplementation can stimulate muscle protein synthesis in aged rats, possibly through the protection of leucine metabolism (27). Furthermore, Vitamin E and C supplementation combined with resistance training has been shown to both increase fat free mass and muscle mass index in older adults more than resistance training alone (24).

Indicators of oxidative stress (lipid peroxidation measured by malondialdehyde (MDA)) have been shown to increase immediately after heavy resistance training in humans (30). MDA levels returned to baseline in subjects who consumed a diet that was supplemented with Vitamin E, whereas MDA levels continued to be elevated 24 hours after resistance exercise in the non-supplemented subjects (30). However, this is not a universal finding because dietary supplementation with Vitamin $\mathrm{E}$ does not completely protect elderly men from oxidative damage caused by exercise (1). This may be due to low levels of Vitamin $C$ in the elderly, which could reduce the effectiveness of Vitamin $E$ to protect against exercise-induced damage in the elderly (1). Thus, both Vitamins $E$ and $C$ may be important for effectively protecting muscles in aged people against oxidative damage. 
Vitamin $C$ is a highly effective water-soluble antioxidant primarily found in the cytosol and extracellular fluid. Even in small amounts, Vitamin $\mathrm{C}$ can protect proteins, lipids, carbohydrates, and nucleic acids from damage by pro-oxidants generated during normal metabolism. Vitamin $\mathrm{E}$ and glutathione also rely on Vitamin $\mathrm{C}$ for restoration back to their reduced isoforms. Vitamin $\mathrm{C}$ supplementation has been reported to have a protective effect against exercise-induced muscle damage (20). Though some studies have shown that taking antioxidants such as Vitamins $\mathrm{E}$ and $\mathrm{C}$ will prevent damage to tissues by reducing oxidant production, chronic use of these antioxidants could hinder the positive adaptive response that exercise has on the endogenous antioxidant defense system (36). It is not clear if Vitamin C has a direct role in muscle recovery from exercise, or if it has an indirect role in this process.

Resistance training has been shown to be an effective means of increasing muscular size and strength, although the extent of the increase is attenuated with aging. However, repetitive mechanical resistant-type loading exacerbates oxidative stress in muscles of aged rodents, whereas it appears to be well buffered in muscles of young adult animals (38). Oxidative stress increases in skeletal muscle after acute exercise; however, chronic exercise enhances the endogenous antioxidant defenses and decreases production of pro-oxidants resulting in lower indices of oxidative stress. Previous data have shown that aging reduces the adaptive capacity of muscle to buffer the increased oxidant production imposed by chronic repetitive loading. The reduced buffering capacity may compromise the muscles' abilities to hypertrophy and/or to improve muscle function in aged animals.

Although more work is needed in this area, the combined data suggest that antioxidant supplementation may be a potential strategy for reducing exercise-induced oxidative stress and reduce sarcopenia in the elderly. However, this is not a straight forward issue, because although Vitamin $E$ and $C$ supplementation will reduce oxidative stress post exercise, the reduction in oxidative stress may inhibit redox sensitive pathways that are associated with the positive adaptation to exercise.

Previous work suggests that there is only a partial ability for endogenous antioxidant enzymes to compensate for the increased oxidative insult in tibialis anterior muscles of aged rats in response to chronic repetitive loading as compared to young adult animals (38). The current study tested the hypothesis that dietary supplementation with Vitamins $E$ and $C$ would lessen oxidant activity and oxidative damage in tibialis anterior muscles of aged rats subjected to chronic repetitive loading. Furthermore, in this study we assessed whether dietary supplementation with Vitamins $E$ and $C$ would attenuate the increase in basal levels of oxidative stress associated with aging allowing for a more complete adaptation in oxidative enzymes and improvements in muscle function after 4.5 weeks repetitive loading in the aged rats.

\section{Methods}

Experimental design. The left tibialis anterior muscles of young (12 weeks of age; $\mathrm{n}=14$ ) and old (30 months of age; $\mathrm{n}=14$ ) Fischer 344 Brown $x$ Norway rats were subjected to repetitive loading exercise. Seven animals from each age group were randomly assigned to a diet supplemented with Vitamin E $(30,000 \mathrm{mg} / \mathrm{kg})$ and Vitamin $\mathrm{C}(2 \%$ by weight), or normal non-supplemented (NS) rat chow containing $126 \mathrm{mg} / \mathrm{kg}$ of Vitamin $\mathrm{E}$ and $0 \%$ Vitamin $\mathrm{C}$. All animals had free access to rat chow and water. The non-supplemented animals were a subset of animals described in another study (38). All experimental procedures carried approval from the Institutional Animal Use and Care Committee from West Virginia University School of Medicine. The animal care standards were followed by adhering to the recommendations for the care of laboratory animals as advocated by the American Association for Accreditation of 
Laboratory Animal Care (AAALAC) and fully conformed to the American Physiological Society's "Guiding Principles for Research Involving Animals and Human Beings."

Muscle function. Maximal isometric muscle force, positive work, and negative work were assessed in the left exercised and right control limbs on a custom-built dynamometer (9). The dorsi flexor muscle group was activated indirectly through electrical stimulation of the common peroneal nerve via platinum stimulating electrodes (Grass Medical Instruments, Quincy MA, USA). Muscle stimulation for all protocols was a $120 \mathrm{~Hz}$ square wave pulse at $200 \mu \mathrm{s}$ pulse duration, and 4 volts. Dorsiflexor isometric force was measured at an ankle angle of 90 deg using a $300 \mathrm{~ms}$ stimulation duration. Positive and negative work was calculated from stretchshortening contractions (9). The stretch-shortening contraction was performed by activating the dorsiflexor muscles for $300 \mathrm{~ms}$ then moving the load cell fixture from $70^{\circ}$ to $140^{\circ}$ at an angular velocity of $500^{\circ} \mathrm{s}$. The load cell fixture was immediately returned to $70^{\circ}$. Activation was continued for $300 \mathrm{~ms}$ after cessation of the movement. The change in force output over a training session was assessed by averaging the first three sessions as a pre value and the last three sessions as a post value and calculating the percent difference between the two.

Unilateral repetitive loading exercise. Repetitive loading consisted of 3 sessions per week for 4.5 weeks, of 80 stretch/shortening (i.e., eccentric / concentric) contraction cycles per session (9). This method has been previously shown to produce a hypertrophic response in young adult rats (9) although aging attenuates the hypertrophic response to these loading conditions $(9,38)$.

Muscle preparation. Forty-eight hours after the last exercise session, the tibialis anterior of both loaded and control limbs were removed with the animal under anesthesia (2\% isoflurane). The rats were then euthanized, via an overdose of ketamine/xylazine $(30 \% / 70 \%$, $\mathrm{v} / \mathrm{v})$. The tibialis anterior muscles were washed in phosphate buffered saline (PBS) (137 mM $\mathrm{NaCl}, 2.7 \mathrm{mM} \mathrm{KCl}, 10 \mathrm{mM}$ sodium phosphate dibasic, $2 \mathrm{mM}$ potassium phosphate monobasic and a $\mathrm{pH}$ of 7.4), blotted dry then weighed. A section of the muscle was obtained for the determination of the ratio of reduced glutathione (GSH) to oxidized glutathione (GSSG). The remaining muscle was snap frozen in liquid nitrogen and stored at $-80^{\circ} \mathrm{C}$.

RNA Isolation. Sixty micrograms of frozen muscle was homogenized in $1 \mathrm{ml}$ of TriReagent (Molecular Research Center, Cincinnati, $\mathrm{OH}$ ) with a motorized blade homogenizer. The RNA was isolated according to our standard procedures $(31,38)$. The RNA was treated with DNAse I using a DNA-free kit (Ambion, Austin, TX) and quantified using a BioRad SmartSpec 3000. The RNA samples were quantified if their 260:280 ratio was 1.7 or greater.

Reverse Transcription-Polymerase Chain Reaction (RT-PCR). Two micrograms of total RNA were reversed transcribed using $1.0 \mu \mathrm{l}$ of random primers, $1.0 \mu \mathrm{l}$ of $10 \mathrm{mM} \mathrm{dNTP}$, and $1.0 \mu \mathrm{l}$ of SuperScript II reverse transcriptase (Invitrogen/Life Technologies, Bethesda MD) as previously described (38). The resulting complimentary DNA (cDNA) was stored at $-80^{\circ} \mathrm{C}$ or used for PCR analyses.

Primers for the genes of interest were designed as follows: CuZnSOD sense-5'AGGCCGTGTGCGTGCTGA-3'; anti-sense-5'-CCCAATCACACCACAAGCCA-3'; GPx-1 sense5'-CCTCGTGGCCTGGTGGTCCT-3'; anti-sense-5'-AGGGGTTGCTAGGCTGCTTGGA-3'. The primers for MnSOD and catalase were the same as previously published by our lab (38). Preliminary experiments were conducted to ensure that the number of PCR cycles were completed in the linear range of amplification for each gene of interest. PCR products were 
verified by restriction digestion based on predicted PCR sequences. Routine PCR amplification was conducted using PCR buffer, MgCl2, $5 \mathrm{mM}$ dNTPs, $100 \mathrm{ng} / \mathrm{ml}$ of primer pairs, $18 \mathrm{~S}$ primer pairs, $1.0 \mu \mathrm{l}$ of Taq DNA polymerase, and1.0 $\mu \mathrm{l}$ of cDNA (38). Amplification of PCR products were performed in a thermocycler using: a denaturing step at $95^{\circ} \mathrm{C}$ for $45 \mathrm{~s}$, an annealing step for $45 \mathrm{~s}$, and an extension step at $72^{\circ} \mathrm{C}$ for $45 \mathrm{~s}$. $20 \mu \mathrm{l}$ of each PCR product was separated by electrophoresis on $1.5 \%$ agarose gels. The gels were stained with ethidium bromide to visualize the PCR products. The signal from each PCR gene product was expressed as a ratio to the $18 \mathrm{~S}$ signal from the same PCR product. The PCR signals were recorded via a digital camera (Kodak 290) and the signals were quantified in arbitrary units as optical density $\mathrm{x}$ band area, using 1D Kodak image analysis software (Eastman Kodak Company, Rochester, NY).

Muscle Protein Fractionation. Cytoplasmic and nuclear protein fractions were obtained from $75 \mathrm{mg}$ of frozen tibialis anterior using methods as reported previously by our lab $(38,42)$. Muscle samples were homogenized in $500 \mu \mathrm{l}$ of ice-cold lysis buffer $(10 \mathrm{mM} \mathrm{NaCl}, 1.5$ $\mathrm{mM} \mathrm{MgCl}_{2}, 20 \mathrm{mM} \mathrm{HEPES}$ at $\mathrm{pH} 7.4,20 \%$ glycerol, $0.1 \%$ Triton X-100, and $10 \mu \mathrm{M}$ dithioreitol) with a mechanical homogenizer. A lower concentration of dithioreitol was used than in previous studies $(38,42)$, to prevent interference with subsequent enzyme activity assays. Muscle homogenates were centrifuged at $800 \mathrm{rpm}$ for 5 -minutes at $4^{\circ} \mathrm{C}$. The supernatants were collected and centrifuged three times at $3500 \mathrm{~g}$ for 5 -minutes at $4^{\circ} \mathrm{C}$. The resulting supernatant was collected as the nuclei-free cytosolic fraction and divided into two equal portions; the first portion was frozen at $-80^{\circ} \mathrm{C}$ until needed, and a protease inhibitor cocktail containing $104 \mathrm{mM} 4$ [2-aminoethyl]-benzenesulfonylflouride hydrochloride (AEBSF), 0.8mM aprotinin, $2 \mathrm{mM}$ leupeptin, 4mM bestatin, $1.5 \mathrm{mM}$ pepstatin A and $1.4 \mathrm{mME}-64$ (Sigma-Aldrich, St. Louis, Mo, USA) was added to the second portion before it was frozen at $-80^{\circ} \mathrm{C}$. Protein concentrations for each sample were determined in triplicate via a DC protein concentration assay (Bio-Rad, Hercules, CA). The cytosolic fraction was used in the following assays: $\mathrm{H}_{2} \mathrm{O}_{2}$ concentration, catalase activity, GPx activity, CuZnSOD and MnSOD activity and western immunoblots.

Western immunoblots. The protein content of glutathione peroxidase-1 (GPx-1), catalase, copper-zinc superoxide dismutase, (CuZnSOD) and manganese superoxide dismutase (MnSOD) was measured in the cytosolic protein fractions. Thirty $\mu \mathrm{g}$ of protein was loaded into each well of a 4-12\% gradient polyacrylamide gel (Novex, Invitrogen) and separated by routine SDS-polyacrylamide gel electrophoresis (PAGE) for 1.5 hours at $20^{\circ} \mathrm{C}$ and transferred to a nitrocellulose membrane. The membranes were blocked in $5 \%$ non-fat milk protein (NFM) for 1-hour at room temperature then incubated in appropriate dilutions of primary antibodies (diluted in 1\% NFM in Tris-buffered saline with $0.05 \%$ Tween-20 (TBS-T) overnight at $4^{\circ} \mathrm{C}$. The membranes were washed in TBS-T followed by incubation in appropriate dilutions of secondary antibodies (diluted in 5\% NFM in TBS-T) that were conjugated to horseradish peroxidase. The protein signals were developed using a chemiluminescent substrate (ECL Advanced, Amersham Bioscience) and visualized by exposing the membranes to X-ray films (BioMax MS-1; Eastman Kodak). Digital records were captured by a Kodak 290 camera and protein bands quantified using 1-D analysis software (Eastman Kodak, USA). The bands were quantified as optical density (OD) $x$ band area and expressed in arbitrary units.

Hydrogen peroxide $\left(\mathrm{H}_{2} \mathrm{O}_{2}\right.$ ) levels. A fluorescent $\mathrm{H}_{2} \mathrm{O}_{2}$ detection kit (Cell Technology, Mountain View, CA) was used to determine the amount of $\mathrm{H}_{2} \mathrm{O}_{2}$ in the muscle tissue. Reagents and standards were prepared as recommended by the manufacturer. Briefly, $50 \mu \mathrm{L}$ of controls, samples, or $\mathrm{H}_{2} \mathrm{O}_{2}$ dilutions were mixed with $50 \mu \mathrm{L}$ of the reaction cocktail in each well to initiate the reaction. The plate was incubated in the dark for 10 minutes, at $20^{\circ} \mathrm{C}$ and fluorescence was detected with an excitation at 530nm and measured at 590nm. All analyses were done in 
duplicate and the samples were normalized to muscle protein concentration in each sample via a DC protein concentration assay (Bio-Rad, Hercules, CA).

GSH and GSH/GSSG Ratio. Glutathione (GSH), oxidized glutathione (GSSG) and the GSH/GSSG ratio were determined by a BIOXYTECH GSH/GSSG-412 (Oxis International, Beverly Hills, CA) assay. Muscle tissue ( 40 mg) was homogenized immediately after dissection in $530 \mu \mathrm{l}$ cold 5\% metaphosphoric acid (MPA) for the GSH sample and for the GSSG sample $\sim 40 \mathrm{mg}$ of muscle tissue was homogenized immediately after dissection in $500 \mu \mathrm{l}$ cold $5 \%$ metaphosphoric acid (MPA) and $30 \mu \mathrm{l}$ of M2VO scavenger. Homogenates were then frozen in liquid nitrogen and stored at $-80^{\circ} \mathrm{C}$ until analyzed.

The assay was preformed as described by the manufacturer. Briefly, cold $5 \%$ MPA was added to each sample mixed, and centrifuged at $1000 \mathrm{xg}$ for 10 minutes. $50 \mu \mathrm{l}$ of sample and the appropriate buffer and $50 \mu$ of chromogen and enzyme were mixed and incubated at room temperature. 50 $\mu$ of NADPH was added and the absorbance of each sample was read every $60 \mathrm{sec}$ at $412 \mathrm{~nm}$ for three minutes. The protein concentration for each sample was determined via a DC protein concentration assay (BIO RAD). Signals from each sample were normalized to the corresponding protein content of that sample.

Oxidative DNA damage as measured by 8-hydroxy-2'-deoxyguanosine (8-OHdG). DNA was extracted from the muscle via DNeasy Tissue Kit (Qiagen, Valencia, CA). DNA was used if it had a minimum 260:280 ratio of 1.8. Oxidized DNA was determined on $50 \mu$ of DNA by a BIOXYTECH 8-OhdG ELISA (enzyme linked immunoassay) according to the manufacturer's recommendations (Oxis International, Beverly Hills, CA). Briefly, DNA was incubated with the primary antibody, washed, and then incubated in secondary antibody. The chromogen was added to each well, and incubated at room temperature in the dark for 15 minutes. The reaction was terminated and the samples were read at an absorbance of $450 \mathrm{~nm}$. Samples were normalized to the DNA concentration measured via a spectrophotmeter (ND1000, NanoDrop, Wilmington, DE). All analyses were done in duplicate.

Lipid peroxidation. Malondialdehyde (MDA) and 4-hydroxyalkenals (HAE) were measured as an indication of lipid peroxidation using the method and reagents from Oxis International, CA (BIOXYTECH LPO-586). Briefly, $100 \mathrm{mg}$ of muscle was homogenized in icecold PBS, containing $5 \mu \mathrm{L} 0.5 \mathrm{M}$ butylated hydroxytoluene (BHT) in acetonitrile per $1 \mathrm{ml}$ of tissue homogenate. The muscle homogenate was centrifuged at $3000 \mathrm{~g}$ at $4^{\circ} \mathrm{C}$ and the supernatant was used for the assay and protein determination. The muscle sample was incubated in the appropriate reagents according to the manufacturer's instructions, and centrifuged at $15,000 \mathrm{~g}$. An absorbance reading of the supernatant was obtained at $586 \mathrm{~nm}$. Samples were normalized for differences in the amount of muscle protein in each sample as determined by a DC protein concentration assay (Bio-Rad, Hercules, CA).

Catalase Activity. A catalase activity assay kit (\# 219265, EMD/Calbiochem, San Diego, CA) was used to determine the activity level of catalase in repetitively loaded and control muscles, according to the manufacturer's recommendations. All analyses were completed in duplicate and samples were read at an absorbance of $520 \mathrm{~nm}$. The data were normalized to muscle protein in each sample via a DC protein concentration assay (Bio-Rad, Hercules, CA).

Manganese Superoxide Dismutase (MnSOD) and Copper-Zinc Superoxide Dismutase (CuZnSOD). A commercially available assay (\#574601, EMD/Calbiochem, San Diego, CA) was used to measure total SOD and MnSOD activity. CuZnSOD was calculated by 
subtracting the value for MnSOD activity from the total SOD activity. The assay was performed with modifications to the manufacturer's directions and all samples and standards were measured in duplicate. Briefly, the muscle was homogenized in $20 \mathrm{mM}$ HEPES buffer, $\mathrm{pH} 7.2$, containing $1 \mathrm{mM}$ EGTA, $210 \mathrm{mM}$ mannitol, and $70 \mathrm{mM}$ sucrose and centrifuged at $1000 \mathrm{~g}$ for 10 minutes. The assay was performed in a 96-well plate with each sample being treated with and without $10 \mu \mathrm{L}$ of $12 \mathrm{mM}$ potassium cyanide. Potassium cyanide was used to inhibit CuZnSOD, resulting in the detection of only MnSOD activity. The reagents and samples were protected from white light and incubated at $26^{\circ} \mathrm{C}$ for 20 minutes with periodic shaking. The absorbance was measured at $450 \mathrm{~nm}$ using a 96 -well plate reader (Dynex Tech., Chantilly VA., USA).

Glutathione Peroxidase (GPx). A commercially available cellular GPx assay (\#35319, EMD/Calbiochem, San Diego, CA) was used to measure GPx activity in the cytosolic fractions of the muscle homogenates. The assay was performed with several modifications to the manufacturer's directions. Briefly, a portion of each muscle was homogenized in a buffer containing 50mM Tris- $\mathrm{HCl}$, pH 7.5, $5 \mathrm{mM}$ EDTA, $1 \mathrm{mM}$ DTT. The homogenate was centrifuged at $10,000 \mathrm{~g}$ for $15 \mathrm{~min}$ at $4^{\circ} \mathrm{C}$ and the supernatant was used for the assay. All reagents and samples were equilibrated to $25^{\circ} \mathrm{C}$ and the remaining assay procedures followed manufacturer's guidelines. The absorbance was measured at $340 \mathrm{~nm}$ using a 96-well plate reader (DYNEX technologies, Chantilly Va., USA). Each sample and control was performed in duplicate.

Statistical analyses. Statistical analyses were performed using an SPSS 18.0 software package. Statistical significance of the data was calculated by a multiple analyses of variance (MANOVA). When significant $F$ scores were indentified from the MANOVA, subsequent protected one-way analysis of variance followed by Tukey post-hoc tests were used to identify differences between means. Statistical significance was accepted at $p<0.05$. Data are reported as mean \pm standard error mean (SEM).

\section{Results}

Body Weight. The average body weight of the aged animals was significantly $(p<0.05)$ more than the young animals. A subset of the control non-supplemented animals used in this study was included in data reported previously (38). The body weight characteristics of all of the animals examined in this study are shown in Table 4.1. Bodyweight did not change over the course of the study in either the control or Vitamin E\&C supplemented animals.

\section{Insert Table 4.1}

Muscle Wet Weight. Repetitive loading for 4.5 weeks resulted in a significant increase in tibialis anterior muscle wet weight in the exercised limb of both the young adult $(690 \pm 20 \mathrm{mg}$ vs. $780 \pm 40 \mathrm{mg}, \mathrm{p}<0.05)$ and the aged adult $(670 \pm 30 \mathrm{mg}$ vs. $720 \pm 30 \mathrm{mg}, \mathrm{p}<0.05)$ nonsupplemented rats as compared with the contra-lateral control muscle. Similar results were observed in the exercised limb from Vitamin E\&C supplemented rats, where the muscle wet weight of the tibialis anterior muscle from young adult rats increased $17.8 \%$ (720 $\pm 30 \mathrm{mg}$ vs. $850 \pm 40 \mathrm{mg}, \mathrm{p}<0.05)$ and $7.7 \%(670 \pm 30$ vs. $720 \pm 20 \mathrm{mg}, \mathrm{p}<0.05)$ in the aged adults (Figure 4.1).

\section{Insert Figure 4.1}

Muscle Function. Maximal force, positive work and negative work were greater in control non-exercised muscles from young adult compared to aged rats. Maximal isometric force increased $(p<0.05)$ by $48 \%$ in the young adult non-supplemented $(0.053 \pm 0.003 \mathrm{~N} / \mathrm{g}$ body 
weight vs. $0.082 \pm 0.03 \mathrm{~N} / \mathrm{g}$ body weight) and $40 \%$ Vitamin E\&C supplemented $(0.055 \pm 0.007$ $\mathrm{N} / \mathrm{g}$ body weight vs. $0.079 \pm 0.006 \mathrm{~N} / \mathrm{g}$ body weight) animals (Figure $2 \mathrm{~A}$ ) after the 14 repetitive loading sessions. Negative work was also similarly increased $(p<0.05)$ by $35.7 \%$ in the young adult non-supplemented (2.93 $\pm 0.29 \mathrm{~J} / \mathrm{g}$ body weight vs. $4.11 \pm 0.22 \mathrm{~J} / \mathrm{g}$ body weight) and $31.9 \%$ Vitamin E\&C supplemented $(2.92 \pm 0.21 \mathrm{~J} / \mathrm{g}$ body weight vs. $4.03 \pm 0.36 \mathrm{~J} / \mathrm{g}$ body weight) animals at the end of the training period. Positive work increased $(p<0.05)$ in the trained vs. control muscles of both the young adult non-supplemented (35.9\%)(2.42 $\pm 0.13 \mathrm{~J} / \mathrm{g}$ body weight vs. $3.45 \pm 0.14 \mathrm{~J} / \mathrm{g}$ body weight) and Vitamin E\&C supplemented (30.6\%) $(2.51 \pm 0.37$ $\mathrm{J} / \mathrm{g}$ body weight vs. $3.39 \pm 0.2 \mathrm{~J} / \mathrm{g}$ body weight 9 ) rats. Furthermore, positive work increased by $37.7 \%$ in the control non-exercised muscles of aged rats that consumed the Vitamin E\&C supplemented diet $(1.54 \pm 0.3 \mathrm{~J} / \mathrm{g}$ body weight vs. $2.34 \pm 0.24 \mathrm{~J} / \mathrm{g}$ body weight) compared to non-supplemented animals.

Maximal isometric force and negative work were unchanged by exercise training in aged rats in either dietary group (Figure 4.2A and 4.2B). Positive work improved in the aged animals that consumed the Vitamin E\&C diet, but it did not change in the muscles of the aged nonsupplemented animals during the training period (Figure 4.2C).

\section{Insert Figure 4.2}

$\mathrm{H}_{2} \mathrm{O}_{2}$. Muscle levels of $\mathrm{H}_{2} \mathrm{O}_{2}$ were elevated in the loaded muscles by $37.7 \%$ in young adult (543 $\pm 35 \mathrm{RFU} / \mathrm{mg}$ protein vs. $748 \pm 45 \mathrm{RFU} / \mathrm{mg}$ protein) and $44.8 \%$ in aged muscles of the non-supplemented animals (696 $\pm 46 \mathrm{RFU} / \mathrm{mg}$ protein vs. $1008 \pm 75 \mathrm{RFU} / \mathrm{mg}$ protein), suggesting a treatment effect and that chronic loading elevated oxidative stress. Vitamin E\&C supplementation lowered $\mathrm{H}_{2} \mathrm{O}_{2}$ in both control and repetitively loaded tibialis anterior muscle from young adult and aged rats (Figure 4.3). $\mathrm{H}_{2} \mathrm{O}_{2}$ concentration data expressed as a $\mu \mathrm{mol} / \mathrm{mg}$ protein are discussed in the Limitation and Future Directions section within chapter 7. (Figure 7.2)

\section{Insert Figure 3}

Total Glutathione. Total glutathione in the tibialis anterior muscle was $33 \%$ lower in the non-exercised muscles of aged as compared with young adult rats $(p<0.05)$. Vitamin $E \& C$ lowered the total glutathione concentration by $41 \%$ in the non-exercised control muscles from young adult animals ( $243 \pm 46 \mu \mathrm{M} / \mathrm{mg}$ protein vs. $141 \pm 18 \mu \mathrm{M} / \mathrm{mg}$ protein), but it did not alter total glutathione levels in non-exercised muscles of aged animals (Figure 4.4A). In the young adult non-supplemented animals, muscle levels of total glutathione were not improved with exercise training, however, exercise training increased total glutathione by $43 \%$ as compared to control muscles in young adult animals that were fed the vitamin E\&C supplemented diet (141 \pm 18 vs. $203 \pm 10 \mu \mathrm{M} / \mathrm{mg}$ protein) (Figure 4.4A). In contrast, Vitamin E\&C supplementation did not alter total glutathione in exercised muscles from aged rats (Figure 4.4A).

GSH/GSSG ratio. The GSH/GSSG ratio was not increased by training in muscles from young adult non-supplemented animals when comparisons were made to the control muscles (Figure 4B). However, the tibialis anterior muscles from the aged non-supplemented animals had a significant reduction in the GSH/GSSG ratio in the loaded $(p<0.05)$ muscles as compared to exercise-matched muscles in the young adult animals. The GSH/GSSG ratio was lower $(p<0.05)$ in the loaded and control muscles of the aged non-supplemented rats as compared to the young adult non-supplemented rats. The combination of Vitamin E\&C supplementation and 
repetitive loading significantly increased $(p<0.05)$ the $\mathrm{GSH} / \mathrm{GSSG}$ ratio by $36.1 \%$ in exercised tibialis anterior muscles from the young adult (16.9 $\pm 1.4 \mathrm{vs.} 23 \pm 2)$ animals as compared to the intra-animal control muscles. Vitamin E\&C supplementation did not improve GSH/GSSG in the unexercised control muscles from young adult or aged animals (Figure 4.4B).

\section{Insert Figure 4.4}

Lipid Peroxidation. Aging increased the level of lipid oxidation by $79.6 \%$ as shown by greater MDA + HAE levels in control muscles from aged non-supplemented rats as compared to muscles from young adult non-supplemented animals $(1.67 \pm 0.2 \mu \mathrm{M} / \mathrm{mg}$ protein vs. $2.99 \pm 1.7$ $\mu \mathrm{M} / \mathrm{mg}$ protein, $\mathrm{p}<0.01$; Figure $4.5 \mathrm{~A}$ ). Repetitive loading appeared to activate adaptive responses in muscles of aged non-supplemented animals because MDA + HAE levels were lower in the loaded than control muscles of aged animals. Furthermore, Vitamin E\&C supplementation suppressed the increase in lipid peroxidation associated with aging, but a combination of exercise and supplementation showed no greater decline in lipid peroxidation than either treatment did individually. No significant difference in MDA + HAE levels was observed among the control or chronically loaded muscles of either the non-supplemented or Vitamin E\&C supplemented young adult animals, or the aged Vitamin E\&C supplemented animals.

DNA Damage. The aged muscle showed a $33.4 \%$ increase $(p<0.05)$ in the basal level of oxidative DNA damage ( $2.86 \pm 0.28 \mathrm{ng} / \mu \mathrm{g}$ DNA vs. $3.82 \pm 0.2 \mathrm{ng} / \mu \mathrm{g}$ DNA) as indicated by the increase in $8-\mathrm{OHdG}$ detected in control muscles from aged non-supplemented animals as compared to the control muscles from young adult non-supplemented animals. Chronic repetitive loading did not change $8-\mathrm{OHdG}$ in muscles of young adult (non-supplemented or Vitamin E\&C) or aged non-supplemented animals. In young adult animals, Vitamin E\&C supplementation lowered 8-OHdG levels in control muscles by $38.4 \%(2.86 \pm 0.28 \mathrm{ng} / \mu \mathrm{g}$ DNA vs. $1.76 \pm 0.2 \mathrm{ng} / \mu \mathrm{g}$ DNA) and by $19.9 \%$ in exercised muscles $(2.59 \pm 0.33 \mathrm{ng} / \mu \mathrm{g}$ DNA vs. 2.08 $\pm 0.28 \mathrm{ng} / \mu \mathrm{g}$ DNA). In aged rats, Vitamin E\&C reduced $8-O H d G$ levels in control muscles by $40.1 \%(3.82 \pm 0.2 \mathrm{ng} / \mu \mathrm{g}$ DNA vs. $2.29 \pm 0.28)$ and by $20.4 \%$ in exercised muscles $(4.13 \pm 0.16$ $\mathrm{ng} / \mu \mathrm{g}$ DNA vs. $3.29 \pm 0.29 \mathrm{ng} / \mu \mathrm{g}$ DNA) when compared to animals that consumed the nonsupplemented control diet (Figure 4.5B).

\section{Insert Figure 4.5}

\section{Glutathione Peroxidase (GPx).}

Enzyme Activity. There was a loading effect but no age effect on GPx activity in the rat non-supplemented tibialis anterior muscle. Chronic repetitive loading significantly increased GPx activity in muscles from both young adult (123\%; $52.1 \pm 13.1 \mathrm{mU} / \mathrm{mg}$ protein vs. $116.2 \pm$ $18.3 \mathrm{mU} / \mathrm{mg}$ protein) and aged non-supplemented animals $(71.8 \% ; 67.5 \pm 21 \mathrm{mU} / \mathrm{mg}$ protein vs. $116 \pm 18.5 \mathrm{mU} / \mathrm{mg}$ protein). GPx activity was similar in muscles from non-supplemented young and aged rodents. Vitamin E\&C supplementation lowered total GPx activity in the tibialis anterior muscle from both control (60\%; $52.1 \pm 13.1 \mathrm{mU} / \mathrm{mg}$ protein vs. $23 \pm 6.3 \mathrm{mU} / \mathrm{mg}$ protein) and exercised muscles (194\%; $116.2 \pm 18.3 \mathrm{mU} / \mathrm{mg}$ protein vs. $45.6 \pm 13 \mathrm{mU} / \mathrm{mg}$ protein) from young adult rats. GPx activity was also reduced in control (48\%; $67.5 \pm 21 \mathrm{mU} / \mathrm{mg}$ protein vs. $34.7 \pm 8 \mathrm{mU} / \mathrm{mg}$ protein) and exercised muscles (100\%; $116 \pm 18.5 \mathrm{mU} / \mathrm{mg}$ protein vs. $33.4 \pm 13$ $\mathrm{mU} / \mathrm{mg}$ protein) from aged animals. Repetitive loading exercise increased GPx activity in the muscles from young rats in the Vitamin E\&C supplementation group, but had it no additive effect in the muscles from aged supplemented animals (Figure 4.6A). 
GPx protein abundance. Protein levels for GPx-1 increased with Vitamin E\&C supplementation in both young adult and aged muscle. Exercise did not have a significant effect on GPx-1 protein concentrations (Figure 4.6B).

Changes in GPx mRNA. No significant differences were found among GPx-1 mRNA within any of the non-supplemented muscle samples. There was a $41.8 \%$ reduction in GPx-1 mRNA expression in the Vitamin E\&C supplemented tibialis anterior muscle from young control muscle, which was reversed in the exercised muscle from young Vitamin E\&C supplemented animals. Vitamin E\&C supplementation reduced GPx-1 mRNA expression in both control and exercised muscles from aged animals (Figure 4.6C).

\section{Insert Figure 4.6}

\section{Catalase.}

Enzyme Activity. Catalase activity was significantly greater in the tibialis anterior muscle from all groups of the aged animals when compared to their treatment matched young adult counterparts. Repetitive loading did not significantly alter catalase activity in muscles from the non-supplemented young adult rats or aged rats, nor did it alter catalase activity in the muscle from young adult animals that were feed the Vitamin E\&C supplemented diet. Catalase activity was significantly higher in control muscles of aged vs. young adult animals, and it increased in loaded muscles of aged animals as compared to young adult animals $(p<0.05)$ (Figure 4.7A).

Catalase protein abundance. Repetitive loading exercise did not alter catalase protein abundance in the tibialis anterior muscles of any group. Similarly, catalase protein abundance was not altered by aging within the non-supplemented animals. Vitamin E\&C supplementation increased catalase protein content by $\sim 60 \%$ in the young adult control muscles as well as the aged control $(\sim 292 \%)$ and exercised $(\sim 246 \%)$ muscles when compared to their age-matched non-supplemented counterparts as determined by western blot analyses (Figure 4.7B).

Changes in catalase mRNA. Catalase mRNA was significantly greater in muscles of young vs. aged rats. Exercise did not produce any significant changes in muscle catalase mRNA levels within the any of the animal groups. Supplementation with Vitamin E\&C reduced catalase mRNA levels from both control and exercised tibialis anterior muscle in the young adult by $24.7 \%$ and $22.6 \%$, respectively. In a similar fashion to young animals, catalase mRNA expression was $44.4 \%$ and $43.9 \%$, lower in control and exercised muscles, respectively, of Vitamin E\&C treated aged animals (Figure 4.7C).

\section{Insert Figure 4.7}

\section{Copper-Zinc Superoxide Dismutase (CuZnSOD)}

Enzyme Activity. Repetitive loading increased CuZnSOD enzyme activity $(p<0.05)$ by $64.1 \%(2.34 \pm 0.33 \mathrm{mU} / \mathrm{mg}$ protein vs. $3.84 \pm 0.5 \mathrm{mU} / \mathrm{mg}$ protein in non-supplemented and $35.7 \%$ (8.33 $\pm 1.2 \mathrm{mU} / \mathrm{mg}$ protein vs. $11.31 \pm 2.18 \mathrm{mU} / \mathrm{mg}$ protein) in Vitamin E\&C supplemented muscles from young adult animals as compared to the contra-lateral control muscles. No significant changes in enzyme activity were observed as a result of repetitive loading in the tibialis anterior muscle from aged animals. Surprisingly, Vitamin E\&C supplementation increased CuZnSOD enzyme activity in control $(255 \% ; 2.34 \pm 0.33 \mathrm{mU} / \mathrm{mg}$ protein vs. $8.33 \pm 1.2 \mathrm{mU} / \mathrm{mg}$ protein) and repetitive loaded tibialis anterior muscles (195\%; 3.84 
$\pm 0.5 \mathrm{mU} / \mathrm{mg}$ protein vs. $11.31 \pm 2.18 \mathrm{mU} / \mathrm{mg}$ protein) of young animals. CuZnSOD enzyme activity was increased (20\%; $4.32 \pm 1.1 \mathrm{mU} / \mathrm{mg}$ protein vs. $5.2 \pm 0.75 \mathrm{mU} / \mathrm{mg}$ protein) in repetitively loaded muscles of aged rats as compared to muscles that were obtained from nonsupplemented old animals (Figure 4.8A).

CuZnSOD protein abundance. CuZnSOD protein abundance was not different between muscles obtained from non-supplemented or Vitamin E\&C supplemented young adult rats. CuZnSOD protein abundance was $118 \%$ greater $(p<0.05)$ in non-exercised Vitamin E\&C supplemented compared to non-supplemented control muscles from aged animals $(1.88 \pm 0.85$ vs. $4.12 \pm 0.89$ ) (Figure 4.8B).

Changes in CuZnSOD mRNA. CuZnSOD mRNA content was lower in both nonexercised and exercised muscles of aged rats in the Vitamin E\&C supplemented group compared to aged rats in the non-supplemented group or in young adult animals of either diet group (Figure 4.8C).

\section{$\underline{\text { Insert Figure } 4.8}$}

\section{Manganese Superoxide Dismutase (MnSOD)}

Enzyme Activity. Vitamin E\&C supplementation significantly increased MnSOD activity levels within both the control and repetitive loaded tibialis anterior muscle from the young adult animals. No changes in MnSOD activity were found in muscles from the aged animals (Figure 4.9A).

MnSOD protein abundance. MnSOD protein levels were $113 \%$ greater $(p<0.05)$ in the repetitive loaded muscles of the young adult non-supplemented animals as compared to their contra-lateral control muscles $(p<0.05)$. Nevertheless, aging prevented any loading-induced increase in MnSOD protein abundance in the tibialis anterior muscle. Young and aged animals that were given the Vitamin E\&C diet had greater MnSOD protein abundance in the nonexercised control muscle as compared to non-exercised muscles from non-supplemented animals. Repetitive loading decreased MnSOD protein abundance in the supplemented animals from both age groups (Figure 4.9B).

Changes in MnSOD mRNA. The changes that were observed in MnSOD protein levels did not seem to be driven by the alterations in MnSOD mRNA. The only significant changes in MnSOD mRNA levels were found in the aged Vitamin E\&C supplemented animals, where supplementation lowered mRNA levels in the tibialis anterior muscles from exercise control and repetitively loaded limbs (Figure 4.9C).

\section{$\underline{\text { Insert Figure } 4.9}$}




\section{Discussion}

Oxidative damage has long been implicated as a factor that progresses the aging process (17). Oxidative damage occurs in both type I and type II fiber types of aged animals (12), and is thought to underlie at least part of the deterioration in skeletal muscle with aging (4, 38). The aim of this study was to investigate the efficacy of dietary antioxidant supplementation to improve oxidative stress in skeletal muscle in aged rodents in response to repetitive loading. We chose to examine the tibialis anterior muscle, because it is composed of predominantly type II fibers, which are thought to be more susceptible to oxidative stress than type I fibers because their antioxidant defenses are less extensive. It was hypothesized that dietary supplementation with Vitamin E\&C would lessen the oxidant activity and oxidative damage in tibialis anterior muscles in an age-dependent manner. The sub-hypothesis was that Vitamins E\&C supplementation would attenuate the increase in basal levels of oxidative stress associated with aging, allowing for improved adaptation in oxidative enzymes and muscle function after 4.5 weeks of repetitive loading in the aged rats. The novel results of this investigation show that dietary supplementation with Vitamins E\&C reduced oxidant levels in repetitively loaded muscles of aged rats, but there was no improvement in accumulation of muscle mass in the tibialis anterior muscle over 4.5 weeks of loading. Specifically, fortifying normal rat chow with Vitamin $\mathrm{E} \& \mathrm{C}$, lowered the concentrations of $\mathrm{H}_{2} \mathrm{O}_{2}$, increased the ratio of $\mathrm{GSH} / \mathrm{GSSG}$, reduced indices of oxidative damage to DNA (8-OHdG) and cellular lipids (malondialdehyde \& 4hydroxyalkenals) in repetitively loaded tibialis anterior muscles from young adult and aged rats. Vitamin E\&C supplementation did not improve maximal force production after more than four weeks of repetitive loading in muscles of aged animals. However, importantly, positive work output improved after exercise training in the dorisflexors of aged animals that received the Vitamin E\&C supplemented diet.

Age-Related Adaptations of Muscle Weight to Repetitive Loading. Tibialis anterior muscle mass increased in response to 4.5 weeks of repetitive loading in aged rats (38), but the exercise-trained muscle in the aged animals only improved to a point that was similar to control untrained levels in the young adult animals. These results are consistent with previous observations in rodents using the same loading approach as the current study (38), or other models of loading in rodents (11) and humans (22) all showing that aging attenuates, but does not prevent muscle adaptation to loading until very old ages $(6,33)$. To our knowledge, this is the first report that has evaluated the aging-specific effects of repetitive resistance training in combination with Vitamin E\&C supplementation on changes in muscle weight. Contrary to our expectations, fortifying the diet with Vitamins $E \& C$ in an attempt to reduce oxidative stress during repetitive loading exercise did not provide any additive effect to improvements in muscle weight in either young adult or aged rats. This implies that oxidative stress associated with aging may not be a limiting factor for protein accumulation in repetitively loaded muscles of aged animals. An alternative explanation is that the level of Vitamin E\&C supplementation was too low to fully overcome any limitations to protein accumulation that occur in response to repetitive loading in muscles of aged rodents. Likely the antioxidant capacity of muscles in young adult animals was already sufficient to balance loading-induced increases in oxidative stress, so that elevating antioxidants via Vitamins E\&C did not provide any greater improvement in muscle hypertrophy.

Age-Dependent Adaptations to Antioxidant Supplementation on Muscle function After Repetitive Loading. Repetitive loading increased maximal isometric dorsiflexor force production by $>40 \%$, positive work (work performed during the concentric portion of each contraction) by $>31 \%$, and negative work (work performed during the eccentric portion of each contraction) by $>30 \%$ in young adult rats. The repetitively loaded tibialis anterior muscle weight 
was not improved by the antioxidant supplementation, and since this muscle provides the greatest contribution to dorsiflexion, it is not surprising that Vitamin E\&C supplementation did not further improve maximal dorsiflexion isometric force, or positive and negative work in the dorsiflexors of young adult rats. In contrast to the young adult rats, non-supplemented aged rats were unable to improve maximal force, positive or negative work over the training period. While Vitamin E\&C supplementation did not improve either maximal force or negative work, the positive work was improved by $38 \%$ in the aged rats that received the Vitamin E\&C fortified diet. These findings indicate that although muscle size was not enhanced (and therefore maximal isometric force was not improved) by the antioxidant diet in the aged animals, the high oxidant environment of the aged muscle likely contributed to a rapid loss of force during each contraction in the non-supplemented animals. Vitamin E\&C supplementation likely buffered (at least in part) the additional oxidant production imposed by repetitive loading, such that force was better maintained during each shortening contraction. As reactive oxygen species are mediators of muscle fatigue (34), it is therefore possible that Vitamin E\&C acts to lower oxidative stress and thereby reducing fatigue within each contraction, and in doing so, improves positive work in muscles of aged animals.

Aging Increases Oxidative Stress but Vitamin E\&C Reduces Oxidative Stress in Loaded Muscles. Several studies report an age-related increase of lipid peroxidation, oxidative modification to proteins, and DNA damage $(4,8,13,38,41)$. Similarly, the results of the current study suggest that the tibialis anterior muscles from aged rats are under greater oxidative stress than muscles from young adult rats. In addition to the age-associated increase in oxidative stress, repetitive loading also elevated the oxidative load in skeletal muscles.

$\boldsymbol{H}_{2} \mathrm{O}_{2}$. The increase that we observed in cytosolic $\mathrm{H}_{2} \mathrm{O}_{2}$ content in the exercised tibialis anterior muscle is consistent with previous data showing that muscle contractions increase oxidant production $(4,10,23,29,30,38)$. Hydrogen peroxide is a relatively stable pro-oxidant that in biological systems is most commonly produced from the dismutation of superoxide. It is commonly assumed that during exercise most of the increases in $\mathrm{H}_{2} \mathrm{O}_{2}$ are the result of superoxide production.

In general, this study supports the idea that Vitamin E\&C supplementation increases the ability of the muscle to buffer oxidant production associated with aging and exercise. To the authors knowledge the current data are the first to show that Vitamin E\&C supplementation directly lowers cytosolic $\mathrm{H}_{2} \mathrm{O}_{2}$ concentrations in both control and exercised tibialis anterior muscle from young adult and aged animals. It has been previously shown via electron spin resonance spectroscopy that Vitamin E supplementation lowers the concentrations of free radicals produced during 30 min of exhaustive swimming exercise, however this study did not further distinguish the type or location of radicals being produced (23). Furthermore, no difference was reported in the muscles of non-exercised control animals (23). The majority of the data that report a decrease in oxidant production after exercise with Vitamin E\&C supplementation have measured oxidative damage to lipids, protein and DNA, but they generally have failed to measure oxidant production $(7,19,20,24,30,35)$. In the current study, Vitamin E\&C supplementation lowered cytosolic $\mathrm{H}_{2} \mathrm{O}_{2}$ concentrations in the aged muscle to the same level as the young adult, and both the young adult and aged muscle from the supplemented animals were lower than the control limb of the young adult non-supplemented tibialis anterior muscle. These data suggest that fortification of the rat's diet with Vitamins E\&C was effective at increasing the oxidant buffering capacity, but combining exercise with supplementation did not further increase the buffering capacity of the tibialis anterior muscle to oxidative stress. 
Glutathione. Total glutathione, and especially reduced glutathione (GSH), have important roles in protecting cells from oxidant damage. This protective function is achieved by direct conjugation with radicals as well as functioning as an electron donor in redox reactions. The redox reaction oxidizes GSH to GSSG while $\mathrm{H}_{2} \mathrm{O}_{2}$ and other peroxides are reduced (26). The ratio of reduced to oxidized glutathione (GSH/GSSG) is a good indicator of the redox status of the muscle. The results of this study show that aging decreased both the total GSH abundance and the GSH/GSSG ratio in skeletal muscle. This suggests a reduced potential for buffering oxidative stress in aged muscles. In addition, the GSH/GSSG ratio was further lowered in repetitively loaded muscles of non-supplemented aged rats as compared to muscles in young adult animals. This indicates that aging reduced the ability to tolerate increased oxidative stress in chronically loaded skeletal muscles.

Interestingly, total GSH was lower in muscles from Vitamin E\&C supplemented young adult rats as compared to non-supplemented animals. In contrast, Vitamin E\&C supplemented aged rats did not further reduce skeletal muscle GSH abundance. Nevertheless, Vitamin E\&C supplementation increased the GSH/GSSG ratio in the both the young adult and aged tibialis anterior muscle after chronic repetitive loading exercise. These data are consistent with the $\mathrm{H}_{2} \mathrm{O}_{2}$ data, and together this is indicative of increases in oxidant production during exercise. These data suggest that aging increased oxidative stress and therefore lowered the GSH/GSSG ratio as compared to muscles in young adult animals, and that aging reduced that ability to tolerate increased oxidative stress in chronically loaded skeletal muscles. Furthermore, Vitamin E\&C supplementation provided an effective buffer against oxidant stress in response to loading. It is not clear why the decrease in cytosolic $\mathrm{H}_{2} \mathrm{O}_{2}$ concentrations did not increase the GSH/GSSG ratio of non-exercised tibialis anterior muscle from young adult or aged animals receiving Vitamin E\&C supplementation.

Oxidative Damage to DNA. Oxidative DNA damage (8-OHdG) increased with aging but not with repetitive loading exercise. This is consistent with previous data which indicate that aging is associated with increases in oxidative DNA damage $(32,38,39)$. Furthermore, longterm exercise does not appear to elevate oxidative damage to DNA $(38,39)$, although the mode, duration and intensity of the exercise along with sampling procedures, may play a significant role in determining the effect that chronic exercise has on increased oxidative DNA damage in skeletal muscle. For example, in contrast to our current study using repetitive loading as a model of resistance exercise, 8 weeks of treadmill running resulted in an attenuation of the age-associated increase in 8-OHdG levels, and increased the activity of DNA repair in aged rats (32). It is likely that the differences in these studies are the result of the difference in the mode of exercise (high intensity, low duration vs. low intensity, high duration). Furthermore, chronic aerobic exercise has been shown to increase the mitochondria's oxidant buffering capacity and reduce oxidant production via the mitochondrial electron transport chain, whereas chronic resistance training has not been shown to elicit the same degree of adaptation within the mitochondria. It is also important to note that mitochondrial DNA is more susceptible to oxidative damage than nuclear DNA, so aerobic exercise-induced changes of oxidative stress may provide significant protection to mitochondria DNA, whereas this would likely not occur with resistance types of exercise. In the current study, Vitamin E\&C supplementation decreased the 8-OHdG content in both young adult and aged muscle. This suggests that the antioxidant diet had a profound effect on buffering and reducing oxidative stress, resulting in lower DNA damage in muscles of both young adult and aged animals. Previous work has shown that Vitamin E supplementation decreased 8-OHdG in muscle of young men but supplementation failed to show a similar effect in elderly men (39). The variability of the subjects' heath/dietary 
status might explain some of the variability in the different responses of subjects to antioxidant supplementation.

Lipids. In contrast to DNA, the current data suggests that the increase in cellular damage to lipids associated with aging can be attenuated after chronic repetitive loading. The beneficial effects of exercise on lowering levels of lipid peroxidation has been observed in previous investigations $(1,30,38)$. The current study shows evidence that Vitamin E\&C supplementation is as effective at reducing the elevated concentrations of MDA + HAE associated with aging as chronic repetitive loading alone. The current data is in agreement with previous work showing that aging increases oxidative stress $(2,4,21)$ and that Vitamin supplementation (especially Vitamin E) protects lipids from oxidative damage (23) observed during exercise and aging. However, there was not an additive effect of combining exercise with Vitamin E\&C supplementation.

\section{Adaptation of Antioxidant Systems to Repetitive Loading and Antioxidant}

Supplementation. The current investigation measured transcription, protein levels and enzyme activity levels of endogenous antioxidant enzymes catalase, glutathione peroxidase, MnSOD and CuZnSOD . Overall the results do not support the likelihood that transcriptional control is a mechanism leading to increases in activity of the endogenous antioxidant enzymes. Instead, these data are consistent with the previously suggested notion that the endogenous antioxidant enzymes activities are regulated via various levels of post-transcriptional and/or posttranslational controls $(18,38)$. However, the current data do not support the view that Vitamin E\&C supplementation inhibits the positive adaptations to exercise within all of the endogenous antioxidant enzymes (36). The data in the current study suggest that there is an age-dependent effect of repetitive loading and Vitamin E\&C supplementation within the tibialis anterior muscle. Vitamin E\&C supplementation increased activity levels of catalase, MnSOD and CuZnSOD in both the exercise and control limbs from the young adult animals. There was no change in MnSOD activity but CuZnSOD and catalase also increased in the muscles of aged rats supplemented with Vitamins E\&C. Although this not a universal finding $(15,36)$ our data are consistent with reports that antioxidant vitamin supplementation increases the activities of the enzymatic antioxidants in both healthy (40) as well as diseased animals with chronic elevations in oxidative stress (14).

Antioxidant supplementation has been previously reported to have a detrimental effect on producing expected antioxidant adaptations to chronic training $(15,36)$. However, any detrimental effect may be due in part to the method of administering the supplement. For example, antioxidant supplementation after chronic training that is provided in a concentrated form (oral gavage or pill) likely induces a bolus effect and may reduce intestinal absorption. Whereas, in this study, rather than one mega dose, we provided the fortification of the animal's food which would more likely represent more constant systemic levels of Vitamin E\&C. It is not currently known how the endogenous antioxidants enzyme levels would respond to the longterm effects of a diet fortified with Vitamin E\&C taken throughout a period of chronic exercise, as compared to a single supplemented dose of Vitamin E\&C that would be given after adaptation to chronic exercise.

\section{Conclusion}

The current study provides data to show that chronic exercise and Vitamin E\&C supplementation lower indices of oxidative damage (i.e. 8-OHdG, MDA + HAE) associated with aging. However, repetitive loading and Vitamin E\&C supplementation affected DNA damage and lipid peroxidation differently. This raises the possibility that aging and repetitive loading 
exercise increase oxidant production via different mechanisms. Several potential mechanisms exist that include elevations of oxidative stress via neutrophils and other infiltrating immune cells, mitochondria respiration, NADPH oxidase or xanthine oxidase activity. This possibility warrants additional studies, because previous work has suggested that aging increases oxidant production via the mitochondrial electron transport chain whereas exercise induced increase in muscle oxidants originate from multiple sources (4).

Assessing effectiveness of Vitamin E\&C supplementation in preventing exercise-induced oxidative stress has been difficult to determine from previous studies. This is the result of a wide variance in study designs and experimental conditions (i.e. subject/ animal species, experimental conditions, length of study, dose of supplement, means of supplement administration and mode of exercise). Nevertheless, the data in our current study clearly show that Vitamin E\&C supplementation lessens the oxidant activity and oxidative damage in tibialis anterior muscles from young and aged rats subjected to chronic repetitive loading. Furthermore, Vitamin E\&C supplementation attenuated basal levels of oxidative stress associated with aging. Muscle size and other functional measurements were unaffected by Vitamin E\&C supplementation, in aged rats, but there were important improvements in positive work in the aged animals after 4.5 week of repetitive loading that received the dietary supplementation. Additional studies are required to determine if skeletal muscles in elderly humans who supplement their diet with Vitamin E\&C during chronic resistance types of muscle loading, will respond in a similar fashion to the rodents in the current study. 
Table Legend

Table 4.1 Body Mass of Young and Aged Rats Pre and Post 14 sessions of repetitive loading. Data are mean \pm SEM and presented as the mass of the rats before the first exercise session and after the $14^{\text {th }}$ training session in grams. $\dagger$, indicates a significant difference $(p<0.05)$ from young exercise and diet-matched control rats. NS, non-supplemented diet.

Figure Legends

Figure 4.1 Repetitive loading induces muscle hypertrophy in the Tibialis Anterior Muscle. Tibialis anterior muscle wet weight is reported for young and aged rats that received no dietary supplement (NS) or a diet supplemented with Vitamin E\&C (Vit E\&C). Data are expressed as mean \pm SEM. *, significant difference between age-matched control and repetitive loaded TA muscle assigned at $p<0.05$; $\dagger$, a significant difference $(p<0.05)$ from young exercise and diet-matched control muscles; $\S$, significant difference $(p<0.05)$ from age-matched animals on the non-supplemented diet.

Figure 4.2 Repetitive loading increased muscle functional measurements in young adult dorsiflexor muscles while maintaining function in aged dorsiflexor muscles. (A) Maximal isometric force generated in the dorsiflexors from young and aged rats during each of the 14 training sessions. Data are expressed as the average maximum isometric force for all animals in Newtons (N) normalized to body mass (BM) in grams (g) produced during each exercise session \pm SEM. There was no significant difference in muscle wet weight of the animals in the two diet groups. (B) Negative work generated from a single eccentric/concentric movement performed at the start of each training session from the young and aged dorsiflexor muscles during each of the 14 training sessions. There was not a significant difference between diets. (C) Positive work generated from a single eccentric /concentric movement preformed at the start of each training session from the young and aged dorsiflexor muscles during each of the 14 training sessions. $\S$, indicates that there was a significant difference $(p<0.05)$ from agematched animals on the non-supplemented (NS) diet. Data are expressed as the mean \pm SEM. The solid line represents the linear regression for all age-matched points. Maximal isometric force, negative work and positive work generated from the young animals was significantly different $(p<0.05)$ from aged dorsiflexor muscles at all time points.

Figure 4.3 Vitamin E\&C supplementation attenuated the increase in hydrogen peroxide $\left(\mathrm{H}_{2} \mathrm{O}_{2}\right)$ concentration associated with exercise \& aging. The $\mathrm{H}_{2} \mathrm{O}_{2}$ concentration was determined fluorometrically. The data are expressed as mean $\pm \mathrm{SEM}$ of relative fluorescent units (RFU) per mg of total protein homogenate. ${ }^{*}$, significant difference $(p<0.05)$ between age-matched repetitively loaded muscle and contra-lateral control muscle; $\dagger$, a significant difference $(p<0.05)$ between young exercise and diet-matched control muscles; $\S$, significant difference $(p<0.05)$ between age-matched muscles from animals on the nonsupplemented (NS) diet.

Figure 4.4 Ratio of reduced glutathione to oxidized glutathione (GSH/GSSG) \& total glutathione content. (A) Data are depicted as the ratio of GSH to GSSG normalized to total protein content. Lower ratios are an indication of increased oxidative stress. (B) Data indicate total glutathione concentration normalized to total protein content. The normalized data are presented as mean \pm SEM. * , significant difference $(p<0.05)$ between age-matched repetitively loaded muscle and contra-lateral control muscle; $\dagger$, a significant difference $(p<0.05)$ between young exercise and diet-matched control muscles; $\S$, significant difference $(p<0.05)$ between age-matched muscles from animals on the non-supplemented (NS) diet. 
Figure 4.5 Vitamin E\&C supplementation decreased evidence of oxidative damage associated with repetitive loading exercise and aging. (A) The data represent oxidative damage as indicated by malondialdehyde (MDA) plus 4-hydroxyalkenals (HAE) normalized to total protein content. (B) Data are provided as mean \pm SEM and they are expressed as the nannogram concentration of 8-hydroxy-2'-deoxyguanosine (8-OHdG) per $\mu \mathrm{g}$ of DNA; *, significant difference $(p<0.05)$ of repetitively loaded muscle from contra-lateral control muscle; $\dagger$, a significant difference $(p<0.05)$ from young exercise and diet-matched control muscles; $\S$, significant difference $(p<0.05)$ from age-matched animals on the non-supplemented $(N S)$ diet.

Figure 4.6 Glutathione peroxidase (GPx) regulation with repetitive loading and Vitamin E\&C supplementation. (A) Total GPx activity was expressed as $\mathrm{mU}$ of GPx per ml of muscle homogenate normalized per mg of protein in the homogenate. (B) GPx-1 protein expression was determined in the total cytosolic fraction by western immunoblots. The data are expressed as optical density (OD) $\mathrm{x}$ band area, and presented as relative optical density. The inserts show representative blots for GPx-1 and $\beta$-tubulin in young and aged (control and repetitive loading) tibialis anterior muscle. (C) GPx-1 mRNA expression was determined by RTPCR. The data are expressed as optical density (OD) $x$ band area, and presented as relative optical density. The inserts show representative gels for GPx-1 mRNA and 18s rRNA in young and aged (control and repetitively loaded) muscle. All data are presented as mean \pm SEM; *, significant difference $(p<0.05)$ between age-matched repetitively loaded muscle and contralateral control muscle; $\uparrow$, a significant difference $(p<0.05)$ between young exercise and dietmatched control muscles; $\S$, significant difference $(p<0.05)$ between age-matched animals on the non-supplemented (NS) diet; C, control; RL, repetitively loaded; $Y$, young; $A$, aged; E\&C, diet supplemented with Vitamin E\&C.

Figure 4.7 Catalase regulation with repetitive loading and Vitamin E\&C supplementation. (A) Catalase activity was determined at $520 \mathrm{~nm}$ and expressed as $\mathrm{nM}$ of catalase per $\mathrm{ml}$ of homogenate normalized per $\mathrm{mg}$ of protein in homogenate. (B) Catalase protein expression was determined in the total cytosolic fraction by western immunoblots. The data are expressed as optical density (OD) $x$ band area, and presented as relative optical density. The inserts show representative blots for catalase and $\beta$-tubulin in young and aged (control and repetitively loaded) muscles. (C) Catalase mRNA expression was determined by RT-PCR. The data are expressed as optical density (OD) $x$ band area, and presented as relative optical density. The inserts show representative gels for catalase mRNA and 18s rRNA in young and aged (control and repetitively loaded) muscles. All data are presented as mean \pm SEM; * , significant difference $(p<0.05)$ between age-matched repetitively loaded muscle and contra-lateral control muscle; $\uparrow$, a significant difference $(p<0.05)$ between young exercise and diet-matched control muscles; $\S$, significant difference $(p<0.05)$ between age-matched animals on the non-supplemented (NS) diet; E\&C, diet supplemented with Vitamin E\&C; C, control; RL, repetitively loaded; $Y$, young; $A$, aged.

Figure 4.8 CuZn superoxide dismutase (CuZnSOD) regulation with repetitive loading and Vitamin E\&C supplementation. (A) CuZnSOD activity was expressed as mU of CuZnSOD per $\mathrm{ml}$ of homogenate normalized per $\mathrm{mg}$ of protein in homogenate. (B) CuZnSOD protein expression was determined in the total cytosolic fraction by western immunoblot. The data are expressed as optical density (OD) $x$ band area, and presented as relative optical density. The inserts show representative blots for CuZnSOD and $\beta$-tubulin in young and aged (control and repetitive loading) TA muscle. (C) CuZnSOD mRNA expression was determined by RT-PCR. The data are expressed as optical density (OD) $x$ band area, and presented as 
relative optical density. The inserts show representative gels for CuZnSOD mRNA and 18s rRNA in young and aged (control and repetitively loaded) muscle. All data are presented as mean \pm SEM; * , significant difference $(p<0.05)$ between age-matched repetitively loaded muscle and contra-lateral control muscle; $\dagger$, a significant difference $(p<0.05)$ between young exercise and diet-matched control muscles; $\S$, significant difference $(p<0.05)$ between agematched animals on the non-supplemented (NS) diet; E\&C, diet supplemented with Vitamin E\&C; C, control; RL, repetitively loaded; $Y$, young; $A$, aged.

Figure 4.9 Mn superoxide dismutase (MnSOD) regulation with repetitive loading and Vitamin E\&C supplementation. (A) MnSOD activity was determined after inhibiting CuZnSOD activity by potassium cyanide. MnSOD was expressed as $\mathrm{mU}$ of MnSOD per $\mathrm{ml}$ of homogenate normalized per $\mathrm{mg}$ of protein in homogenate. (B) MnSOD protein expression was determined in the total cytosolic fraction by western immunoblot. The data are expressed as optical density (OD) $x$ band area, and presented as relative optical density. The inserts show representative blots for MnSOD and $\beta$-tubulin in young and aged (control and repetitively loaded) muscle. (C) MnSOD mRNA expression was determined by RT-PCR. The data are expressed as optical density (OD) $\mathrm{x}$ band area, and presented as relative optical density. The inserts show representative gels for MnSOD mRNA and 18s rRNA in young and aged (control and repetitive loaded) muscle. All data are presented as mean $\pm \mathrm{SEM}$; *, significant difference $(p<0.05)$ between age-matched repetitively loaded muscle and contra-lateral control muscle; $\dagger$, a significant difference $(p<0.05)$ between young exercise and diet-matched control muscles; $\S$, significant difference $(p<0.05)$ between age-matched animals on the non-supplemented $(N S)$ diet; E\&C, diet supplemented with Vitamin E\&C; C, control; RL, repetitively loaded; Y, young; A, aged. 
Table 4.1

Body Mass of Young and Aged Rats Pre and Post 14 sessions of Repetitive Loading

\begin{tabular}{lllll}
\hline & Young NS & Young Vit. E\&C & Aged NS & Age Vit. E\&C \\
\hline Pre-RL (g) & $343.5 \pm 10.9$ & $350.1 \pm 26.1$ & $513.8 \pm 88.4 \dagger$ & $491 \pm 63.5 \dagger$ \\
Post-RL (g) & $328.1 \pm 11.8$ & $340.2 \pm 27.8$ & $467.2 \pm 91 \dagger$ & $441 \pm 55.5 \dagger$ \\
\hline
\end{tabular}

Each value expressed in grams as a mean \pm SEM

NS = non-supplemented 
Figure 4.1

\section{Tibialis Anterior Muscle Wet Weight Control

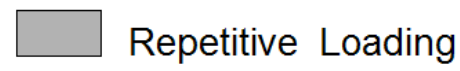

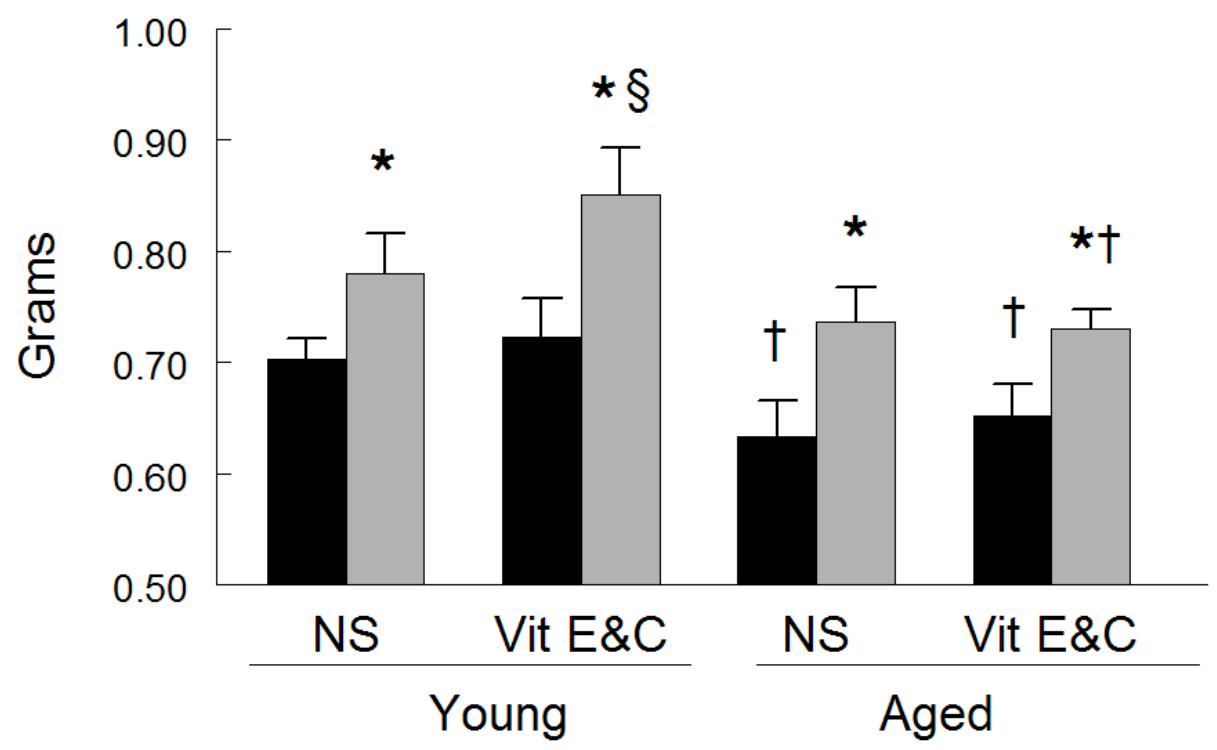


Figure 4.2
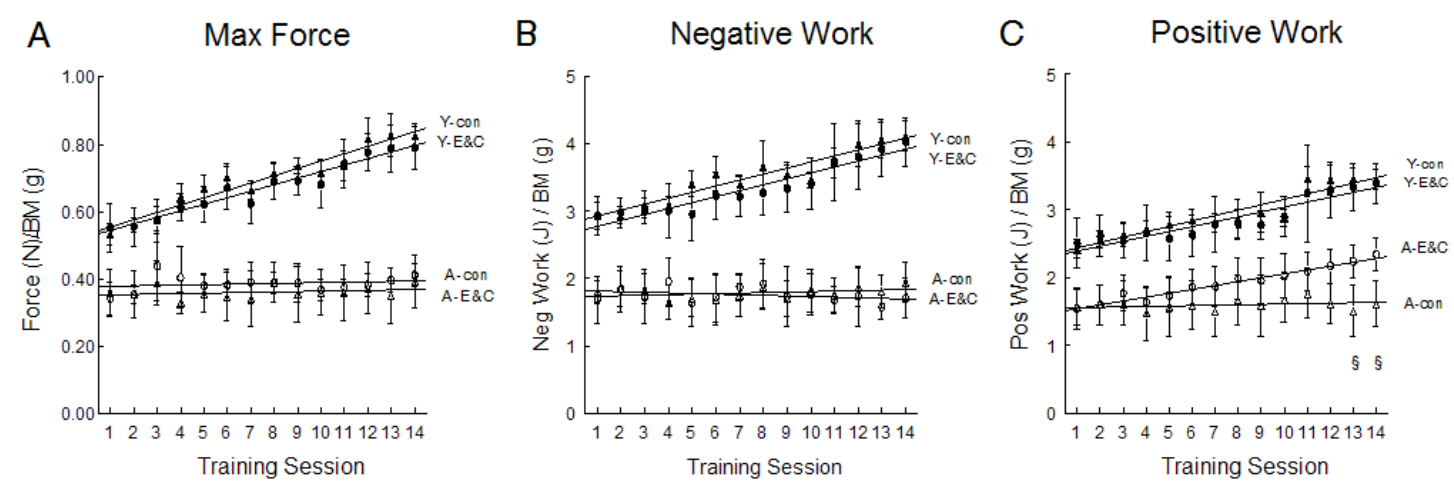
Figure 4.3

\section{Hydrogen Peroxide}

Control

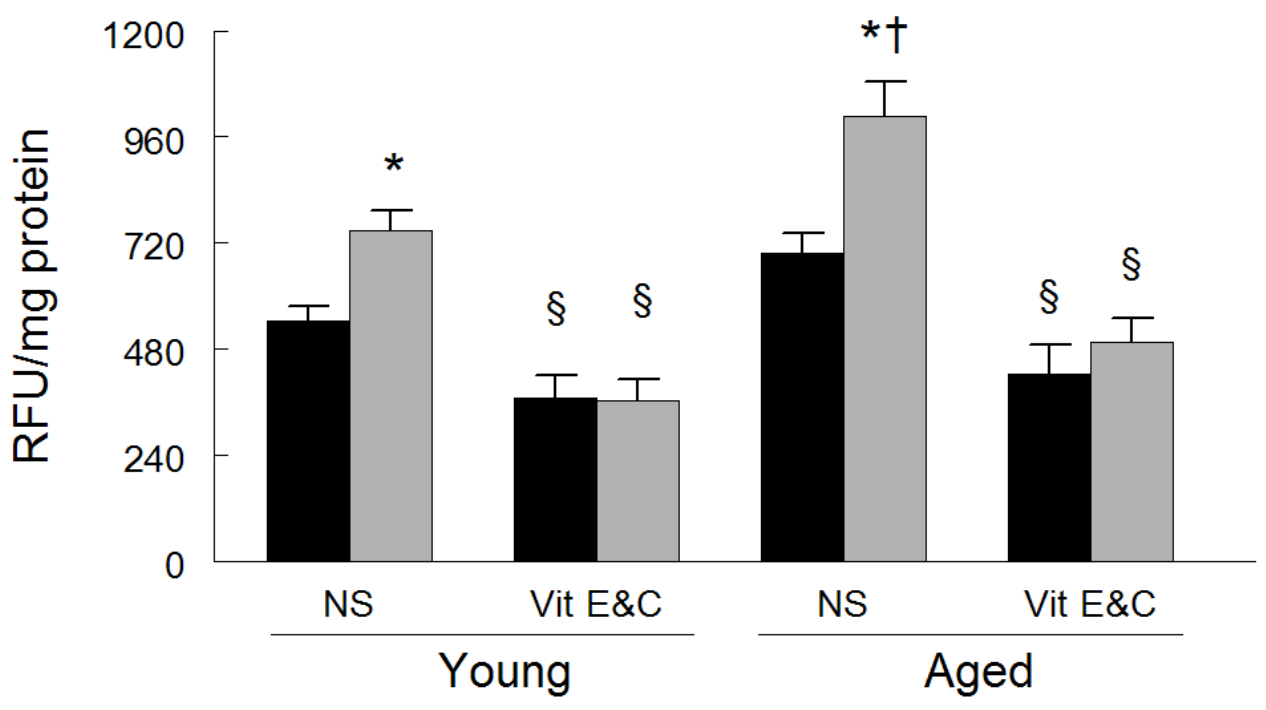


Figure 4.4
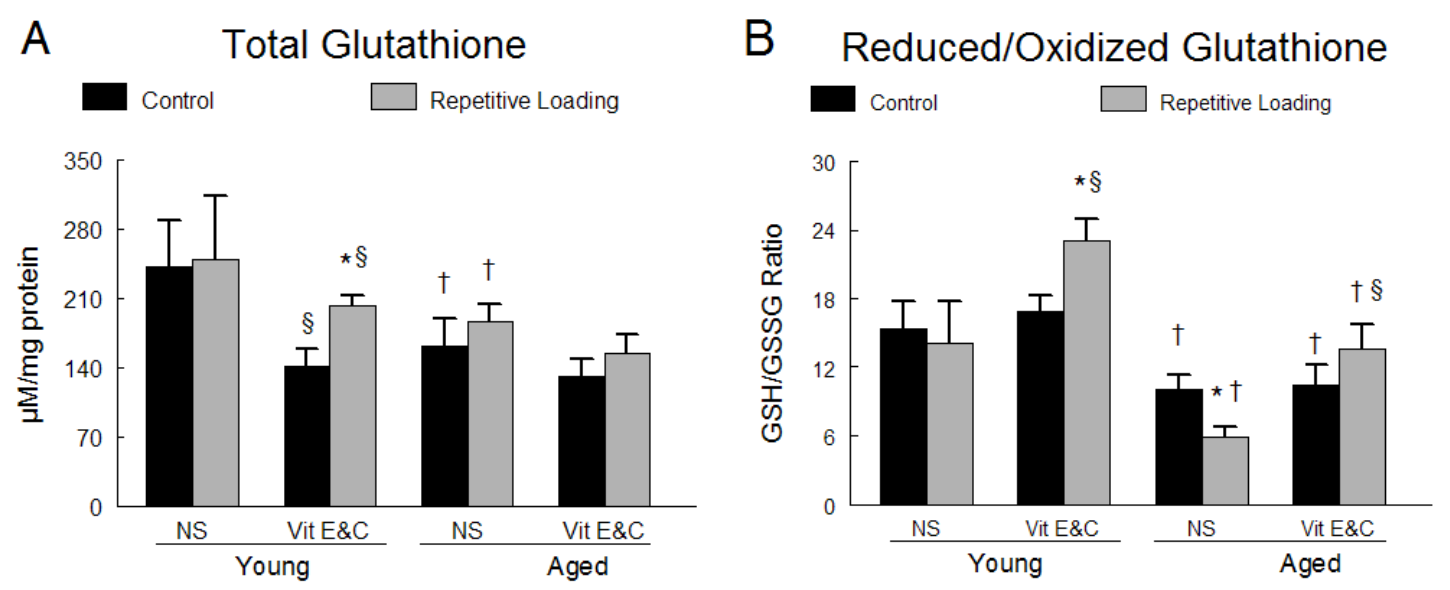
Figure 4.5

A

Lipid Preoxidation

Malondialdehyde (MDA) + 4-hydroxyalkenals (HAE)

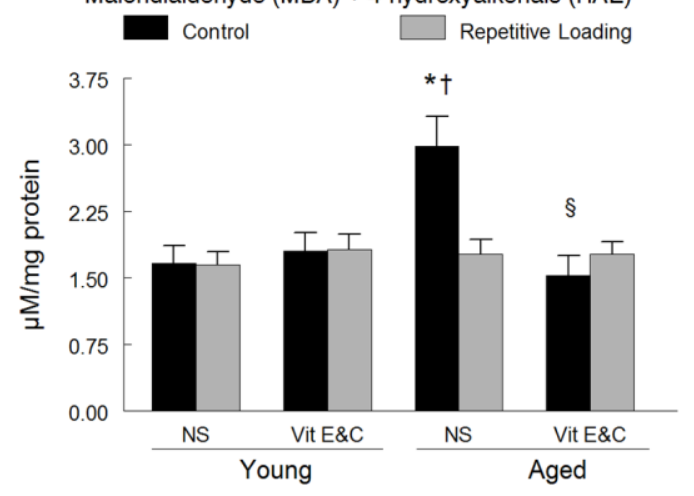

B

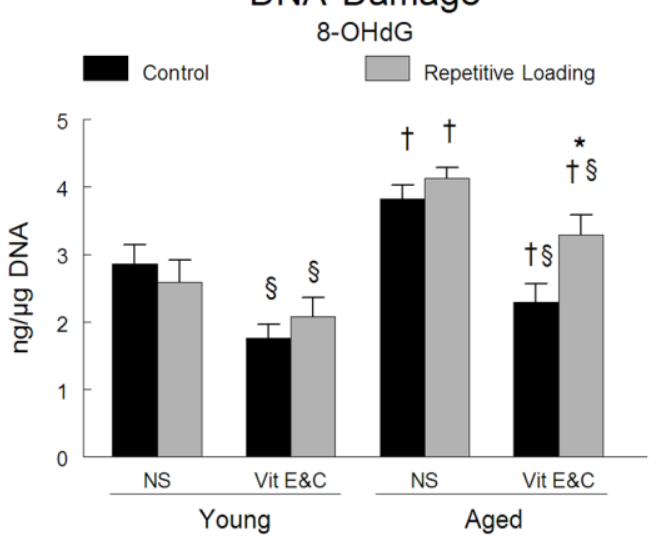


Figure 4.6
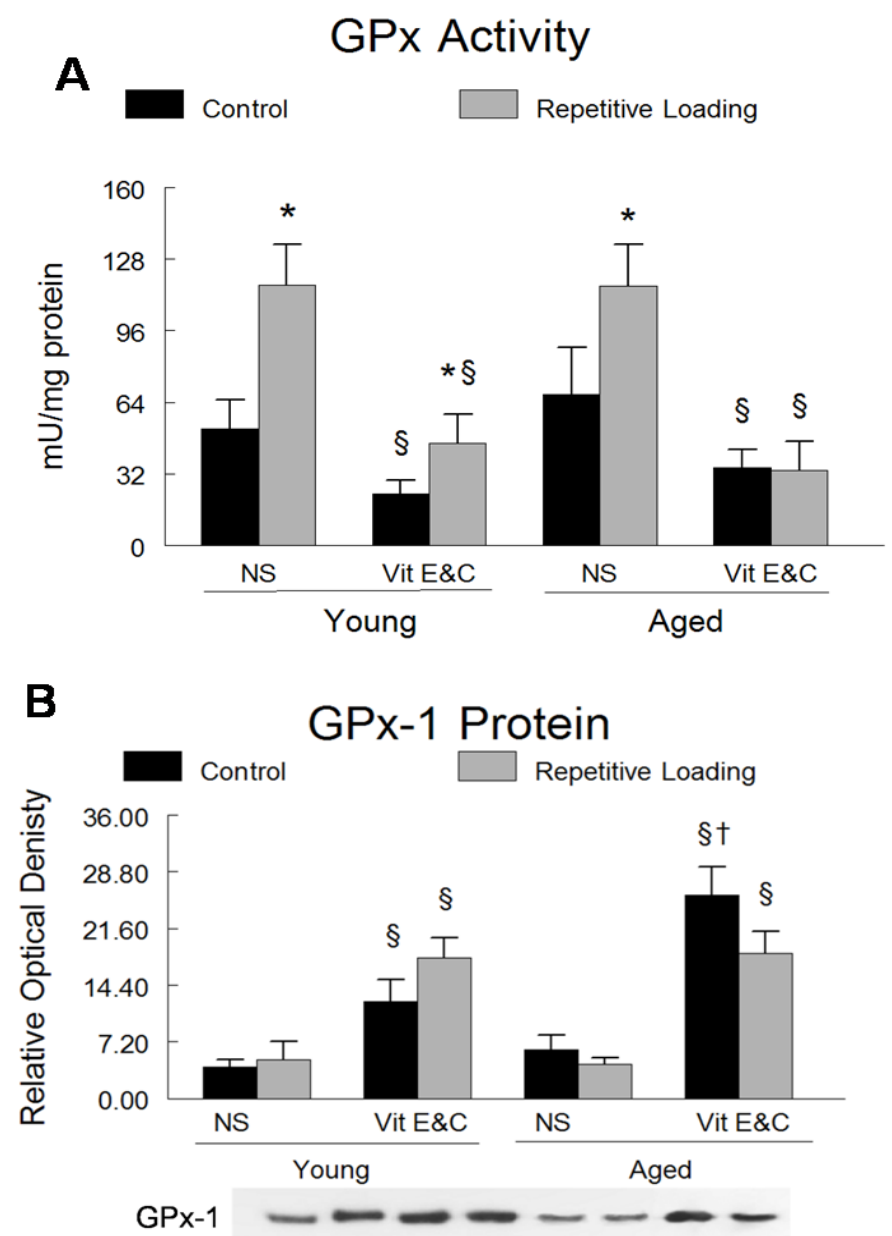

B-tubulin $-\frac{-}{\mathrm{C}} \mathrm{RL} \quad \underline{\mathrm{C}} \mathrm{RL} \quad \frac{\mathrm{C}}{\mathrm{RL}}-\frac{-}{\mathrm{Y} E \Omega C}$

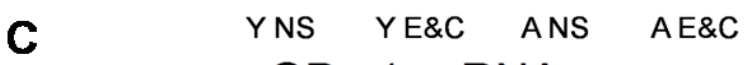

GPX-1 mRNA

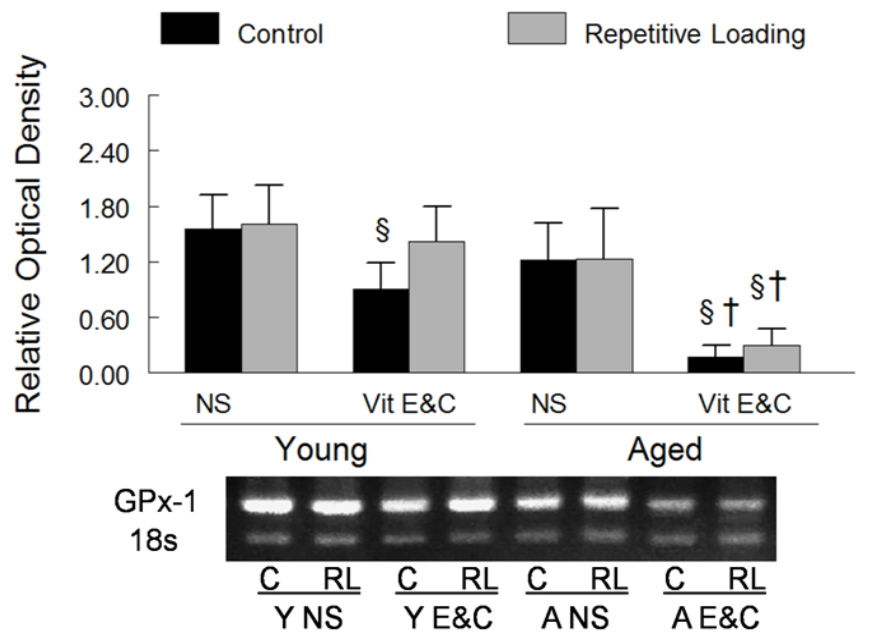


Figure 4.7
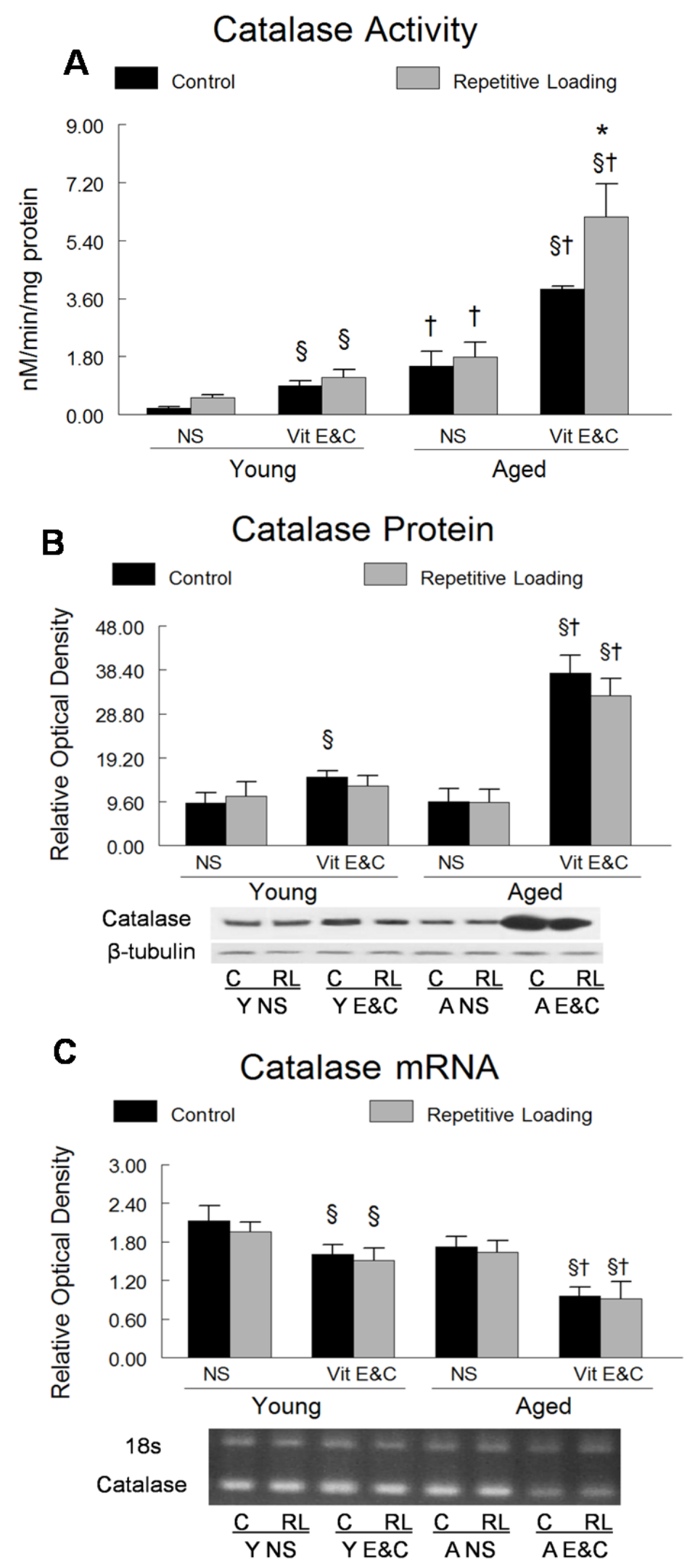
Figure 4.8

\section{A}

\section{CuZnSOD Activity}

Control

Repetitive Loading
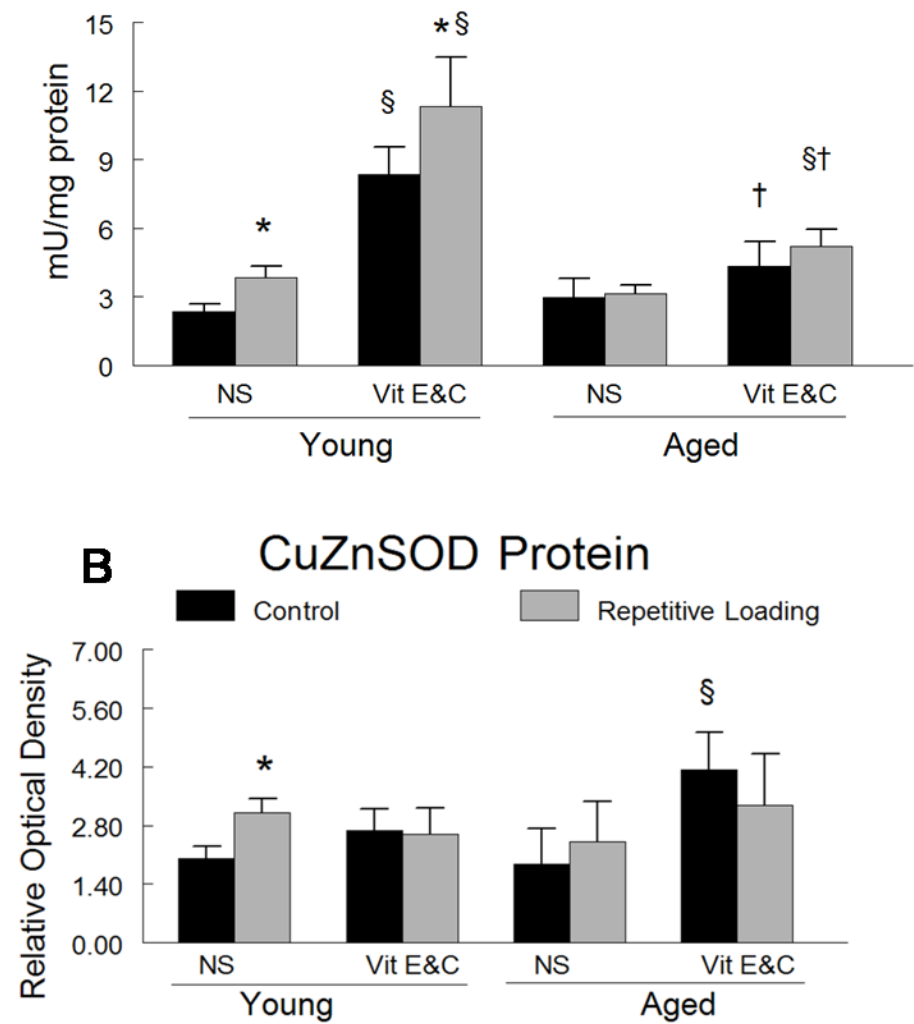

$\beta$-tubulin

CuZnSOD
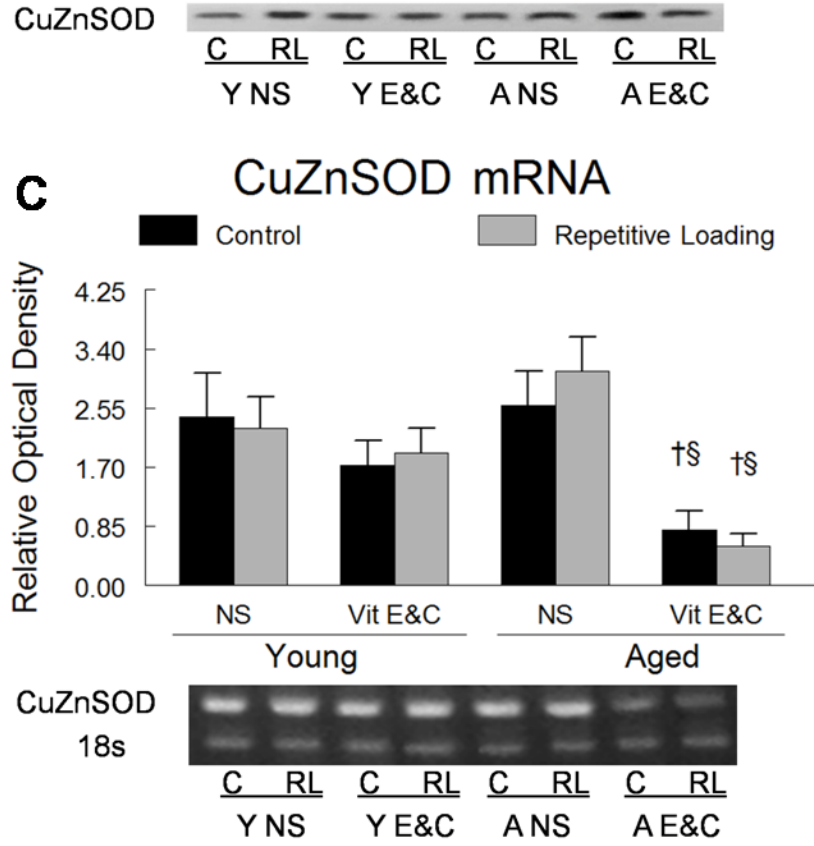
Figure 4.9
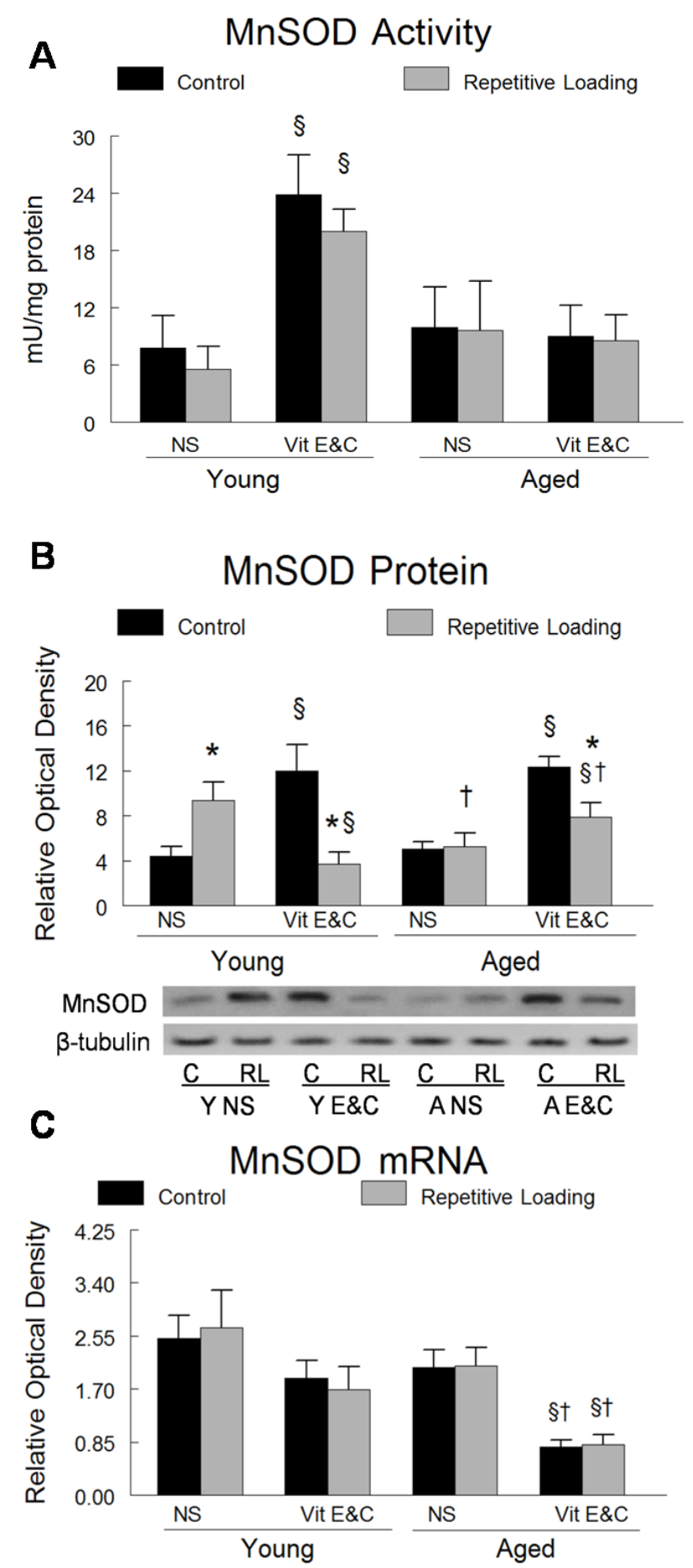

$18 s$

MnSOD

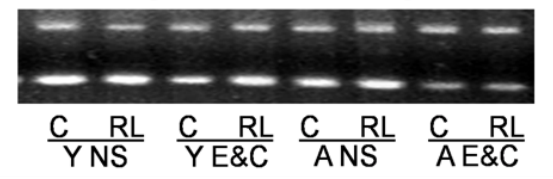




\section{Reference List}

1. Alessio HM and Blasi ER. Physical activity as a natural antioxidant booster and its effect on a healthy life span. Res Q Exerc Sport 68: 292-302, 1997.

2. Asano S, Rice KM, Kakarla S, Katta A, Desai DH, Walker EM, Wehner P and Blough ER. Aging influences multiple indices of oxidative stress in the heart of the Fischer 344/NNia x Brown Norway/BiNia rat. Redox Rep 12: 167-180, 2007.

3. Bartali B, Frongillo EA, Guralnik JM, Stipanuk MH, Allore HG, Cherubini A, Bandinelli S, Ferrucci $L$ and Gill TM. Serum micronutrient concentrations and decline in physical function among older persons. JAMA 299: 308-315, 2008.

4. Bejma $\mathbf{J}$ and $\mathbf{J i}$ LL. Aging and acute exercise enhance free radical generation in rat skeletal muscle. J Appl Physiol 87: 465-470, 1999.

5. Beyer RE. The Role of Ascorbate in Antioxidant Protection of Biomembranes Interaction with Vitamin-e and Coenzyme-Q. Journal of Bioenergetics and Biomembranes 26: 349-358, 1994.

6. Blough ER and Linderman JK. Lack of skeletal muscle hypertrophy in very aged male Fischer 344 x Brown Norway rats. J Appl Physiol 88: 1265-1270, 2000.

7. Chang CK, Huang HY, Tseng HF, Hsuuw YD and Tso TK. Interaction of vitamin E and exercise training on oxidative stress and antioxidant enzyme activities in rat skeletal muscles. Journal of Nutritional Biochemistry 18: 39-45, 2007.

8. Chen CN, Brown-Borg HM, Rakoczy SG and Thompson LV. Muscle disuse: adaptation of antioxidant systems is age dependent. $J$ Gerontol A Biol Sci Med Sci 63: 461-466, 2008.

9. Cutlip RG, Baker BA, Geronilla KB, Mercer RR, Kashon ML, Miller GR, Murlasits Z and Alway SE. Chronic exposure to stretch-shortening contractions results in skeletal muscle adaptation in young rats and maladaptation in old rats. Appl Physiol Nutr Metab 31: 573-587, 2006.

10. Davies KJ, Quintanilha AT, Brooks GA and Packer L. Free radicals and tissue damage produced by exercise. Biochem Biophys Res Commun 107: 1198-1205, 1982.

11. Degens $\mathbf{H}$ and Alway SE. Skeletal muscle function and hypertrophy are diminished in old age. Muscle Nerve 27: 339-347, 2003.

12. Fugere NA, Ferrington DA and Thompson LV. Protein nitration with aging in the rat semimembranosus and soleus muscles. J Gerontol A Biol Sci Med Sci 61: 806-812, 2006.

13. Gianni P, Jan KJ, Douglas MJ, Stuart PM and Tarnopolsky MA. Oxidative stress and the mitochondrial theory of aging in human skeletal muscle. Exp Gerontol 39: 13911400, 2004. 
14. Giray B, Kan E, Bali M, Hincal F and Basaran $\mathbf{N}$. The effect of vitamin E supplementation on antioxidant enzyme activities and lipid peroxidation levels in hemodialysis patients. Clin Chim Acta 338: 91-98, 2003.

15. Gomez-Cabrera MC, Domenech E, Romagnoli M, Arduini A, Borras C, Pallardo FV, Sastre $\mathbf{J}$ and Vina $\mathbf{J}$. Oral administration of vitamin $\mathrm{C}$ decreases muscle mitochondrial biogenesis and hampers training-induced adaptations in endurance performance. $A m \mathrm{~J}$ Clin Nutr 87: 142-149, 2008.

16. Guigoz $\mathbf{Y}$, Lauque $\mathbf{S}$ and Vellas $\mathbf{B J}$. Identifying the elderly at risk for malnutrition. The Mini Nutritional Assessment. Clin Geriatr Med 18: 737-757, 2002.

17. Harman D. Aging: a theory based on free radical and radiation chemistry. J Gerontol 11: 298-300, 1956.

18. Hollander J, Bejma J, Ookawara T, Ohno H and Ji LL. Superoxide dismutase gene expression in skeletal muscle: fiber-specific effect of age. Mech Ageing Dev 116: 33-45, 2000.

19. Itoh H, Ohkuwa T, Yamazaki Y, Shimoda T, Wakayama A, Tamura S, Yamamoto T, Sato $\mathbf{Y}$ and Miyamura $\mathbf{M}$. Vitamin $\mathbf{E}$ supplementation attenuates leakage of enzymes following 6 successive days of running training. Int J Sports Med 21: 369-374, 2000.

20. Jakeman $\mathbf{P}$ and Maxwell S. Effect of antioxidant vitamin supplementation on muscle function after eccentric exercise. Eur J Appl Physiol Occup Physiol 67: 426-430, 1993.

21. Ji LL. Antioxidant signaling in skeletal muscle: a brief review. Exp Gerontol 42: 582-593, 2007.

22. Kosek DJ, Kim JS, Petrella JK, Cross JM and Bamman MM. Efficacy of 3 days/wk resistance training on myofiber hypertrophy and myogenic mechanisms in young vs. older adults. J Appl Physiol 101: 531-544, 2006.

23. Kumar CT, Reddy VK, Prasad M, Thyagaraju K and Reddanna P. Dietary Supplementation of Vitamin-E Protects Heart-Tissue from Exercise-Induced Oxidant Stress. Mol Cell Biochem 111: 109-115, 1992.

24. Labonte M, Dionne IJ, Bouchard DR, Senechal M, Tessier D, Khalil A, Labonte M, Bobeuf F, Tessier D, Khalil A and Dionne IJ. Effects of antioxidant supplements combined with resistance exercise on gains in fat-free mass in healthy elderly subjects: a pilot study. J Am Geriatr Soc 56: 1766-1768, 2008.

25. Leotsinidis M, Alexopoulos A, Schinas V, Kardara M and Kondakis X. Plasma retinol and tocopherol levels in greek elderly population from an urban and a rural area: associations with the dietary habits. Eur J Epidemiol 16: 1009-1016, 2000.

26. Maher P. The effects of stress and aging on glutathione metabolism. Ageing Res Rev 4: 288-314, 2005. 
27. Marzani B, Balage M, Venien A, Astruc T, Papet I, Dardevet D and Mosoni L. Antioxidant supplementation restores defective leucine stimulation of protein synthesis in skeletal muscle from old rats. J Nutr 138: 2205-2211, 2008.

28. McArdle A, Vasilaki A and Jackson M. Exercise and skeletal muscle ageing: cellular and molecular mechanisms. Ageing Res Rev 1: 79-93, 2002.

29. McArdle F, Pattwell DM, Vasilaki A, McArdle A and Jackson MJ. Intracellular generation of reactive oxygen species by contracting skeletal muscle cells. Free Radic Biol Med 39: 651-657, 2005.

30. McBride JM, Kraemer WJ, Triplett-McBride T and Sebastianelli W. Effect of resistance exercise on free radical production. Med Sci Sports Exerc 30: 67-72, 1998.

31. Pistilli EE, Jackson JR and Alway SE. Death receptor-associated pro-apoptotic signaling in aged skeletal muscle. Apoptosis 11: 2115-2126, 2006.

32. Radak Z, Naito H, Kaneko T, Tahara S, Nakamoto H, Takahashi R, Cardozo-Pelaez F and Goto S. Exercise training decreases DNA damage and increases DNA repair and resistance against oxidative stress of proteins in aged rat skeletal muscle. Pflugers Arch 445: 273-278, 2002.

33. Raue U, Slivka D, Minchev K and Trappe S. Improvements in whole muscle and myocellular function are limited with high-intensity resistance training in octogenarian women. J Appl Physiol 106: 1611-1617, 2009.

34. Reid MB. Free radicals and muscle fatigue: Of ROS, canaries, and the IOC. Free Radic Biol Med 44: 169-179, 2008.

35. Rinne T, Mutschler E, Wimmer-Greinecker G, Moritz A and Olbrich HG. Vitamins C and $\mathrm{E}$ protect isolated cardiomyocytes against oxidative damage. Int J Cardiol 75: 275$281,2000$.

36. Ristow M, Zarse K, Oberbach A, Kloting N, Birringer M, Kiehntopf M, Stumvoll M, Kahn CR and Bluher M. Antioxidants prevent health-promoting effects of physical exercise in humans. Proc Natl Acad Sci U S A 106: 8665-8670, 2009.

37. Rokitzki L, Logemann E, Sagredos AN, Murphy M, Wetzelroth W and Keul J. LipidPeroxidation and Antioxidative Vitamins Under Extreme Endurance Stress. Acta Physiologica Scandinavica 151: 149-158, 1994.

38. Ryan MJ, Dudash HJ, Docherty M, Geronilla KB, Baker BA, Haff GG, Cutlip RG and Alway SE. Aging-Dependent Regulation of Antioxidant Enzymes and Redox Status in Chronically Loaded Rat Dorsiflexor Muscles. J Gerontol A Biol Sci Med Sci 63: 10151026, 2008.

39. Sacheck JM, Milbury PE, Cannon JG, Roubenoff R and Blumberg JB. Effect of vitamin $\mathrm{E}$ and eccentric exercise on selected biomarkers of oxidative stress in young and elderly men. Free Radic Biol Med 34: 1575-1588, 2003. 
40. Shireen KF, Pace RD, Mahboob M and Khan AT. Effects of dietary vitamin E, C and soybean oil supplementation on antioxidant enzyme activities in liver and muscles of rats. Food Chem Toxicol 46: 3290-3294, 2008.

41. Siu PM, Pistilli EE and Alway SE. Age-dependent increase in oxidative stress in gastrocnemius muscle with unloading. J Appl Physiol 105: 1695-1705, 2008.

42. Siu PM, Pistilli EE, Ryan MJ and Alway SE. Aging sustains the hypertrophyassociated elevation of apoptotic suppressor X-linked inhibitor of apoptosis protein (XIAP) in skeletal muscle during unloading. J Gerontol A Biol Sci Med Sci 60: 976-983, 2005.

43. Van Remmen H, Hamilton ML and Richardson A. Oxidative damage to DNA and aging. Exerc Sport Sci Rev 31: 149-153, 2003. 


\title{
Chapter 5
}

Regulation of oxidative stress and xanthine oxidase activity by resveratrol after isometric contractions in gastrocnemius muscles of aged mice.

\author{
Michael J. Ryan, Janna R. Jackson and Stephen E. Alway
}

Laboratory of Muscle Biology and Sarcopenia, Division of Exercise Physiology, West Virginia University School of Medicine, Morgantown, West Virginia 26506 


\begin{abstract}
This study tested the hypothesis that resveratrol supplementation would lower oxidative stress in exercised muscles of aged mice. Young (3 mo) and aged (27mo) C57BL/6 mice received a control, or a $0.05 \%$ trans-resveratrol supplemented diet. Twenty maximal electricallyevoked isometric contractions of the plantar flexors of one limb were obtained in anesthetized mice for 3 consecutive days. Resveratrol supplementation blunted the exercise-induced increase in xanthine oxidase activity in muscles from young $(25 \%)$ and aged $(53 \%)$ mice. Resveratrol lowered $\mathrm{H}_{2} \mathrm{O}_{2}$ levels in control (13\%) and exercised $(38 \%)$ muscles from aged animals, and increased the ratio of GSH/GSSG in exercised muscles from young (38\%) and aged $(135 \%)$ mice. Resveratrol prevented the increase in lipid oxidation, increased catalase activity, and increased MnSOD activity in exercised muscles from aged mice. These data show that dietary resveratrol reduces muscle indicators of oxidative stress in response to isometric contractions in aged mice.
\end{abstract}




\section{Introduction}

The causes of decreased muscle function associated with advanced aging are multifactoral and include, muscle atrophy (sarcopenia), alterations in motor unit activity and declines in metabolic efficiency. Exercise is a countermeasure that is partially effective in reversing the loss of muscle function. While muscles in aged mammals will effectively adapt to chronic resistance exercise, via improved muscular strength and muscle fiber hypertrophy, these adaptations are generally smaller than that reported in muscles from younger adult humans and animals $(30,41)$. The mechanisms that regulate this attenuated adaptation to resistance exercise with advanced aging (12) are unknown, but it is possible that this may be mediated, at least in part, by the detrimental systemic effects associated with elevated oxidative stress (16).

The additive effects of an increase in oxidant production and an attenuated antioxidant buffering capacity leaves aged skeletal muscles more vulnerable to oxidative stress and subsequently, oxidative damage. Age-related increases in oxidative stress have been associated with diminished muscular strength and physical performance (6). Specifically, elevated levels of oxidants have been shown to depress muscle force (2), alter myofilament function $(2,28,29)$ and increase recovery time following injury $(27,38)$.

The xanthine oxidase system has been shown to be an important source of oxidant production in the vascular endothelium (23) and also a contributing factor to oxidative stress during strenuous exercise $(17,42,47)$. A high demand on anaerobic metabolism, coupled with intermittent localized obstruction of blood flow and subsequent reperfusion within contracting muscles raises the question as to whether xanthine oxidase may also be an important source of oxidant production during intense resistance exercises. Previous studies have observed that after resistance training, type II fibers are preferentially hypertrophied in both young and aged muscle $(30,40)$. Additionally, type II fibers tend to be more susceptible to oxidative damage than type I fibers (35), therefore the increased oxidant production associated with aging could preferentially limit the ability of type II fibers to adapt to exercise training.

Resveratrol (3,4',5-trihydroxystilbene), is a fat-soluble phytoalexin that over the past few years has gained recognition as an effective antioxidant and anti-aging nutraceutical $(5,37,39)$. In vitro experiments with high doses of resveratrol have shown resveratrol to be effective at scavenging oxidants (46) and inhibiting low density lipoprotein (LDL) oxidation (10). Whereas high concentrations of resveratrol appear to be an effective antioxidant $(8,46)$, there is currently little evidence to show that a low concentration of resveratrol supplementation is an effective oxidant scavenger in vivo (9). Resveratrol appears to improve muscle function in response to aerobic exercise. However, it is not clear if this is related to an antioxidant function of this compound. Furthermore, it is not known if resveratrol would reduce oxidative stress, including xanthine oxidase activity, oxidative damage, and/or muscle fatigue associated with acute resistance types of exercise. This is an important question to be considered in designing exercise programs for the elderly, because resistance types of exercise have been shown to develop considerable oxidative stress (41) and this coupled with an age-related elevation in the basal levels of oxidative stress within skeletal muscle may increase the susceptibility of aged muscle to oxidative damage with exercise.

The objective of this investigation was to evaluate the efficacy of dietary resveratrol to attenuate oxidative stress that is induced via isometric contractions in muscles of aged rodents. Isometric exercise provides an approach that eliminates the potential for oxidant production to be the result of muscle damage related to inflammatory cell infiltration that has been observed in the muscles of aged animals in response to concentric and eccentric repetitive loading exercise (4). In the present investigation, it was hypothesized that resveratrol would reduce the indices of 
isometric exercise-induced oxidative stress in muscles of aged mice. Furthermore, we hypothesized that resveratrol supplementation would improve muscle function and attenuate the loss of force during acute repetitive isometric contractions from muscles of aged mice.

\section{Methods}

Animals. Experiments were conducted on 16 young adult (3-5 month) and 16 aged (2628 month) C57BL/6 mice obtained from the National Institute on Aging colony (Harlan, Indianapolis, IN). The mice were housed in pathogen-free conditions at $\sim 20^{\circ} \mathrm{C}$. All mice had free access to water and either a control diet ( $N=8$ young adult $\& N=8$ aged) (AIN-76A Rodent Diet, Research Diets Inc, New Brunswick, NJ), or an identical diet that contained $0.05 \%$ resveratrol ( $\mathrm{N}=8$ young adult \& $\mathrm{N}=8$ aged) (Research Diets Inc, New Brunswick, NJ) for a total 10 days. The mice were given the experimental diet (control or resveratrol) for seven (7) days prior to the first exercise session and then kept on the same diet throughout the three (3) days exercise. Resveratrol was purchased from Orchid Pharmaceuticals (Nungambakkam, India). All experimental procedures carried approval from the Institutional Animal Use and Care Committee from West Virginia University School of Medicine. The animal care standards followed the recommendations for the care of laboratory animals as advocated by the American Association for Accreditation of Laboratory Animal Care (AAALAC) and fully conformed to the American Physiological Society's "Guiding Principles for Research Involving Animals and Human Beings."

Isometric Exercise. Mice were anesthetized with a mixture of oxygen (97\%) and isoflurane gas (3\%) using a small animal anesthetic system (Isotec 5, Ohmeda). The left knee was secured in flexion by placing a metal rod on the lateral side of the knee. The left foot was secured to a footplate connected to a servomotor (Cambridge Technology Inc. Model 6350*350, Cambridge, MA. The ankle joint was aligned with the axis of rotation of the servomotor. Electrically evoked contractions of the plantar flexor muscles were accomplished by electrically stimulating (10v, $100 \mathrm{~Hz}, 200 \mu \mathrm{s}$ pulses) the tibial nerve via inserting platinum electrodes (Grass Medical Instruments) through the skin so that they were flanking either side of the nerve. The left plantar flexor muscle group from each animal was subjected to 20 , electrically evoked, five second isometric contractions (10v, $100 \mathrm{~Hz}, 200 \mu$ s pulses) with a 25 second recovery period between contractions, resulting in a daily 10 minute session for three consecutive days. The contralateral limb served as an intra-animal control.

Muscle functional data were collected as a force $x$ time curve during isometric contractions for each session. The exercise sessions were performed on a custom-built mouse dynamometer. Briefly, the mouse was placed on a heated plate $\left(37^{\circ} \mathrm{C}\right)$ with its right side down. Dynamic Muscle Control (DMC) software (Aurora Scientific Inc., Aurora, Ontario, Canada) was used to control the servomotor providing for the angular position of the foot. Muscle contractions were stimulated using a High-Power Bi-Phase Current Stimulator (Aurora Scientific Inc., Aurora, Ontario, Canada). Data files from the DMC software were analyzed by the Dynamic Muscle Analysis software (Aurora Scientific Inc., Aurora, Ontario, Canada).

Muscle levels of hydrogen peroxide $\left(\mathrm{H}_{2} \mathrm{O}_{2}\right) . \mathrm{H}_{2} \mathrm{O}_{2}$ content in control and exercised mouse gastrocnemius muscles was measured by a fluorescent assay according to the manufacture's recommendations (Cell Technology, Mountain View, CA). The sample fluorescence was detected at an excitation of $530 \mathrm{~nm}$ and measured at $590 \mathrm{~nm}$. All analyses were completed in duplicate. The data from the tissue samples were normalized to the muscle protein concentration of each sample, as measured by a DC protein concentration assay (BioRad Hercules, CA). Each sample and standard was performed in duplicate. 
Total Glutathione \& reduced glutathione/oxidized glutathione (GSH/GSSG) content of aged \& exercised muscles. A BIOXYTECH GSH/GSSG-412 (Oxis International, CA) assay kit was used to determine the total glutathione and the GSH/GSSG ratio in control and exercised gastrocnemius muscles of young and aged mice. For total GSH measurements, approximately $40 \mathrm{mg}$ of fresh muscle was homogenized immediately after dissection in $530 \mu \mathrm{l}$ of cold 5\% metaphosphoric acid (MPA). GSSG was obtained on tissue samples after homogenization in $500 \mu \mathrm{l}$ cold $5 \%$ metaphosphoric acid (MPA) and $30 \mu \mathrm{l}$ of a M2VO scavenger. The tissue homogenates were flash frozen and stored at $-80^{\circ} \mathrm{C}$ until time of analysis.

The assay was conducted according to the recommendations of the manufacturer and as described previously (41). The reaction was imitated by adding $50 \mu$ of NADPH and the absorbance of each sample was read every $60 \mathrm{sec}$ at $412 \mathrm{~nm}$ for three minutes. The protein concentration of each sample was measured with a DC protein concentration assay (Bio-Rad Hercules, CA). The optical density from each sample was normalized to the protein content of the respective sample. Each sample and standard was performed in duplicate.

Muscle levels of Xanthine Oxidase activity. An Amplex Red® xanthine oxidase assay (\#A22182, Invitrogen, Eugene, OR) was used to measure xanthine oxidase activity, xanthine and hypoxanthine concentration in the gastrocnemius muscle homogenates by following the manufacturer's suggestions. Briefly, tissue homogenates were mixed with $100 \mu \mathrm{M}$ Amplex $\operatorname{Red} \circledast, 0.4 \mathrm{U} / \mathrm{mL}$ horseradish peroxidase and $200 \mu \mathrm{M}$ hypoxanthine and incubated at $37^{\circ} \mathrm{C}$ in the dark. Fluorescence was measured in a microplate reader using an excitation of 530 $\mathrm{nm}$ and emission detection at $590 \mathrm{~nm}$. Each sample was corrected for background fluorescence and then normalized to protein concentrations (Bio-Rad Hercules, CA) of the original samples. Hypoxanthine and xanthine were measured in the same manner; however, xanthine oxidase was used in the assay instead of hypoxanthine. Relative concentrations of hypoxanthine and xanthine concentrations were determined by comparing sample values relative fluorescent units (RFU). Each sample and standard was performed in duplicate.

Muscle levels of lipid peroxidation. Malondialdehyde (MDA) and 4-hydroxyalkenals (HAE) were measured using Bioxytech LPO-586 reagents (Oxis International, CA) as an indicator for the levels of lipid peroxidation in the gastrocnemius muscle samples as described previously (41). Briefly, $75 \mathrm{mg}$ of muscle was homogenized in ice-cold PBS containing $0.5 \mathrm{M}$ butylated hydroxytoluene in acetonitrile. The tissue samples were homogenized and the supernatant was used for the lipid peroxidation assay and also to determine the protein content of the sample. The resulting optical density signals were measured with an absorbance at $586 n m$ (DYNEX technologies, Chantilly Va., USA). The protein content of the sample was determined (Bio-Rad, Hercules, CA) and used to normalize the optical density of each sample. Each sample and standard was performed in duplicate.

Glutathione Peroxidase in exercised and control muscles. Cellular glutathione peroxidase was used to measure glutathione peroxidase activity in gastrocnemius muscle homogenates according to the manufacture's recommendations (\#35319, EMD/Calbiochem, San Diego, CA), and as previously described (41). Briefly, muscle samples were homogenized in PBS (pH 7.5) containing 5mM EDTA and $1 \mathrm{mM}$ DTT, and then centrifuged. The supernatant was used for the glutathione peroxidase assay. The resulting absorbance was measured at 340 $\mathrm{nm}$ (DYNEX technologies, Chantilly Va., USA). Each sample and standard was performed in duplicate.

Catalase activity. The activity of catalase was determined in gastrocnemius muscle homogenates (\# 219265, EMD/Calbiochem, San Diego, CA) as described previously (41). The samples were read on a microplate reader (DYNEX technologies, Chantilly, VA) at an 
absorbance of $520 \mathrm{~nm}$. All analyses were measured in duplicate and the samples were normalized to the corresponding protein concentration (Bio-Rad Hercules, CA).

Activity levels of Manganese Superoxide Dismutase (MnSOD) and Copper-Zinc Superoxide Dismutase (CuZnSOD). Superoxide dismutase was measured using a commercially available SOD Assay Kit II (\#574601, EMD/Calbiochem, San Diego, CA). Both total SOD and MnSOD activity were obtained. CuZnSOD was determined from assuming that CuZnSOD was the result of subtracting MnSOD activity from the total SOD activity. The assay was performed with slight modifications to the manufacturer's directions and all samples and standards were measured in duplicate as described previously by our laboratory (41). Briefly, gastrocnemius muscle samples were homogenized in (20mM HEPES buffer, containing $1 \mathrm{mM}$ EGTA, $210 \mathrm{mM}$ mannitol, and $70 \mathrm{mM}$ sucrose and the insoluble material was discarded. The supernatant was incubated either with, or, without, $12 \mathrm{mM}$ potassium cyanide to inhibit CuZnSOD and extracellular SOD activity. The sample absorbance was measured at $450 \mathrm{~nm}$ using a 96-well plate reader (Dynex Tech., Chantilly VA., USA).

mRNA levels of endogenous antioxidant enzymes. mRNA for GPX-1, Catalase, MnSOD and CuZnSOD were measured in the gastrocnemius muscle using reverse transcription-polymerase chain reaction (RT-PCR) according to methods previously published by our laboratory $(41,44)$. Briefly, total RNA was reversed transcribed using random primers, dNTP, and SuperScript II reverse transcriptase (Invitrogen/Life Technologies, Bethesda, MD). The primers for CuZnSOD, MnSOD, GPx-1, and catalase have been previously described (41). The signal from the gene was expressed as a ratio to the $18 \mathrm{~S}$ signal from the same PCR product. The PCR product from each reaction was separated by agarose gel electrophoresis. The gels were stained with ethidium bromide and the resulting signals were digitally captured (Kodak 290) and the signals were quantified using 1D Kodak image analysis software (Eastman Kodak Company, Rochester, NY).

Statistical analysis. All statistical analyses were performed using SPSS software package (version 13, Chicago, IL). Comparison of means was determined using analyses of variance (ANOVA) to examine the main effect of aging, exercise and resveratrol supplementation. Pair-wise comparisons were assessed post hoc using least significant difference (LSD) tests. Statistical significance was established at $p<0.05$. Data are reported as mean \pm standard error mean (SEM).

\section{Results}

Body Weights and Food Intake. The average body weight of the aged animals was significantly $(p<0.05)$ more than the young animals $(33.0 \pm 0.8 \mathrm{~g}$ vs. $25.5 \pm 0.7 \mathrm{~g})$. There was not a significant difference in body weight between non-supplemented and resveratrol

supplemented animals, in either age group. Similarly, there was no observed difference in food intake between the control and resveratrol supplemented diets. While young adult animals had a similar food consumption ( $3.1 \pm 0.3 \mathrm{~g} /$ day) as aged animals ( $3.8 \pm 0.4 \mathrm{~g} / \mathrm{day})$, when normalized to body weight, the young animals received a greater amount of resveratrol per day $(156.1 \pm 18.1 \mathrm{~g}$ resveratrol $/ \mathrm{kg}$ BW vs. $113.5 \pm 26.5 \mathrm{~g}$ resveratrol $/ \mathrm{kg} \mathrm{BW})$.

Muscle Functional Measurements. Maximal isometric plantar flexion force was recorded for each evoked contraction. Data was plotted as a force $x$ time curve for each isometric contraction from each session. Representative data of the first and last contraction from the third day in the young adult (Figure 5.1C\&D) and aged (Figure 5.1E\&F) mice is shown in Figure 5.1. The greatest contributor to plantar flexion is the gastrocnemius muscle. The maximal isometric force recorded on the third day (which was the first contraction of that day) was normalized to the animal's body weight. Maximal plantar flexion isometric force normalized 
to body weight was $25 \%$ and $27 \%$ greater in young adult than aged animals that consumed the control or the resveratrol supplemented diet, respectively. Resveratrol supplementation did not have a significant influence on maximal isometric force in either the young adult or the aged animals (Figure 5.1A).

The fatigability of the plantar flexors within each training session was assessed by comparing the net loss of force from the first contraction of the session to subsequent contractions. Neither aging, nor resveratrol, had any significant affect on the maximal force produced during the first five contractions of the exercise session. However, after the fifth contraction, on the third day, the aged animals on the control diet and the aged animals on the resveratrol diet showed a greater maintenance of force than young animals on the control diet $(p<0.05)$. No significant differences in fatigability were observed in the aged animals that received control, or resveratrol supplemented diets, whereas, young animals who were supplemented with resveratrol showed an improved maintenance of force over the exercise session (Figure 5.1B).

\section{$\underline{\text { Insert Figure } 5.1}$}

Muscle levels of $\mathrm{H}_{2} \mathrm{O}_{2} . \mathrm{H}_{2} \mathrm{O}_{2}$ was measured in gastrocnemius muscle homogenates as an indicator of oxidant production in basal and exercised conditions. Muscle homogenate levels of $\mathrm{H}_{2} \mathrm{O}_{2}$ were elevated in isometrically exercised muscles by $31 \%$ in young adult mice (1848 vs. $2428 \mathrm{RFU} / \mathrm{mg}$ protein) and 19\% in aged in the animals (3689 vs. $4401 \mathrm{RFU} / \mathrm{mg}$ protein) on the control diet compared to the age-matched non-exercised control limb $(p<0.05)$ (Figure 5.2). This indicates that acute isometric exercise elevated muscle oxidant production. Control and repetitively loaded muscles from aged animals had $99 \%$ and $81 \%$ higher levels of $\mathrm{H}_{2} \mathrm{O}_{2}$, respectively, than their treatment matched muscles from young adult mice $(p<0.05)$ (Figure 5.2). Fortifying the standard diet with resveratrol lead to a $24 \%(p<0.05)$ increase in $\mathrm{H}_{2} \mathrm{O}_{2}$ in the young exercised gastrocnemius muscles. Resveratrol significantly lowered $\mathrm{H}_{2} \mathrm{O}_{2}$ levels in both control and exercised muscles by $13 \%$ and $38 \%$ respectively, from aged animals $(p<0.05)$ (Figure 2). Isometric exercise did not affect muscle levels of $\mathrm{H}_{2} \mathrm{O}_{2}$ in the young adult mice that received a diet supplemented with resveratrol. However, resveratrol significantly reduced $\mathrm{H}_{2} \mathrm{O}_{2}$ by $15 \%$ in the exercised muscles of aged mice compared with non-exercised mice fed the control diet (3190 vs. $2693 \mathrm{RFU} / \mathrm{mg} /$ protein) (Figure 5.2).

\section{$\underline{\text { Insert Figure } 5.2}$}

Hypoxanthine \& Xanthine Oxidase activities. Hypoxanthine, a product of purine degradation and a substrate for xanthine oxidase was measured in young adult and aged gastrocnemius muscles. Hypoxanthine increased by $36 \%(p<0.05)$ with aging. Furthermore, isometric exercise increased muscle levels of hypoxanthine by $21 \%(p<0.05)$ in young adult mice and by $20 \%(p<0.05)$ in aged mice. Resveratrol supplementation blunted the increase in hypoxanthine in muscles from both young adult and aged mice, but it did not reduce the elevated levels of hypoxanthine associated with aging (Figure 5.3A).

The activity of xanthine oxidase in gastrocnemius muscles from aged animals was elevated by $168 \%$ compared to muscles from young adult mice $(258.9$ vs. $692.3 \mathrm{RFU} / \mathrm{mg}$ protein, $p<0.05$; Figure 5.3B). Resveratrol supplementation lowered xanthine oxidase activity in the non-exercised muscle from aged mice by $16 \%$ (692.3 vs. 582.9 RFU/mg protein, $p<0.05$; Figure 5.3B), but it had no effect on the non-exercised control muscle from young adult mice. Compared to the contralateral control muscles, isometric exercise increased xanthine oxidase activity by $38 \%(p<0.05)$ in gastrocnemius muscles from young adult mice and by $18 \%(p<0.05)$ in muscles from aged animals on the control diet. Resveratrol supplementation blunted the 
increase in xanthine oxidase activity associated with exercise in the young adult muscle by $25 \%$ $(p<0.05)$ and reduced xanthine oxidase activity in the aged gastrocnemius by $53 \%(p<0.05)$

(Figure 5.3B). Resveratrol supplementation in the aged isometrically-exercised animals resulted in a $50 \%(p<0.05)$ reduction in muscle xanthine oxidase activity when compared to the nonexercised muscle (Figure 5.3B).

\section{$\underline{\text { Insert Figure } 5.3}$}

The concentration of glutathione. Total glutathione decreased by $26 \%(p<0.05)$ in the control diet, non-exercised gastrocnemius muscle of aged mice (115 $\pm 18 \mu \mathrm{M} / \mathrm{mg}$ protein) compared with young adult muscle $(156 \pm 26)$. However, in the exercised gastrocnemius muscle form the mice receiving the control diet there was no significant difference between the young adult (153 $\pm 15 \mu \mathrm{M} / \mathrm{mg}$ protein) and the aged muscles (126 $\pm 17 \mu \mathrm{M} / \mathrm{mg}$ protein). Exercise alone failed to produce any changes in total glutathione within either age group receiving the control or the resveratrol fortified diet. A combination of resveratrol and exercise produced a $27 \%$ $(p<0.05)$ increase in total glutathione in the young adult animals $(195 \pm 27 \mu \mathrm{M} / \mathrm{mg}$ protein $)$ when compared to the young exercised animals that did not receive the fortified diet $(153 \pm 15 \mu \mathrm{M} / \mathrm{mg}$ protein), but no difference were observed in the aged animals. Resveratrol supplementation in the non-exercised limb did not produce any significant differences in either age group.

The ratio of reduced to oxidized glutathione (GSH/GSSG). The GSH/GSSG ratio was $31 \%$ lower in control, non-exercised muscles of aged mice $(9.5 \pm 1.3)$ compared with young mice (13.9 \pm 2.5$)$. This reduction in the GSH/GSSG ratio is indicative of an increase in oxidants as a result of both aging and exercise and may also be the result of impaired GSH metabolism and replenishment (11). The GSH/GSSG ratio was not altered by resveratrol in non-exercised control muscles from either young adult, or aged mice (Figure 4B). Isometric exercise decreased the GSH/GSSG ratio by $39 \%(p<0.05)$ and $43 \%(p<0.05)$ in the muscles of young and aged mice that were fed the control diet (Figure 5.4B). However, resveratrol supplementation prevented the exercise-induced decrease in the GSH/GSSG ratio in the gastrocnemius muscle, such that GSH/GSSG was 38\% and $135 \%$ greater in muscles from resveratrol treated exercised young and aged mice, respectively, as compared to muscles from age-matched mice on the control diets.

\section{$\underline{\text { Insert Figure } 5.4}$}

Muscle lipid peroxidation levels. Aging increased total amounts of lipid peroxidation in non-exercised control gastrocnemius muscles by $57 \%$ as shown by the greater MDA + HNE levels from control muscles from aged non-supplemented rats compared to control muscles from young adult non-supplemented animals ( 2.86 vs. $4.49 \mu \mathrm{M} / \mathrm{mg}$ protein, $\mathrm{p}<0.05$; Figure 5.5 ). Three days of isometric exercise failed to alter lipid peroxidation levels within muscles from the young adult mice but it increased MDA + HAE levels by $63 \%$ (4.49 vs. $7.31 \mu \mathrm{M} / \mathrm{mg}$ protein, $\mathrm{p}<0.05$; Figure 5.5) in the muscles from aged non-supplemented mice. Resveratrol supplementation completely prevented the increase in MDA + HNE levels associated with exercise in the muscles from aged mice, but resveratrol did not blunt the increase in lipid peroxidation associated with aging. Both control and isometrically exercised muscles from aged resveratrol supplemented animals showed a $\sim 53 \%(p<0.05)$ increase in MDA + HAE levels when compared to their young adult counterparts. Resveratrol supplementation had no effect on lipid peroxidation in the young adult animals.

\section{$\underline{\text { Insert Figure } 5.5}$}


Glutathione peroxidase (GPx) and catalase enzyme activity and mRNA abundance. There was no apparent aging, or exercise effect on GPx activity in the non-supplemented gastrocnemius muscle. Furthermore, resveratrol supplementation did not lead to any changes in GPx activity in the control, or exercised muscle from young adult animals. However, GPx activity increased $15 \%(p<0.05)$ in control and $12 \%(p<0.05)$ in exercised muscles from aged mice with resveratrol supplementation (Figure 5.6A). There were no significant changes that were found among GPx-1 mRNA within any of the muscle samples (Figure 5.6B).

Catalase activity was higher in the gastrocnemius muscle from the aged animals when compared to their treatment matched young adult counterparts. Neither isometric exercise, nor resveratrol supplementation, showed any significant changes in catalase activity within muscles from young adult animals. There was a $42 \%$ increase $(p<0.05)$ in catalase activity with isometric exercise in the aged animals on the standard diet and a $19 \%$ increase $(p<0.05)$ with the resveratrol supplemented diet. Resveratrol supplementation increased catalase activity within the aged animals by $50 \%(p<0.05)$ in the non-exercised control and $25 \%(p<0.05)$ in the isometrically exercised gastrocnemius muscle (Figure 5.6C). Similar to the enzyme activity data, catalase mRNA content was greater in the gastrocnemius muscle from all groups of the aged animals when compared to their treatment matched young adult counterparts. Supplementation with resveratrol increased catalase mRNA levels in the gastrocnemius muscle from both young adult and aged animals. However, exercise did not produce any significant changes in catalase mRNA levels within any of the groups (Figure 5.6D).

\section{$\underline{\text { Insert Figure } 5.6}$}

Superoxide dismutase enzyme activity and mRNA levels. Isometric exercise increased CuZnSOD enzyme activity $(p<0.05)$ by $27 \%$ in non-supplemented and $19 \%$ in resveratrol supplemented muscles from young adult animals, compared to their contra-lateral control muscles. Within the gastrocnemius muscles from the aged animals, exercise increased CuZnSOD activity by $25 \%(p<0.05)$ in the animals fed the standard diet, but no differences were observed between the control and exercised muscles of resveratrol supplemented animals. No significant changes in enzyme activity were observed as a result of aging in any of the groups (Figure 5.7A). No significant differences were found among CuZnSOD mRNA within any of the muscle samples (Figure 5.7B).

MnSOD activity was $10 \%$ greater in the non-exercised control gastrocnemius muscle from aged animals compared to young animals ( 0.89 vs. $0.80 \mathrm{U} / \mathrm{mg}$ protein). Surprisingly, isometric exercise lead to a decrease in MnSOD activity in the gastrocnemius muscle from young adult animals feed the standard diet, whereas exercise had no affect on MnSOD activity in the muscles from aged animals. Resveratrol supplementation increased MnSOD activity by $10-15 \%$ in all groups and removed any differences between groups due to aging, or exercise (Figure 5.7C). While isometric exercise did not induce any changes in mRNA transcription for MnSOD, resveratrol feeding lead to a $~ 90 \%$ increase in MnSOD transcription in exercised and a $\sim 50 \%$ increase in control muscles from both age groups (Figure 5.7D).

\section{$\underline{\text { Insert Figure } 5.7}$}

\section{Discussion}

Oxidative stress is elevated with aging in most tissues, including skeletal muscle $(14,25$, 41). Increased reactive oxygen species (ROS) production may contribute to aging-induced skeletal muscle wasting (i.e., sarcopenia) $(15,41)$. Although exercise is a useful approach to counter aging-induced sarcopenia, it also increases oxidative stress levels within the exercising muscles $(15,25,33)$. The additive effects of an increase in oxidant production and an 
attenuated antioxidant buffering capacity potentially leaves aged skeletal muscles more vulnerable to oxidative damage. The novel data in this study show that dietary resveratrol reduces oxidative stress, including xanthine oxidase activity, in control and exercised muscles of aged mice.

Xanthine oxidase as one source of exercise-induced oxidant stress

Although it is clear that oxidative stress is elevated in response to both acute exercise and aging, it has not been conclusively established that xanthine oxidase contributes to the increased oxidant production with advanced age in skeletal muscle. In the present study, we show that both xanthine oxidase activity and hypoxanthine levels are elevated in gastrocnemius muscles from aged mice, compared to young adult mice. This is consistent with data showing that xanthine oxidase activity was higher in the gastrocnemius muscles from aged rats when compared to young animals (18), and in plasma from older vs. young adult humans (3). Nevertheless, this contrasts with other data in humans that have shown an absence of ageassociated increases in endothelial xanthine oxidase in antecubital venous cells from the young and older subjects (13).

We anticipated that our model of repetitive maximal isometric contractions would increase oxidant stress in the exercised muscles. Our data show that repeated isometric exercise increased hypoxanthine levels, xanthine oxidase activity, and $\mathrm{H}_{2} \mathrm{O}_{2}$ production in the gastrocnemius muscles of both young and aged mice. These data are consistent with previous evidence that xanthine oxidase is, at least in part, responsible for oxidant production during exhaustive exercise

\section{Resveratrol reduces oxidative stress}

Resveratrol has been shown to exert a variety of health benefits that include the direct scavenging of ROS $(46)$, the inhibition of xanthine oxidase $(24,26)$ and the activation of intracellular pathways that improve metabolism and induce mitochondrial biogenesis $(5,32)$. The current study suggests that resveratrol supplementation lowers muscle indices of oxidative stress $\left(\mathrm{H}_{2} \mathrm{O}_{2}\right.$, xanthine oxidase activity, GSH/GSSG ratio and lipid peroxidation) associated with both normal aging and isometric exercise in aged mice. In fact, muscle xanthine oxidase activity and $\mathrm{H}_{2} \mathrm{O}_{2}$ production were lower in exercised muscles from aged mice, than in muscles of agematched non-exercised, non-supplemented control muscles. In addition, resveratrol supplementation abolished the increase in xanthine oxidase activity and $\mathrm{H}_{2} \mathrm{O}_{2}$ production associated with isometric contractions in muscles from young mice. Together these data suggest that there may be an additive benefit to combining resveratrol supplementation with isometric exercise, especially in aged skeletal muscle.

As expected, the short duration of resveratrol supplementation in the current study affected $\mathrm{H}_{2} \mathrm{O}_{2}$ concentrations, xanthine oxidase activity, and lipid peroxidation to a greater degree with exercise than aging. It is therefore likely that aging and isometric exercise may regulate oxidant production via different mechanisms. For example, isometric exercise increased the activity of the cytosolic antioxidant enzymes, catalase and CuZnSOD, along with an increase in xanthine oxidase activity, implying that at least part of the increase in $\mathrm{H}_{2} \mathrm{O}_{2}$ production with isometric exercise is not originating from the mitochondria. This possibility is in agreement with observations showing that aging increases oxidant production via mitochondrial sources, whereas exercise increases oxidants in muscles from multiple sources, including xanthine oxidase (6).

Resveratrol's putative role in reducing oxidative stress is likely a combination of many factors. When taken orally, trans-resveratrol is well-absorbed by mammals, but its bioavailability is low due to its rapid first pass metabolism (48). Therefore, its role as a direct scavenger of 
reactive oxygen species (9) is likely to be limited. The most likely mechanism by which resveratrol can attenuate the increase in oxidative stress due to aging and exercise lies in its ability to induce transcriptional changes via the activation of silent mating type information regulation 2 homolog (Sirt1) (37). Sirt1 is a NAD ${ }^{+}$dependent histone deacetylase that is upstream of a wide variety of cellular pathways involved in energy homeostasis, longevity, cell survival and apoptosis. Increases in Sirt1 transcription have been shown to occur after 3 days of resveratrol supplementation (45). Sirt1 activation sequentially leads to energetic adaptations within the muscle by activating the metabolic regulators PPARy co-activator (PGC-1 $\alpha$ ) and AMP kinase (AMPK) and in turn enhancing components of the mitochondrial electron transport chain, $\beta$-oxidation and ATPases $(5,32)$. Although speculative, one possibility is that resveratrol might reduce uncoupling of the mitochondrial electron transport chain, leading to an increased availability of ATP and decreased superoxide formation. Previous findings have demonstrated that increases in post-exercise concentrations of hypoxanthine are accurate predictors of muscle energy depletion (7) and adenine nucleotide degradation during exercise (43). Our current data show increased hypoxanthine concentrations after exercise, which is indicative of elevated ATP utilization and depletion (43). Resveratrol supplementation decreased hypoxanthine levels following exercise, and this is consistent with the idea that resveratrol increased ATP availability to the exercising muscles. Nevertheless, the data in this study do not provide insight into whether greater ATP availability and/or improvement in mitochondria function are important outcomes for reducing oxidative stress after resveratrol supplementation.

\section{Antioxidant enzymes and resveratrol}

To our knowledge, this is the first investigation to examine the effects of resveratrol supplementation on the regulation of the endogenous antioxidant system in response to isometric exercise in young and aged animals. Our study measured transcription and activity levels of the endogenous antioxidant enzymes catalase, glutathione peroxidase, MnSOD and CuZnSOD. In general, the results do not support transcriptional control as a mechanism for altering the activity levels of the endogenous antioxidant enzymes within the muscles of nonsupplemented animals. Instead, these data are consistent with previous data that indicate the activity of the endogenous antioxidant enzymes are regulated via various levels of posttranscriptional and/or post-translational controls $(21,41)$. Insufficient tissue was available in this study to determine if the protein levels of endogenous antioxidant enzymes had been altered by short-term resveratrol treatment.

Several studies have shown that there is no aging-induced change in MnSOD or CuZnSOD activity, although loss of CuZnSOD exacerbates muscle loss with aging (35). Furthermore, over-expression of antioxidant enzymes does not improve life span (49). Our data indicate that aging did not alter the activity of GPx and CuZnSOD; however, aging increased the enzyme activity of MnSOD and catalase and catalase mRNA content. This increase in catalase transcription may be attributed to an attempt to compensate for the inability of the glutathione system to buffer $\mathrm{H}_{2} \mathrm{O}_{2}$. Age-related increases in catalase activity have been proposed as a potential means to counterbalance the depletion of glutathione levels in metabolically active tissues (34). Differences in age-dependent transcriptional control of the other endogenous antioxidant enzymes between our current study and that reported in other studies $(20,41)$ may be due to differences in environmental conditions, animal models, or the muscles that were investigated.

Short-term adaptation of antioxidant enzymes to isometric exercise in both young adult and aged animals appeared to occur via an increase in catalase and CuZnSOD activity, two enzymes that are primarily located in the cytosol. Catalase activity increased only in the aged animals after isometric contraction whereas, CuZnSOD increased in muscles from both the young adult and aged mice after isometric contractions. However, isometric contractions did not 
have an effect on mRNA content for any of the endogenous antioxidant enzymes (GPx, catalase, CuZnSOD or MnSOD) investigated in the current study. These observations are similar to previous data from our lab (41), where 4.5 weeks of repetitive loading exercise in the rat tibialis anterior muscle increased the activity of both catalase and CuZnSOD without changing mRNA content for these enzymes.

The absence of changes in mRNA suggests that post-transcriptional modifications might be responsible for either enhancing the capacity of the active site of the antioxidant enzymes, or perhaps reducing protein degradation leading to increased enzyme content. Similarly, it has been shown that increases in CuZnSOD protein levels occur without changes in mRNA content after a single bout of endurance exercise (19).

Resveratrol supplementation increased the endogenous antioxidant enzymes, catalase and MnSOD (39), which are located in close proximity to the sites of electron transport production of ATP. For example, MnSOD is localized to the mitochondrial matrix where it protects the mitochondria from oxidative damage. In addition, catalase is found in low concentrations in the cytosol and it is thought to be contained mainly within peroxisomes, which are sites of fatty acid oxidation. This fits well with previous observations showing that resveratrol supplementation increases the transcription and the activity of both catalase $(31,37)$ and MnSOD (37, 39). Furthermore, resveratrol can increase mitochondrial components of aerobic metabolism via its activation of Sirt1 $(5,37)$.

No effect of resveratrol on muscle force

The data in the current study show that resveratrol supplementation did not improve the maximal isometric force output of the plantar flexors muscle group from either the young adult, or aged animals, at any point of the acute three-day exercise regime. Furthermore, maximal isometric force did not change significantly from the first to the third exercise session (Figure $1 \mathrm{~A}$ ) in either young adult or aged mice. This is not surprising, given the relatively short duration of the supplementation and exercise intervention in this study. We did not anticipate that this short exercise period would result in hypertrophic adaptations, and therefore they were not measured.

Resveratrol does not improve muscle fatigability in aged mice

Muscle fatigability was measured as the relative decline in maximal isometric force by comparing the first and twentieth contraction in the third exercise session. Muscles from aged animals in either the control, or the resveratrol group had significantly greater fatigue resistance than muscles from young animals that where fed a control diet (Figure 1B). The greater relative decrease in fatigue over the 20 contractions may be due to an age dependent shift in muscle fiber type towards a greater percentage of type I fibers $(22,36)$. The larger sized fibers from the young adult animals would produce a greater maximal force and have a greater rate of ATP utilization (increased cross bridge cycling, greater calcium release and therefore greater ATP utilization by sarco/endoplasmic reticulum $\mathrm{Ca}^{2+}$-ATPase (SERCA) pumps, greater heat production) than the aged muscle, therefore having greater relative decline in force over time. However, the similar relative changes in hypoxanthine observed during exercise in the young adult and the aged animals would imply that if ATP utilization was greater in the young animals, then young muscle possess a mechanism that limited purine degradation even though ATP supplies were not fully restored. Further research is needed to fully understand the agedependent difference in muscle fatigue found in the current model of isometric exercise.

The plantar flexor muscles from young adult animals supplemented with resveratrol had a significantly lower decline in muscle force over the 20 contractions $(-27.5 \pm 1.6 \%)$ than animals that were fed the control diet $(-37.4 \pm 7.9 \%)$. The decline in maximal isometric force 
was similar in resveratrol supplemented young adult animals and aged animals from either control $(-42.9 \pm 4.1 \%)$, or resveratrol diet $(44.4 \pm 5.1 \%)$ groups.

Previous studies have reported that resveratrol supplementation improved mitochondria function and reduced fatigue associated with aerobic exercise $(5,32)$. Our data show for the first time that resveratrol reduces muscle fatigue in response to repetitive anaerobic (isometric) contractions, and therefore this effect is not activity specific. However, the effect of resveratrol with regard to repetitive exercise occurs only in muscles of young animals. It is possible that resveratrol increased the availability of ATP, by enhancing the density and efficiency of the mitochondrial electron transport chain, by increasing $\beta$-oxidation and by increasing ATPase content $(5,32,37)$ in muscles of young mice. This possibility is plausible because increases in hypoxanthine have been shown to be predictors of muscle ATP exhaustion (7) and hypoxanthine concentrations were lower in muscles from resveratrol supplemented mice in our current study. However, this investigation does not provide any direct evidence for this possibly, because we did not measure mitochondrial density or efficiency, nor did we measure skeletal muscle ATP content.

If resveratrol has an age-specific effect on fatigue resistance, it might be argued to act in a muscle fiber-type specific manner. For example, there is a well known increase in type I muscle fibers with aging, and muscles with a high percentage of type I fibers (e.g. soleus) appear to be more resistant to resveratrol-induced increases in mitochondrial enzymatic activity and oxidative capacity than the gastrocnemius muscle (primarily composed of type II fibers) (32). Nevertheless, fiber type specific responses cannot explain all of the effects of resveratrol, because even if there were some age-induced shift towards type I fibers, the gastrocnemius muscle, in the aged mouse still has a high percentage of type II fibers. Furthermore, mitochondria volume density is not a good predictor of fatigue resistance to isometric exercise (1), and therefore improvements in mitochondria number, or size, would be anticipated to have minimal, or no effects on isometric fatigability.

Another possibility to account for the improved fatigue resistance to maximal isometric exercise in muscles from young animals is that resveratrol could directly diminish exerciseinduced oxidant production which, have been shown to be a mediator of muscle fatigue (38). However, we do not regard this as a strong putative mechanism, because resveratrol decreased the exercise-induced elevation in $\mathrm{H}_{2} \mathrm{O}_{2}$ levels and other indices of oxidative stress in muscles from both young and aged mice yet, despite clear reductions in oxidative stress, resveratrol did not improve muscle fatigue resistance in aged animals. These findings indicate that acute increases in oxidative stress, including modulation of $\mathrm{H}_{2} \mathrm{O}_{2}$, are not sufficient to moderate acute fatigue responses to maximal isometric exercise in skeletal muscle with aging.

\section{Conclusion}

The current data suggest that resveratrol supplementation reduces oxidant production and oxidative damage in gastrocnemius muscles from young adult and aged mice subjected to short-term isometric exercise. Resveratrol supplementation also diminishes the basal levels of oxidative stress associated with aging. Functional measurements of maximal isometric force and rate of fatigue were unaffected by resveratrol supplementation in the aged animals. Further work is required to understand the role that fortifying a normal diet with resveratrol may have on the adaptive response of skeletal muscle to long-term exercise with aging. 


\section{Figure Legends}

Figure 5.1

Maximal plantar flexor isometric force after 3 consecutive days of isometric

exercise. (A) Data are expressed as the mean \pm SEM of the maximal isometric force recorded on the third day of exercise by the left plantar flexor muscles normalized to the body weight of the animal. † signifies a difference $(p<0.05)$ from young adult diet-matched muscles. (B) Data are expressed as the mean \pm SEM of the relative difference between the maximal isometric force on the first contraction and the force produced on subsequent contractions. All force measurements were normalized to body weight. * indicates a significant difference $(p<0.05)$ in the aged non-supplemented control and resveratrol supplemented diet from young nonsupplemented control diet. $¥$ indicates a significant difference $(p<0.05)$ in the young adult animals in the resveratrol supplemented diet group, from animals in the young adult nonsupplemented control diet group. (C-F) Representative force $x$ time curves from the third consecutive exercise session in the resveratrol treated young adult and aged animals. Force (in grams) is shown on the $y$-axis and time (in seconds) is shown on the x-axis. (C) First contraction of the $3^{\text {rd }}$ day in a young adult animal. (D) Twentieth contraction of the $3^{\text {rd }}$ day in a young adult animal. (E) First contraction of the $3^{\text {rd }}$ day in an aged animal. (F) Twentieth contraction of the third day in an aged animal.

Figure 5.2

Resveratrol attenuated the increase in hydrogen peroxide $\left(\mathrm{H}_{2} \mathrm{O}_{2}\right)$ concentration associated with exercise and aging. The $\mathrm{H}_{2} \mathrm{O}_{2}$ concentration was determined fluorometrically in muscles of mice after three days of isometric exercise. The animals were fed a control diet, or a diet containing $0.05 \%$ resveratrol. Data are expressed as relative fluorescent units (RFU) per $\mathrm{mg}$ of total protein in the gastrocnemius homogenate. The normalized data are presented as mean \pm SEM. * significant difference $(p<0.05)$ of isometrically exercised muscle from contralateral control muscle; $\dagger$ a significant difference $(p<0.05)$ from young exercise and diet-matched control muscles; $\S$ significant difference $(p<0.05)$ from age-matched animals on the nonsupplemented diet.

\section{Figure 5.3}

Resveratrol attenuated the increase in xanthine oxidase and hypoxanthine.

Relative concentrations of hypoxanthine $(\mathbf{A})$ and enzymatic activity of xanthine oxidase (B) were determined fluorometrically. Data are expressed as $\mu$ moles of hypoxanthine per mg protein or relative fluorescent units (RFU) per mg of total protein in gastrocnemius homogenates. The normalized data are presented as mean \pm SEM. * significant difference $(p<0.05)$ between isometrically exercised muscles from contra-lateral control muscles; $\dagger$ a significant difference $(p<0.05)$ from young exercised and diet-matched control muscles; $\S$ significant difference $(p<0.05)$ from age-matched animals in the control (non-supplemented) diet group.

\section{Figure 5.4}

Total glutathione content \& ratio of reduced glutathione to oxidized glutathione (GSH/GSSG). (A) Data indicate total glutathione concentration normalized to total protein content. (B) Data are depicted as the ratio of GSH to GSSG normalized to total protein content. Lower GSH/GSSG ratios are an indication of increased oxidative stress. The normalized data are presented as mean \pm SEM. * significant difference $(p<0.05)$ of isometrically exercised muscle from contra-lateral control muscle; $\dagger$ a significant difference $(p<0.05)$ from young exercise and diet-matched control muscles; $\S$ significant difference $(p<0.05)$ from age-matched animals on the non-supplemented diet. 
Figure 5.5

Resveratrol supplementation decreased lipid peroxidation associated with isometric exercise, but not aging. The level of lipid peroxidation was estimated from malondialdehyde (MDA) plus 4-hydroxyalkenals (HAE) levels that were normalized to total protein content in the muscle sample. The normalized data are presented as mean \pm SEM. *, significant difference $(p<0.05)$ of isometrically exercised muscles from contra-lateral control muscles; $\dagger$, a significant difference $(p<0.05)$ from young exercised and diet-matched control muscles; $\S$, significant difference $(p<0.05)$ from age-matched animals on the non-supplemented diet.

Figure 5.6

Glutathione peroxidase (GPx) activity, GPx-1 mRNA, catalase activity and catalase mRNA regulation with isometric exercise and resveratrol supplementation (A) Total GPx activity is expressed as $\mathrm{mU}$ of GPx per $\mathrm{ml}$ of homogenate normalized per $\mathrm{mg}$ of protein in homogenate. (B) GPx-1 mRNA expression was determined by RT-PCR. The data are expressed as optical density (OD) $x$ band area, and expressed as a relative optical density. The inserts show representative gels for GPx-1 mRNA and 18s rRNA in young and aged (control and isometric exercised) gastrocnemius muscle. (C) Total catalase activity is expressed as $n M$ of activity per min normalized per mg of protein in the homogenate. (D) Catalase mRNA expression was determined by RT-PCR. The data are expressed as optical density (OD) $x$ band area, and expressed as a relative optical density. The inserts show representative gels for catalase mRNA and 18s mRNA in muscles from young and aged (control and isometrically exercised) mice. For all graphs the data are presented as mean $\pm \mathrm{SEM}$; *, significant difference $(p<0.05)$ of isometrically exercised muscles from contra-lateral control muscles; $\dagger$, a significant difference $(p<0.05)$ from young exercise and diet-matched control muscles; $\S$, significant difference $(p<0.05)$ from age-matched animals on the non-supplemented diet. YCC, Youngcontrol diet-control non-exercise; YCE, Young- control diet-exercised; YRC, Young-resveratrolcontrol non-exercise; YRE, Young-resveratrol-exercised; ACC, Aged-control diet-control nonexercise; ACE, Aged- control diet-exercised; ARC, Aged-resveratrol-control non-exercised; ARE, Aged-resveratrol-exercised.

\section{Figure 5.7}

Superoxide dismutase activity and mRNA regulation with isometric exercise and resveratrol supplementation. (A) Copper-Zinc superoxide (CuZnSOD) activity was expressed as $U$ of CuZnSOD per mg of protein in the homogenate. A unit was defined as the amount of enzyme needed to exhibit $50 \%$ dismutation of the superoxide radical. (B) CuZnSOD mRNA expression was determined by RT-PCR. The data are expressed as optical density (OD) $x$ band area, and reported as relative optical density. The inserts show representative gels for CuZnSOD mRNA and 18s rRNA in gastrocnemius muscles from young and aged (control and isometric exercised) mice. (C) Manganese superoxide dismutase (MnSOD) activity was determined expressed as $U$ of MnSOD per mg of protein in homogenate. A unit was defined as the amount of enzyme needed to exhibit $50 \%$ dismutation of the superoxide radical. (D) MnSOD mRNA expression was determined by RT-PCR. The data are expressed as optical density (OD) $x$ band area, and expressed as relative optical density. The inserts show representative gels for MnSOD mRNA and 18s rRNA in gastrocnemius muscles from young and aged (control and isometric exercised) mice. For all graphs the normalized data are presented as mean \pm SEM; * , significant difference $(p<0.05)$ of isometrically exercised muscles from contra-lateral control muscles; $\dagger$, a significant difference $(p<0.05)$ from young exercise and dietmatched control muscles; $\S$, significant difference $(p<0.05)$ from age-matched animals on the non-supplemented diet. YCC, Young-control diet-control non-exercise; YCE, Young- control diet-exercised; YRC, Young-resveratrol-control non-exercise; YRE, Young-resveratrolexercised; ACC, Aged-control diet-control non-exercise; ACE, Aged-control diet-exercised; ARC, Aged-resveratrol-control non-exercised; ARE, Aged-resveratrol-exercised. 
Figure 5.1

A

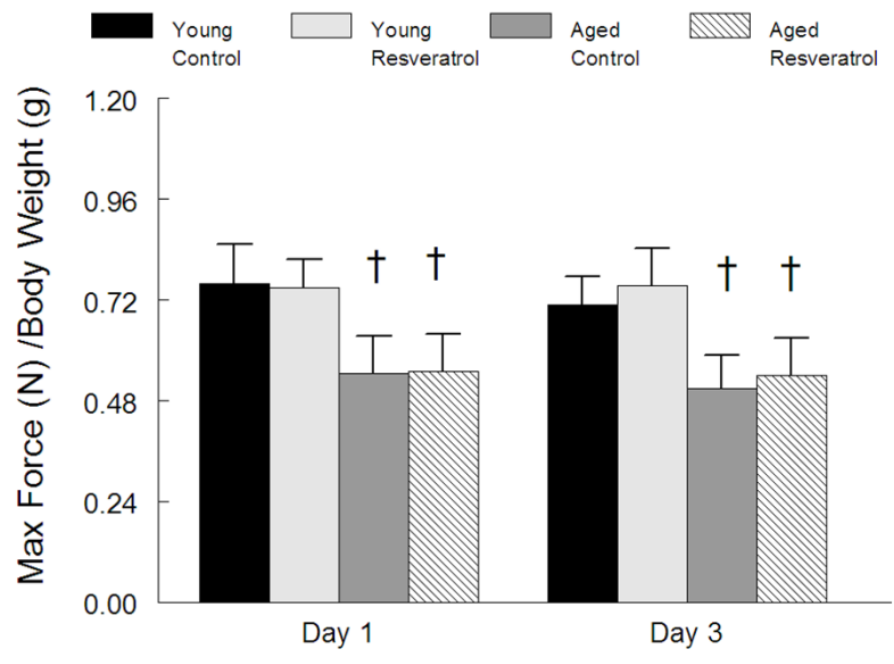

B Decline in Maximal Isometric Force Each Contraction of 3rd Day

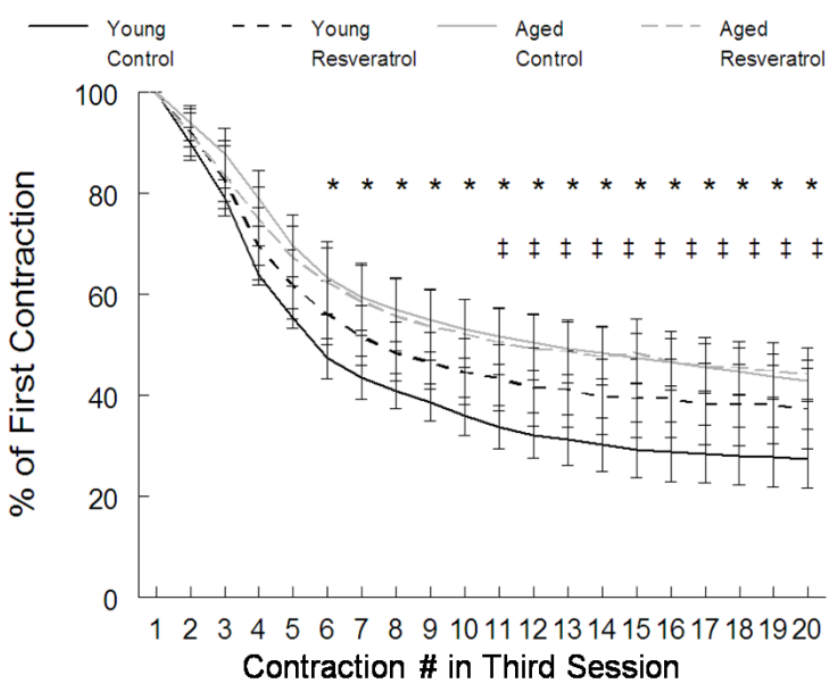

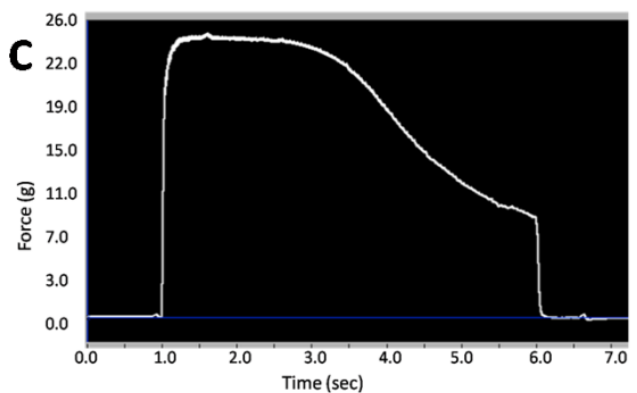
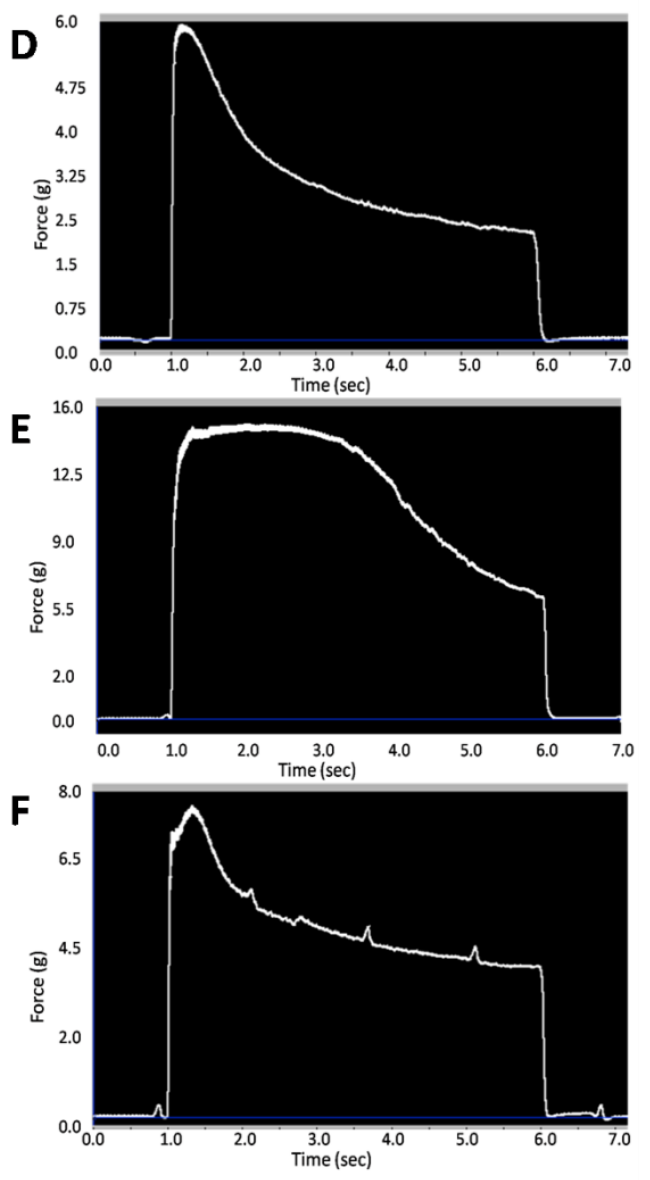
Figure 5.2

\section{Hydrogen Peroxide}

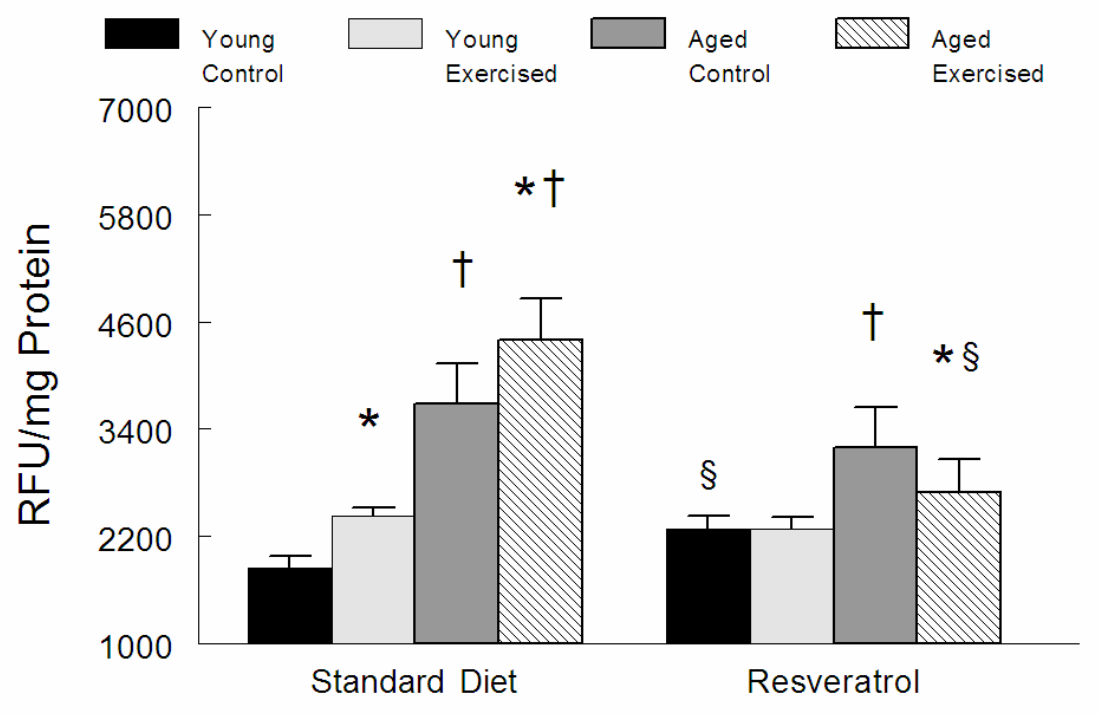


Figure 5.3
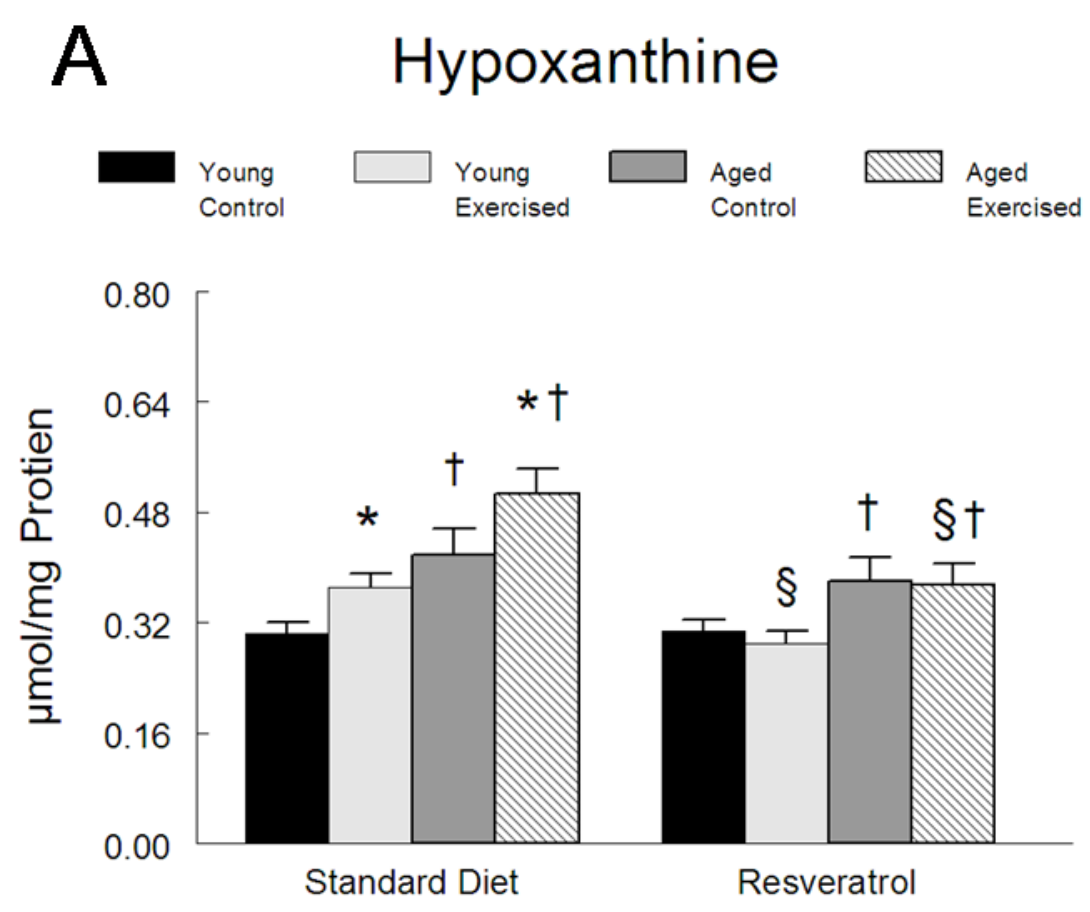

\section{B Xanthine Oxidase}

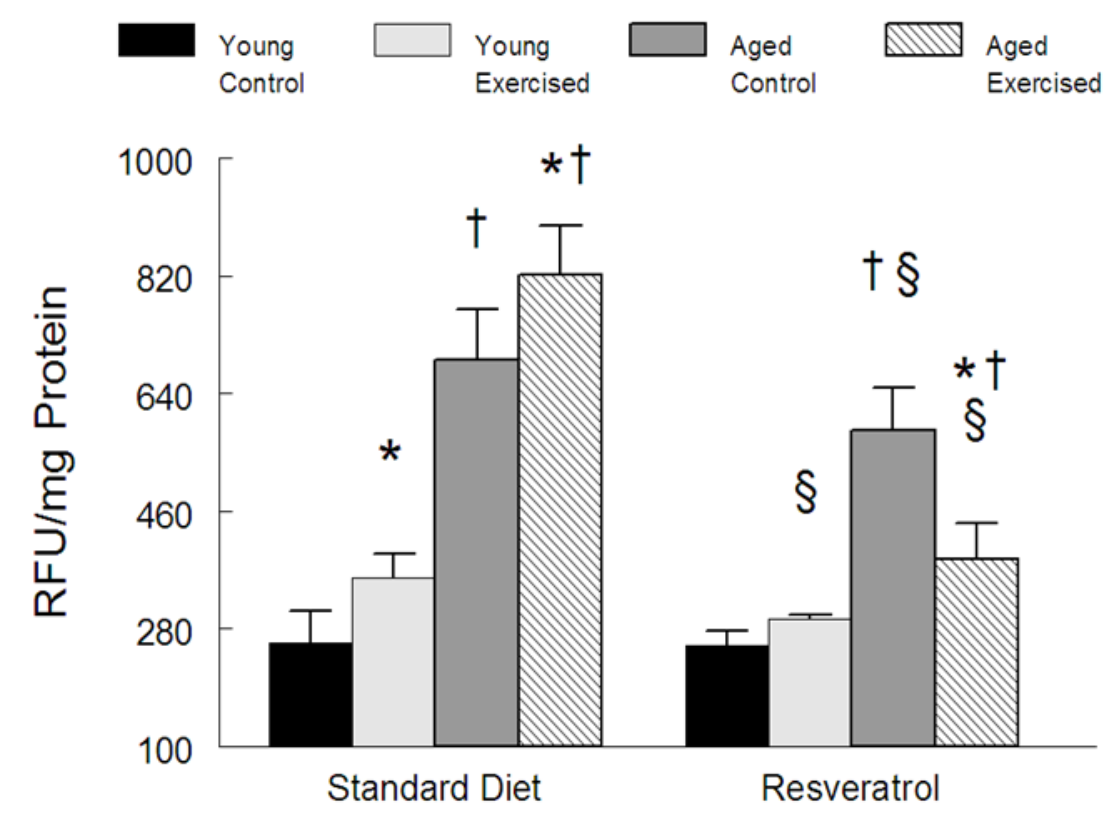


Figure 5.4
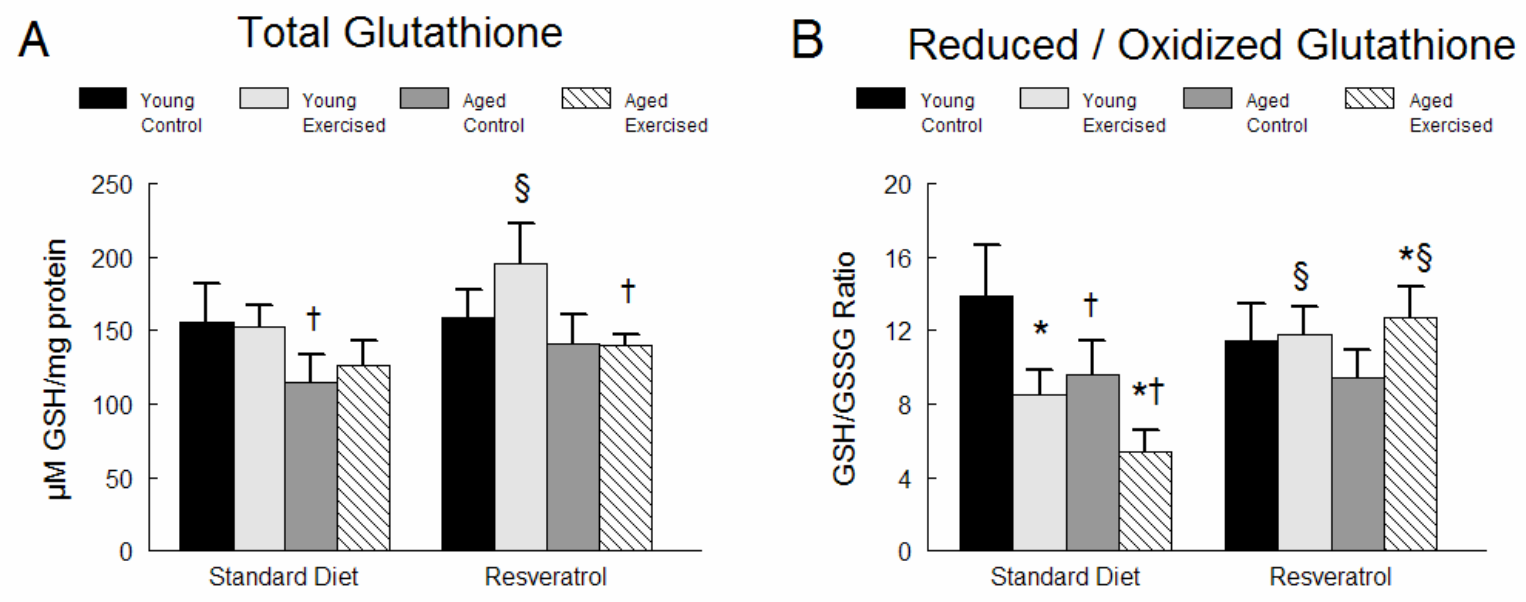

Figure 5.5

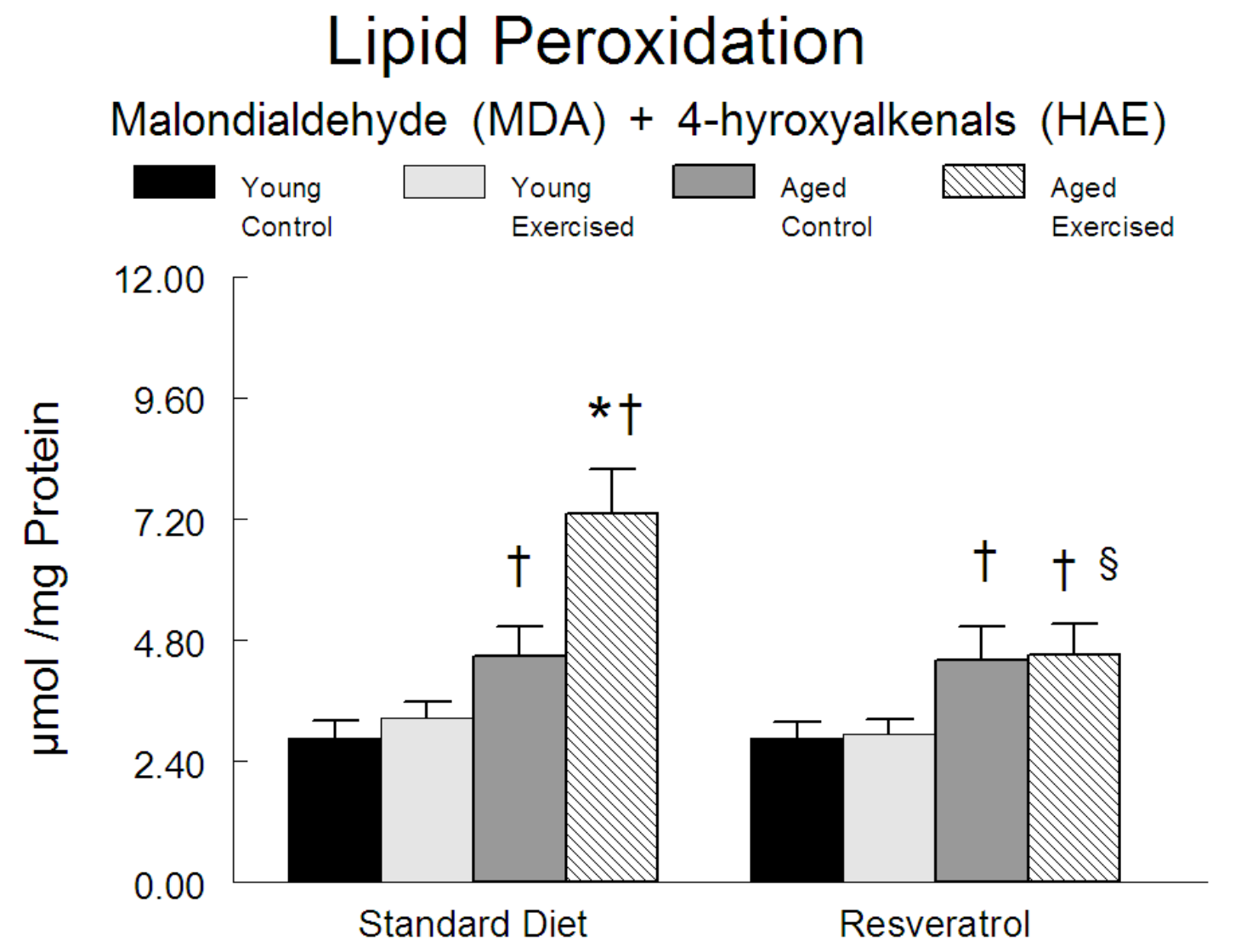


Figure 5.6

A Glutathione Peroxidase Activity
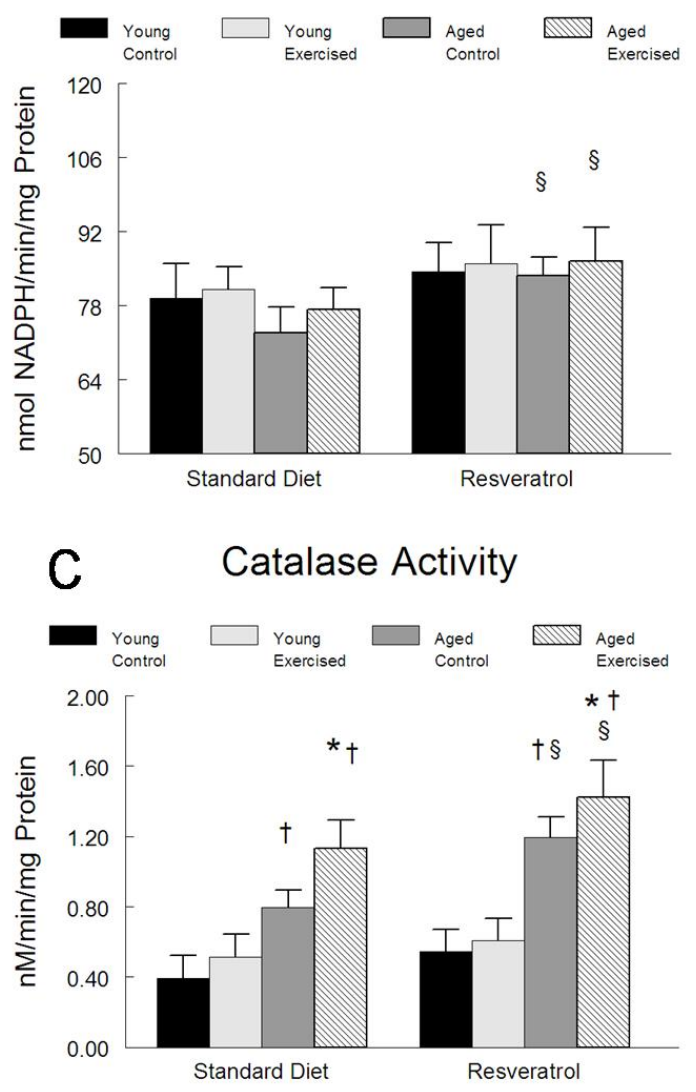

B Glutathione Peroxidase-1 mRNA

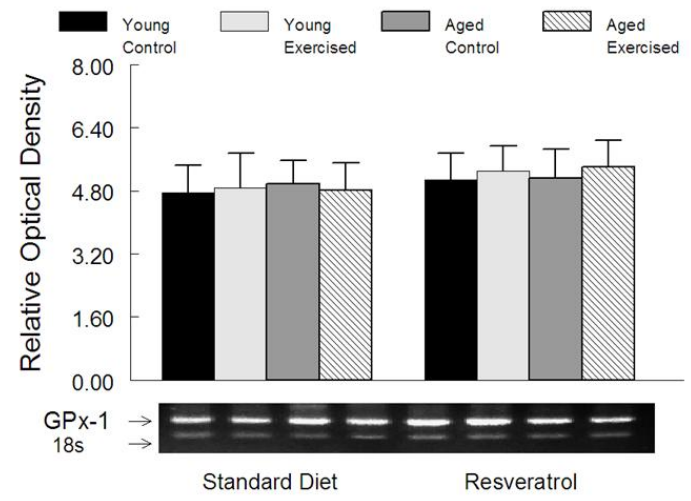

D Catalase mRNA

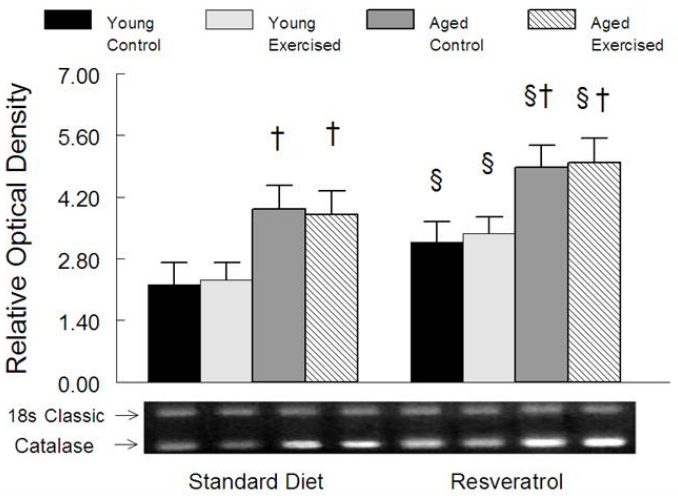


Figure 5.7
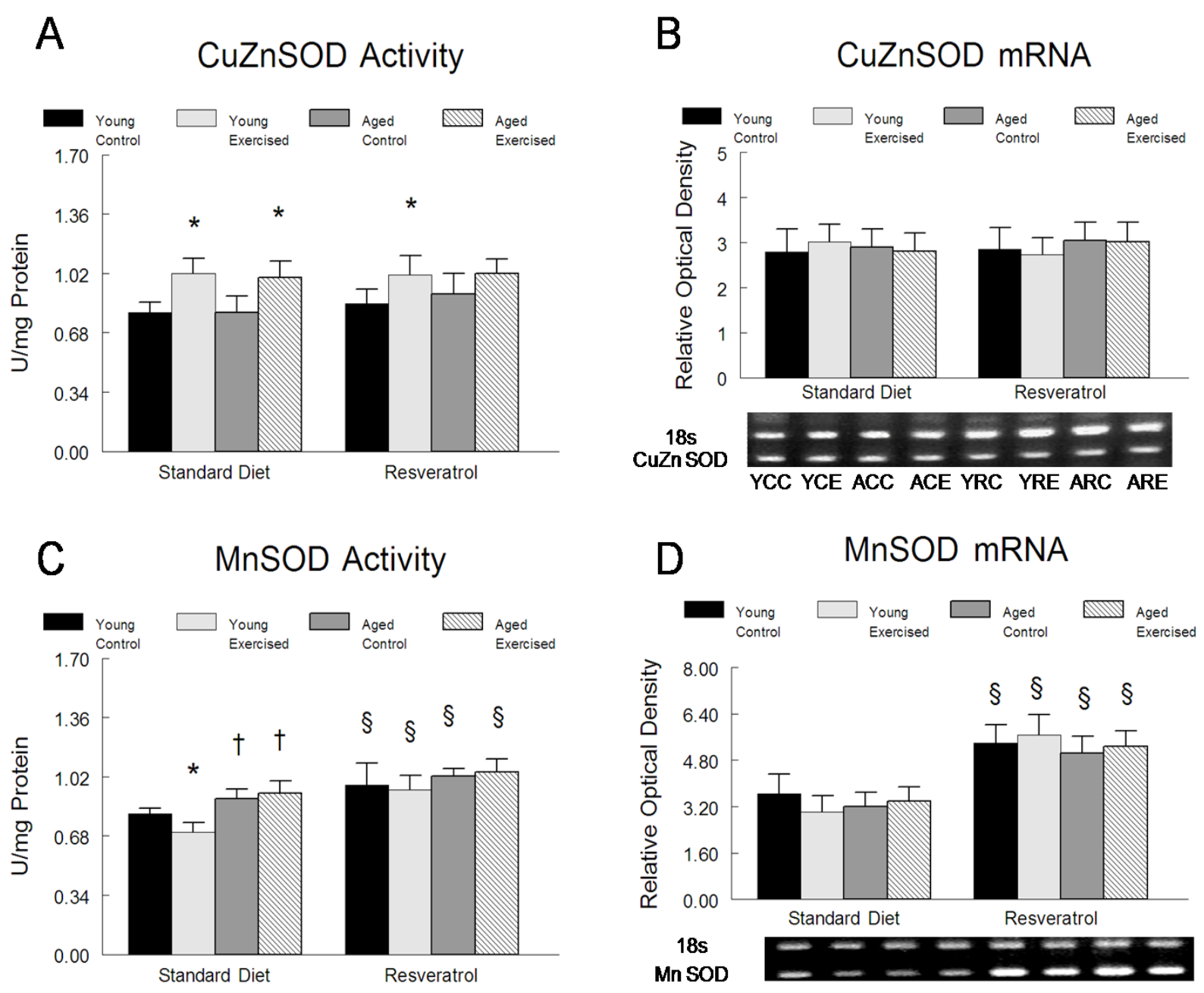

YCC YCE ACC ACE YRC YRE ARC ARE 
Reference List

1. Alway SE. Is fiber mitochondrial volume density a good indicator of muscle fatigability to isometric exercise? J Appl Physiol 70: 2111-2119, 1991.

2. Andrade FH, Reid MB, Allen DG and Westerblad H. Effect of hydrogen peroxide and dithiothreitol on contractile function of single skeletal muscle fibres from the mouse. $J$ Physiol 509 ( Pt 2): 565-575, 1998.

3. Aranda R, Domenech E, Rus AD, Real JT, Sastre J, Vina J and Pallardo FV. Agerelated increase in xanthine oxidase activity in human plasma and rat tissues. Free Radic Res 41: 1195-1200, 2007.

4. Baker BA, Mercer RR, Geronilla KB, Kashon ML, Miller GR and Cutlip RG. Stereological analysis of muscle morphology following exposure to repetitive stretchshortening cycles in a rat model. Appl Physiol Nutr Metab 31: 167-179, 2006.

5. Baur JA, Pearson KJ, Price NL, Jamieson HA, Lerin C, Kalra A, Prabhu VV, Allard JS, Lopez-Lluch G, Lewis K, Pistell PJ, Poosala S, Becker KG, Boss O, Gwinn D, Wang M, Ramaswamy S, Fishbein KW, Spencer RG, Lakatta EG, Le Couteur D, Shaw RJ, Navas P, Puigserver P, Ingram DK, de Cabo R and Sinclair DA. Resveratrol improves health and survival of mice on a high-calorie diet. Nature 444: 337-342, 2006.

6. Bejma $\mathbf{J}$ and $\mathbf{J i} \mathbf{L L}$. Aging and acute exercise enhance free radical generation in rat skeletal muscle. J Appl Physiol 87: 465-470, 1999.

7. Bianchi GP, Grossi G, Bargossi AM, Fiorella PL and Marchesini G. Can oxypurines plasma levels classify the type of physical exercise? J Sports Med Phys Fitness 39: 123127, 1999.

8. Bisht K, Wagner KH and Bulmer AC. Curcumin, resveratrol and flavonoids as antiinflammatory, cyto- and DNA-protective dietary compounds. Toxicology 2009.

9. Bradamante S, Barenghi L and Villa A. Cardiovascular protective effects of resveratrol. Cardiovasc Drug Rev 22: 169-188, 2004.

10. Brito $\mathbf{P}$, Almeida $\mathbf{L M}$ and Dinis TC. The interaction of resveratrol with ferrylmyoglobin and peroxynitrite; protection against LDL oxidation. Free Radic Res 36: 621-631, 2002.

11. Chen CN, Brown-Borg HM, Rakoczy SG, Ferrington DA and Thompson LV. Aging impairs the expression of the catalytic subunit of glutamate cysteine ligase in soleus muscle under stress. J Gerontol A Biol Sci Med Sci 65: 129-137, 2010.

12. Degens $\mathbf{H}$ and Alway SE. Control of muscle size during disuse, disease, and aging. Int $J$ Sports Med 27: 94-99, 2006.

13. Eskurza I, Kahn ZD and Seals DR. Xanthine oxidase does not contribute to impaired peripheral conduit artery endothelium-dependent dilatation with ageing. J Physiol 571: 661-668, 2006. 
14. Figueiredo PA, Powers SK, Ferreira RM, Appell HJ and Duarte JA. Aging impairs skeletal muscle mitochondrial bioenergetic function. $J$ Gerontol A Biol Sci Med Sci 64: 2133, 2009.

15. Fulle S, Protasi F, Di Tano G, Pietrangelo T, Beltramin A, Boncompagni S, Vecchiet $\mathbf{L}$ and Fano $\mathbf{G}$. The contribution of reactive oxygen species to sarcopenia and muscle ageing. Experimental Gerontology 39: 17-24, 2004.

16. Harman D. Aging: a theory based on free radical and radiation chemistry. $J$ Gerontol 11 : 298-300, 1956.

17. Hellsten $\mathbf{Y}$, Hansson HA, Johnson L, Frandsen $\mathbf{U}$ and Sjodin B. Increased expression of xanthine oxidase and insulin-like growth factor I (IGF-I) immunoreactivity in skeletal muscle after strenuous exercise in humans. Acta Physiol Scand 157: 191-197, 1996.

18. Hofer T, Marzetti E, Xu J, Seo AY, Gulec S, Knutson MD, Leeuwenburgh C and Dupont-Versteegden EE. Increased iron content and RNA oxidative damage in skeletal muscle with aging and disuse atrophy. Exp Gerontol 43: 563-570, 2008.

19. Hollander J, Bejma J, Ookawara T, Ohno H and Ji LL. Superoxide dismutase gene expression in skeletal muscle: fiber-specific effect of age. Mech Ageing Dev 116: 33-45, 2000.

20. Hollander J, Bejma J, Ookawara T, Ohno H and Ji LL. Superoxide dismutase gene expression in skeletal muscle: fiber-specific effect of age. Mech Ageing Dev 116: 33-45, 2000.

21. Hollander J, Bejma J, Ookawara T, Ohno H and Ji LL. Superoxide dismutase gene expression in skeletal muscle: fiber-specific effect of age. Mech Ageing Dev 116: 33-45, 2000.

22. Holloszy JO, Chen M, Cartee GD and Young JC. Skeletal muscle atrophy in old rats: differential changes in the three fiber types. Mech Ageing Dev 60: 199-213, 1991.

23. Houston M, Estevez A, Chumley P, Aslan M, Marklund S, Parks DA and Freeman BA. Binding of xanthine oxidase to vascular endothelium. Kinetic characterization and oxidative impairment of nitric oxide-dependent signaling. J Biol Chem 274: 4985-4994, 1999.

24. Huang XF, Li HQ, Shi L, Xue JY, Ruan BF and Zhu HL. Synthesis of resveratrol analogues, and evaluation of their cytotoxic and xanthine oxidase inhibitory activities. Chem Biodivers 5: 636-642, 2008.

25. Ji LL, Leeuwenburgh C, Leichtweis S, Gore M, Fiebig R, Hollander J and Bejma J. Oxidative stress and aging. Role of exercise and its influences on antioxidant systems. Ann N Y Acad Sci 854: 102-117, 1998.

26. Jia Z, Zhu H, Misra BR, Mahaney JE, Li Y and Misra HP. EPR studies on the superoxide-scavenging capacity of the nutraceutical resveratrol. Mol Cell Biochem 313: 187-194, 2008. 
27. Kaneko T, Tahara S, Taguchi T and Kondo H. Accumulation of oxidative DNA damage, 8-oxo-2'-deoxyguanosine, and change of repair systems during in vitro cellular aging of cultured human skin fibroblasts. Mutat Res 487: 19-30, 2001.

28. Kondo H, Kodama J, Kishibe T and Itokawa Y. Oxidative Stress During Recovery from Muscle Atrophy. FEBS Lett 326: 189-191, 1993.

29. Kondo H, Miura M and Itokawa Y. Antioxidant Enzyme-Systems in Skeletal-Muscle Atrophied by Immobilization. Pflugers Arch 422: 404-406, 1993.

30. Kryger Al and Andersen JL. Resistance training in the oldest old: consequences for muscle strength, fiber types, fiber size, and MHC isoforms. Scand J Med Sci Sports 17: 422-430, 2007.

31. Kumar A, Kaundal RK, lyer S and Sharma SS. Effects of resveratrol on nerve functions, oxidative stress and DNA fragmentation in experimental diabetic neuropathy. Life Sci 80: 1236-1244, 2007.

32. Lagouge M, Argmann C, Gerhart-Hines Z, Meziane H, Lerin C, Daussin F, Messadeq N, Milne J, Lambert P, Elliott P, Geny B, Laakso M, Puigserver P and Auwerx J. Resveratrol improves mitochondrial function and protects against metabolic disease by activating SIRT1 and PGC-1alpha. Cell 127: 1109-1122, 2006.

33. McArdle A and Jackson MJ. Exercise, oxidative stress and ageing. J Anat 197 Pt 4: 539$541,2000$.

34. Meng $\mathbf{Q}$, Wong $\mathbf{Y T}$, Chen $\mathbf{J}$ and Ruan $\mathbf{R}$. Age-related changes in mitochondrial function and antioxidative enzyme activity in fischer 344 rats. Mech Ageing Dev 128: 286-292, 2007.

35. Muller FL, Song W, Liu YH, Chaudhuri A, Pieke-Dahl S, Strong R, Huang TT, Epstein CJ, Roberts LJ, Csete M, Faulkner JA and Van Remmen H. Absence of CuZn superoxide dismutase leads to elevated oxidative stress and acceleration of agedependent skeletal muscle atrophy. Free Radic Biol Med 40: 1993-2004, 2006.

36. Pansarasa $\mathbf{O}$, Felzani $\mathbf{G}$, Vecchiet $\mathbf{J}$ and Marzatico $\mathbf{F}$. Antioxidant pathways in human aged skeletal muscle: relationship with the distribution of type II fibers. Exp Gerontol 37: 1069-1075, 2002.

37. Pearson KJ, Baur JA, Lewis KN, Peshkin L, Price NL, Labinskyy N, Swindell WR, Kamara D, Minor RK, Perez E, Jamieson HA, Zhang Y, Dunn SR, Sharma K, Pleshko N, Woollett LA, Csiszar A, Ikeno Y, Le Couteur D, Elliott PJ, Becker KG, Navas P, Ingram DK, Wolf NS, Ungvari Z, Sinclair DA and de Cabo R. Resveratrol delays agerelated deterioration and mimics transcriptional aspects of dietary restriction without extending life span. Cell Metab 8: 157-168, 2008.

38. Reid MB. Free radicals and muscle fatigue: Of ROS, canaries, and the IOC. Free Radic Biol Med 44: 169-179, 2008.

39. Robb EL, Winkelmolen L, Visanji N, Brotchie J and Stuart JA. Dietary resveratrol administration increases MnSOD expression and activity in mouse brain. Biochem Biophys Res Commun 372: 254-259, 2008. 
40. Roman WJ, Fleckenstein J, Straygundersen J, Alway SE, Peshock R and Gonyea WJ. Adaptations in the Elbow Flexors of Elderly Males After Heavy-Resistance Training. $J$ Appl Physiol 74: 750-754, 1993.

41. Ryan MJ, Dudash HJ, Docherty M, Geronilla KB, Baker BA, Haff GG, Cutlip RG and Alway SE. Aging-Dependent Regulation of Antioxidant Enzymes and Redox Status in Chronically Loaded Rat Dorsiflexor Muscles. J Gerontol A Biol Sci Med Sci 63: 1015-1026, 2008.

42. Sachdev S and Davies KJA. Production, detection, and adaptive responses to free radicals in exercise. Free Radic Biol Med 44: 215-223, 2008.

43. Sahlin $\mathbf{K}$, Tonkonogi $\mathbf{M}$ and Soderlund $\mathbf{K}$. Plasma hypoxanthine and ammonia in humans during prolonged exercise. Eur J Appl Physiol Occup Physiol 80: 417-422, 1999.

44. Siu PM and Alway SE. Mitochondria-associated apoptotic signalling in denervated rat skeletal muscle. J Physiol 565: 309-323, 2005.

45. Smith JJ, Kenney RD, Gagne DJ, Frushour BP, Ladd W, Galonek HL, Israelian K, Song J, Razvadauskaite G, Lynch AV, Carney DP, Johnson RJ, Lavu S, Iffland A, Elliott PJ, Lambert PD, Elliston KO, Jirousek MR, Milne JC and Boss O. Small molecule activators of SIRT1 replicate signaling pathways triggered by calorie restriction in vivo. BMC Syst Biol 3: 31, 2009.

46. Stojanovic S, Sprinz $\mathbf{H}$ and Brede O. Efficiency and mechanism of the antioxidant action of trans-resveratrol and its analogues in the radical liposome oxidation. Arch Biochem Biophys 391: 79-89, 2001.

47. Vina J, Gimeno A, Sastre J, Desco C, Asensi M, Pallardo FV, Cuesta A, Ferrero JA, Terada LS and Repine JE. Mechanism of free radical production in exhaustive exercise in humans and rats; role of xanthine oxidase and protection by allopurinol. IUBMB Life 49: 539-544, 2000.

48. Wenzel E, Soldo T, Erbersdobler H and Somoza V. Bioactivity and metabolism of transresveratrol orally administered to Wistar rats. Mol Nutr Food Res 49: 482-494, 2005.

49. Zhang Y, Ikeno Y, Qi W, Chaudhuri A, Li Y, Bokov A, Thorpe SR, Baynes JW, Epstein C, Richardson A and Van RH. Mice deficient in both Mn superoxide dismutase and glutathione peroxidase-1 have increased oxidative damage and a greater incidence of pathology but no reduction in longevity. J Gerontol A Biol Sci Med Sci 64: 1212-1220, 2009. 


\section{Chapter 6}

\section{Inhibition of xanthine oxidase reduces oxidative stress and improves muscle function in exercised skeletal muscle from aged mice}

Michael J. Ryan, Janna R. Jackson and Stephen E. Alway

Laboratory of Muscle Biology and Sarcopenia, Division of Exercise Physiology, West

Virginia University School of Medicine, Morgantown, West Virginia 26506 


\begin{abstract}
Oxidative stress is a putative factor responsible for reducing function and increasing apoptotic signaling in skeletal muscle with aging. This study examined the contribution and functional significance of the xanthine oxidase enzyme as a potential source of oxidant production in aged skeletal muscle during repetitive isometric exercise. Xanthine oxidase activity was inhibited in young adult and aged mice via a subcutaneously placed time release (2.5 $\mathrm{mg} / \mathrm{day})$ allopurinol pellet, 7 days prior to the start of exercise. Mice were anesthetized, then the left posterior tibial nerve was subjected to 20, five second square wave pulses (10v, $100 \mathrm{~Hz}, 200 \mu$ s pulses), with 25 seconds between stimulus trains to produce maximal isometric contractions of the plantar flexor muscle group. The exercise was repeated for three consecutive days; the contralateral limb served as an intra-animal control. A force $x$ time curve was obtained for each isometric contraction. Compared to young mice, xanthine oxidase activity was greater in the gastrocnemius muscle of aged mice (65\%) and it increased after isometric exercise in muscles from both young (33\%) and aged (28\%) mice. Allopurinol treatment attenuated the exercise-induced increase in oxidative stress, but it did not affect elevated basal levels of oxidative stress associated with aging. Furthermore, inhibition of xanthine oxidase activity decreased caspase-3 activity, but had no effect on other markers of mitochondrial associated apoptosis. Additionally, the inhibition of xanthine oxidase increased maximal isometric force in the plantar flexor muscles from aged mice (35\%). Our results suggest that repetitive isometric contractions increased xanthine oxidase activity, which contributes to exercise-induced oxidative stress in muscles of aged mice.
\end{abstract}




\section{Introduction}

The fundamental mechanisms contributing to aging are poorly understood, but a large body of evidence supports the hypothesis that oxidative stress (21) contributes to aging in many tissues. Oxidative stress occurs when the cellular production of oxidants exceeds the physiological buffering capacity of the tissue. Increases in oxidative stress have been proposed as a principal component leading to skeletal muscle loss with aging (sarcopenia). Loss of myonuclei via apoptosis is another likely contributor to sarcopenia. However, oxidative stress and apoptosis may not be mutually exclusive events with aging. Rather, the elevation in oxidative stress that occurs with aging can regulate redox-sensitive signaling pathways $(31,33$, 38 ), increase catabolic gene expression $(11,40,42,64)$, and activate apoptotic pathways (35, $41,60)$, thereby contributing to the progression of sarcopenia.

Mitochondria are a major source of oxidant production in skeletal muscle $(5,46)$. The consequence of prolonged exposure to relatively high levels of oxidants reduces mitochondrial membrane integrity and antioxidant enzyme activity (46). In addition, oxidants can lead to increased mitochondria permeability and the release of mitochondria specific proteins including, apoptosis inducing factor (AIF) and cytochrome $c$ into the cytosol through the mitochondrial transition pore. AIF release initiates a caspase independent pathway, while cytosolic cytochrome $\mathrm{c}$ initiates the caspase cascade resulting in DNA fragmentation and myonuclear apoptosis. Thus, mitochondria may be important for regulation of both oxidative stress and apoptotic signaling in aging skeletal muscle.

The functional implications of elevated oxidative stress in skeletal muscle include reduced muscle specific force (7), altered myofilament function $(2,37)$, and elevated muscle fatigue (54). Although exercise is used as a strategy to attempt to reduce sarcopenia and improve muscle function, acute exercise will also increase free radical generation in skeletal muscle (9). This has important implications in a highly metabolic tissue such as skeletal muscle, where basal oxidant production is already increased with aging and exercise has the potential to further increase oxidant production by as much as $80 \%$ (5).

There are three major sources of oxidant production with exercise. These include infiltrating immune cells, mitochondrial respiration and xanthine oxidase activity (39). The magnitude and the sources of oxidant production are dependent on the mode, duration and intensity of exercise. Increased xanthine oxidase activity within the vascular endothelium (28), is a contributing factor associated with oxidative stress and damage during exhaustive exercise (4, $14,22,58,63)$. Allopurinol, which is a structural isomer of hypoxanthine, acts as a competitive inhibitor to xanthine oxidase protecting cells from oxidative damage associated with exhaustive exercise (63). It has been hypothesized that the activation of the enzyme, xanthine oxidase, during exhaustive exercise is similar to the process observed during ischemia-reperfusion injury $(44,51,63)$. During repetitive muscle contractions, the combination of increased ATP utilization and intermittent localized periods of ischemia due to muscle contractions will facilitate adenine nucleotide degradation and accumulation of hypoxanthine (See Figure 6.1).

Subsequent to the elevation in hypoxanthine, xanthine dehydrogenase is converted to xanthine oxidase either reversibly by oxidation, or irreversibly via proteolysis $(8,48)$. Conversion of xanthine dehydrogenase to xanthine oxidase has been shown to be dependent on both calcium and oxidant concentrations (45). During muscle contractions, intracellular calcium concentrations are elevated, which in turn, may activate proteases that cause the irreversible conversion of xanthine dehydrogenase to xanthine oxidase. Furthermore, increased 
oxidant production may lead to the oxidation of cysteine residues on xanthine dehydrogenase forming disulfide bonds resulting in the reversible conversion to xanthine oxidase (48).

During muscle relaxation the influx of oxygen rich blood catalyzes the reaction of xanthine oxidase with hypoxanthine and oxygen to from xanthine and superoxide. Within the muscle environment, $\mathrm{H}_{2} \mathrm{O}_{2}$ concentrations are expected to increase via the accumulation of superoxide formed by xanthine oxidase activity, mitochondrial sources and NADPH oxidase activity, since the superoxide anion is quickly dismutated to $\mathrm{H}_{2} \mathrm{O}_{2}$ by SOD. Decreases in antioxidant capacity with aging and exercise may lead to an increase in contractile protein and mitochondrial damage caused by an augmented duration and exposure to oxidants thus potentially accelerating muscle loss $(30,47,66)$.

Xanthine oxidase has been reported to make important contributions to oxidative stress in the heart $(59)$ and gastrocnemius muscles $(3,18,57)$ from aged rodents; however, this agedependent elevation in xanthine oxidase activity is not observed universally (15). Xanthine oxidase activity contributes, at least in part, to an increase in oxidant production during exhaustive exercise, but it is not known if xanthine oxidase is an important source of oxidant production with moderate exercise aged animals. Therefore, the purpose of this investigation was to determine the contribution of the xanthine oxidase enzyme as a source of oxidant production during repetitive isometric exercise and to determine if it further contributes to oxidative stress in aged skeletal muscle. A second aim of this study was to determine if increased xanthine oxidase levels plays a role in regulating the decreased functional capacity and increased apoptotic signaling in aged muscles. We tested the hypothesis that the inhibition of xanthine oxidase will improve the redox environment within muscle by reducing oxidative stress and thus preserving functional capacity in aged animals after isometric exercise. The second hypothesis tested was that xanthine oxidase-associated oxidative stress will exacerbate the release of pro-apoptotic mitochondrial proteins into the cytosol resulting in increased apoptotic signaling in aged skeletal muscle after exercise but decreasing xanthine oxidase activity by allopurinol will prevent these negative changes in aging muscles.

\section{Methods}

All experimental procedures were carried out with approval from the Institutional Animal Use and Care Committee from West Virginia University School of Medicine. The animal care standards were followed by adhering to the recommendations for the care of laboratory animals as advocated by the American Association for Accreditation of Laboratory Animal Care (AAALAC) and fully conformed to the American Physiological Society's "Guiding Principles for Research Involving Animals and Human Beings."

A subcutaneous $2.5 \mathrm{mg} 21$ day release allopurinol pellet (Innovative Research of America Inc., Sarasota, FI) was implanted subcutaneously over the dorsal cervical column in anesthetized mice (Isotec 5, Ohmeda; $3 \%$ isoflurane $/ 97 \% \mathrm{O}_{2}$ ), seven days prior to the start of the exercise protocol. The incision was closed with a $9 \mathrm{~mm}$ wound clip. A sham surgery was performed on control animals. A total of 32 young adult (3-5 months) and 32 aged (26-28 months) C57BL/6 mice were randomly separated into groups receiving the allopurinol pellet, or only the sham surgery ( $n=16$ per treatment group). Each treatment group was randomly divided into groups of eight animals, where the gastrocnemius muscles from one group of eight were individually processed for whole muscle homogenate and RNA isolation while the gastrocnemius muscles from the other eight animals of the treatment group were individually homogenized and separated into a mitochondrial fraction and a mitochondrial free cytosolic fraction. 
Isometric exercises were conducted on a custom-built mouse dynamometer that has been previously described (57). Briefly, mice were anesthetized with a mixture of oxygen (97\%) and isoflurane gas (3\%) and placed on their right side on a heated plate. The left ankle was positioned at $90^{\circ}$ of flexion and was aligned with the axis of rotation of the servomotor (Cambridge Technology Inc. Model 6350^350, Cambridge, MA). The foot was secured to the foot plate connected to the servomotor. Dynamic Muscle Control software (Aurora Scientific Inc., Aurora, Ontario, Canada) controlled a servomotor providing for the angular position of the foot. Muscle contractions of the plantar flexor muscles were stimulated via subcutaneously placing platinum electrodes (Grass Medical Instruments) on either side of the tibial nerve. Electrode placement was tested via a short stimulation of the nerve to cause plantar flexion. Electrode placement was assumed to be correct when the foot would plantar flex without any visible appearance of eversion, or inversion, of the foot. Twenty electrically evoked (10v, 100 $\mathrm{Hz}, 200 \mu \mathrm{s}$ pulses) isometric contractions of the plantar flexor muscle group were obtained in one limb. Each contraction train lasted for five seconds, and a 25 second recovery period occurred between subsequent contractions. Isometric contractions were conducted over three consecutive days in the left limb, while the contralateral limb served as the intra-animal control. Muscle functional data was collected as a force $x$ time curve during isometric contractions for each session and values were normalized to each animal's body weight. The contractile data were analyzed by Dynamic Muscle Analysis software (Aurora Scientific Inc., Aurora, Ontario, Canada).

Mitochondrial isolation. The gastrocnemius muscle was dissected with the mice under deep anesthesia (5\% isoflurane / 95\% oxygen). Careful precautions were made to keep the blood supply to the gastrocnemius intact until it was removed. Mitochondria and mitochondria free cytosolic muscle fractions were obtained by protease digestion from the myofibrils, followed by centrifugation, using modifications of the manufacture's recommendations (MITOISO1-1KT, Sigma-Aldrich Co., St Louis, MO). Briefly, the gastrocnemius muscle was placed on ice and minced in a $1.5 \mathrm{ml}$ Eppendorf tube. Samples were washed and re-suspended in an extraction buffer containing $0.25 \mathrm{mg} / \mathrm{ml}$ trypsin. After a 20 minute incubation period, albumin was added to a final concentration of $10 \mathrm{mg} / \mathrm{ml}$ to quench the proteolytic reaction. Samples were washed and re-suspended in the extraction buffer, then homogenized with a Teflon pestle for two strokes of five seconds each. The homogenate was then centrifuged at $1100 \mathrm{~g}$ for 5 minutes. The supernatant was transferred to a new tube and centrifuged at $11,000 \mathrm{~g}$ for 10 minutes. The supernatant was collected as mitochondrial free, cytosolic fraction. The mitochondrial pellet was suspended in a storage buffer containing sucrose.

Whole gastrocnemius muscle homogenates concentration of $\mathrm{H}_{2} \mathrm{O}_{2}$. Hydrogen peroxide $\left(\mathrm{H}_{2} \mathrm{O}_{2}\right)$ levels in the muscle tissue were determined by utilizing a fluorescent $\mathrm{H}_{2} \mathrm{O}_{2}$ detection kit (Cell Technology, Mountain View, CA). Whole muscles were homogenized in phosphatebuffered saline (PBS) (ph=7.4). Reagents and standards were prepared as recommended by the manufacturer with slight modifications and have been previously described (57). Samples were normalized to the muscle protein concentration of each sample as determined by a DC protein concentration assay (Bio-Rad, Hercules, CA). All analyses were done in duplicate.

Total concentration of Glutathione, oxidized glutathione and the reduced glutathione/oxidized glutathione (GSH/GSSG) ratio of aged \& exercised gastrocnemius muscles. The concentration of total glutathione (tGSH) and oxidized (GSSG) glutathione was ascertained by the use of a Bioxytech GSH/GSSG-412 assay kit (Oxis International, CA). Furthermore the data were expressed as the ratio of reduced to oxidized glutathione 
(GSH/GSSG). The assay was preformed according to the manufacturer's directions and have been previously described (57). Briefly, gastrocnemius muscle tissue ( 40 mg) was homogenized immediately after dissection in $530 \mu \mathrm{l}$ of cold buffer (5\% metaphosphoric acid for the tGSH or $5 \%$ metaphosphoric acid and M2VO scavenger for the GSSG sample). The appropriate amounts of sample chromogen and enzyme were mixed and incubated at room temperature. NADPH was added and the absorbance $(412 \mathrm{~nm})$ of each sample was read for three consecutive minutes. The concentration for each sample was determined via a DC protein concentration assay (Bio-Rad, Hercules, CA). Signals from each sample were normalized to the corresponding protein content of that sample.

Xanthine Oxidase activity \& hypoxanthine concentration in the gastrocnemius whole muscle homogenate. A commercially available Amplex Red® XO Assay Kit (\#A22182, Invitrogen, Eugene, OR) was used to measure Hypoxanthine concentrations as well as xanthine oxidase activity in muscle homogenates. The methods have been described previously in our laboratory (57). Fluorescence was measured in a microplate reader using an excitation of 530 $\mathrm{nm}$ and emission detection at $590 \mathrm{~nm}$. Each sample was corrected for background fluorescence by subtracting the values derived from the non-xanthine containing wells. Values were normalized to protein concentrations for the original samples. Xanthine oxidase was substituted for hypoxanthine and added to the Amplex Red® reagent to obtain measurements for hypoxanthine concentrations. Hypoxanthine concentrations were determined by comparing sample values to values obtained from a standard curve.

Lipid peroxidation in the whole gastrocnemius muscle homogenate. Malondialdehyde (MDA) and 4-hydroxyalkenals (HAE) were measured using the method and reagents from Oxis International, CA (BIOXYTECH LPO-586) and have been previously described (57). Briefly, 75$100 \mathrm{mg}$ of each gastrocnemius muscle was homogenized in ice-cold PBS and $5 \mu \mathrm{L} 0.5 \mathrm{M}$ butylated hydroxytoluene (BHT) in acetonitrile. Absorbance of the supernatant was obtained at $586 \mathrm{~nm}$. The samples were normalized for differences in the amount of protein in each sample as determined by a DC protein concentration assay (Bio-Rad, Hercules, CA).

Glutathione Peroxidase (GPx) in the whole gastrocnemius muscle homogenate. A commercially available cellular GPx Assay Kit (\#35319, EMD/Calbiochem, San Diego, CA) was used to measure GPx activity in gastrocnemius muscle homogenates (57). Briefly, a portion of each muscle was homogenized in PBS (pH 7.5) containing 5mM EDTA and 1mM DTT. The homogenate was centrifuged at $10,000 \mathrm{~g}$ and the supernatant was used for the assay. All reagents and samples were equilibrated to $25^{\circ} \mathrm{C}$ and the assay was preformed according to the manufacturer's directions. The absorbance was measured at $340 \mathrm{~nm}$ using a 96 -well plate reader (DYNEX technologies, Chantilly Va., USA). Each sample and standard was performed in duplicate.

Catalase Activity in whole gastrocnemius muscle homogenate. A commercially available Amplex Red® Catalase Assay Kit (\#A22180, Invitrogen, Eugene, OR) was used to measure the activity of the catalase enzyme in whole muscle homogenates. Briefly, $25 \mu$ of homogenates were mixed with $25 \mu \mathrm{l}$ of $40 \mu \mathrm{M} \mathrm{H}_{2} \mathrm{O}_{2}$ solution and allowed to incubate in the dark for $30 \mathrm{mins}$ at room temperature. After 30 mins the sample containing solution was mixed with $50 \mu \mathrm{M}$ Amplex® Red, $0.4 \mathrm{U} / \mathrm{mL}$ horseradish peroxidase and incubated at $37^{\circ} \mathrm{C}$ in the dark. Fluorescence was measured in a microplate reader using an excitation of $530 \mathrm{~nm}$ and emission detection at $590 \mathrm{~nm}$. The change in fluorescence was determined by subtracting the sample value from that of the no-catalase control. The concentration of catalase was determined by comparing the sample to a standard curve. All analyses were measured in duplicate and the 
samples were normalized to the protein concentration in each sample as assessed using a DC protein concentration assay (Bio-Rad, Hercules, CA).

Manganese Superoxide Dismutase (MnSOD) activity in the mitochondrial fraction of the gastrocnemius muscle. A commercially available SOD Assay Kit II (\#706002, Cayman Chemical Company, Ann Arbor, MI) was used to measure MnSOD activity in the mitochondrial fraction. The assay was performed with slight modifications to the manufacturer's directions and all samples and standards were measured in duplicate. The assay was performed in a 96-well plate with each sample being treated with $10 \mu \mathrm{L}$ of $12 \mathrm{mM}$ potassium cyanide to inhibit any residual CuZn and extracellular SOD activities. The absorbance was measured at $450 \mathrm{~nm}$ using a 96-well plate reader (Dynex Tech., Chantilly VA., USA). The samples were normalized to the protein concentration in each sample as assessed using a DC protein concentration assay (BioRad, Hercules, CA).

Copper-Zinc Superoxide Dismutase (CuZnSOD) activity in the cytosolic fraction of the gastrocnemius muscle. CuZnSOD activity was determined in the mitochondrial free fraction with slight modifications to the manufacturer's directions as described (57) and all samples and standards were measured in duplicate (\#706002, Cayman Chemical Company, Ann Arbor, MI). The assay was performed in a 96-well plate and the absorbance was measured at $450 \mathrm{~nm}$ using a 96-well plate reader (Dynex Tech., Chantilly VA., USA). The samples were normalized to the protein concentration in each sample as assessed using a DC protein concentration assay (Bio-Rad, Hercules, CA).

Measuring mRNA concentrations of antioxidant enzymes in the gastrocnemius muscle. CuZnSOD, MnSOD, catalase and GPX-1 mRNA were determined by means of reverse transcription-polymerase chain reaction (RT-PCR) according previously published procedures from our laboratory $(56,60)$. Briefly, RNA was isolated from sixty micrograms of the gastrocnemius muscle homogenized in $1 \mathrm{ml}$ of Tri-Reagent (Molecular Research Center, Cincinnati, OH). RNA purity was accessed using a minimum 260:280 ratio of 1.7. RNA was reversed transcribed using random primers, dNTP, and SuperScript II reverse transcriptase (Invitrogen/Life Technologies, Bethesda MD). The primers for CuZnSOD, MnSOD, GPx-1, and catalase have been previously published (56). The signal from the gene was expressed as a ratio to the $18 \mathrm{~S}$ signal from the same PCR product. The PCR product from each reaction was separated on a $1.5 \%$ agarose gel containing ethidium bromide via electrophoresis. The resulting signals were digitally captured (Kodak DC290) and quantified using 1D Kodak image analysis software (Eastman Kodak Company, Rochester, NY).

Fluorometric Caspase-Activity Assay. The proteolytic activities of caspase- 9 and caspase-3 were determined by using commercially available substrates (caspase-3 AC-DEVDAFC \& caspase-9Ac-LEHD, Alexis Biochemical, San Diego, CA). Briefly, 50 $\mu$ l of caspase activity buffer (50mM PIPES, $0.1 \mathrm{mM}$ EDTA, 10\% glycerol \& $1 \mathrm{mM}$ DTT), $50 \mu$ l of the cytosolic fraction of the gastrocnemius muscle homogenate without protease inhibitor, and $10 \mu \mathrm{l}$ of substrate $(1 \mathrm{mM})$ were combined in a 96-well fluorescent microplate. Caspase activity was accessed using a fluorescent microplate reader set at a wavelength of $400 \mathrm{~nm}$ for excitation and $505 \mathrm{~nm}$ for emission. The microplate was incubated for 2 -hours at $37^{\circ} \mathrm{C}$ with caspase activity being determined by subtracting the time 2 -hour reading from the initial reading. Caspase activity is expressed as the relative fluorescent units normalized to the protein concentration of each muscle sample (RFU / mg protein). 
Western Immunoblots. The protein content of CuZnSOD, apoptosis inducing factor (AIF) and cytochrome $\mathrm{C}$ were measured in the cytosolic (mitochondrial free) fractions and MnSOD was measured in the mitochondrial fractions of the gastrocnemius muscle. Thirty $\mu \mathrm{g}$ of protein was loaded into each well of a $4-12 \%$ gradient polyacrylamide gel (Novex, Invitrogen, Eugene, $\mathrm{OR}$ ) and separated by routine SDS-polyacrylamide gel electrophoresis (PAGE) for 1.5 hours at $20^{\circ} \mathrm{C}$ followed by transfer to a nitrocellulose membrane. All membranes were blocked in $5 \%$ non-fat milk protein (NFM) for 1-hour at room temperature. Membranes were incubated in the appropriate dilutions of primary antibodies (diluted in tris-buffered saline with $0.05 \%$ Tween-20 (TBS-T) and $.002 \%$ sodium Azide overnight at $4{ }^{\circ} \mathrm{C}$ ). Membranes were washed in TBS-T followed by incubation in the appropriate dilutions of secondary antibodies (diluted in 5\% NFM in TBS-T) conjugated to horseradish peroxidase. Signals were developed using a chemiluminescent substrate (ECL Advanced, Amersham Bioscience, Fairfield, CT) and visualized by exposing the membranes to X-ray films (BioMax MS-1; Eastman Kodak, Rochester, NY). Digital records were captured by a Kodak 290 camera and protein bands were quantified using 1-D analysis software (Eastman Kodak, Rochester, NY). Bands were quantified as optical density $(\mathrm{OD}) \mathrm{x}$ band area and expressed in arbitrary units.

Statistical analysis. Statistical analyses carried out using the SPSS version 13 statistical software package (Chicago, IL). Analyses of variance (ANOVA) were implemented to observe the main effect of exercise, aging and allopurinol administration. Where the $F$ value reached significance, least significant difference (LSD) post hoc analysis was performed to assess where the significant differences occurred. Statistical significance was recognized at $p<0.05$. Data are reported as the mean \pm standard error of the mean (SEM). 


\section{Results}

Xanthine Oxidase activity. Xanthine oxidase activity was $65 \%$ and $59 \%$ greater in control non-exercised and isometrically exercised $(2.08 \pm .192 \mathrm{mU} / \mathrm{mg}$ young vs. $3.23 \pm .416 \mathrm{mU} / \mathrm{mg}$ aged) gastrocnemius muscles compared to mice that received the sham surgeries (Figure $6.2 \mathrm{~A})$. Isometric exercise increased xanthine oxidase activity in muscle by $33 \%$ in young adult and $28 \%$ in aged animals compared to the contralateral control muscles. Allopurinol administration blunted the exercise-induced increase in xanthine oxidase activity on all treatment and control gastrocnemius muscles. Furthermore, allopurinol reduced xanthine oxidase levels of aged muscles so that there were no differences between any of the allopurinol treated muscles (Figure 6.2A).

Hypoxanthine. Hypoxanthine which is a product of purine degradation and a substrate for xanthine oxidase was measured in young adult and aged gastrocnemius muscle. The hypoxanthine concentration was $62 \%$ greater in muscles of aged animals $(0.41 \pm 0.07 \mu \mathrm{mol} / \mathrm{mg}$ in young vs. $0.667 \pm 0.09 \mu \mathrm{mol} / \mathrm{mg}$ in aged) (Figure 6.2B). While isometric exercise increased hypoxanthine concentrations in both the young adult (31\%) and aged (54\%) muscles, allopurinol did not change hypoxanthine concentrations in either control or exercised muscles in young or aged animals (Figure 6.2B).

\section{Insert Figure 6.2}

Hydrogen peroxide $\left(\mathrm{H}_{2} \mathrm{O}_{2}\right)$. $\mathrm{H}_{2} \mathrm{O}_{2}$ was measured as an indicator of oxidant production. Whole muscle homogenate levels of $\mathrm{H}_{2} \mathrm{O}_{2}$ were elevated with isometric exercise in young adult $(24 \%)$ and in aged (44\%) animals receiving the sham surgeries as compared to the agematched control limb $(\mathrm{p}<0.05) . \mathrm{H}_{2} \mathrm{O}_{2}$ was higher in both control $(21 \%)$ and isometrically exercised $(39 \%)$ muscles $(p<0.05)$ of aged animals as compared to young adult animals. Allopurinol attenuated the increase in $\mathrm{H}_{2} \mathrm{O}_{2}$ associated with isometric exercise in both age groups (Figure 6.3A).

Lipid Peroxidation. The levels of malondialdehyde (MDA) and 4-hydroxyalkenals (HAE), both products of lipid peroxidation, were $56 \%$ greater in non-exercised gastrocnemius muscles of aged vs. young adult mice (3.06 $\pm 0.64 \mu \mathrm{M} / \mathrm{mg}$ young vs. $4.8 \pm 0.64 \mu \mathrm{M} / \mathrm{mg}$ aged). Isometric exercise elevated lipid peroxidation within the young adult muscles by $29 \%(3.06 \pm 0.64 \mu \mathrm{M} / \mathrm{mg}$ vs. $3.95 \pm 0.74 \mu \mathrm{M} / \mathrm{mg})$ and by $92 \%$ in the aged muscles $(4.8 \pm 0.64 \mu \mathrm{M} / \mathrm{mg}$ vs. $9.2 \pm 1.76$ $\mu \mathrm{M} / \mathrm{mg}$ ). Allopurinol blunted the increase in MDA + HNE levels associated with exercise in the young adult (3.22 $\pm 0.61 \mu \mathrm{M} / \mathrm{mg}$ controls vs. $3.27 \pm 0.78 \mu \mathrm{M} / \mathrm{mg}$ exercised) and aged muscles $(5.17 \pm 1.09 \mu \mathrm{M} / \mathrm{mg}$ vs. $5.68 \pm 1.2 \mu \mathrm{M} / \mathrm{mg})$. Allopurinol did not depress lipid peroxidation in control muscles of aged mice (4.80 $\pm 0.64 \mu \mathrm{M} / \mathrm{mg}$ sham surgery vs. $5.17 \pm 1.09 \mu \mathrm{M} / \mathrm{mg}$ allopurinol) (Figure 6.3B).

\section{Insert Figure 6.3}

Glutathione. Glutathione (GSH) is a major tissue antioxidant that provides reducing equivalents for the reduction of hydrogen peroxide to water. In a reaction catalyzed by glutathione peroxidase, two GSH molecules form a disulfide bond resulting in the oxidized form of glutathione (GSSG). The ratio of reduced to oxidized glutathione (GSH/GSSG) is used an indicator of oxidative stress. As shown in Figure 6.4A, the concentration of GSH was 21\% lower in muscles of aged as compared with young mice. Although it approached significance $(p=0.066)$, the GSSG concentration was not different in muscles obtained from young or aged 
mice (Figure 6.4B). The ratio of reduced to oxidized glutathione (GSH/GSSG) was 35\% lower $(p<0.05)$ in muscles of aged vs. young adult animals (Figure $6.4 \mathrm{C})$. The $\mathrm{GSH} / \mathrm{GSSG}$ ratio was reduced in exercised gastrocnemius muscles of both young (15.02 \pm 2.2 control vs. $9 \pm 1.4$ exercised) and aged animals (9.7 \pm 0.98 control vs. $3.2 \pm 0.54$ exercised) (Figure $4 \mathrm{C}$ ). Allopurinol treatment prevented the exercise-induced decrease in the GSH/GSSG ratio in muscles from the young mice and partially attenuated the decrease in muscles from aged mice. These data suggest that aging reduced the concentration of glutathione and consequently lowered the GSH/GSSG ratio in these muscles, thus reducing the ability of the gastrocnemius muscle to tolerate increased oxidative production resulting from exercise.

\section{Insert Figure 6.4}

Glutathione Peroxidase (GPx). Neither aging, isometric exercise, nor xanthine oxidase inhibition produced any significant changes in glutathione peroxidase enzyme activity or GPx-1 mRNA levels within gastrocnemius muscles (Figure 6.5A and Figure 6.5B).

Manganese Superoxide Dismutase (MnSOD). MnSOD activity was 37\% greater in the gastrocnemius muscles from aged animals compared to young adults (Figure 6.5C). Neither isometric exercise nor allopurinol had any significantly affect on MnSOD activity in either age group. Aging, isometric exercise and xanthine oxidase inhibition failed to affect muscle levels of MnSOD mRNA (Figure 6.5D).

\section{Insert Figure 6.5}

Catalase. The enzymatic activity of catalase was $66 \%$ greater in the gastrocnemius muscles from aged animals compared to young adult animals (Figure 6.6A) whereas catalase mRNA was $\sim 180 \%$ greater in muscles from old (3.87 \pm 0.51 Relative Optical Density) vs. young adult (2.06 \pm 0.49 Relative Optical Density) mice (Figure 6.6C). Neither catalase protein levels, nor mRNA content, were affected by allopurinol. Isometric exercise increase catalase activity by $\sim 20 \%$ in the muscles from aged animal, but it had no affect on catalase activity in the young adult animals ( $0.366 \pm 0.05 \mathrm{nM} / \mathrm{min} / \mathrm{mg}$ non-exercised vs. $0.414 \pm 0.08 \mathrm{nM} / \mathrm{min} / \mathrm{mg}$ exercised). However, exercise in aged gastrocnemius muscles did not elicit a significant increase in catalase protein abundance or mRNA content. The increase in catalase activity associated with exercise in the aged gastrocnemius muscles was completely attenuated with allopurinol administration ( $0.612 \pm 0.11 \mathrm{nM} / \mathrm{min} / \mathrm{mg}$ non-exercised vs. $0.606 \pm 0.1 \mathrm{nM} / \mathrm{min} / \mathrm{mg}$ exercised). Isometric exercise did not alter catalase protein abundance, or mRNA content in the gastrocnemius muscle from young adult or aged animals (Figure 6.6B and Figure 6.6C).

Copper-Zinc Superoxide Dismutase (CuZnSOD). CuZnSOD activity was $11 \%$ greater in control gastrocnemius muscles of aged animals as compared with young animals $(1.06 \pm 0.08$ $\mathrm{U} / \mathrm{mg}$ young vs. $1.23 \pm 0.08 \mathrm{U} / \mathrm{mg}$ aged, $\mathrm{P}<0.05)$ ) (Figure 6.6D). Allopurinol treatment did not affect CuZnSOD activity in control muscles. Isometric exercise increased CuZnSOD activity by $16 \%$ in muscles from the young adult animals and by $11 \%$ in the aged animals $(1.23 \pm 0.08$ $\mathrm{U} / \mathrm{mg}$ aged non-exercised vs. $1.37 \pm 0.07$ aged exercised). Exercise also increased CuZnSOD protein abundance by $73 \%$ in muscles from young adult mice $(15.67 \pm 2.9$ Relative Optical Density non-exercised vs. $27.17 \pm 2.7$ Relative Optical Density exercised) and $62 \%$ in the muscles from aged mice (14.14 \pm 3.2 Relative Optical Density non-exercised vs. $23 \pm 4.7$ Relative Optical Density exercised) (Figure 6.6E). Allopurinol suppressed the exercise-induced increase in CuZnSOD activity and protein content in muscles from both young and aged mice. CuZnSOD mRNA levels were not altered by age, exercise or allopurinol (Figure 6.6F). 
Insert Figure 6.6

Pro-apoptotic mitochondrial signaling proteins. Caspase- 9 and -3 activities were measured in the cytosolic fraction of the gastrocnemius muscle. Caspase- 9 activity and caspase-3 were $122 \%$ and $85 \%$ greater in muscles from aged compared to young adult mice. Although exercise did not increase caspase- 9 activity, caspase- 3 activity was $30 \%$ greater in exercised as compared to non-exercised muscles of aged mice. Neither caspase- 9 nor caspase-3 was increased by exercise in young animals. Allopurinol did not alter either control or exercised muscles of young or aged animals (Figure 6.7A\&B).

Mitochondrial proteins, cytochrome $\mathrm{c}$ and apoptosis inducing factor (AIF) are released from the mitochondria in response to pro-apoptotic stimuli. When cytochrome $c$ and AIF are present in the cytosol this suggests that mitochondrial permeability has increased via opening of mitochondria permeability pores/channels. Both cytochrome c ( 237\%) (Figure 6.7C) and AIF ( 725\%) (Figure 6.7D) were higher in the cytosolic fractions of gastrocnemius muscles from aged animals compared to muscles from young adult mice. Neither exercise nor allopurinol altered cytochrome c or AIF accumulation in the cytosol of muscles of young or aged mice.

Insert Figure 6.7

Muscle Functional Measurements. Plantar flexor maximal isometric muscle force was measured as an indicator of muscle function. The gastrocnemius muscle provides the greatest contribution to plantar flexion. A representation of the raw data for the first and $20^{\text {th }}$ contraction from the last exercise session in the young adult and aged mice is shown in Figure $8 \mathrm{C}-\mathrm{F}$. The maximal isometric force recorded for the third day (which was the first contraction of that day) was normalized to the animal's body weight (BW) in grams (g). Maximal isometric force per gram of body weight was $36.6 \%$ lower in the muscles of aged animals compared to the young adult animals. Maximal isometric force in the plantar flexors from aged mice was $35 \%$ greater $(p<0.05)$ in animals provided allopurinol as compared to animals given the sham surgery, but allopurinol had no effect on force production in the young adult animals. Maximal isometric force was similar in the first and third exercise session in control and allopurinol groups for either young adult or aged mice (Figure 6.8A).

The rate of fatigue for the plantar flexors was assessed by calculating the net loss of force throughout the exercise session relative to the first contraction. Fatigue resistance was greater in muscles from the aged animals, but allopurinol had no effect on isometric muscle fatigue in either young adult or aged animals (Figure 6.8B).

\section{Insert Figure 6.8}

\section{Discussion}

The main findings from this study are: 1) Acute isometric exercise and aging increased xanthine oxidase, hypoxanthine and markers of oxidative stress and damage. 2) Reducing xanthine oxidase via allopurinol suppressed the isometric exercise-associated elevations in $\mathrm{H}_{2} \mathrm{O}_{2}$, and lipid peroxidation, prevented the exercise-induced loss of $\mathrm{GSH}$, and prevented the increase of catalase and CuZnSOD activities, but had no effect on GPx and MnSOD activity or mRNA in exercised muscles of aged animals. 3) Allopurinol suppressed the isometric exerciseinduced increase in caspase-3 activities in exercised muscles of aged animals, but did not reduce other markers of apoptotic signaling associated with aging or exercise. 
Increased oxidant production and damage have been shown to be associated with exercise $(1,9,14,17,29,39,48,56,63)$ and aging $(5,13,16,21,34,43,49,56,65)$. Our data are consistent with these findings, because we found that isometric exercise and aging both lead to increases in $\mathrm{H}_{2} \mathrm{O}_{2}$ concentrations, lipid peroxidation, xanthine oxidase activity and a decrease in the GSH/GSSG ratio in skeletal muscle. Furthermore, our data suggest that there is an additive effect of exercise and aging in gastrocnemius muscles of mice. Non-damaging isometric muscle contractions have been shown to elevate superoxide production in the extracellular space of the gastrocnemius muscle in mice (18). We would anticipate that the additional superoxide from the isometric contractions in the current study would be quickly converted to $\mathrm{H}_{2} \mathrm{O}_{2}$ by $\mathrm{SOD}$, and this conversion could account for most of the observed increase $\mathrm{H}_{2} \mathrm{O}_{2}$ content. $\mathrm{H}_{2} \mathrm{O}_{2}$, has the potential to induce widespread oxidant damage simply because it easily crosses cellular membranes.

Xanthine oxidase is a source of oxidative stress in isometric exercise.

Xanthine oxidase has been shown to be present in endothelial cells from human skeletal muscle (23) and despite its location, it is relevant to muscle function because it affects the responses of human muscle to exercise $(10,19,20)$. The present data suggest that xanthine oxidase activity increased with aging and also is elevated with isometric exercise in muscles of both aged and young adult mice. The inhibition of xanthine oxidase via allopurinol reduced the indices of oxidative stress associated with exercise $\left(\mathrm{H}_{2} \mathrm{O}_{2}\right.$ concentration, lipid peroxidation and the GSH/GSSG ratio). These data are consistent with the idea that xanthine oxidase makes an important contribution to oxidant production during exhaustive exercise $(17,18,22,53,57,63)$. Furthermore, increases in post-exercise concentrations of hypoxanthine are accurate predictors of muscle energy exhaustion (6) during exercise. It is likely that the additional hypoxanthine was converted to xanthine and superoxide via xanthine oxidase. Although superoxide formation was not measured, recent data that show increased superoxide is produced and released into the extracellular space via after isometric muscle (18).

\section{The impact of allopurinol on endogenous antioxidant enzymes in aging and exercised muscles}

In general, mRNA content for antioxidant enzymes was not altered by allopurinol or aging. These data suggest that the observed differences in protein content and activity for antioxidant enzymes arise from post-transcriptional and/or post-translational modifications $(25,56,57)$. In contrast with other antioxidant enzymes, catalase mRNA was greater in muscles of old vs. young animals (Figure $6 \mathrm{C}$ ). The increased catalase mRNA, activity and protein content may be an attempt to counterbalance the depletion of glutathione levels observed within aging (46).

\section{The affects of exercise and xanthine oxidase inhibition on the endogenous antioxidant enzymes \\ Oxidant sensitive transcription factors such as nuclear factor kappaB (NF-кB) have been} shown to up-regulate antioxidant gene expression in response to exercise $(17,26,32)$. However the attenuation of oxidant production via inhibition of xanthine oxidase has been shown to prevent NF-kB activation and the subsequent upregulation of MnSOD transcriptional activity after exhaustive aerobic treadmill running (17). In contrast, we did not find evidence for transcriptional regulation of GPx, catalase, CuZnSOD or MnSOD after acute exercise. Nevertheless, the activities of the cytosolic localized antioxidants CuZnSOD and catalase were greater in both young adult and aged gastrocnemius muscles in response to isometric exercise. This might be in part a result of the need to buffer cytosolic oxidants arising from anaerobic metabolic pathways, as compared aerobic types of exhaustive exercise $(17,26,32)$ which, 
would be expected to have greater need to buffer mitochondria associated antioxidants arising from oxidative metabolism.

It has been postulated that low levels of oxidative stress can promote beneficial adaptive response including an improved antioxidant defense capacity, because preventing oxidative stress associated with exercise prevents these positive adaptations $(17,55)$. For example, in the current study, inhibition of xanthine oxidase-induced oxidative stress by allopurinol blunted the increase in cytosolic protein content and activity of CuZnSOD in response to isometric. Xanthine oxidase inhibition also attenuated the increase in catalase activity associated with exercise in the aged animals. Together, inhibition of xanthine oxidase reduced the need for an increase in antioxidant enzymes in response to exercise.

\section{Allopurinol reduces apoptotic signaling in aged muscles}

The current data are consistent with previous findings from our lab and others, that aging is associated with increases in apoptotic signaling in skeletal muscle $(12,52,60)$. Mitochondrial proteins, cytochrome $c$ and AIF were both elevated in the cytosolic fraction of the muscle homogenates. Downstream from mitochondrial-release of cytochrome $c$, the activity of the initiator caspase-9 was elevated in conjunction with the executioner caspase-3.

Aging has been associated with a depolarization of the mitochondrial membrane, decreased mitochondrial respiratory activity and decreased antioxidant enzyme activity (46). This decrease leads to a detrimental release and accumulation of oxidants within the cells (46). While most antioxidants likely originate from the mitochondria in aging muscles $(5,62)$ our data show that xanthine oxidase also contributes to oxidant production in aging and exercised muscles.

Increased cellular stress can activate redox sensitive pathways that initiate mitochondria apoptotic signaling $(12,24,60,61)$. Aged skeletal muscle has elevated basal oxidant production, and exhaustive aerobic exercise further increases oxidant production (5) and apoptotic signaling (36). In this investigation we show increased caspase-3 activity without significant increases in caspase- 9 activity or cytosolic cytochrome $c$ in the exercised gastrocnemius muscle of aged mice. These findings are consistent with other observations in gastrocnemius muscle in aged rats, where exhaustive exercise increased caspase- 3 activity without changes in caspase- 9 activity (36). These data suggest that exercise-associated elevations in caspase- 3 activity in the aged gastrocnemius muscle may be triggered via the extrinsic apoptotic pathway rather than through the mitochondria.

Allopurinol blunted the increase in caspase-3 activity in the exercised gastrocnemius muscle from aged animals. Although this suggests that xanthine oxidase activity has a role in regulating apoptotic signaling, this is likely not through mitochondria signaling pathways, because allopurinol had no effect on suppressing the elevated levels of cytochrome $c$, AIF, caspase- 9 and caspase- 3 associated with aging. Further research is needed to determine the upstream mechanisms resulting from the increase in caspase- 3 activity with exercise and if allopurinol blunts extrinsic apoptotic signaling in response to aging and exercise.

Allopurinol affects maximal isometric force in aged animal

An important novel finding in this study is that allopurinol administration increased plantar flexor maximal isometric force by $35 \%$, without having an effect on the young adult animals. Our data in young adult animals differs from recent data from Gomez-Cabrera and colleagues (18) who reported a loss of in vitro maximal force production in extensor digitorum longus and soleus 
muscles from young ( 3 months of age) mice that were incubated with oxypurinol (the active metabolite of allopurinol). These differences may have been the result of different experimental approaches (in vitro vs. in vivo and/or the muscle being study. Nevertheless, the data in the current study suggest that suppressing xanthine oxidase has the potential to improve in vivo maximal force production in aged muscles.

Muscle fatigue during repetitive isometric contractions

Similar to previous observations from our lab (57), in this study we found that relative muscle fatigue was less in muscles of aged as compared to young adult animals. This may be due, at least in part to, shifting towards a greater percentage of type I fibers $(27,50)$. Although allopurinol administration did increase maximal isometric force in the aged animals it did not significantly influence the rate at which force declined in either age group. This is consistent with a recent in vivo study that found no improvement in fatigability of hind limb muscles of young mice in response to an in vitro protocol of repeated electrical stimulation (18).

\section{Conclusion}

The data in this study indicate that xanthine oxidase derived oxidant production has a wide range of effects on skeletal muscle physiology and function in aged mice. In this study we sought to determine if xanthine oxidase played an important role in oxidant stress-induced regulation of aging after isometric contractions. We did not anticipate that the relatively short duration of xanthine oxidase inhibition used in the current experimental protocol would be adequate to relieve the chronic basal elevations in oxidative stress that is associated with advanced aging. Our findings suggest that aging and repetitive in vivo isometric contractions increase xanthine oxidase activity in the gastrocnemius muscles from both young adult and aged mice. We recognize that additional studies are needed to determine if long-term inhibition of xanthine oxidase will provide positive improvements in skeletal muscle redox status, oxidative stress or function of aged animals.

The suppression of exercise-induced antioxidant enzymes by allopurinol in aged muscles might be viewed as a negative adaptation. However, another perspective is that antioxidant inhibition of xanthine oxidase activity reduced oxidative stress in aged muscles and removed the need for short-term adaptation of the endogenous antioxidant enzymes catalase and CuZnSOD to repetitive isometric contractions. Acute reduction of xanthine oxidase levels in aging muscles by allopurinol reduced caspase-3 but not other indicators of mitochondria associated apoptosis. Additional studies are required to determine if long-term inhibition of xanthine oxidase will have an important role in reducing apoptotic signaling in mitochondria or extrinsic pathways. Finally, xanthine oxidase inhibition improved maximal isometric force in the plantar flexor muscles from the aged mice. From a clinical perspective, it is important to determine if allopurinol will provide an effective strategy for reducing oxidant stress and improving loss of muscle function with aging in exercising humans. 


\section{Figure Legends}

Figure 6.1 Mechanism of oxidant production via xanthine oxidase pathway. GPx (Glutathione Peroxidase), GSH (Reduced Glutathione), GS-SG (Oxidized Glutathione), GR (Glutathione Reductase), $\mathrm{H}_{2} \mathrm{O}_{2}$ (Hydrogen Peroxide)

Figure 6.2Allopurinol attenuated the increase in xanthine oxidase activity, hypoxanthine associated with exercise. (A) Activity of xanthine oxidase was determined fluorometrically. Data are expressed as $\mathrm{mU}$ of activity per $\mathrm{mg}$ of total protein in gastrocnemius muscle homogenate. One unit of xanthine activity is defined as the amount of enzyme that will form $1 \mathrm{mg}$ purpurogallin from pyrogallol in 20 seconds at $\mathrm{pH} 6.0$ at $20^{\circ} \mathrm{C}$. (B) Hypoxanthine data are expressed as $\mu \mathrm{mol}$ concentration per $\mathrm{mg}$ of total protein in the gastrocnemius muscle homogenate. The normalized data are presented as mean \pm SEM. * significant difference $(p<0.05)$ between isometrically exercised muscles from contra-lateral control muscles; $\S$ signifies a significant effect of aging within the sham surgery or allopurinol treatment groups $(p<0.05)$. $†$ signifies a significant effect $(p<0.05)$ of allopurinol treatment.

Figure 6.3 Inhibition of xanthine oxidase activity attenuated the increase in hydrogen peroxide $\left(\mathrm{H}_{2} \mathrm{O}_{2}\right)$ concentration and lipid peroxidation associated with exercise. (A) The $\mathrm{H}_{2} \mathrm{O}_{2}$ concentrations were determined a fluorometrically. Data are expressed as $\mu \mathrm{mol}$ per $\mathrm{mg}$ of total protein in gastrocnemius muscle homogenate. (B) Data are combined malondialdehyde (MDA) and 4-hydroxyalkenals (HAE) and are normalized to the total protein concentration in the gastrocnemius muscle homogenate. The normalized data are presented as the mean $\pm \mathrm{SEM}$. * significant difference $(p<0.05)$ of isometric exercised muscle from contra-lateral control muscle; $\S$ signifies a significant difference $(p<0.05)$ due to aging. $†$ signifies a significant difference $(p<0.05)$ of the allopurinol treatment.

Figure 6.4Concentration of total glutathione, oxidized glutathione (GSSG) and the ratio of reduced glutathione (GSH) / GSSG. (A) The concentration of total glutathione is expressed as $\mu \mathrm{M}$ GSH normalized to total protein concentration $(\mathrm{mg})$ in the gastrocnemius homogenate. (B) The concentration of oxidized glutathione is expressed as $\mu \mathrm{M}$ GSSG normalized to the total protein concentration $(\mathrm{mg})$ of the gastrocnemius homogenate. (C) Data are depicted as the ratio of GSH to GSSG normalized to total protein content. Lower ratios are an indication of increased oxidative stress. The normalized data are presented as mean \pm SEM. * significant difference $(p<0.05)$ of isometric exercised muscle from contra-lateral control muscle; $\S$ signifies a significant difference $(p<0.05)$ within either the sham surgery or allopurinol treatment groups due to aging. $\dagger$ signifies a significant difference $(p<0.05)$ due to the allopurinol treatment.

Figure 6.5 Glutathione peroxidase (GPx) and Manganese superoxide dismutase (MnSOD) activity \& mRNA regulation with isometric exercise and allopurinol treatment. For all graphs the normalized data are presented as mean \pm SEM. $\S$ signifies a significant difference $(p<0.05)$ within the sham surgery or allopurinol treatment groups due to aging. $(A)$ Total GPx activity is expressed as nmol decrease in NADPH per minute normalized to $\mathrm{mg}$ of to total protein concentration in the gastrocnemius homogenate. (B) GPx-1 mRNA expression was determined from the total muscle homogenate by RT-PCR. The data are expressed as optical density (OD) $x$ band area normalized to $18 \mathrm{~s}$ rRNA, and expressed in relative optical density. The inserts show representative gels for GPx-1 mRNA and 18s rRNA in young and aged (control and isometrically exercised) gastrocnemius muscle. (C) MnSOD activity was 
determined in the mitochondrial fraction of the gastrocnemius muscle homogenate. MnSOD activity is expressed as $U$ of MnSOD per $\mathrm{ml}$ of homogenate normalized to $\mathrm{mg}$ of protein in homogenate. One unit was defined as the amount of enzyme needed to exhibit $50 \%$ dismutation of the superoxide radical. (D) MnSOD mRNA expression was determined from the total muscle homogenate by RT-PCR. The data are expressed as optical density (OD) $x$ band area, normalized to 18s rRNA and expressed in relative optical density. The inserts show representative gels for MnSOD mRNA and 18s rRNA in young and aged (control and isometric exercised) gastrocnemius muscle.

YCC= Young, Control surgery, Control non-exercise; YCE $=$ Young, Control surgery, Exercised; YAC=Young, Allopurinol, Control non-exercise; YAE= Young, Allopurinol, Exercised; $\mathbf{A C C}=$ Aged, Control surgery, Control non-exercise; $\mathbf{A C E}=$ Aged, Control surgery, Exercised; $\mathbf{A A C}=$ Aged, Allopurinol, Control non-exercised; AAE Aged, Allopurinol, Exercised

Figure 6.6Catalase and Copper zinc superoxide dismutase (CuZnSOD) activity, protein expression \& mRNA regulation with isometric exercise and allopurinol treatment. For all graphs the normalized data are presented as mean \pm SEM. * significant difference $(p<0.05)$ of isometrically exercised muscles from contra-lateral control muscles; $\S$ signifies a significant difference $(p<0.05)$ within the sham surgery or allopurinol treatment groups due to aging. $†$ signifies a significant difference $(p<0.05)$ due to the allopurinol treatment. $(A)$ Total catalase activity is expressed as nmol of activity per min normalized to $\mathrm{mg}$ of total protein in the gastrocnemius homogenate. (B) Catalase protein expression was determined in the mitochondrial free cytosolic fraction by western immunoblot. The data are expressed as optical density (OD) x band area, normalized to GAPDH and expressed in relative optical density. The inserts show representative blots for catalase and GAPDH content young and aged gastrocnemius muscle. (C) Catalase mRNA expression was determined by RT-PCR from the total muscle homogenate. The data are expressed as optical density (OD) $\mathrm{x}$ band area, normalized to 18s rRNA and expressed in relative optical density. The inserts show representative gels for catalase mRNA and 18s rRNA in young and aged (control and isometric exercised) gastrocnemius muscles. (D) CuZnSOD activity was determined in the mitochondrial free cytosolic fraction of gastrocnemius muscle homogenate. CuZnSOD activity is expressed as $\mathrm{U}$ of CuZnSOD per $\mathrm{ml}$ of homogenate normalized to $\mathrm{mg}$ of protein in homogenate. One unit was defined as the amount of enzyme needed to exhibit $50 \%$ dismutation of the superoxide radical. (E) CuZnSOD protein expression was determined in the mitochondrial free cytosolic fraction by western immunoblot. The data are expressed as optical density (OD) $\mathrm{x}$ band area, normalized to GAPDH and expressed in relative optical density. The inserts show representative blots for CuZnSOD and GAPDH content in gastrocnemius muscles. (F) CuZnSOD mRNA expression was determined by RT-PCR from total muscle homogenate. The data are expressed as optical density (OD) $x$ band area, normalized to $18 \mathrm{~s} r R N A$ and expressed in relative optical density. The inserts show representative gels for CuZnSOD mRNA and 18s rRNA in young and aged (control and isometric exercised) gastrocnemius muscle.

YCC= Young, Control surgery, Control non-exercise; YCE= Young, Control surgery, Exercised; YAC=Young, Allopurinol, Control non-exercise; $\mathbf{Y A E}=$ Young, Allopurinol, Exercised; $\mathbf{A C C}=$ Aged, Control surgery, Control non-exercise; $\mathbf{A C E}=$ Aged, Control surgery, Exercised; $\mathbf{A A C}=$ Aged, Allopurinol, Control non-exercised; AAE Aged, Allopurinol, Exercised

Figure 6.7 Aging increases apoptotic signaling. For all graphs the normalized data are presented as mean \pm SEM. * significant difference $(p<0.05)$ of isometric exercised muscle from contra-lateral control muscle; $\S$ signifies a significant difference $(p<0.05)$ within the sham 
surgery or allopurinol treatment groups due to aging. $\uparrow$ signifies a significant difference $(p<0.05)$ due to the allopurinol treatment. Caspase-9 (A) and caspase-3 (B) levels were determined in the mitochondrial free cytosolic fraction of the gastrocnemius muscle homogenate by a fluorometric assay. Data are expressed as Relative Fluorescent Unit (RFU) per mg of protein in the homogenate. (C) Cytosolic Cytochrome $\mathrm{C}$ protein expression was determined in the mitochondrial free fraction of the gastrocnemius homogenate by western immunoblot. The data are expressed as optical density (OD) $\mathrm{x}$ band area, normalized to GAPDH and expressed in relative optical density. The inserts show representative blots for cytochrome $c$ and GAPDH in young and aged (control and repetitive loading) gastrocnemius muscle. (D) Cytosolic AIF protein expression was determined in the mitochondrial free fraction of the gastrocnemius homogenate by western immunoblot. The data are expressed as optical density (OD) $x$ band area, normalized to GAPDH and expressed in relative optical density. The inserts show representative blots for AIF and GAPDH in young and aged (control and repetitive loading) gastrocnemius muscle.

$Y C C=$ Young, Control surgery, Control non-exercise; $Y C E=$ Young, Control surgery, Exercised; $\mathbf{Y A C}=$ Young, Allopurinol, Control non-exercise; $\mathbf{Y A E}=$ Young, Allopurinol, Exercised; $\mathbf{A C C}=$ Aged , Control surgery, Control non-exercise; $\mathbf{A C E}=$ Aged, Control surgery, Exercised; AAC $=$ Aged, Allopurinol, Control non-exercised; AAE Aged, Allopurinol, Exercised

Figure 6.8Maximal isometric forces from the plantar flexor muscles. (A) Data are expressed as the mean \pm SEM of the maximal isometric force $(\mathrm{N})$ recorded on the third day of exercise by the left plantar flexor muscle group normalized to the body weight in grams ( $g$ BW) of the animal. $\S$ signifies a difference $(\mathrm{p}<0.05)$ due to aging. (B) Data are expressed as the mean \pm SEM of the relative difference between the maximal isometric forces produced on the each contraction to the maximal isometric force on the first contraction. All force measurements were normalized to body weight $(\mathrm{g}) .{ }^{*}$ indicates a significant difference $(\mathrm{p}<0.05)$ in both the aged sham surgery and allopurinol treatment animals versus the young adult sham surgery and allopurinol treatment animals. (C-F) Representative force $x$ time curves from the $3^{\text {rd }}$ exercise session in the allopurinol treated young adult and aged animals. (C) First contraction of the $3^{\text {rd }}$ day in a young adult animal. (D) Twentieth contraction of the $3^{\text {rd }}$ day in a young adult animal. (E) First contraction of the $3^{\text {rd }}$ day in an aged animal. (F) Twentieth contraction of the $3^{\text {rd }}$ day in an aged animal. 
Figure 6.1

\section{Mechanism for Oxidant Production via Xanthine Oxidase}

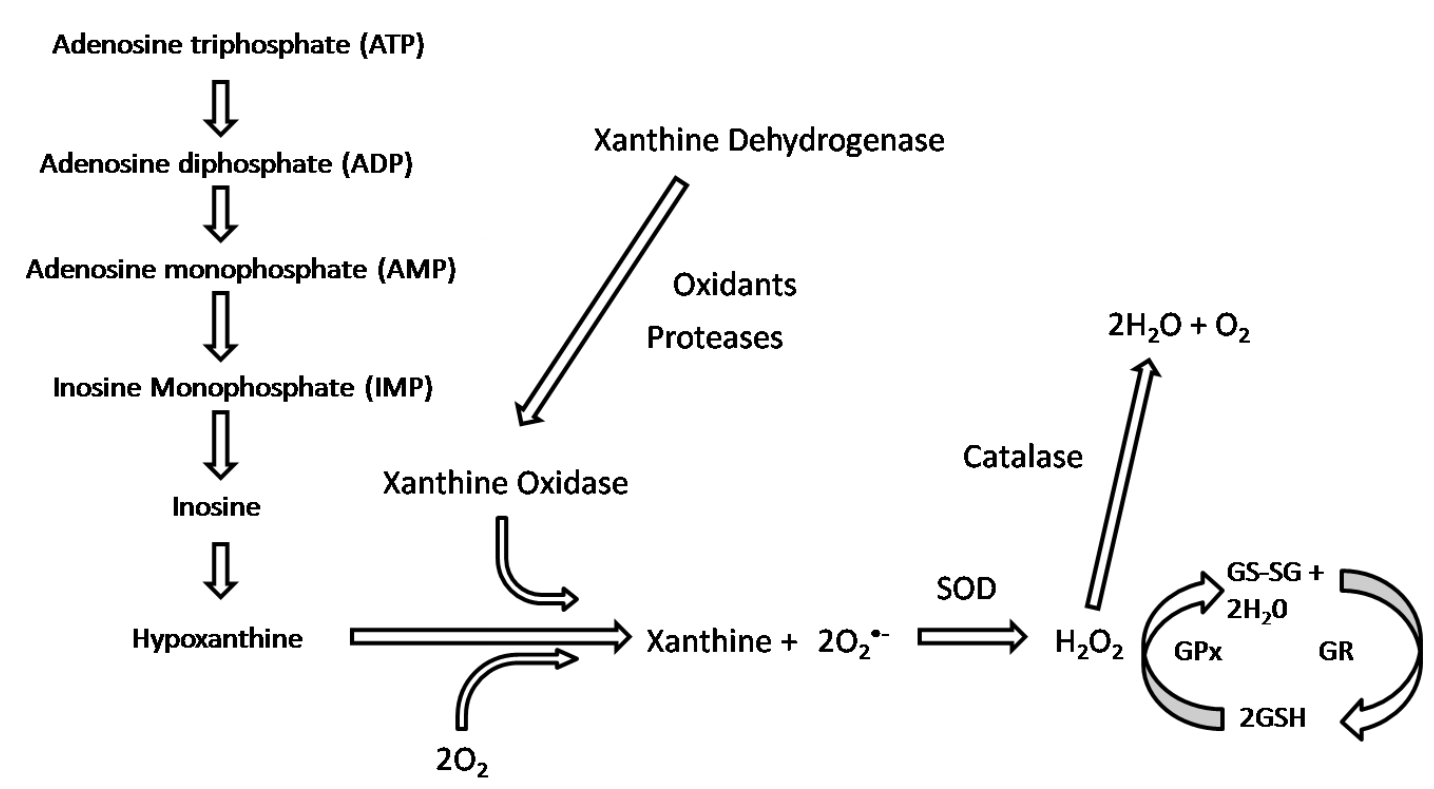


Figure 6.2
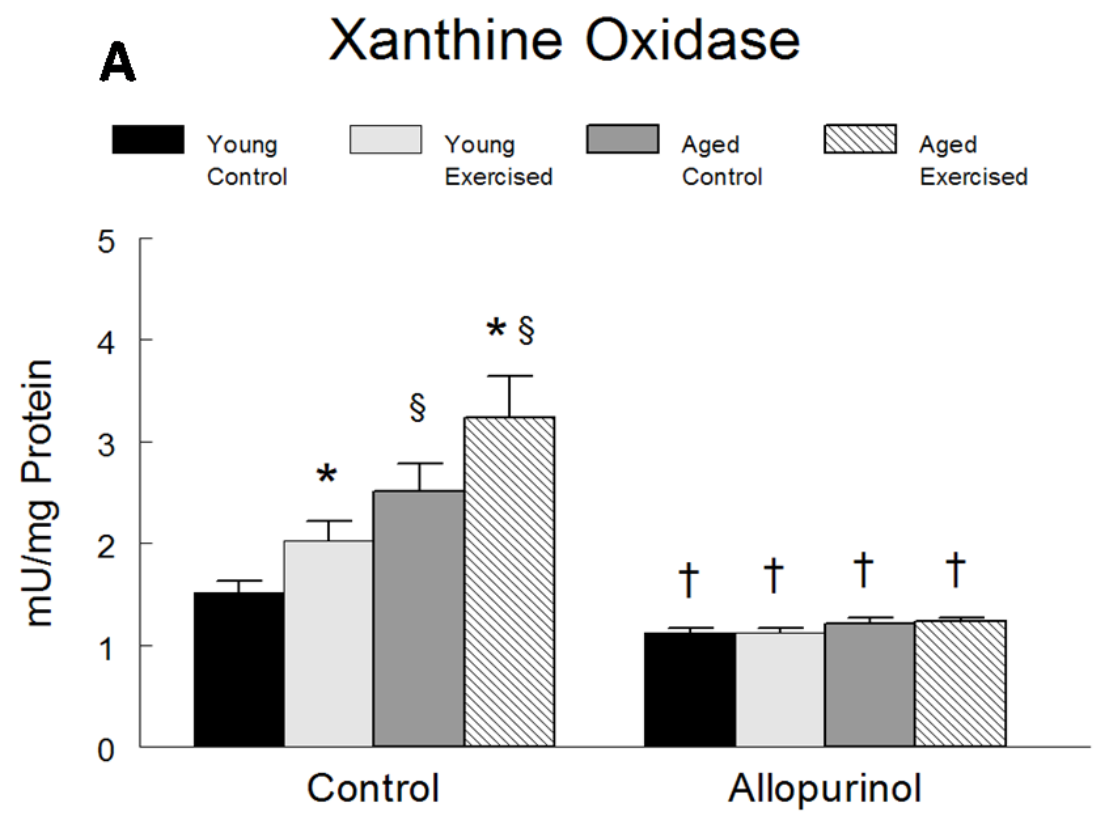

B

Hypoxanthine

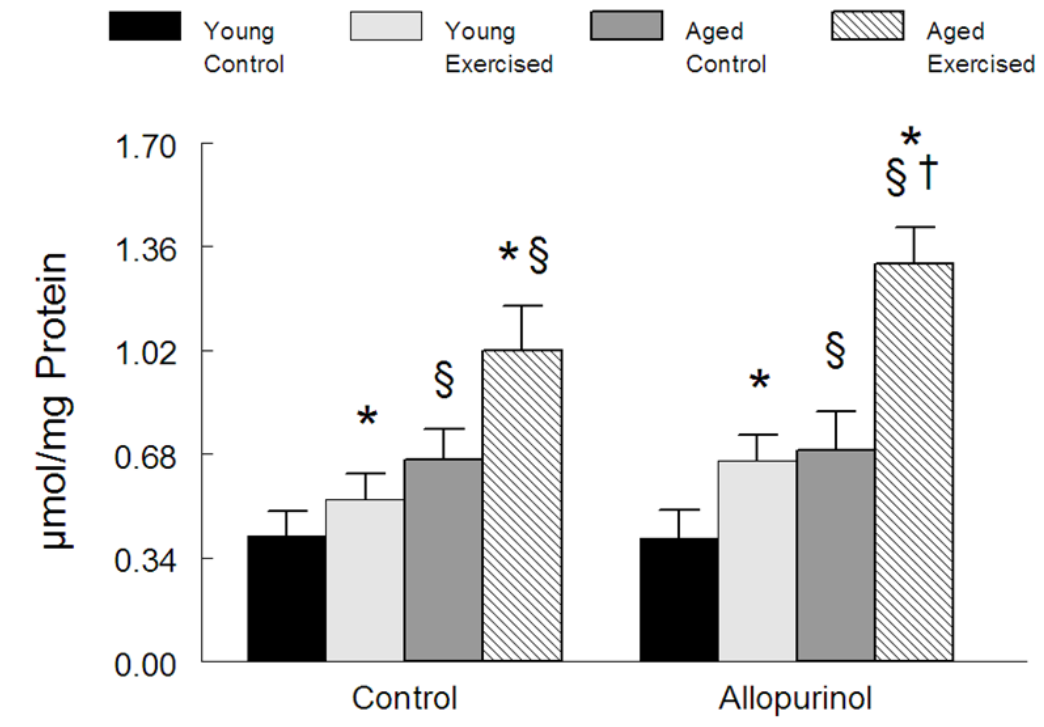


Figure 6.3
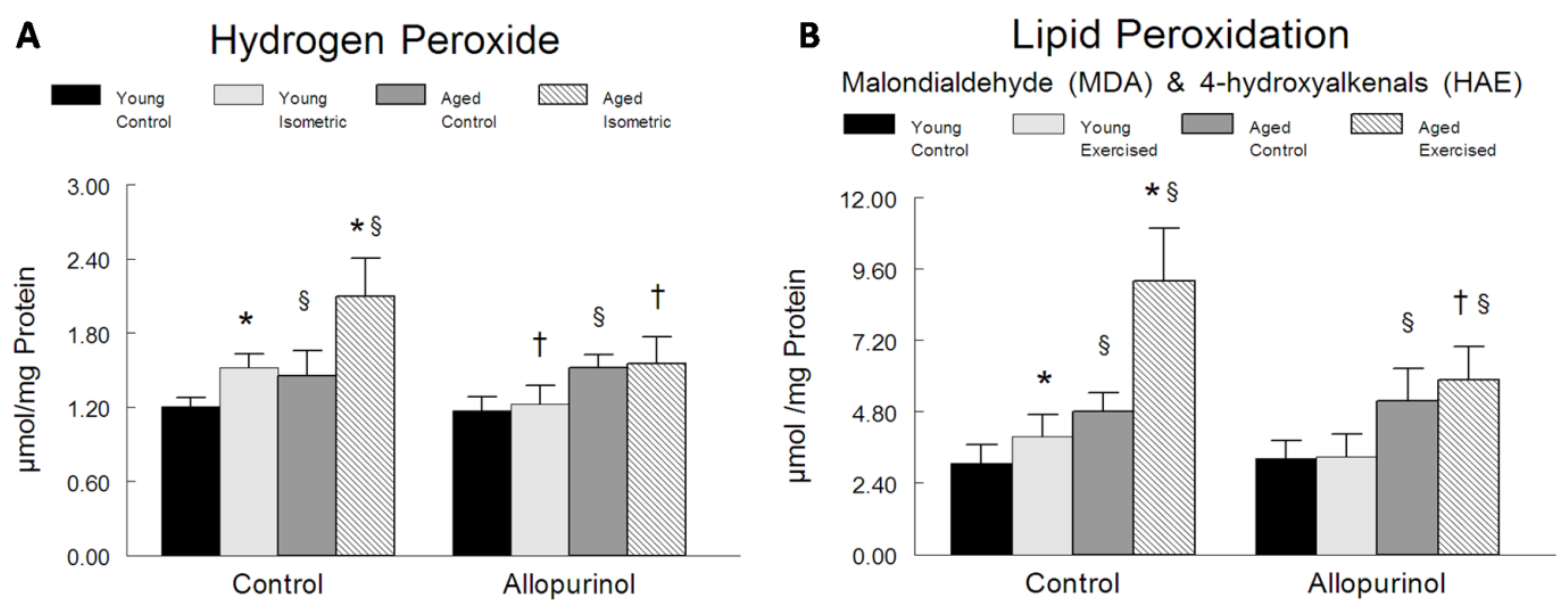
Figure 6.4
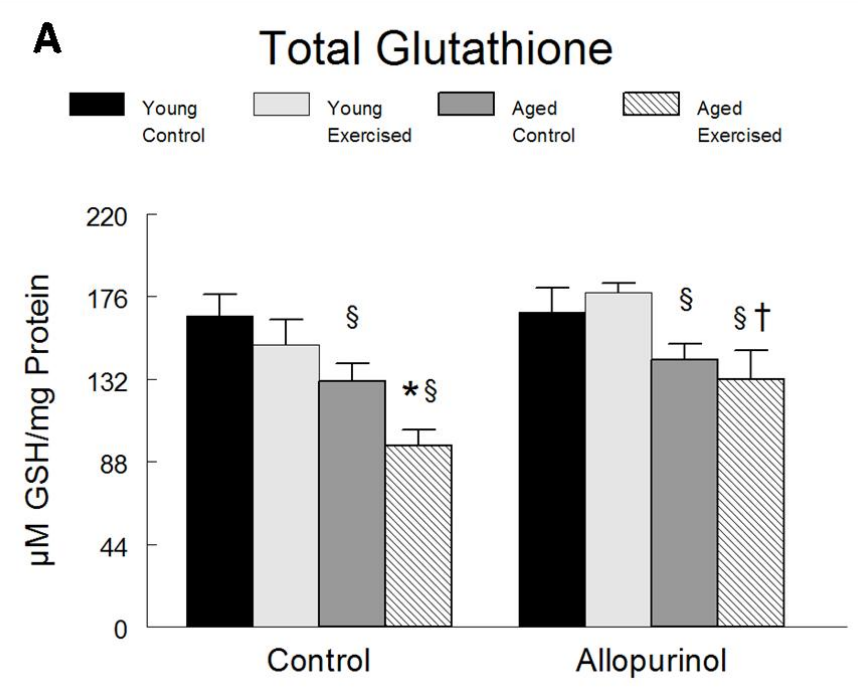

B

B Oxidized Glutathione
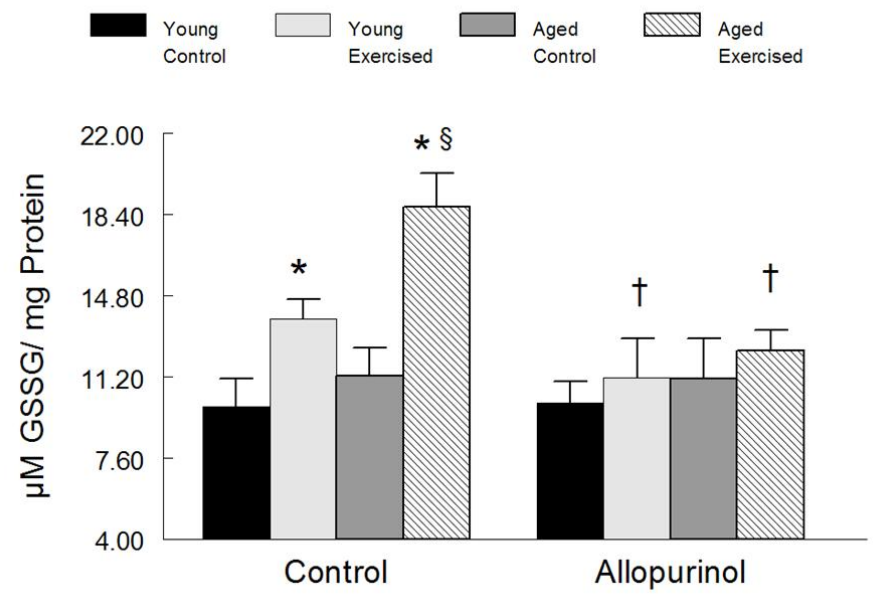

C

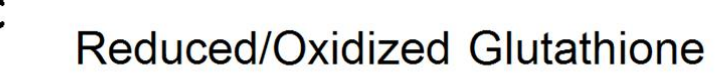

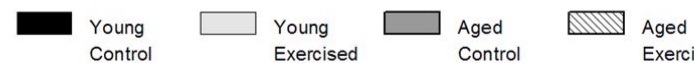

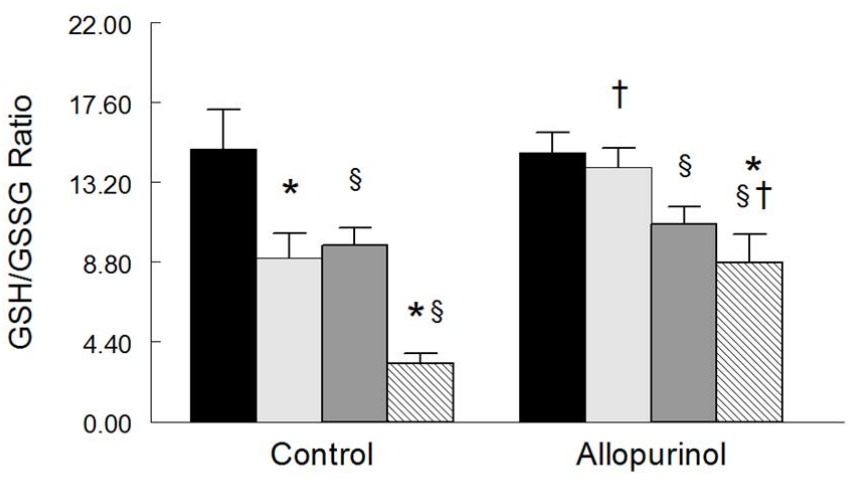


Figure 6.5
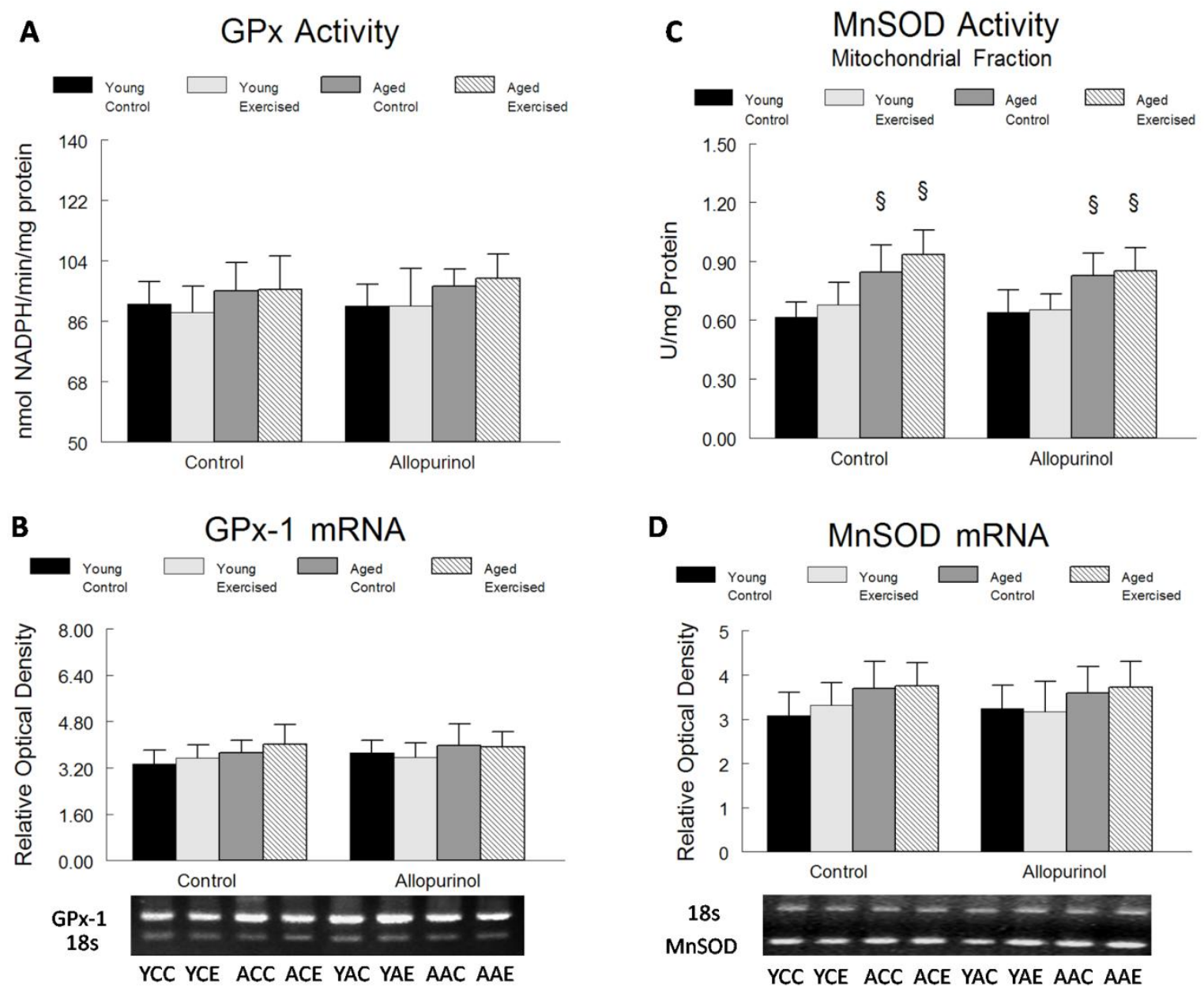
Figure 6.6
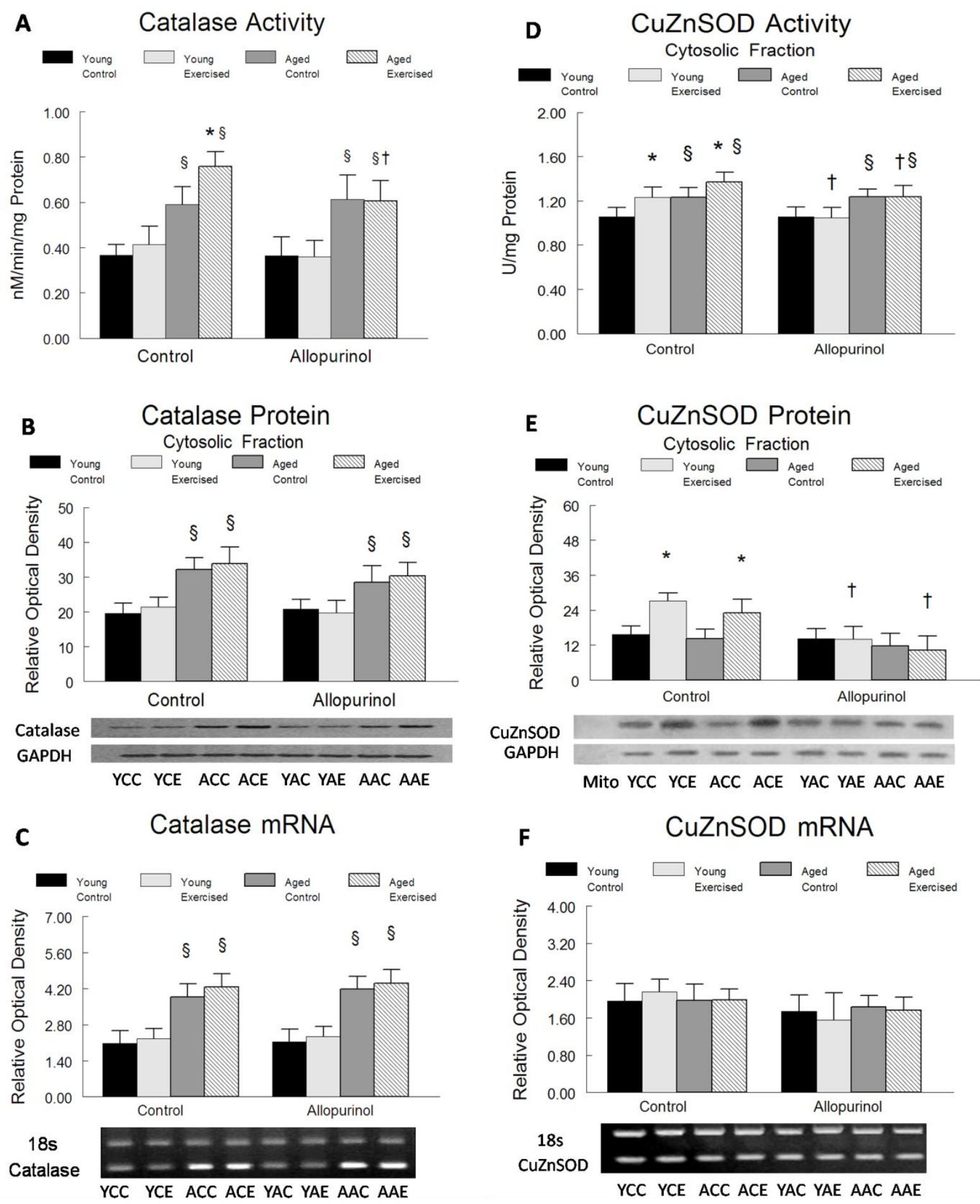
Figure 6.7
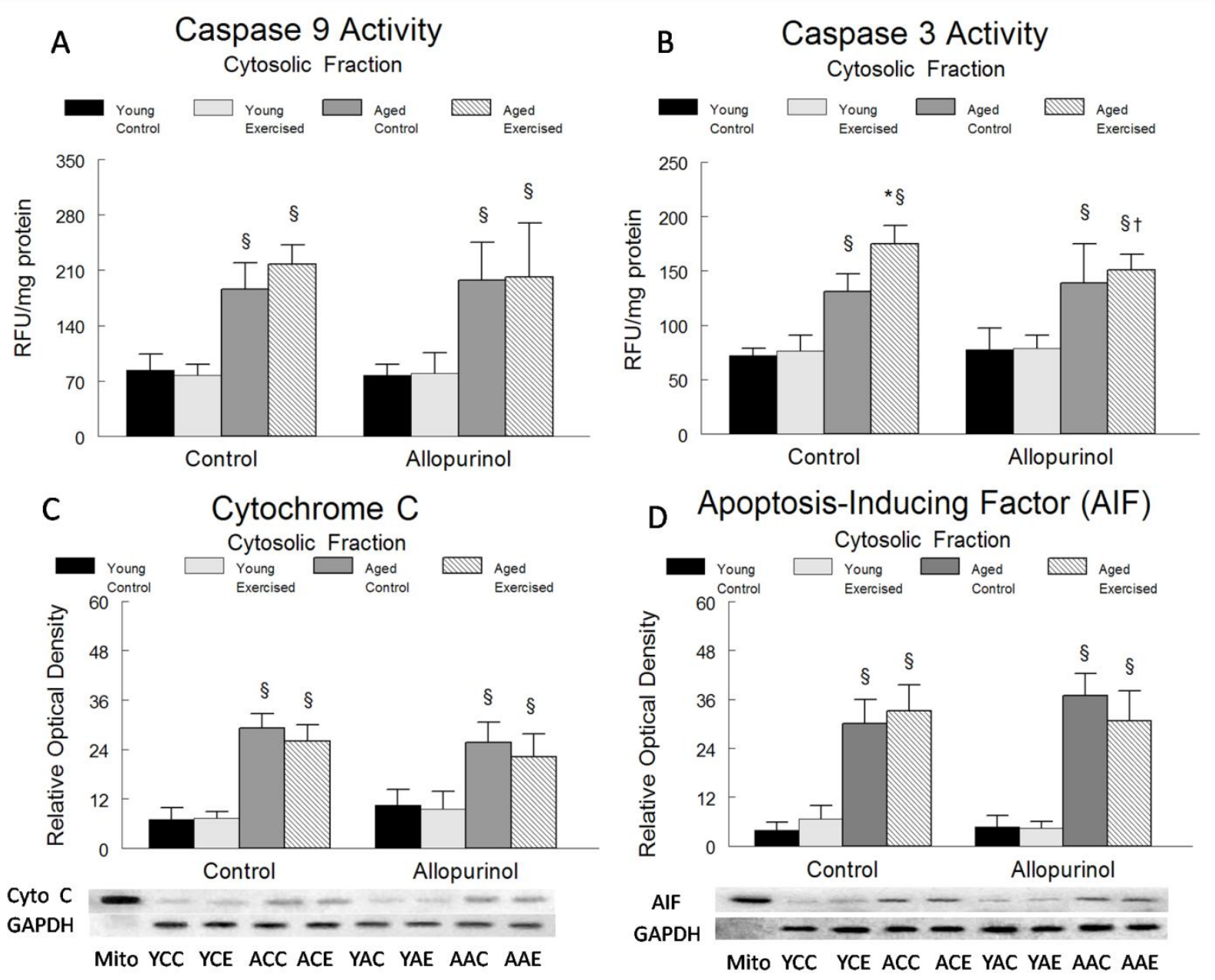
Figure 6.8

A Maximal Isometric Force Comparison of the first contraction on days $1 \& 3$

Young Control MW Young Allopurinol

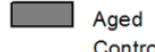

Aged
Control

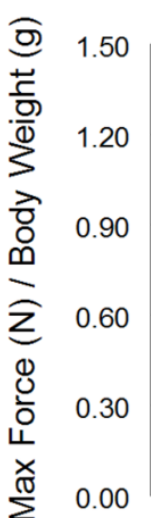

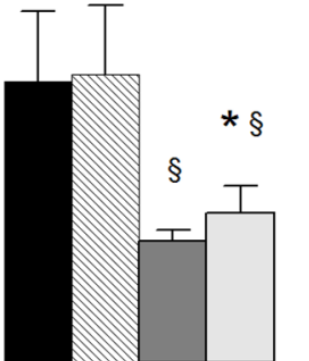

Day1

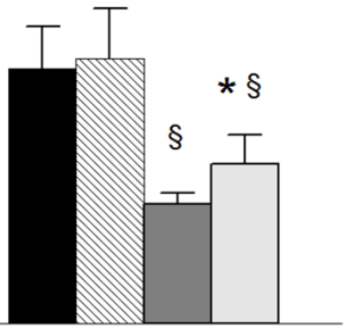

Day3
Aged Allopurinol

B Decline in Maximal Isometric Force Each Contraction of 3rd Day

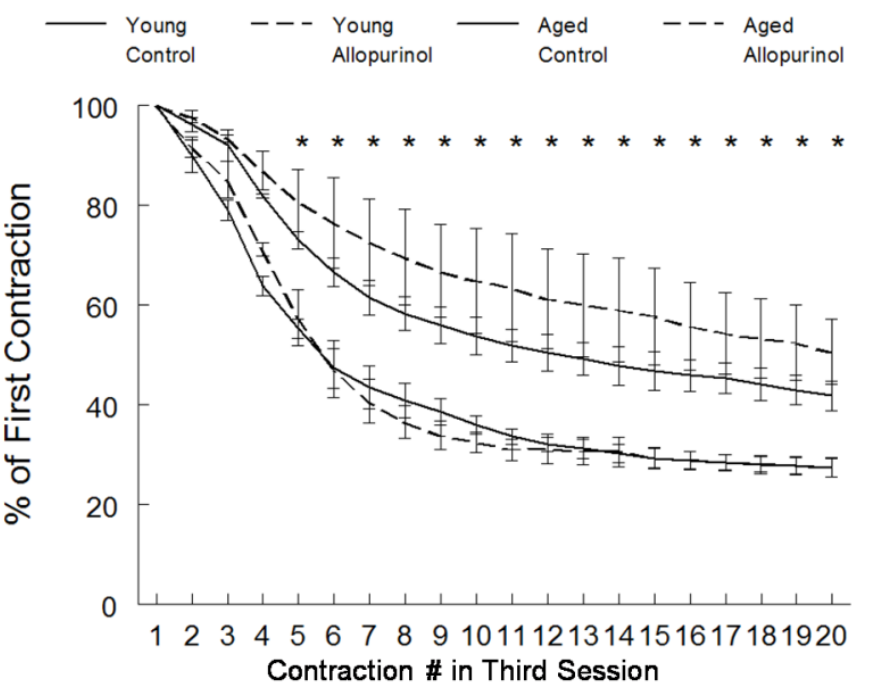

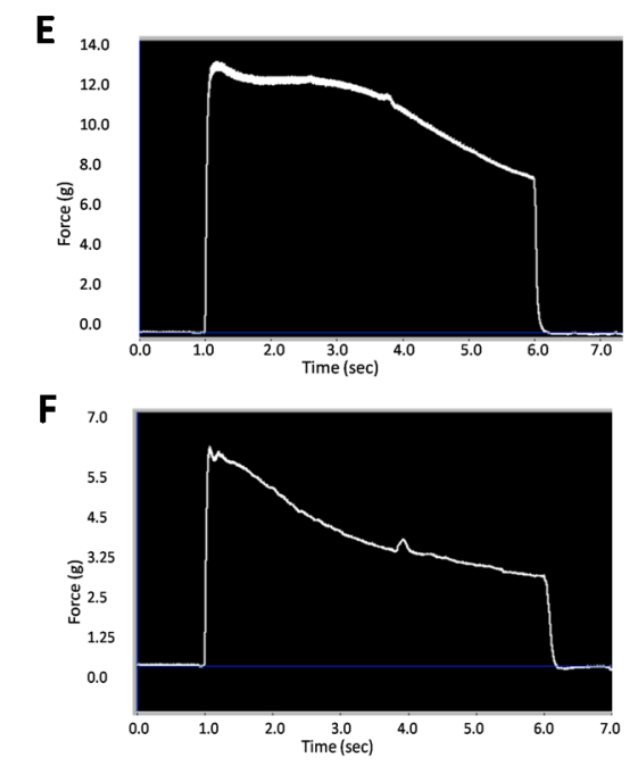
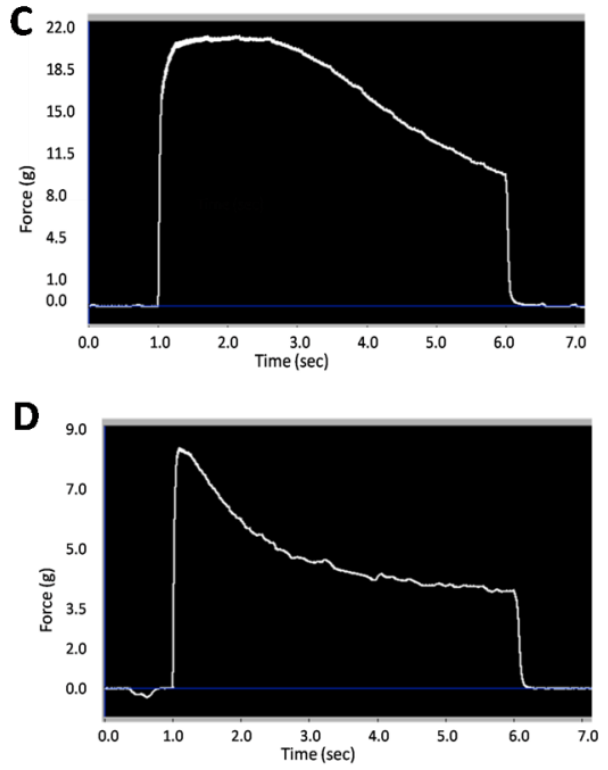
Reference List

1. Alessio HM, Hagerman AE, Fulkerson BK, Ambrose J, Rice RE and Wiley RL. Generation of reactive oxygen species after exhaustive aerobic and isometric exercise. Med Sci Sports Exerc 32: 1576-1581, 2000.

2. Andrade FH, Reid MB, Allen DG and Westerblad H. Effect of hydrogen peroxide and dithiothreitol on contractile function of single skeletal muscle fibres from the mouse. $J$ Physiol 509 ( Pt 2): 565-575, 1998.

3. Aranda R, Domenech E, Rus AD, Real JT, Sastre J, Vina J and Pallardo FV. Agerelated increase in xanthine oxidase activity in human plasma and rat tissues. Free Radic Res 41: 1195-1200, 2007.

4. Ashraf $\mathbf{M}$ and Samra ZQ. Subcellular-Distribution of Xanthine-Oxidase During Cardiac Ischemia and Reperfusion - An Immunocytochemical Study. J Submicr Cyt Path 25: 193-201, 1993.

5. Bejma $\mathbf{J}$ and Ji LL. Aging and acute exercise enhance free radical generation in rat skeletal muscle. J Appl Physiol 87: 465-470, 1999.

6. Bianchi GP, Grossi G, Bargossi AM, Fiorella PL and Marchesini G. Can oxypurines plasma levels classify the type of physical exercise? J Sports Med Phys Fitness 39: 123127, 1999.

7. Clanton TL, Zuo $\mathbf{L}$ and Klawitter P. Oxidants and skeletal muscle function: physiologic and pathophysiologic implications. Proc Soc Exp Biol Med 222: 253-262, 1999.

8. Corte ED and Stirpe F. The regulation of rat liver xanthine oxidase. Involvement of thiol groups in the conversion of the enzyme activity from dehydrogenase (type D) into oxidase (type O) and purification of the enzyme. Biochem J 126: 739-745, 1972.

9. Davies KJ, Quintanilha AT, Brooks GA and Packer L. Free radicals and tissue damage produced by exercise. Biochem Biophys Res Commun 107: 1198-1205, 1982.

10. Delample D, Durand F, Severac A, Belghith M, Mas E, Michel F, Cristol JP, Hayot M and Prefaut C. Implication of xanthine oxidase in muscle oxidative stress in COPD patients. Free Radic Res 42: 807-814, 2008.

11. DeMartino GN and Ordway GA. Ubiquitin-proteasome pathway of intracellular protein degradation: implications for muscle atrophy during unloading. Exerc Sport Sci Rev 26: 219-252, 1998.

12. Dirks AJ and Leeuwenburgh C. Aging and lifelong calorie restriction result in adaptations of skeletal muscle apoptosis repressor, apoptosis-inducing factor, X-linked inhibitor of apoptosis, caspase-3, and caspase-12. Free Radic Biol Med 36: 27-39, 2004.

13. Doherty TJ. Aging and sarcopenia. Journal of Applied Physiology 95: 1717-1727, 2003.

14. Duarte JA, Appell HJ, Carvalho F, Bastos ML and Soares JM. Endothelium-derived oxidative stress may contribute to exercise-induced muscle damage. Int J Sports Med 
14: 440-443, 1993.

15. Eskurza I, Kahn ZD and Seals DR. Xanthine oxidase does not contribute to impaired peripheral conduit artery endothelium-dependent dilatation with ageing. J Physiol 571: 661-668, 2006.

16. Fulle S, Protasi F, Di Tano G, Pietrangelo T, Beltramin A, Boncompagni S, Vecchiet $\mathbf{L}$ and Fano $\mathbf{G}$. The contribution of reactive oxygen species to sarcopenia and muscle ageing. Experimental Gerontology 39: 17-24, 2004.

17. Gomez-Cabrera MC, Borras C, Pallardo FV, Sastre J, Ji LL and Vina J. Decreasing xanthine oxidase-mediated oxidative stress prevents useful cellular adaptations to exercise in rats. J Physiol 567: 113-120, 2005.

18. Gomez-Cabrera MC, Close GL, Kayani AC, McArdle A, Vina J and Jackson MJ. Effect of xanthine oxidase-generated extracellular superoxide on skeletal muscle force generation. Am J Physiol Regul Integr Comp Physiol 298: R2-R8, 2010.

19. Gomez-Cabrera MC, Martinez A, Santangelo G, Pallardo FV, Sastre J and Vina J. Oxidative stress in marathon runners: interest of antioxidant supplementation. $\mathrm{Br} J$ Nutr 96 Suppl 1: S31-S33, 2006.

20. Gomez-Cabrera MC, Pallardo FV, Sastre J, Vina J and Garcia-del-Moral L. Allopurinol and markers of muscle damage among participants in the Tour de France. JAMA 289: 2503-2504, 2003.

21. Harman D. Aging: a theory based on free radical and radiation chemistry. J Gerontol 11: 298-300, 1956.

22. Hellsten $\mathbf{Y}$, Ahlborg G, Jensen-Urstad M and Sjodin B. Indication of in vivo xanthine oxidase activity in human skeletal muscle during exercise. Acta Physiol Scand 134: 159160, 1988.

23. Hellsten Y, Frandsen U, Orthenblad N, Sjodin B and Richter EA. Xanthine oxidase in human skeletal muscle following eccentric exercise: a role in inflammation. J Physiol 498 ( Pt 1): 239-248, 1997.

24. Hibaoui Y, Roulet E and Ruegg UT. Melatonin prevents oxidative stress-mediated mitochondrial permeability transition and death in skeletal muscle cells. $J$ Pineal Res 47: 238-252, 2009.

25. Hollander J, Bejma J, Ookawara T, Ohno H and Ji LL. Superoxide dismutase gene expression in skeletal muscle: fiber-specific effect of age. Mech Ageing Dev 116: 33-45, 2000.

26. Hollander J, Fiebig R, Gore M, Ookawara T, Ohno H and Ji LL. Superoxide dismutase gene expression is activated by a single bout of exercise in rat skeletal muscle. Pflugers Arch 442: 426-434, 2001.

27. Holloszy JO, Chen M, Cartee GD and Young JC. Skeletal muscle atrophy in old rats: differential changes in the three fiber types. Mech Ageing Dev 60: 199-213, 1991. 
28. Houston M, Estevez A, Chumley P, Aslan M, Marklund S, Parks DA and Freeman BA. Binding of xanthine oxidase to vascular endothelium. Kinetic characterization and oxidative impairment of nitric oxide-dependent signaling. J Biol Chem 274: 4985-4994, 1999.

29. Jackson MJ, Pye $\mathbf{D}$ and Palomero J. The production of reactive oxygen and nitrogen species by skeletal muscle. J Appl Physiol 102: 1664-1670, 2007.

30. Jang YC, Lustgarten MS, Liu Y, Muller FL, Bhattacharya A, Liang H, Salmon AB, Brooks SV, Larkin L, Hayworth CR, Richardson A and Van Remmen H. Increased superoxide in vivo accelerates age-associated muscle atrophy through mitochondrial dysfunction and neuromuscular junction degeneration. FASEB J 2009.

31. Ji LL. Antioxidant signaling in skeletal muscle: a brief review. Exp Gerontol 42: 582-593, 2007.

32. Ji LL, Gomez-Cabrera MC, Steinhafel N and Vina J. Acute exercise activates nuclear factor (NF)-kappaB signaling pathway in rat skeletal muscle. FASEB J 18: 1499-1506, 2004.

33. Ji LL, Gomez-Cabrera MC and Vina J. Role of nuclear factor kappaB and mitogenactivated protein kinase signaling in exercise-induced antioxidant enzyme adaptation. Appl Physiol Nutr Metab 32: 930-935, 2007.

34. Ji LL, Leeuwenburgh C, Leichtweis S, Gore M, Fiebig R, Hollander $\mathbf{J}$ and Bejma J. Oxidative stress and aging. Role of exercise and its influences on antioxidant systems. Ann N Y Acad Sci 854: 102-117, 1998.

35. Kagan VE, Tyurina YY, Bayir H, Chu CT, Kapralov AA, Vlasova II, Belikova NA, Tyurin VA, Amoscato A, Epperly M, Greenberger J, Dekosky S, Shvedova AA and Jiang $\mathbf{J}$. The "pro-apoptotic genies" get out of mitochondria: oxidative lipidomics and redox activity of cytochrome c/cardiolipin complexes. Chem Biol Interact 163: 15-28, 2006.

36. Kocturk S, Kayatekin BM, Resmi H, Acikgoz O, Kaynak C and Ozer E. The apoptotic response to strenuous exercise of the gastrocnemius and solues muscle fibers in rats. Eur J Appl Physiol 102: 515-524, 2008.

37. Kondo H, Kodama J, Kishibe T and Itokawa Y. Oxidative Stress During Recovery from Muscle Atrophy. FEBS Lett 326: 189-191, 1993.

38. Kramer HF and Goodyear LJ. Exercise, MAPK, and NF-kappaB signaling in skeletal muscle. J Appl Physiol 103: 388-395, 2007.

39. Leeuwenburgh $\mathbf{C}$ and Heinecke JW. Oxidative stress and antioxidants in exercise. Current Medicinal Chemistry 8: 829-838, 2001.

40. Li YP, Chen Y, Li AS and Reid MB. Hydrogen peroxide stimulates ubiquitin-conjugating activity and expression of genes for specific E2 and E3 proteins in skeletal muscle 
myotubes. Am J Physiol Cell Physiol 285: C806-C812, 2003.

41. Lysiak JJ, Zheng S, Woodson R and Turner TT. Caspase-9-dependent pathway to murine germ cell apoptosis: mediation by oxidative stress, BAX, and caspase 2. Cell Tissue Res 328: 411-419, 2007.

42. Mantovani G, Madeddu C, Maccio A, Gramignano G, Lusso MR, Massa E, Astara G and Serpe R. Cancer-related anorexia/cachexia syndrome and oxidative stress: an innovative approach beyond current treatment. Cancer Epidemiol Biomarkers Prev 13: 1651-1659, 2004.

43. McArdle A and Jackson MJ. Exercise, oxidative stress and ageing. J Anat $197 \mathrm{Pt} 4$ : 539-541, 2000.

44. McCord JM, Roy RS and Schaffer SW. Free radicals and myocardial ischemia. The role of xanthine oxidase. Adv Myocardiol 5: 183-189, 1985.

45. McNally JS, Saxena A, Cai H, Dikalov S and Harrison DG. Regulation of xanthine oxidoreductase protein expression by hydrogen peroxide and calcium. Arterioscler Thromb Vasc Biol 25: 1623-1628, 2005.

46. Meng Q, Wong $\mathbf{Y T}$, Chen $\mathbf{J}$ and Ruan R. Age-related changes in mitochondrial function and antioxidative enzyme activity in fischer 344 rats. Mech Ageing Dev 128: 286-292, 2007.

47. Muller FL, Song W, Liu YH, Chaudhuri A, Pieke-Dahl S, Strong R, Huang TT, Epstein CJ, Roberts LJ, Csete M, Faulkner JA and Van Remmen H. Absence of CuZn superoxide dismutase leads to elevated oxidative stress and acceleration of agedependent skeletal muscle atrophy. Free Radic Biol Med 40: 1993-2004, 2006.

48. Nishino $\mathbf{T}$ and Nishino $\mathbf{T}$. The conversion from the dehydrogenase type to the oxidase type of rat liver xanthine dehydrogenase by modification of cysteine residues with fluorodinitrobenzene. J Biol Chem 272: 29859-29864, 1997.

49. Pansarasa O, Bertorelli L, Vecchiet J, Felzani G and Marzatico F. Age-dependent changes of antioxidant activities and markers of free radical damage in human skeletal muscle. Free Radic Biol Med 27: 617-622, 1999.

50. Pansarasa $\mathbf{O}$, Felzani $\mathbf{G}$, Vecchiet $\mathbf{J}$ and Marzatico $\mathbf{F}$. Antioxidant pathways in human aged skeletal muscle: relationship with the distribution of type II fibers. Exp Geronto/ 37: 1069-1075, 2002.

51. Parks DA, Williams TK and Beckman JS. Conversion of xanthine dehydrogenase to oxidase in ischemic rat intestine: a reevaluation. Am J Physiol 254: G768-G774, 1988.

52. Pistilli EE and Alway SE. Systemic elevation of interleukin-15 in vivo promotes apoptosis in skeletal muscles of young adult and aged rats. Biochem Biophys Res Commun 373: 20-24, 2008.

53. Radak Z, Asano K, Inoue M, Kizaki T, Oh-Ishi S, Suzuki K, Taniguchi N and Ohno H. Superoxide dismutase derivative reduces oxidative damage in skeletal muscle of rats 
during exhaustive exercise. J Appl Physiol 79: 129-135, 1995.

54. Reid MB. Free radicals and muscle fatigue: Of ROS, canaries, and the IOC. Free Radic Biol Med 44: 169-179, 2008.

55. Ristow M, Zarse K, Oberbach A, Kloting N, Birringer M, Kiehntopf M, Stumvoll M, Kahn CR and Bluher M. Antioxidants prevent health-promoting effects of physical exercise in humans. Proc Natl Acad Sci U S A 106: 8665-8670, 2009.

56. Ryan MJ, Dudash HJ, Docherty M, Geronilla KB, Baker BA, Haff GG, Cutlip RG and Alway SE. Aging-Dependent Regulation of Antioxidant Enzymes and Redox Status in Chronically Loaded Rat Dorsiflexor Muscles. J Gerontol A Biol Sci Med Sci 63: 10151026, 2008.

57. Ryan MJ, Jackson JR and Alway SE. Suppresion of oxidative stress by resveratrol after isometric contractions in gastrocnemius muscles of aged mice. J Gerontol A Biol Sci Med Sci In Press: 2010.

58. Sachdev S and Davies KJA. Production, detection, and adaptive responses to free radicals in exercise. Free Radic Biol Med 44: 215-223, 2008.

59. Schoutsen B and de Jong JW. Age-dependent increase in xanthine oxidoreductase differs in various heart cell types. Circ Res 61: 604-607, 1987.

60. Siu PM, Pistilli EE and Alway SE. Apoptotic responses to hindlimb suspension in gastrocnemius muscles from young adult and aged rats. Am J Physiol Regul Integr Comp Physiol 289: R1015-R1026, 2005.

61. Siu PM, Wang Y and Alway SE. Apoptotic signaling induced by $\mathrm{H} 2 \mathrm{O} 2$-mediated oxidative stress in differentiated C2C12 myotubes. Life Sciences 84: 468-481, 2009.

62. Vasilaki A, Mansouri A, Remmen H, van der Meulen JH, Larkin L, Richardson AG, McArdle A, Faulkner JA and Jackson MJ. Free radical generation by skeletal muscle of adult and old mice: effect of contractile activity. Aging Cell 5: 109-117, 2006.

63. Vina J, Gimeno A, Sastre J, Desco C, Asensi M, Pallardo FV, Cuesta A, Ferrero JA, Terada LS and Repine JE. Mechanism of free radical production in exhaustive exercise in humans and rats; role of xanthine oxidase and protection by allopurinol. IUBMB Life 49: 539-544, 2000.

64. Wouters EF, Creutzberg EC and Schols AM. Systemic effects in COPD. Chest 121: 127S-130S, 2002.

65. Zerba E, Komorowski TE and Faulkner JA. Free radical injury to skeletal muscles of young, adult, and old mice. Am J Physiol 258: C429-C435, 1990.

66. Zhang Y, Ikeno Y, Qi W, Chaudhuri A, Li Y, Bokov A, Thorpe SR, Baynes JW, Epstein C, Richardson A and Van RH. Mice deficient in both Mn superoxide dismutase and glutathione peroxidase- 1 have increased oxidative damage and a greater incidence of pathology but no reduction in longevity. J Gerontol A Biol Sci Med Sci 64: 1212-1220, 2009. 


\section{Chapter 7}

\section{Summary and Conclusions}

Michael J. Ryan 


\section{Summary of research findings}

The data presented in this project are consistent with previous studies that have shown an increase in oxidative stress within the skeletal muscle environment in response to exercise $(1,18,21,29,65,97)$ and advanced aging $(7,20,25,38,53,72,77,101)$. Specifically, in this study exercise and aging elevated lipid peroxidation, xanthine oxidase activity, the concentration of $\mathrm{H}_{2} \mathrm{O}_{2}$, and decreased the GSH/GSSG ratio in skeletal muscle. In addition, there was an agerelated exacerbation of exercise-induced oxidative stress in the aged muscle. Together, these data provide support for a new hypothesis: increases in xanthine oxidase activity are responsible for the majority of the oxidative stress associated with resistance training models of anaerobic exercise.

The inhibition of xanthine oxidase by allopurinol attenuated the increase in oxidative stress associated with isometric exercise, but reduction of xanthine oxidase did not reduce oxidative stress that was associated with aging. These conclusions support the central hypothesis of this project that "skeletal muscles from aged animals will show increased evidence of oxidative stress during resistance exercise (repetitive loading) and antioxidant supplementation will increase the aged muscles' oxidative buffering capacity, thus attenuating the increase in oxidative stress associated with aging. Increased xanthine oxidase activity will be a contributing factor to the increase in oxidative stress in response to resistance exercise (i.e. repetitive loading) and aging". One difference from the original hypothesis that was not supported by the data were that the age related increase in xanthine oxidase activity did not appear to be a contributing factor to the oxidative stress associated with aging.

Another objective of this investigation was to evaluate the efficacy of reducing oxidative stress on the adaptive response of skeletal muscle to repetitive loading exercise in aging rodents. To achieve this objective, three methods of reducing oxidative stress were utilized; the antioxidants vitamins E\&C were used to buffer oxidants (specific aim 1), the nutraceutical resveratrol was used to inhibit oxidant production (specific aim 2) and the pharmacological agent allopurinol was used to attenuate oxidant production specifically through the inhibition of xanthine oxidase activity (specific aim 3). While all three approaches effectively lowered oxidative stress $\left(\mathrm{H}_{2} \mathrm{O}_{2}\right.$, the $\mathrm{GSH} / \mathrm{GSSG}$ ratio, lipid peroxidation) associated with exercise, there was not a consistent pattern of response in endogenous antioxidant enzymes to the experimental interventions used in this study.

\section{The affects of reducing oxidative stress on muscle function}

Oxidative stress has been shown to depress muscular force (12), alter myofilament function $(2,58)$, mediate muscle fatigue $(88)$ and/or modify contraction-induced calcium release $(3,19,22,82)$. Therefore, it was hypothesized in all three of the specific aims of this investigation that reducing aging related oxidative stress would improve muscle function in the aged animals. The animal models of in vivo repetitive loading that were implemented in these studies proved useful because the input parameters on the muscle were tightly controlled, thus any changes in performance parameters can be attributed to alterations within the muscle environment. Although methods using resistance training in conscious animals have been developed $(98,99)$, there are several problems with these approaches: a) it is difficult to motivate animals to exercise with resistance loads, b) using food rewards for exercise in aged animals is problematic and will result in loss of body weight, c) rests interval between repetitions in voluntary exercise are variable, and d) animal compliance to repeated voluntary 
exercise is poor. Therefore, conscious animals models cannot rule out the possibility that changes in input parameters affect the results. Within the scope of the current studies the biomechanical loading signature (input parameters, i.e. frequency, intensity, duration along of the contraction along with the direction of movement and the speed of movement) for each contraction was identical. Because all motor units within the muscles were contracted simultaneously, the current models eliminated preferential fiber type recruit patterns. Although in the current models of repetitive loading the physiological recruitment patterns were altered, the force produced was within the physiological capabilities of the muscle. Within endurance training models of exercise; the ramp principle of fiber type recruitment would imply that at low to moderate intensities the slow oxidative and/or fast glycolytic-oxidative fibers would contract a greater number of times than the fast glycolytic fibers, which may result in "pockets" of greater oxidative stress based on input parameters.

In general, the current data supports the notion that muscle function declines with advanced aging, yet muscle is still able to adapt to exercise $(10,24,37,60,92,93)$. Nevertheless, these adaptations are generally less than that reported in muscles from young adults. While some elements of muscle function were improved, other aspects of function did not improve when oxidative stress was reduced. For example, vitamin E\&C supplementation in the aged rats showed a 38\% improvement in positive work, but failed to improve either maximal force or negative work. Resveratrol supplementation did not improve maximal isometric force; however, somewhat surprisingly it did improve the young muscles ability to resist fatigue without affecting the fatigue in the aged muscle. Furthermore, allopurinol administration improved maximal isometric force in the aged animals, but failed to show any significant improvements in the fatigue resistance.

The improvements in positive work with vitamin E\&C supplementation and the increase in maximal isometric force produced in the animals administered allopurinol can be directly related to the reduction in oxidative stress. However, with resveratrol supplementation it is unknown if the improved resistance to fatigue was a result of an increase in ATP availability or a diminished exercise-induced oxidant formation. Previous studies have reported that resveratrol supplementation reduced fatigue associated with aerobic exercise $(6,62)$. The increased resistance to fatigue has been attributed to increases in the density and efficiency of the proteins associated with the mitochondrial electron transport chain, by increasing $\beta$-oxidation and/or by increasing ATPase content $(6,62,80,95)$. These novel data represent the first evidence that resveratrol can reduce muscle fatigue in response to repetitive anaerobic (isometric) contractions.

\section{Responses of endogenous antioxidant enzymes to exercise}

Proper control of expression and activity of the endogenous antioxidant enzymes is the key component to the maintenance of redox homeostasis. Many of the endogenous antioxidant enzymes have been shown to be controlled via both transcriptional regulators and posttranscriptional and/or post-translational mechanisms. The antioxidant enzymes may be rapidly activated to manage acute oxidative stress due to a single bout of exercise or gradually upregulated in response to chronic oxidative stress associated with aging or exercise training. However the overall response to either acute or chronic exercise may vary depending on the mode of exercise and the fiber type make up of the muscle $(5,39,41,46,55,64,78,79,83$, 84).

The majority of the research on the response of the antioxidant enzyme to exercise training has utilized moderate to exhaustive endurance activity as the mode of exercise. Some 
of the general conclusions have shown that; (I) MnSOD activity has consistently been shown to increase with exercise training in an intensity-dependent manner(39, 46, 63, 64, 83), whereas CuZnSOD activity shows little change to chronic training(33, 39, 46, 55, 63). (II) GPx activity increases after endurance training $(64,84)$, and (III) exercise training effects on catalase activity has produced conflicting results $(33,39,55,63,64,83)$.

Mitogen-activated protein kinases (MAPKs) and nuclear factor kappaB (NF-KB) are two major redox-sensitive signal transduction pathways that have been shown to activate the gene expression of a number of enzymes and proteins that have an important role in the management of oxidative stress (52). Elevated oxidant production associated with exercise has been shown to activate MAPK, which in turn activates NF-kB in skeletal muscle resulting in increased gene expression of MnSOD and catalase $(30,50,59)$. When antioxidants are used to diminish exercised induced oxidative stress it has been shown to attenuate the activation of the MAPK/ NF-KB signaling pathway resulting in a failure of exercise to elevate gene expression of endogenous antioxidant enzymes MnSOD and catalase.

\section{MnSOD Regulation}

The response of MnSOD to acute and chronic aerobic exercise has been widely studied. An acute bout of aerobic exercise has been shown to up-regulate NF-kB expression and activation leading to elevated MnSOD expression $(30,34,44,76)$. Tumor necrosis factor-alpha (TNFa), Interleukin-1(IL-1) and early growth-responsive-1 (Egr-1) have all been shown to upregulate MnSOD gene expression through interactions with NF-KB binding to the promoter region of the MnSOD gene $(17,40,56,69)$.

Chronic endurance training has been shown to increase mRNA expression and increase both the protein content and activity of MnSOD (76). This suggests that in response to chronic endurance training MnSOD activity increased by transcriptional control. However, this is not a universal finding; Gore et al. (34) showed that endurance training in rats increased protein concentration of MnSOD by $66 \%$, but had no affect on MnSOD mRNA abundance or enzyme activity. One difference between these two studies was the muscle in which MnSOD activity was measured from; the first being the soleus and the second the deep vastus lateralis. The soleus consists of primarily slow oxidative fibers while the deep vastus lateralis is composed of a large percentage of fast oxidative-glycolytic fibers. However, chronic exercise has been shown to change the enzymatic profile of the deep vastus lateralis to become similar to a slow oxidative fiber (35). Based on that evidence, it would be expected that the MnSOD expression and activity would increased as the fibers became more oxidative. There is a paucity of data on the regulation of MnSOD in response to either acute or chronic resistance training. Parise et al. (79) showed that neither acute or chronic resistance training in elderly men altered MnSOD activity and recently it has been shown that acute electrical stimulation did not affect MnSOD activity but did increase mRNA expression (81).

MnSOD also requires post-translational modification to become an active enzyme (68). MnSOD protein is produced as a large precursor enzyme (apoMnSOD) with several steps of modification required to become active. The superoxide radical is the most common activator of MnSOD, when apoMnSOD is produced it contains an $\mathrm{Fe}^{2+}$ in the active site, as the concentration of superoxide increases, $\mathrm{Mn}^{2+}$ is oxidized to $\mathrm{Mn}^{3+}$, which replaces $\mathrm{Fe}^{2+}$ thereby activating the enzyme (85). Furthermore, there are several mechanisms that inactivate MnSOD, they include; metal mis-incorporation, glycation, S-glutathionylation, phosphorylation, nitration and high concentrations of $\mathrm{H}_{2} \mathrm{O}_{2}(68)$. 


\section{CuZnSOD Regulation}

It is generally thought that acute aerobic exercise will activate the CuZnSOD enzyme and increase its activity without changes in its mRNA and protein levels $(47,54)$, however not all studies have shown changes in CuZnSOD activity in response to acute exercise $(44,81,86)$. Increases in CuZnSOD activity associated with acute exercise have been suggested to be regulated via post-translational modifications to the protein (47). The most likely signal for increasing CuZnSOD activity is superoxide itself (9) and since CuZnSOD has a very short halflife, research suggests a transit regulation of the enzyme activity in response to superoxide concentrations (47). This suggestion is supported by training studies that have shown that chronic endurance exercise in rats can elevate CuZnSOD activity by $29 \%$, without changes in enzyme protein content or mRNA expression (76). As with endurance training, progressive resistance training has resulted in a significant increase in CuZnSOD activity (79) however this may be due to increased mRNA expression and protein content (26).

Few studies have shown insight into the effect of exercise on the redox sensitive gene regulation of $\mathrm{CuZnSOD}$ expression in skeletal muscle. In contrast to the promoter region in MnSOD, the promoter region of the CuZnSOD gene (SOD1) is not known to contain as many regulatory sequences (47). Interestingly, the product of the dismutation of superoxide, $\mathrm{H}_{2} \mathrm{O}_{2}$, has been shown to increase activation of CuZnSOD gene expression, due to a $\mathrm{H}_{2} \mathrm{O}_{2}$-responsive element (HRE) on the promoter region of the SOD1 gene (100).

\section{GPX Regulation}

Like MnSOD, the promoter region on the GPx contains both NFKB and AP-1 binding sites (47). The gene for GPx-1 has also been shown to have two oxygen-responsive elements (15) that in response to depleted concentrations of oxygen, increase GPx activity proportional to the elevation of mRNA expression $(14,47)$. Exercise has commonly been shown to increase GPx activity $(47,48,64)$ and similar to MnSOD the response of GPx activity to exercise training was muscle specific $(63,64,83)$. Furthermore, it has been shown that the extent of the increase in GPx activity is associated with the duration of exercise however it is relatively independent of intensity. Even though the literature consistently shows that its GPx activity is increases after an acute bout of exercise and endurance training little is known in regards to GPx's response to resistance training and what data is available does not show increases in GPx activity with progressive resistance training $(26,79)$.

\section{Catalase Regulation}

Catalase is a heme containing antioxidant enzyme whose expression is largely transcriptionally regulated (67). Catalase is regulated by transcription factors binding one of two CCAAT boxes in the promoter region $(67,75)$. Nuclear factor-Y (NF-Y) a redox sensitive transcription factor (71) has been shown to increase catalase gene expression in mouse muscle cells in response to increases in $\mathrm{H}_{2} \mathrm{O}_{2}$ concentrations (67).

The response of catalase activity to either acute or chronic exercise has produced inconsistent and sometimes conflicting results $(26,33,39,55,63,64,79,81,83)$. Catalase catalyses the conversion of $\mathrm{H}_{2} \mathrm{O}_{2}$ into water and oxygen and is found in high concentrations in the peroxisomes. The catalytic efficiency of the catalase is very high, which might explain the inconsistency in the response to exercise. Because of the high efficiency of the enzyme, increases in activity may not be needed to handle the increase in $\mathrm{H}_{2} \mathrm{O}_{2}$ associated with exercise. Catalase activity could also be linked to GPx activity, Powers et al (84), suggested 
that, when cellular levels of $\mathrm{H}_{2} \mathrm{O}_{2}$ are low, GPx is more active and catalase activity might not increase until higher $\mathrm{H}_{2} \mathrm{O}_{2}$ concentrations are achieved.

Within the scope of the current set of experiments the regulation of antioxidant enzyme levels in aged and exercised muscles occur by translational or post- translational mechanisms. A summary of the changes in activity (Figure 7.1A), protein content (Figure 7.1B) and mRNA expression (Figure 7.1C) are presented in Figure 7.1. The results from the current studies do not support transcriptional control as a mechanism leading to increases in activity of the endogenous antioxidant enzymes in response to exercise and only in the mice (specific aims 2 \& 3) did age result in an increase in catalase mRNA resulting in increased catalase activity. Across all three investigations exercise and antioxidant treatment did not result in consistent changes in the activity of the endogenous antioxidant enzymes. A possibility for this could be the different species, but also could be attributed to the different exercise protocols and different muscles that were investigated.

In sharp contrast to the observed increase in MnSOD with endurance training, both chronic and short term repetitive loading failed to alter MnSOD activity. Furthermore, consistent throughout all of the studies was an age-dependent increase in catalase activity. In the mice the elevation in catalase activity was accompanied by an increase mRNA expression, however the rats showed no increase in mRNA and/or protein levels in the rat vitamin E\&C study. The regulation of GPx appeared to be dependent on the species of rodent used in the investigation. In the rats (specific aim 1), GPx activity was significantly elevated with exercise, independent of changes in transcriptional or translational activity and was unaffected by aging. However, GPx activity was unaltered by exercise or aging within the mouse studies (specific aim $2 \& 3$ ). Activity of the catalase enzyme showed a response opposite to GPx activity in the nonantioxidant treated animals. The short term exercise program in the mice studies increased catalase activity, but chronic exercise training in the rats did not alter catalase activity.

Even though these data support the suggestion by Powers et al (84) of a differential response in catalase and GPx activity, this is not a consistent response observed by all (64). A major limitation in comparing the responses of endogenous antioxidant enzymes between the rats in the vitamin E\&C study and the mice in the resveratrol and the allopurinol investigations was the differences in the duration of the exercise protocols. The vitamin E\&C study (specific aim 1) characterized the response of antioxidant enzymes to chronic exercise, whereas the resveratrol (specific aim 2) and the allopurinol (specific aim 3) studies examined the antioxidant and short-term adaptations to isometric exercise. It is unknown if the muscles from mice would have adapted in a similar manner as the rats, if their exercise protocol was the extended for the same duration in both species of rodents.

In general these data are consistent with the notion that the activities of the endogenous antioxidant enzymes are regulated via various levels of post-transcriptional and/or posttranslational controls (42). Furthermore, the response of MnSOD to anaerobic forms of resistance exercise may differ from more commonly examined aerobic $(28,43,49)$ types of exercise. It is speculated that this may be due in part to the utilization of ATP-phoshocreatine and glycolytic metabolic pathways in resistance exercise, versus a strong dependency on oxidative phosphorylation in aerobic exercise. The current data and that of others $(26,79,81)$ support the formation of a new hypothesis stating that resistance types of exercise do not increase MnSOD activity in the same manner that has been observed with endurance exercise. 


\section{Responses of endogenous antioxidant enzymes to reducing oxidative stress}

Analogous to the responses of endogenous antioxidant enzymes to exercise and aging, overall the activities of the endogenous antioxidant enzymes in response to the different methods of reducing oxidative stress appear to be regulated via various mechanisms of posttranscriptional and/or post-translational control. Furthermore, control via transcription, translation and activity of the individual enzymes appeared to vary depending on the method that was used to reduce oxidative stress, the age of the animal and if the muscle underwent exercise training. These data did not support the view that vitamins E\&C supplementation inhibited the positive adaptations to exercise within all of the endogenous antioxidant enzymes $(32,89)$ and in the case of catalase and CuZnSOD, vitamin E\&C supplementation enhanced the adaptive response to exercise. However, the data collected from the allopurinol treated mice would suggest that inhibiting oxidant production via the xanthine oxidase pathway removed the stimulus required to initiate an adaptive response in the endogenous antioxidant system. These differences may suggest that distinct mechanisms of reducing oxidative stress may lead to slightly diverse responses in the adaptation of the endogenous antioxidant enzymes.

It is likely that in the vitamin E\&C study, oxidants were still being produced at a high rate during exercise, even after 4.5 weeks of repetitive exercise. If we assumed that the majority of those oxidants are coming from an increase in endothelial derived xanthine oxidase activity, then large concentrations of vitamin E\&C within the muscle cells might only affect regulation of the endogenous antioxidant enzymes within those muscle cells. However, within the endothelial cells and/or the extracellular space, increased oxidant production may be activating redox sensitive pathways that in turn increase the activity of endogenous antioxidant enzyme specific to that sub-cellular location.

The assumptions of the allopurinol study were that there was never a large increase in oxidant production because the xanthine oxidase activity was inhibited by the drug. It is difficult to compare the resveratrol supplemented animals with the vitamin E\&C and allopurinol studies in this regard because resveratrol has been shown to have direct control over gene regulation that is upstream of a wide variety of cellular pathways involved in energy homeostasis, longevity, cell survival, and apoptosis. For example, within the current investigation, it is unknown if resveratrol increased mitochondrial number which could have resulted in an increase MnSOD activity. Measuring mitochondrial morphology (16) and enzyme levels in resveratrol fed animals would have answered this question. It was assumed that Vitamin E\&C supplementation along with allopurinol would regulate the endogenous antioxidant enzymes solely via reducing oxidative stress and activation of redox sensitive pathways.

\section{Limitations and future directions}

Increased cellular levels of $\mathrm{H}_{2} \mathrm{O}_{2}$ can result in oxidative stress and cause cellular damage. Oxidative damage to cells has been associated with the progression of the aging process and may lead to increased pathological damage associated with advanced aging. Nevertheless, low concentrations of $\mathrm{H}_{2} \mathrm{O}_{2}$ have been shown to be an important signaling molecule that regulates many cellular processes (96). A comprehensive review of the literature by Giorgio et al. (27) lead them propose that in vivo changes in $\mathrm{H}_{2} \mathrm{O}_{2}$ concentrations in the $10^{-8}$ molar range lead to proliferation and increased cellular signaling, whereas changes in the $10^{-6}$ molar range caused growth arrest and cellular damage whereas $10^{-4}$ molar changes induced apoptosis. 
The original intent of this project was to determine if effectiveness of antioxidants in reducing oxidative stress associated with exercise and aging in skeletal muscles. Throughout the scope of this project $\mathrm{H}_{2} \mathrm{O}_{2}$ levels were determined to measure changes in the abundance of oxidants within the skeletal muscle environment. Determining changes in $\mathrm{H}_{2} \mathrm{O}_{2}$ by reporting the data as relative florescent units (RFU) /mg protein was effective in showing changes in $\mathrm{H}_{2} \mathrm{O}_{2}$ between groups within each individual study, however because actual concentrations of $\mathrm{H}_{2} \mathrm{O}_{2}$ were not calculated the interpretation of these data and the direct comparison, between studies within this project and that of others, is limited. In the rat vitamin E\&C study (specific aim 1), going back and determining a standard curve for the $\mathrm{H}_{2} \mathrm{O}_{2}$ data proved to be difficult because the exact gain of the plate reader was not properly recorded. By comparing the readings from the blank wells an estimation of the gain setting was determined and a standard curve was ascertained (Figure 7.2a). This allowed for some interpretation of whether the changes in $\mathrm{H}_{2} \mathrm{O}_{2}$ were involved in cellular signaling or pathological in nature. Within the chronic exercise study in rats (specific aim 1) exercise and aging both increased $\mathrm{H}_{2} \mathrm{O}_{2}$ concentrations (1.5-2.9 x 10-7 $\mathrm{mol} / \mathrm{mg}$ protein) in a range in-between promoting cellular growth and causing damage. Furthermore, because the muscle samples were ascertained 24 hours after the last bout of exercise and the relatively short half life of $\mathrm{H}_{2} \mathrm{O}_{2}$, it is postulated that the current elevations are the result of a signaling response. To further support this notion, the increase in lipid peroxidation associated with exercise in the aged animals was attenuated after 4.5 weeks of exercise training. Vitamin $\mathrm{E} \& \mathrm{C}$ supplementation attenuated the increases in the $\mathrm{H}_{2} \mathrm{O}_{2}$ concentrations associated with aging and exercise.

Within the resveratrol study (specific aim 2) the standard curve was not ascertained at the same time as the RFU data was collected, however the exact settings of the plate reader (i.e. gain) was duplicated to determine a standard curve for $\mathrm{H}_{2} \mathrm{O}_{2}$ concentrations (Figure 7.2b). Interpretation of the $\mathrm{H}_{2} \mathrm{O}_{2}$ concentration data suggests that immediately after exercise $\mathrm{H}_{2} \mathrm{O}_{2}$ concentrations were elevated by $1.7 \times 10^{-6} \mathrm{~mol} / \mathrm{mg}$ protein and was sufficient to increase oxidative damage (lipid peroxidation). In the aged animals exercise increased $\mathrm{H}_{2} \mathrm{O}_{2}$ concentrations by $7 \times 10^{-7} \mathrm{~mol} / \mathrm{mg}$ protein and elevated lipid peroxidation. This would suggest that the increase in $\mathrm{H}_{2} \mathrm{O}_{2}$ associated with aging was sufficient to increase localized oxidative damage within the muscle environment.

Within the allopurinol study (specific aim 3) a standard curve was established at the same time the RFU data was collected (Figure 6.3A). This allowed for more accurate determination of $\mathrm{H}_{2} \mathrm{O}_{2}$ concentrations. The elevation in $\mathrm{H}_{2} \mathrm{O}_{2}$ concentrations in the aged animals was not as great as in the resveratrol study (allopurinol $=3 \times 10^{-7} \mathrm{~mol} / \mathrm{mg}$ protein vs. resveratrol = $17 \times 10^{-7} \mathrm{~mol} / \mathrm{mg}$ protein); however, as in the resveratrol study there was increase in lipid peroxidation suggesting the increase in $\mathrm{H}_{2} \mathrm{O}_{2}$ was sufficient to cause oxidative damage. Similar results were found in the resveratrol and allopurinol studies in regard to the magnitude of the increase in the $\mathrm{H}_{2} \mathrm{O}_{2}$ concentrations (allopurinol $=6 \times 10^{-7} \mathrm{~mol} / \mathrm{mg}$ protein vs. resveratrol $=7$ $\times 10^{-7} \mathrm{~mol} / \mathrm{mg}$ protein) associated with exercise in the gastrocnemius muscle from aged mice. A brief interpretation of these data suggest that acute or short-term resistance exercise produced concentrations of $\mathrm{H}_{2} \mathrm{O}_{2}$ that resulted in cellular damage, however elevations in $\mathrm{H}_{2} \mathrm{O}_{2}$ concentrations associated with chronic resistance exercise may have acted as inter- and/or intra-cellular signals that resulted in the attenuation of oxidative damage associated with exercise in the muscles of the aged animals.

Other limitations of in the vitamin E\&C study (Aim 1) were; (a) xanthine oxidase and NADPH oxidase activity were not measured, so the source of oxidant production (e.g., mitochondria, NADPH oxidase or xanthine oxidase) could not be determined, (b) the specific 
concentration of vitamins E\&C within the blood, the muscle and/or the various cell types within the muscle environment were not measured. Further studies to determine the tissue specific concentrations of vitamins E\&C and the sub-cellular location of oxidant production are needed to obtain a clearer picture of how they affect the regulation of the endogenous antioxidant enzymes in response to anaerobic resistance types of exercise.

The second specific aim was to determine the efficacy of resveratrol supplementation as a possible countermeasure for oxidative stress associated with aging and acute exercise in skeletal muscle. The major limitations in the resveratrol study (specific aim 2) were that the duration of treatment might have been too short to identify all of the potential responses to resveratrol supplementation. It is possible that if the aged animals were given the resveratrol fortified diet for a longer time period they would have shown significant improvements in muscle fatigue as did the young animals. Since it is speculated that resveratrol is acting to reduce oxidant formation by means of Sirt1 activation and improved ATP availability, a longer preexercise time on the resveratrol diet might allow greater activation of the transcriptional mechanisms need to improve adaptation. However, this investigation does not provide any direct evidence of Sirt1 activation, increases in mitochondrial density and/or efficiency, nor did it measure skeletal muscle ATP content. Further research is needed to determine the significance of resveratrol to manipulate metabolic pathways that would increase ATP content and decrease the rate of fatigue.

Future directions that directly extend from the data in the second study include examining the capacity of resveratrol to increase the availability of ATP and decreased superoxide formation in skeletal muscle by reducing uncoupling of the mitochondrial electron transport chain. Possible targets for improving ATP availability should include the mitochondrial electron transport chain, $\beta$-oxidation, and gluconeogenesis. A future study could be designed to test if resveratrol increases ATP availability by increasing $\beta$-oxidation in skeletal muscle via decreasing lipogenesis and increasing lipolysis in adipocytes (95), thus allowing for greater substrate availability for ATP production within the contracting muscle. Moreover, Sirt1 activation via resveratrol has been shown to facilitate the nuclear translocation of forkhead transcription factor-1 (FoxO1) thus activating gluconeogenesis in hepatocytes (23). A future study could evaluate the role of Sirt1 in regulating gluconeogenesis within the liver, and leading to higher blood glucose levels. The ability to maintain blood glucose levels during exercise would lead to an increased glucose availability that the working muscle could use for ATP production via glycolysis.

Another important question that is extended from data in Aims 1 and 2 is whether long term resveratrol supplementation would lower the hypertrophic adaptation to high-intensity, short-duration resistance training. There exists the possibility that resveratrol would inhibit muscle growth in favor of improving aerobic function and endurance. It has been shown that concurrent training (combining diverse contractile activity i.e. high-intensity, short-duration and prolonged, low-intensity) may not be optimal for promoting specific adaptations that would simultaneously promote both anabolic and aerobic responses (13). Similar to resveratrol supplementation, the Sirt1 activated AMPK-PGC-1 $\alpha$ pathway is up-regulated in response to endurance exercise. Additionally, endurance exercise has been shown to repress the Akt/protein kinase B-mammalian target of rapamycin-p70 S6 kinase (Akt-mTOR-S6K) pathway to which would normally increase protein synthesis and muscle growth in response to resistance exercise (4). It is unknown, if a similar response would occur in both animals and humans undergoing long-term resveratrol supplementation simultaneous with resistance training. 
The third specific aim of this project examined how xanthine oxidase inhibition (via allopurinol) affected the increased apoptotic signaling in skeletal muscle from aged animals. It was hypothesized that increased xanthine oxidase activity due to exercise would contribute to decreasing the mitochondrial membrane integrity thus leading to increased apoptotic signaling in aged muscles after exercise. However, it was found that xanthine oxidase does not have a significant role in increasing mitochondrial derived apoptotic signaling. Nevertheless, the inhibition of xanthine oxidase diminished an increase in caspase 3 activity in the aged muscle after isometric contractions. Recent findings imply that increased caspase 3 activity after exhaustive exercise in aged rats is dependent on caspase 8 activation and the extrinsic apoptotic pathway.

The primary limitation of the allopurinol experiments were that direct measures of apoptosis were not examined nor were specific signaling pathways that initiate apoptosis. Future research stemming from these findings in the third aim should focus on determining if the increase in caspase 3 activity initiates an increase in apoptosis and which upstream mechanisms result in the increase of caspase 3 activity are activated by increase in xanthine oxidase activity. These investigations should focus on the extrinsic apoptotic pathway. Fifty minutes of strenuous treadmill running has been shown to increase plasma levels of TNF- $\alpha$ and interleukin-6 (IL-6) which was associated with an increase in apoptosis (57). However, TNF- $\alpha$ and IL- 6 are pro-inflammatory cytokines that increase in response to cellular damage and the isometric contractions used in the current study are assumed to be a form of non-damaging contractile activity. It would be essential to determine if the isometric protocol used in the current study, induced increases in TNF- $\alpha$ and IL- 6 and if so, did TNF- $\alpha$ and IL- 6 increase because contractile damage or if perhaps if exercise-induced oxidative damage leads to inflammation.

TNF- $\alpha$ along with other ligands in the TNF superfamily such as FAS or TRAIL can activate the extrinsic apoptotic pathway when they bind to their receptors (sometimes referred to as death receptors) on the cytoplasmic side of the cellular membrane. This activation of the death receptors stimulates recruitment of Fas-associated death domain protein (FADD) leading to caspase 8 activation subsequent cleaving pro-caspase 3 to its active form. Future directions should characterize the response in death receptor ligands to non-phagocytic xanthine oxidase production and determine if increased extracellular oxidant production via xanthine oxidase increases the death receptor ligands and/or may modify the death receptors themselves. It has recently been shown that increases in intercellular $\mathrm{H}_{2} \mathrm{O}_{2}$ up-regulates the expression of death receptors (94). It is possible that the elevation in intercellular oxidative stress associated with increased mitochondrial dysfunction associated with aging leads to an increase in the death receptors enhancing the cells sensitivity to death receptor ligands.

\section{Recommendations in human populations}

\section{Vitamin E\&C}

The current investigation shows evidence supporting the use of vitamin E\&C as an antioxidant supplement, however the limited scale of these studies make it difficult to produce any practical recommendations in humans. Vitamin E\&C supplementation will decrease evidence of oxidative damage caused by exercise and aging, which traditional has been thought to be a healthy benefit leading to the suggestion that antioxidant consumption needs increased in both athletes and the elderly. However, there is growing evidence that low concentrations of oxidants are needed to induce the expression of antioxidant enzymes in response to exercise. Indeed, recent evidence in humans (90) and rats (31) has suggested that antioxidant supplements like vitamin $\mathrm{C}$ and/or $\mathrm{E}$ can interfere with the benefits of exercise to increase muscle levels of antioxidant enzymes. This phenomenon is best characterized in the concept of 
hormesis, which is a dose-response relationship in which low concentrations of a substance stimulate a response and a high concentrations inhibit a response (8). Hormesis has been applied to the oxidant generating effects of exercise as a means to explain why antioxidant supplementation inhibits muscular force production and blocks many of the beneficial effects of exercise on metabolism and the endogenous antioxidant $(51,87,90)$. In this context oxidants are viewed as beneficial, rather than as deleterious.

It is important to note that the investigations that suggests antioxidant supplementation prevents the health-promoting effects of exercise have been done in young adult humans (90) or rats (31) performing mostly aerobic exercise. In the elderly, the elevation in basal concentrations of oxidants may offset the redox balance, thereby exposing cells to higher levels of oxidants that have the potential to result in oxidative damage to protein, DNA and lipids. In addition to aged-dependent oxidative stress, elderly people often have low plasma concentrations of the antioxidant vitamins, as a result of their nutritional deficiencies $(36,66)$. In contrast, dietary supplementation of vitamin $\mathrm{E}$ has been shown to significantly reduce systolic blood pressure in sedentary elderly individuals (45). A combination of aerobic exercise and antioxidant supplementation in the elderly doubled the drop in their systolic blood pressure and decreased their diastolic blood pressure, as well as enhanced weight loss and significantly improved maximal oxygen uptake $\left(\mathrm{VO}_{2 \max }\right)(45)$. Recent data have suggested that antioxidant supplementation can stimulate muscle protein synthesis in aged rats, possibly through the protection of leucine metabolism (70). In addition, Vitamin E\&C supplementation combined with resistance training has been shown to increase fat free mass and the muscle mass index more than resistance training alone in older adults (61).

Based on the current knowledge of antioxidant supplementation, it should be suggested that a dietary analysis of vitamin intake be performed in elderly persons, as this would highlight possible nutritional deficiencies in their diet. The typical American diet for all age groups tends to be inadequate in supplying the recommended allowance of fresh fruits and vegetables. Europeans consume more fruits and vegetables in their diet than Americans, which has been associated with an overall higher dietary vitamin E\&C intake in Europe countries compared with in the United States (11). The dietary analysis could be used to determine the proper dosages of supplements to be prescribed based on fulfilling the USDA recommended daily allowances (RDA). However, in the elderly, the RDA values may be inadequate to combat the increased oxidant production and the decreased buffering capacity associated with aging (25). Currently, no specific guidelines for vitamins $E$ or $C$ intake exist for elderly Americans. The data collected in this investigation and some of the research highlighted above suggests vitamin E\&C supplementation may be beneficial for the elderly participating in vigorous physical activity. Further research is needed to determine if and to what extent the RDA values need to be adjusted for elderly individuals.

It has been suggested that antioxidant supplementation may be a beneficial countermeasure to the increased oxidant production associated with exercise in young adult athletes. In a study of professional soccer players, dietary supplementation of vitamin E \& C was shown to reduce lipid peroxidation and muscle damage after high intensity workouts, however supplementation failed to enhance athletic performance (102). Additionally, it has been shown that oral consumption of vitamin E\&C in marathon runners prior to competition reduced post-competition creatine kinase levels compared to a placebo group (91), which would be indicative of reduced muscle damage. However, for each study providing evidence for a positive effect there are other studies providing equally convincing evidence for either no effect or, occasionally, a negative effect of antioxidant supplementation (73). 


\section{Resveratrol}

Resveratrol is naturally occurring in the skins and seeds of dark grapes, peanuts, and Japanese knotweed (which is an ingredient in many eastern herbal medicines), among other plants, resveratrol is produced by plants as a defense against molds, UV radiation and other pathogens. Oral resveratrol supplementation has been associated with longer lifespan, improve metabolism, decreased oxidative stress and increased aerobic performance (6). Recent research has suggested that dietary intake of resveratrol, together with habitual exercise, is beneficial for suppressing the decline in physical performance associated with aging (74). Theoretically, resveratrol supplementation sounds beneficial to ones overall health and well being. However, there is a paucity of convincing data from human clinical trials that supports resveratrol supplementation. To the best of my knowledge there are no controlled investigations that have examined resveratrol's effect on athletic performance and therefore it is difficult to make any conclusions regarding the efficacy of resveratrol use by athletes.

Within a quick search of the internet an individual will easily indentify many supplement companies that sell resveratrol, but the potency and purity of many of these supplements are not confirmed and/or regulated and in my opinion simply be a waste of time and money. Further research that establishes dose response and kinetic characteristics of the effects of long term resveratrol supplementation on both animals and humans is needed before any professional, scientifically based recommendation could be given. The existing data on the benefits of resveratrol supplementation surely warrant such investigations; however, caution should be advised to any notions of resveratrol being a "fountain of youth".

\section{Allopurinol}

Allopurinol is a commonly prescribed drug for the treatment of hyperuricemia (high levels of uric acid). Common complications of hyperuricemia include kidney stones and chronic gout. Allopurinol is in a class of medications called xanthine oxidase inhibitors. The distribution of allopurinol is regulated by the government and should only be given to humans when prescribed by a doctor for the treatment and/or prevention of hyperuricemia or as an inhibitor of xanthine oxidase activity in controlled scientific research projects that are monitored by a medical doctor. Therefore, it is premature to consider regular use by allopurinol as a therapeutic aid to reduce oxidative stress in muscles of the elderly who exercise. Nevertheless, other less toxic substances that reduce xanthine oxidase might eventually prove to be of some benefit for reducing oxidative stress in elderly humans.

\section{Conclusion}

The results of this set of investigations show evidence that advanced aging is associated with elevated levels of oxidative stress including oxidative stress from xanthine oxidase. Furthermore, an increase in xanthine oxidase activity provides an important contribution to the oxidative stress associated with resistance exercise (i.e. repetitive loading). Muscles from aged animals have high basal levels of xanthine oxidase, and this is further exacerbated by resistance exercise. Modulation of exercise-induced oxidative stress will effect adaptation of the endogenous antioxidant system and different therapeutic methods of reducing oxidative stress in aged muscle produce slightly different results in muscle function. These studies do not conclusively address the capacity that oxidative stress has on the regulating myonuclear apoptosis, decreasing protein synthesis and/or activating proteolysis pathways, which in turn may contribute to the functional decline in skeletal muscle associated with advanced aging. Further investigations are warranted to find a direct link between oxidative stress and muscle atrophy. 
Further work is required to determine if reducing oxidative stress will improve muscle function, fatigue, or apoptotic signaling in muscles of elderly subjects. A greater awareness of the sub-cellular location of oxidant production related to resistance training may allow researchers to identify potential signaling targets that might be manipulated by supplements and/nutritional therapy in muscles of aging humans. Such treatment strategies may potentially have a great economical value to society, given the expanding costs associated with caring for the increasing elderly population. 
Figure 7.1

\begin{tabular}{|c|c|c|c|c|c|c|c|c|c|c|c|c|c|}
\hline \multirow{2}{*}{\multicolumn{2}{|c|}{ A - Enzyme Activity }} & \multicolumn{3}{|c|}{ GPx activity } & \multicolumn{3}{|c|}{ Catalase activity } & \multicolumn{3}{|c|}{ MnSOD activity } & \multicolumn{3}{|c|}{ CuZnSOD activity } \\
\hline & & Vitamin E\&C & Resveratrol & Allopurinol & Vitamin E\&C & Resveratrol & Allopurinol & Vitamin $E \& C$ & Resveratrol & Allopurinol & Vitamin $E \& C$ & Resveratrol & Allopurinol \\
\hline $\begin{array}{l}\text { Effect of Age in Non-Supl, Control } \\
\text { Muscle }\end{array}$ & $\begin{array}{c}\text { reC vs. } \\
\text { ACC }\end{array}$ & $\Leftrightarrow$ & $\leftrightarrow$ & $\leftrightarrow$ & & & 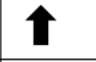 & $\Leftrightarrow$ & 1 & 1 & $\leftrightarrow$ & $\Leftrightarrow$ & \\
\hline $\begin{array}{l}\text { Effect of Exercise in Non-Supl from Aged } \\
\text { mice }\end{array}$ & $\begin{array}{c}\text { ACC vs. } \\
\text { ACE }\end{array}$ & & $\Leftrightarrow$ & $\Leftrightarrow$ & $\Leftrightarrow$ & & & $\Leftrightarrow$ & $\Leftrightarrow$ & $\leftrightarrow$ & $\Leftrightarrow$ & 1 & \\
\hline $\begin{array}{l}\text { Effect of antioxidant on age related } \\
\text { response }\end{array}$ & $\begin{array}{c}\text { ACC vs. } \\
\text { ATC }\end{array}$ & $\Omega$ & & $\Leftrightarrow$ & & & $\Leftrightarrow$ & $\Leftrightarrow$ & & $\Leftrightarrow$ & $\Leftrightarrow$ & $\Leftrightarrow$ & $\Leftrightarrow$ \\
\hline $\begin{array}{l}\text { Effect of Antioxidant on exercise } \\
\text { response in aged muscle }\end{array}$ & $\begin{array}{c}\text { ACE vs. } \\
\text { ATE }\end{array}$ & $\Omega$ & 个 & $\leftrightarrow$ & - & & $\Omega$ & $\Leftrightarrow$ & 1 & $\Leftrightarrow$ & $\Leftrightarrow$ & $\Leftrightarrow$ & $\Omega$ \\
\hline \begin{tabular}{|c|} 
Effect of exercise in the antioxidant \\
supplemented aged animals (Changes in \\
antioxidant only)
\end{tabular} & \begin{tabular}{|c|} 
ATC vs. \\
ATE \\
\end{tabular} & $\Leftrightarrow$ & $\Leftrightarrow$ & $\Leftrightarrow$ & & & $\Leftrightarrow$ & $\Leftrightarrow$ & $\Leftrightarrow$ & $\Leftrightarrow$ & 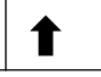 & $\Leftrightarrow$ & $\Leftrightarrow$ \\
\hline
\end{tabular}

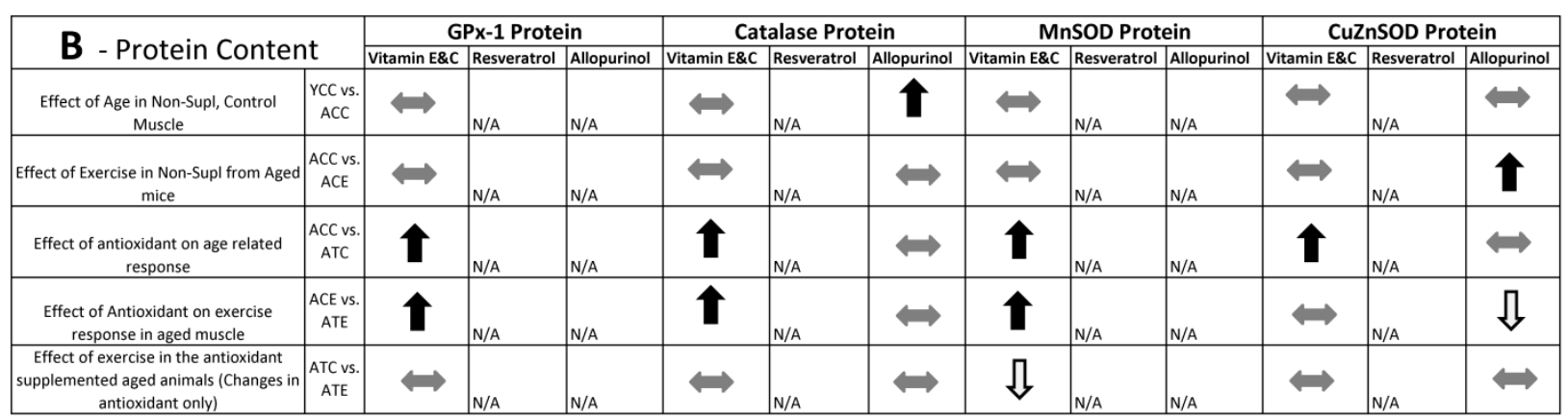

\begin{tabular}{|c|c|c|c|c|c|c|c|c|c|c|c|c|c|}
\hline \multirow{2}{*}{\multicolumn{2}{|c|}{ C - mRNA Expression }} & \multicolumn{3}{|c|}{ GPx-1 mRNA } & \multicolumn{3}{|c|}{ Catalase mRNA } & \multicolumn{3}{|c|}{ MnSOD mRNA } & \multicolumn{3}{|c|}{ CuZnSOD mRNA } \\
\hline & & Vitamin E\&C & Resveratrol & Allopurinol & Vitamin E\&C & Resveratrol & Allopurinol & Vitamin E\&C & Sesveratrol & Allopurinol & Vitamin $E \& C$ & Resveratrol & Allopurinol \\
\hline $\begin{array}{l}\text { Effect of Age in Non-Supl, Control } \\
\text { Muscle }\end{array}$ & $\begin{array}{l}\text { YCC vs. } \\
\text { ACC } \\
\end{array}$ & $\Leftrightarrow$ & $\Leftrightarrow$ & $\Leftrightarrow$ & $\Leftrightarrow$ & & 1 & $\Leftrightarrow$ & 1 & $\Leftrightarrow$ & $\Leftrightarrow$ & $\Leftrightarrow$ & $\Leftrightarrow$ \\
\hline $\begin{array}{l}\text { Effect of Exercise in Non-Supl from Aged } \\
\text { mice }\end{array}$ & $\begin{array}{c}\text { ACC vs. } \\
\text { ACE }\end{array}$ & $\Leftrightarrow$ & $\Leftrightarrow$ & $\Leftrightarrow$ & $\Leftrightarrow$ & $\Leftrightarrow$ & $\Leftrightarrow$ & $\Leftrightarrow$ & $\Leftrightarrow$ & $\Leftrightarrow$ & $\Leftrightarrow$ & $\Leftrightarrow$ & $\Leftrightarrow$ \\
\hline $\begin{array}{c}\text { Effect of antioxidant on age related } \\
\text { response }\end{array}$ & $\begin{array}{l}\text { ACC vs. } \\
\text { ATC }\end{array}$ & $\Omega$ & $\Leftrightarrow$ & $\Leftrightarrow$ & $\Omega$ & & $\Leftrightarrow$ & $\Omega$ & & $\Leftrightarrow$ & 几 & $\Leftrightarrow$ & $\Leftrightarrow$ \\
\hline $\begin{array}{l}\text { Effect of Antioxidant on exercise } \\
\text { response in aged muscle }\end{array}$ & $\begin{array}{l}\text { ACE vs. } \\
\text { ATE }\end{array}$ & ת & $\Leftrightarrow$ & $\Leftrightarrow$ & $\Omega$ & 1 & $\Leftrightarrow$ & $\Omega$ & $\hat{1}$ & $\Leftrightarrow$ & $\Omega$ & $\Leftrightarrow$ & $\Leftrightarrow$ \\
\hline \begin{tabular}{|c|} 
Effect of exercise in the antioxidant \\
supplemented aged animals (Changes in \\
antioxidant only)
\end{tabular} & $\begin{array}{c}\text { ATC vs. } \\
\text { ATE }\end{array}$ & $\Leftrightarrow$ & $\Leftrightarrow$ & $\Leftrightarrow$ & $\Leftrightarrow$ & $\Leftrightarrow$ & $\Leftrightarrow$ & $\Leftrightarrow$ & $\Leftrightarrow$ & $\Leftrightarrow$ & $\Leftrightarrow$ & $\Leftrightarrow$ & $\Leftrightarrow$ \\
\hline
\end{tabular}

Across study comparison of regulation of the endogenous antioxidant enzymes Comparison of the effect of aging, exercise and antioxidant treatment on activity of the endogenous antioxidant enzymes (A), enzyme protein content (B) and enzyme mRNA expression (C). Indicates a significant $(\mathbf{p}<0.05)$ increase in activity. $\rightarrow$ Indicates no significant $(p<0.05)$ change in enzymatic activity. \Indicates a significant $(p<0.05)$ decrease in enzymatic activity. N/A (not applicable) Indicates data was not collected for that variable.

$\mathrm{YCC}=$ Young, Control (non-antioxidant treatment), Control non-exercise; $\mathrm{ACC}=\mathrm{Aged}$, Control (non-antioxidant treatment), Control non-exercise; $\mathrm{ACE}=\mathrm{Aged}$, Control (non-antioxidant treatment), Exercised; ATC $=$ Aged, Treatment (antioxidant), Control non-exercised; ATE = Aged, Treatment (antioxidant), Exercised 
Figure 7.2
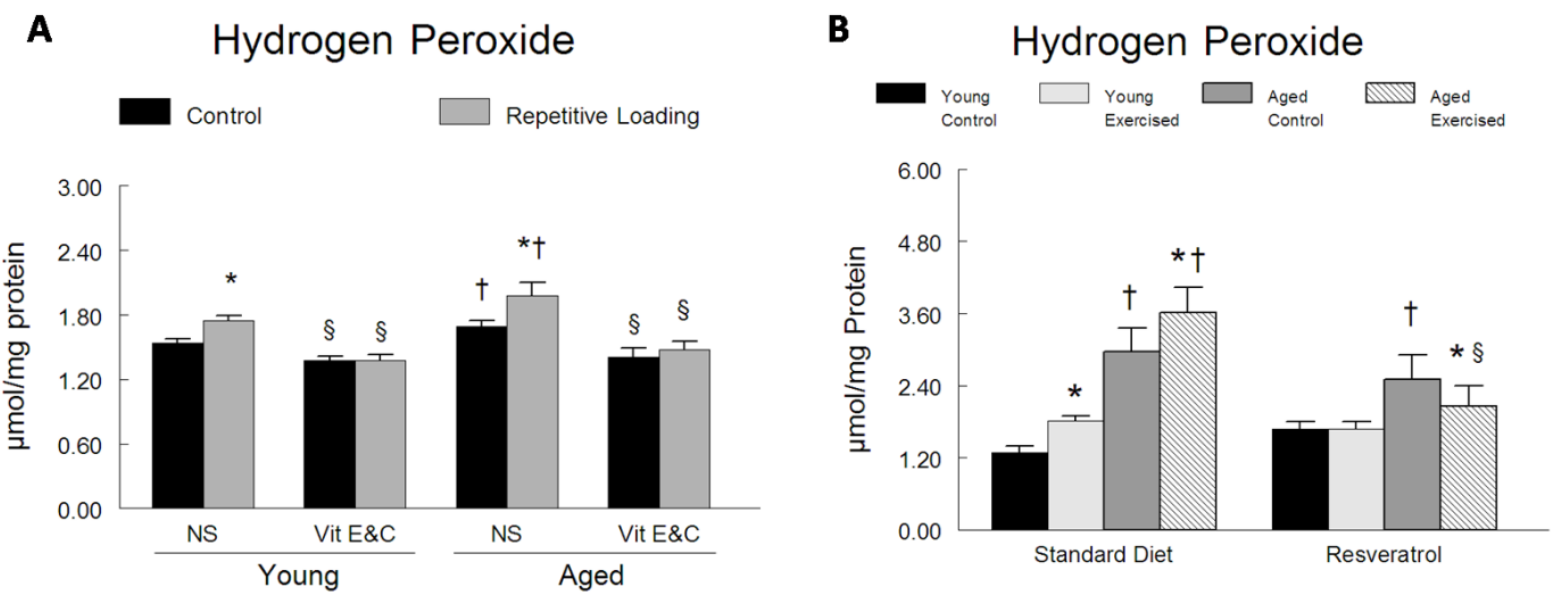

Corrected concentrations for hydrogen peroxide $\left(\mathrm{H}_{2} \mathrm{O}_{2}\right)$ The $\mathrm{H}_{2} \mathrm{O}_{2}$ concentration was determined fluorometrically. The data are expressed as mean \pm SEM of $\mu$ moles per $\mathrm{mg}$ of total protein homogenate. (A) $\mathrm{H}_{2} \mathrm{O}_{2}$ concentrations from the vitamin $\mathrm{E} \& \mathrm{C}$ study (specific aim 1) ${ }^{*}$, significant difference $(p<0.05)$ between age-matched repetitively loaded muscle and contralateral control muscle; $\dagger$, a significant difference $(p<0.05)$ between young exercise and dietmatched control muscles; $\S$, significant difference $(p<0.05)$ between age-matched muscles from animals on the non-supplemented (NS) diet. (B) $\mathrm{H}_{2} \mathrm{O}_{2}$ concentrations from the resveratrol study (specific aim 2) * significant difference $(p<0.05)$ of isometrically exercised muscle from contralateral control muscle; $\dagger$ a significant difference $(p<0.05)$ from young exercise and diet-matched control muscles; $\S$ significant difference $(p<0.05)$ from age-matched animals on the nonsupplemented diet. 
Reference List

1. Alessio HM, Hagerman AE, Fulkerson BK, Ambrose J, Rice RE and Wiley RL. Generation of reactive oxygen species after exhaustive aerobic and isometric exercise. Med Sci Sports Exerc 32: 1576-1581, 2000.

2. Andrade FH, Reid MB, Allen DG and Westerblad H. Effect of hydrogen peroxide and dithiothreitol on contractile function of single skeletal muscle fibres from the mouse. $J$ Physiol 509 ( Pt 2): 565-575, 1998.

3. Anzueto A, Brassard JM, Andrade FH, Lawrence RA, Maxwell LC, Levine SM and Jenkinson SG. Effects of Hyperoxia on Rat Diaphragm Function. Journal of Applied Physiology 77: 63-68, 1994.

4. Atherton PJ, Babraj J, Smith K, Singh J, Rennie MJ and Wackerhage H. Selective activation of AMPK-PGC-1alpha or PKB-TSC2-mTOR signaling can explain specific adaptive responses to endurance or resistance training-like electrical muscle stimulation. FASEB J 19: 786-788, 2005.

5. Barry B.Halliwell and John M.Gutteridge. Free Radicals in Biology and Medicine. Oxford University Press, USA, 2006.

6. Baur JA, Pearson KJ, Price NL, Jamieson HA, Lerin C, Kalra A, Prabhu VV, Allard JS, Lopez-Lluch G, Lewis K, Pistell PJ, Poosala S, Becker KG, Boss O, Gwinn D, Wang M, Ramaswamy S, Fishbein KW, Spencer RG, Lakatta EG, Le Couteur D, Shaw RJ, Navas P, Puigserver P, Ingram DK, de Cabo R and Sinclair DA.

Resveratrol improves health and survival of mice on a high-calorie diet. Nature 444: 337342, 2006.

7. Bejma $\mathbf{J}$ and Ji LL. Aging and acute exercise enhance free radical generation in rat skeletal muscle. J Appl Physiol 87: 465-470, 1999.

8. Calabrese EJ and Baldwin LA. Hormesis: the dose-response revolution. Annu Rev Pharmacol Toxicol 43: 175-197, 2003.

9. Chance B, Sies H and Boveris A. Hydroperoxide metabolism in mammalian organs. Physiol Rev 59: 527-605, 1979.

10. Charette SL, Mcevoy L, Pyka G, Snowharter C, Guido D, Wiswell RA and Marcus R. Muscle Hypertrophy Response to Resistance Training in Older Women. J Appl Physiol 70: 1912-1916, 1991.

11. Chun OK, Floegel A, Chung SJ, Chung CE, Song WO and Koo SI. Estimation of antioxidant intakes from diet and supplements in U.S. adults. J Nutr 140: 317-324, 2010.

12. Clanton TL, Zuo L and Klawitter P. Oxidants and skeletal muscle function: physiologic and pathophysiologic implications. Proc Soc Exp Biol Med 222: 253-262, 1999.

13. Coffey VG, Pilegaard H, Garnham AP, O'Brien BJ and Hawley JA. Consecutive bouts of diverse contractile activity alter acute responses in human skeletal muscle. $J$ Appl Physiol 106: 1187-1197, 2009. 
14. Cowan DB, Weisel RD, Williams WG and Mickle DA. The regulation of glutathione peroxidase gene expression by oxygen tension in cultured human cardiomyocytes. $\mathrm{J} \mathrm{Mol}$ Cell Cardiol 24: 423-433, 1992.

15. Cowan DB, Weisel RD, Williams WG and Mickle DA. Identification of oxygen responsive elements in the 5 '-flanking region of the human glutathione peroxidase gene. J Biol Chem 268: 26904-26910, 1993.

16. Dabkowski ER, Williamson CL, Bukowski VC, Chapman RS, Leonard SS, Peer CJ, Callery PS and Hollander JM. Diabetic cardiomyopathy-associated dysfunction in spatially distinct mitochondrial subpopulations. Am J Physiol Heart Circ Physiol 296: H359-H369, 2009.

17. Das KC, Lewis-Molock $\mathbf{Y}$ and White $\mathbf{C W}$. Thiol modulation of TNF alpha and IL-1 induced MnSOD gene expression and activation of NF-kappa B. Mol Cell Biochem 148: 45-57, 1995.

18. Davies KJ, Quintanilha AT, Brooks GA and Packer L. Free radicals and tissue damage produced by exercise. Biochem Biophys Res Commun 107: 1198-1205, 1982.

19. Diaz PT, She ZW, Davis WB and Clanton TL. Hydroxylation of salicylate by the in vitro diaphragm: evidence for hydroxyl radical production during fatigue. J App/ Physiol 75: 540-545, 1993.

20. Doherty TJ. Aging and sarcopenia. Journal of Applied Physiology 95: 1717-1727, 2003.

21. Duarte JA, Appell HJ, Carvalho F, Bastos ML and Soares JM. Endothelium-derived oxidative stress may contribute to exercise-induced muscle damage. Int J Sports Med 14: 440-443, 1993.

22. Eu JP, Sun J, Xu L, Stamler JS and Meissner G. The skeletal muscle calcium release channel: coupled O2 sensor and NO signaling functions. Cell 102: 499-509, 2000.

23. Frescas $\mathbf{D}$, Valenti $\mathbf{L}$ and Accili $\mathbf{D}$. Nuclear trapping of the forkhead transcription factor FoxO1 via Sirt-dependent deacetylation promotes expression of glucogenetic genes. $J$ Biol Chem 280: 20589-20595, 2005.

24. Frontera WR, Meredith CN, Oreilly KP, Knuttgen HG and Evans WJ. Strength Conditioning in Older Men - Skeletal-Muscle Hypertrophy and Improved Function. J Appl Physiol 64: 1038-1044, 1988.

25. Fulle S, Protasi F, Di Tano G, Pietrangelo T, Beltramin A, Boncompagni S, Vecchiet $\mathbf{L}$ and Fano $\mathbf{G}$. The contribution of reactive oxygen species to sarcopenia and muscle ageing. Experimental Gerontology 39: 17-24, 2004.

26. Garcia-Lopez D, Hakkinen K, Cuevas MJ, Lima E, Kauhanen A, Mattila M, Sillanpaa E, Ahtiainen JP, Karavirta L, Almar M and Gonzalez-Gallego J. Effects of strength and endurance training on antioxidant enzyme gene expression and activity in middleaged men. Scand J Med Sci Sports 17: 595-604, 2007. 
27. Giorgio M, Trinei M, Migliaccio E and Pelicci PG. Hydrogen peroxide: a metabolic byproduct or a common mediator of ageing signals? Nat Rev Mol Cell Biol 8: 722-728, 2007.

28. Gomez-Cabrera MC, Borras C, Pallardo FV, Sastre J, Ji LL and Vina J. Decreasing xanthine oxidase-mediated oxidative stress prevents useful cellular adaptations to exercise in rats. J Physiol 567: 113-120, 2005.

29. Gomez-Cabrera MC, Borras C, Pallardo FV, Sastre J, Ji LL and Vina J. Decreasing xanthine oxidase-mediated oxidative stress prevents useful cellular adaptations to exercise in rats. J Physiol 567: 113-120, 2005.

30. Gomez-Cabrera MC, Borras C, Pallardo FV, Sastre J, Ji LL and Vina J. Decreasing xanthine oxidase-mediated oxidative stress prevents useful cellular adaptations to exercise in rats. J Physiol 567: 113-120, 2005.

31. Gomez-Cabrera MC, Domenech E, Romagnoli M, Arduini A, Borras C, Pallardo FV, Sastre $\mathbf{J}$ and Vina $\mathbf{J}$. Oral administration of vitamin $\mathbf{C}$ decreases muscle mitochondrial biogenesis and hampers training-induced adaptations in endurance performance. $A m \mathrm{~J}$ Clin Nutr 87: 142-149, 2008.

32. Gomez-Cabrera MC, Domenech E, Romagnoli M, Arduini A, Borras C, Pallardo FV, Sastre $\mathbf{J}$ and Vina $\mathbf{J}$. Oral administration of vitamin $\mathbf{C}$ decreases muscle mitochondrial biogenesis and hampers training-induced adaptations in endurance performance. $A m \mathrm{~J}$ Clin Nutr 87: 142-149, 2008.

33. Gomez-Cabrera MC, Domenech E and Vina J. Moderate exercise is an antioxidant: upregulation of antioxidant genes by training. Free Radic Biol Med 44: 126-131, 2008.

34. Gore M, Fiebig R, Hollander J, Leeuwenburgh C, Ohno H and Ji LL. Endurance training alters antioxidant enzyme gene expression in rat skeletal muscle. Can J Physiol Pharmacol 76: 1139-1145, 1998.

35. Green HJ, Reichmann H and Pette D. Fibre type specific transformations in the enzyme activity pattern of rat vastus lateralis muscle by prolonged endurance training. Pflugers Arch 399: 216-222, 1983.

36. Guigoz $\mathbf{Y}$, Lauque $\mathbf{S}$ and Vellas $\mathbf{B J}$. Identifying the elderly at risk for malnutrition. The Mini Nutritional Assessment. Clin Geriatr Med 18: 737-757, 2002.

37. Häkkinen K, Kraemer WJ, Pakarinen A, Triplett-McBride T, McBride JM, Häkkinen A, Alen M, McGuigan MR, Bronks R and Newton RU. Effects of heavy resistance/power training on maximal strength, muscle morphology, and hormonal response patterns in 60-75-year-old men and women. Can J Appl Physiol 27: 213-231, 2002.

38. Harman D. Aging: a theory based on free radical and radiation chemistry. $J$ Gerontol 11: 298-300, 1956.

39. Higuchi M, Cartier LJ, Chen M and Holloszy JO. Superoxide dismutase and catalase in skeletal muscle: adaptive response to exercise. J Gerontol 40: 281-286, 1985. 
40. Ho YS, Howard AJ and Crapo JD. Molecular structure of a functional rat gene for manganese-containing superoxide dismutase. Am J Respir Cell Mol Biol 4: 278-286, 1991.

41. Hollander J, Bejma J, Ookawara T, Ohno H and Ji LL. Superoxide dismutase gene expression in skeletal muscle: fiber-specific effect of age. Mech Ageing Dev 116: 33-45, 2000.

42. Hollander J, Bejma J, Ookawara T, Ohno H and Ji LL. Superoxide dismutase gene expression in skeletal muscle: fiber-specific effect of age. Mech Ageing Dev 116: 33-45, 2000.

43. Hollander J, Fiebig R, Gore M, Ookawara T, Ohno H and Ji LL. Superoxide dismutase gene expression is activated by a single bout of exercise in rat skeletal muscle. Pflugers Arch 442: 426-434, 2001.

44. Hollander J, Fiebig R, Gore M, Ookawara T, Ohno H and Ji LL. Superoxide dismutase gene expression is activated by a single bout of exercise in rat skeletal muscle. Pflugers Arch 442: 426-434, 2001.

45. Jessup JV, Horne C, Yarandi $\mathbf{H}$ and Quindry J. The effects of endurance exercise and vitamin E on oxidative stress in the elderly. Biol Res Nurs 5: 47-55, 2003.

46. Ji LL. Antioxidant enzyme response to exercise and aging. Med Sci Sports Exerc 25: 225-231, 1993.

47. Ji LL. Modulation of skeletal muscle antioxidant defense by exercise: Role of redox signaling. Free Radic Biol Med 44: 142-152, 2008.

48. Ji LL, Dillon D and Wu E. Alteration of antioxidant enzymes with aging in rat skeletal muscle and liver. Am J Physiol 258: R918-R923, 1990.

49. Ji LL, Gomez-Cabrera MC, Steinhafel $\mathbf{N}$ and Vina J. Acute exercise activates nuclear factor (NF)-kappaB signaling pathway in rat skeletal muscle. FASEB J 18: 1499-1506, 2004.

50. Ji LL, Gomez-Cabrera MC, Steinhafel $\mathbf{N}$ and Vina J. Acute exercise activates nuclear factor (NF)-kappaB signaling pathway in rat skeletal muscle. FASEB J 18: 1499-1506, 2004.

51. Ji LL, Gomez-Cabrera MC and Vina J. Exercise and hormesis: activation of cellular antioxidant signaling pathway. Ann N Y Acad Sci 1067: 425-435, 2006.

52. Ji LL, Gomez-Cabrera MC and Vina J. Role of nuclear factor kappaB and mitogenactivated protein kinase signaling in exercise-induced antioxidant enzyme adaptation. Appl Physiol Nutr Metab 32: 930-935, 2007.

53. Ji LL, Leeuwenburgh C, Leichtweis S, Gore M, Fiebig R, Hollander J and Bejma J. Oxidative stress and aging - Role of exercise and its influences on antioxidant systems. Towards Prolongation of the Healthy Life Span 854: 102-117, 1998. 
54. Ji LL, Leeuwenburgh C, Leichtweis S, Gore M, Fiebig R, Hollander $\mathbf{J}$ and Bejma $\mathbf{J}$. Oxidative stress and aging. Role of exercise and its influences on antioxidant systems. Ann N Y Acad Sci 854: 102-117, 1998.

55. Ji LL, Stratman FW and Lardy HA. Antioxidant enzyme systems in rat liver and skeletal muscle. Influences of selenium deficiency, chronic training, and acute exercise. Arch Biochem Biophys 263: 150-160, 1988.

56. Kiningham KK, Xu Y, Daosukho C, Popova B and St Clair DK. Nuclear factor kappaB-dependent mechanisms coordinate the synergistic effect of PMA and cytokines on the induction of superoxide dismutase 2. Biochem J 353: 147-156, 2001.

57. Kocturk S, Kayatekin BM, Resmi H, Acikgoz O, Kaynak C and Ozer E. The apoptotic response to strenuous exercise of the gastrocnemius and solues muscle fibers in rats. Eur J Appl Physiol 102: 515-524, 2008.

58. Kondo H, Kodama J, Kishibe T and Itokawa Y. Oxidative Stress During Recovery from Muscle Atrophy. FEBS Lett 326: 189-191, 1993.

59. Kramer HF and Goodyear LJ. Exercise, MAPK, and NF-kappaB signaling in skeletal muscle. J Appl Physiol 103: 388-395, 2007.

60. Kryger Al and Andersen JL. Resistance training in the oldest old: consequences for muscle strength, fiber types, fiber size, and MHC isoforms. Scand J Med Sci Sports 17: 422-430, 2007.

61. Labonte M, Dionne IJ, Bouchard DR, Senechal M, Tessier D, Khalil A, Labonte M, Bobeuf F, Tessier D, Khalil A and Dionne IJ. Effects of antioxidant supplements combined with resistance exercise on gains in fat-free mass in healthy elderly subjects: a pilot study. J Am Geriatr Soc 56: 1766-1768, 2008.

62. Lagouge M, Argmann C, Gerhart-Hines Z, Meziane H, Lerin C, Daussin F, Messadeq N, Milne J, Lambert P, Elliott P, Geny B, Laakso M, Puigserver P and Auwerx $\mathbf{J}$. Resveratrol improves mitochondrial function and protects against metabolic disease by activating SIRT1 and PGC-1alpha. Cell 127: 1109-1122, 2006.

63. Lambertucci RH, Levada-Pires AC, Rossoni LV, Curi R and Pithon-Curi TC. Effects of aerobic exercise training on antioxidant enzyme activities and mRNA levels in soleus muscle from young and aged rats. Mech Ageing Dev 128: 267-275, 2007.

64. Leeuwenburgh C, Fiebig R, Chandwaney R and Ji LL. Aging and exercise training in skeletal muscle: responses of glutathione and antioxidant enzyme systems. Am J Physiol 267: R439-R445, 1994.

65. Leeuwenburgh $\mathbf{C}$ and Heinecke JW. Oxidative stress and antioxidants in exercise. Current Medicinal Chemistry 8: 829-838, 2001.

66. Leotsinidis $\mathbf{M}$, Alexopoulos A, Schinas V, Kardara M and Kondakis X. Plasma retinol and tocopherol levels in greek elderly population from an urban and a rural area: associations with the dietary habits. Eur J Epidemiol 16: 1009-1016, 2000. 
67. Luo D and Rando TA. The regulation of catalase gene expression in mouse muscle cells is dependent on the CCAAT-binding factor NF-Y. Biochem Biophys Res Commun 303: 609-618, 2003.

68. Macmillan-Crow LA and Cruthirds DL. Invited review: manganese superoxide dismutase in disease. Free Radic Res 34: 325-336, 2001.

69. Maehara K, Oh-Hashi K and Isobe KI. Early growth-responsive-1-dependent manganese superoxide dismutase gene transcription mediated by platelet-derived growth factor. FASEB J 15: 2025-2026, 2001.

70. Marzani B, Balage M, Venien A, Astruc T, Papet I, Dardevet D and Mosoni L. Antioxidant supplementation restores defective leucine stimulation of protein synthesis in skeletal muscle from old rats. J Nutr 138: 2205-2211, 2008.

71. Matuoka K and Yu CK. Nuclear factor Y (NF-Y) and cellular senescence. Exp Cell Res 253: 365-371, 1999.

72. McArdle A and Jackson MJ. Exercise, oxidative stress and ageing. J Anat 197 Pt 4: 539-541, 2000.

73. McGinley C, Shafat A and Donnelly AE. Does antioxidant vitamin supplementation protect against muscle damage? Sports Med 39: 1011-1032, 2009.

74. Murase T, Haramizu S, Ota N and Hase T. Suppression of the aging-associated decline in physical performance by a combination of resveratrol intake and habitual exercise in senescence-accelerated mice. Biogerontol 10: 423-434, 2009.

75. Nenoi M, Ichimura S, Mita K, Yukawa $\mathbf{O}$ and Cartwright IL. Regulation of the catalase gene promoter by Sp1, CCAAT-recognizing factors, and a WT1/Egr-related factor in hydrogen peroxide-resistant HP100 cells. Cancer Res 61: 5885-5894, 2001.

76. Oh-ishi S, Kizaki T, Nagasawa J, Izawa T, Komabayashi T, Nagata N, Suzuki K, Taniguchi $\mathbf{N}$ and Ohno $\mathbf{H}$. Effects of endurance training on superoxide dismutase activity, content and mRNA expression in rat muscle. Clin Exp Pharmacol Physiol 24: 326-332, 1997.

77. Pansarasa O, Bertorelli L, Vecchiet J, Felzani G and Marzatico F. Age-dependent changes of antioxidant activities and markers of free radical damage in human skeletal muscle. Free Radic Biol Med 27: 617-622, 1999.

78. Pansarasa O, Felzani G, Vecchiet $\mathbf{J}$ and Marzatico F. Antioxidant pathways in human aged skeletal muscle: relationship with the distribution of type II fibers. Exp Geronto/37: 1069-1075, 2002.

79. Parise G, Phillips SM, Kaczor JJ and Tarnopolsky MA. Antioxidant enzyme activity is up-regulated after unilateral resistance exercise training in older adults. Free Radical Biology and Medicine 39: 289-295, 2005.

80. Pearson KJ, Baur JA, Lewis KN, Peshkin L, Price NL, Labinskyy N, Swindell WR, Kamara D, Minor RK, Perez E, Jamieson HA, Zhang Y, Dunn SR, Sharma K, 
Pleshko N, Woollett LA, Csiszar A, Ikeno Y, Le Couteur D, Elliott PJ, Becker KG, Navas P, Ingram DK, Wolf NS, Ungvari Z, Sinclair DA and de Cabo R. Resveratrol delays age-related deterioration and mimics transcriptional aspects of dietary restriction without extending life span. Cell Metab 8: 157-168, 2008.

81. Pimenta AS, Lambertucci RH, Gorjao R, Silveira LR and Curi R. Effect of a single session of electrical stimulation on activity and expression of citrate synthase and antioxidant enzymes in rat soleus muscle. Eur J Appl Physiol 102: 119-126, 2007.

82. Posterino GS and Lamb GD. Effects of reducing agents and oxidants on excitationcontraction coupling in skeletal muscle fibres of rat and toad. J Physiol 496 ( Pt 3): 809825, 1996.

83. Powers SK, Criswell D, Lawler J, Ji LL, Martin D, Herb RA and Dudley G. Influence of exercise and fiber type on antioxidant enzyme activity in rat skeletal muscle. $A m \mathrm{~J}$ Physiol 266: R375-R380, 1994.

84. Powers SK and Lennon SL. Analysis of cellular responses to free radicals: focus on exercise and skeletal muscle. Proc Nutr Soc 58: 1025-1033, 1999.

85. Pugh SY, DiGuiseppi JL and Fridovich I. Induction of superoxide dismutases in Escherichia coli by manganese and iron. J Bacteriol 160: 137-142, 1984.

86. Radak Z, Asano K, Inoue M, Kizaki T, Oh-ishi S, Suzuki K, Taniguchi N and Ohno H. Superoxide dismutase derivative reduces oxidative damage in skeletal muscle of rats during exhaustive exercise. J Appl Physiol 79: 129-135, 1995.

87. Radak Z, Chung HY and Goto S. Exercise and hormesis: oxidative stress-related adaptation for successful aging. Biogerontology 6: 71-75, 2005.

88. Reid MB. Free radicals and muscle fatigue: Of ROS, canaries, and the IOC. Free Radic Biol Med 44: 169-179, 2008.

89. Ristow M, Zarse K, Oberbach A, Kloting N, Birringer M, Kiehntopf M, Stumvoll M, Kahn CR and Bluher M. Antioxidants prevent health-promoting effects of physical exercise in humans. Proc Natl Acad Sci U S A 106: 8665-8670, 2009.

90. Ristow M, Zarse K, Oberbach A, Kloting N, Birringer M, Kiehntopf M, Stumvoll M, Kahn CR and Bluher M. Antioxidants prevent health-promoting effects of physical exercise in humans. Proc Natl Acad Sci U S A 106: 8665-8670, 2009.

91. Rokitzki L, Logemann E, Sagredos AN, Murphy M, Wetzelroth W and Keul J. LipidPeroxidation and Antioxidative Vitamins Under Extreme Endurance Stress. Acta Physiologica Scandinavica 151: 149-158, 1994.

92. Roman WJ, Fleckenstein J, Straygundersen J, Alway SE, Peshock R and Gonyea WJ. Adaptations in the Elbow Flexors of Elderly Males After Heavy-Resistance Training. J Appl Physiol 74: 750-754, 1993.

93. Sharman MJ, Newton RU, Triplett-McBride T, McGuigan MR, McBride JM, Häkkinen A, Häkkinen K and Kraemer WJ. Changes in myosin heavy chain 
composition with heavy resistance training in 60- to 75-year-old men and women. Eur $\mathrm{J}$ Appl Physiol 84: 127-132, 2001.

94. Shenoy K, Wu Y and Pervaiz S. LY303511 enhances TRAIL sensitivity of SHEP-1 neuroblastoma cells via hydrogen peroxide-mediated mitogen-activated protein kinase activation and up-regulation of death receptors. Cancer Res 69: 1941-1950, 2009.

95. Szkudelska K, Nogowski L and Szkudelski T. Resveratrol, a naturally occurring diphenolic compound, affects lipogenesis, lipolysis and the antilipolytic action of insulin in isolated rat adipocytes. J Steroid Biochem Mol Biol 113: 17-24, 2009.

96. Veal EA, Day AM and Morgan BA. Hydrogen peroxide sensing and signaling. Mol Cell 26: 1-14, 2007.

97. Vina J, Gimeno A, Sastre J, Desco C, Asensi M, Pallardo FV, Cuesta A, Ferrero JA, Terada LS and Repine JE. Mechanism of free radical production in exhaustive exercise in humans and rats; role of xanthine oxidase and protection by allopurinol. IUBMB Life 49: 539-544, 2000.

98. Wirth O, Gregory EW, Cutlip RG and Miller GR. Control and quantitation of voluntary weight-lifting performance of rats. J Appl Physiol 95: 402-412, 2003.

99. Yarasheski KE, Lemon PW and Gilloteaux J. Effect of heavy-resistance exercise training on muscle fiber composition in young rats. J Appl Physiol 69: 434-437, 1990.

100. Yoo HY, Chang MS and Rho HM. The activation of the rat copper/zinc superoxide dismutase gene by hydrogen peroxide through the hydrogen peroxide-responsive element and by paraquat and heat shock through the same heat shock element. $J$ Biol Chem 274: 23887-23892, 1999.

101. Zerba E, Komorowski TE and Faulkner JA. Free radical injury to skeletal muscles of young, adult, and old mice. Am J Physiol 258: C429-C435, 1990.

102. Zoppi CC, Hohl R, Silva FC, Lazarim FL, Neto JM, Stancanneli M and Macedo DV. Vitamin $\mathrm{C}$ and e supplementation effects in professional soccer players under regular training. J Int Soc Sports Nutr 3: 37-44, 2006. 
Appendix 
Table 7.1

(Reprint of Table 4.1)

Body Mass of Young and Aged Rats Pre and Post 14 sessions of Repetitive Loading

\begin{tabular}{lllll}
\hline & Young NS & Young Vit. E\&C & Aged NS & Age Vit. E\&C \\
\hline Pre-RL (g) & $343.5 \pm 10.9$ & $350.1 \pm 26.1$ & $513.8 \pm 88.4 \dagger$ & $491 \pm 63.5 \dagger$ \\
Post-RL (g) & $328.1 \pm 11.8$ & $340.2 \pm 27.8$ & $467.2 \pm 91 \dagger$ & $441 \pm 55.5 \dagger$ \\
\hline
\end{tabular}

Each value expressed in grams as a mean \pm SEM

NS = non-supplemented

Body Mass of Young and Aged Rats Pre and Post 14 sessions of repetitive loading

Data are mean \pm SEM and presented as the mass of the rats before the first exercise session and after the $14^{\text {th }}$ training session in grams. $\dagger$, indicates a significant difference $(p<0.05)$ from young exercise and diet-matched control muscles. NS, non-supplemented diet. 
Table 7.2

\section{Body Mass of Young and Aged Mice}

\begin{tabular}{lllll}
\hline Study & Young Non-AO & Young AO & Aged Non-AO & Aged AO \\
\hline Resveratrol & $25.4 \pm 0.8$ & $25.5 \pm 0.6$ & $33.1 \pm 0.7^{*}$ & $32.9 \pm 0.9^{*}$ \\
Allopurinol & $26.0 \pm 0.6$ & $25.8 \pm 1.5$ & $33.1 \pm 1.0^{*}$ & $32.8 .0 \pm 0.8^{*}$ \\
\hline
\end{tabular}

Each value expressed in grams as a mean \pm SEM

*Indicates a significant difference $(p<0.05)$ in the aged animals from the young adult treatment matched animals

Non-AO = Non-antioxidant treatment group

$\mathrm{AO}=$ Antioxidant treatment group

Body mass of young and aged mice in the resveratrol and allopurinol studies Data are mean \pm SEM and presented as the mass of the mice in grams. ${ }^{*}$, indicates a significant difference $(p<0.05)$ in the aged mice from the young treatment matched control mice. 